\title{
Hydraulic Testing Around Room Q: Evaluation of the Effects of Mining on the Hydraulic Properties of Salado Evaporites
}

Paul S. Domski, David T. Upton, Richard L. Beauheim

Prepared by

Sandia National Laboratories

Albuquerque, New Mexico 87185 and Livermore, California 94550 for the United States Department of Energy

under Contract DE-AC04-94AL85000:

Approved for public release; distribution

unlimited.

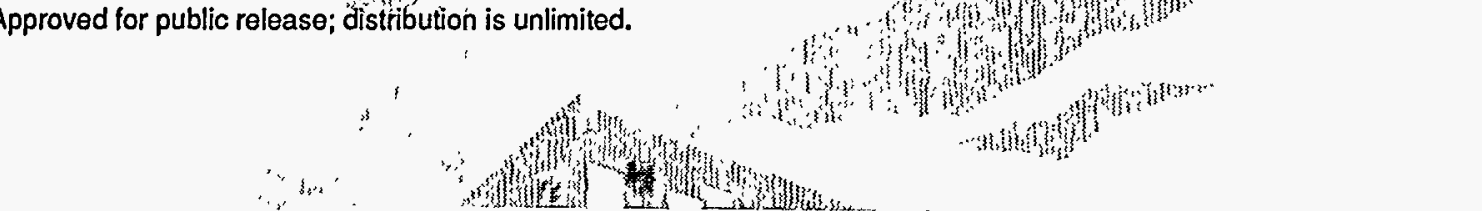

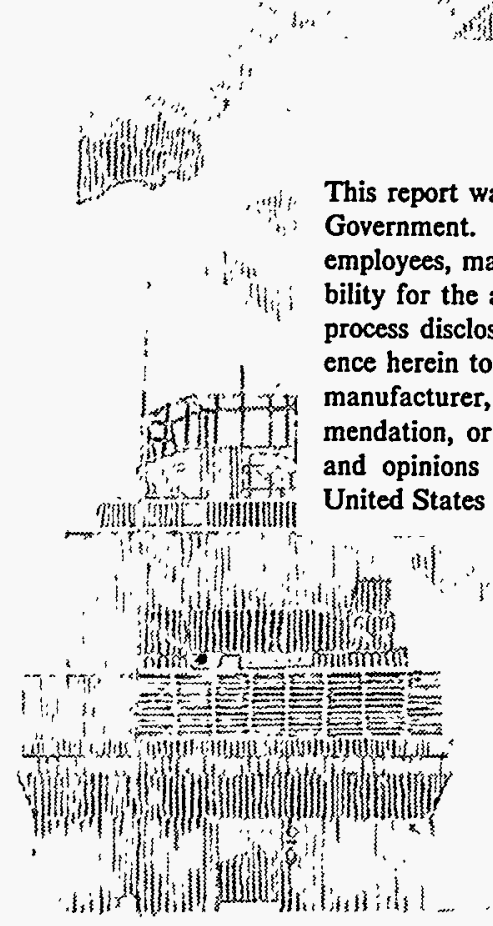

SF2900O(8-81)

\section{DISCLAIMER}

This report was prepared as an account of work sponsored by an agency of the United States Government. Neither the United States Government nor any agency thereof, nor any of their employees, makes any warranty, express or implied, or assumes any legal liability or responsibility for the accuracy, completeness, or usefulness of any information, apparatus, product, or process disclosed, or represents that its use would not infringe privately owned rights. Reference herein to any specific commercial product, process, or service by trade name, trademark, manufacturer, or otherwise does not necessarily constitute or imply its endorsement, recommendation, or favoring by the United States Government or any agency thereof. The views and opinions of authors expressed herein do not necessarily state or reflect those of the United States Government or any agency thereof.

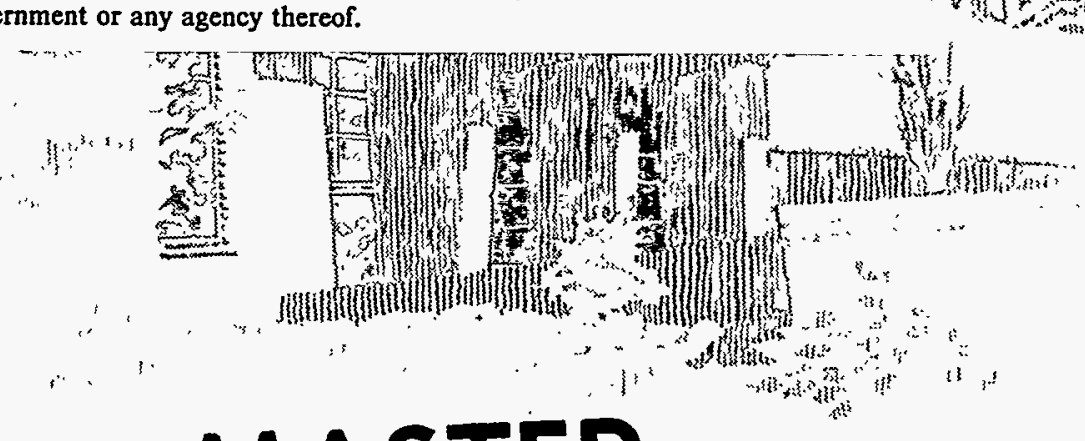

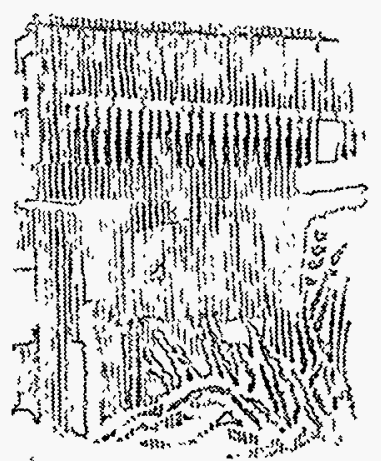

MASTER

DASTRIBUTION OF THS DOCUMENT IS UNLMMTED 
Issued by Sandia National Laboratories, operated for the United States Department of Energy by Sandia Corporation.

NOTICE: This report was prepared as an account of work sponsored by an agency of the United States Government. Neither the United States Government nor any agency thereof, nor any of their employees, nor any of their contractors, subcontractors, or their employees, makes any warranty, express or implied, or assumes any legal liability or responsibility for the accuracy, completeness, or usefulness of any information, apparatus, product, or process disclosed, or represents that its use would not infringe privately owned rights. Reference herein to any specific commercial product, process, or service by trade name, trademark, manufacturer, or otherwise, does not necessarily constitute or imply its endorsement, recommendation, or favoring by the United States Government, any agency thereof or any of their contractors or subcontractors. The views and opinions expressed herein do not necessarily state or reflect those of the United States Government, any agency thereof or any of their contractors.

Printed in the United States of America. This report has been reproduced directly from the best available copy.

Available to DOE and DOE contractors from

Office of Scientific and Technical Information

PO Box 62

Oak Ridge, TN 37831

Prices available from (615) 576-8401, FTS 626-8401

Available to the public from

National Technical Information Service

US Department of Commerce

5285 Port Royal Rd

Springfield, VA 22161

NTIS price codes

Printed copy: A07

Microfiche copy: A01 


\section{DISCLAIMER}

Portions of this document may be illegible in electronic image products. Images are produced from the best available original document. 


\title{
Hydraulic Testing Around Room Q: Evaluation of the Effects of Mining on the Hydraulic Properties of Salado Evaporites
}

\author{
Paul S. Domski \\ David T. Upton \\ INTERA Inc. \\ 1650 University Blvd. NE, Suite 300 \\ Albuquerque, New Mexico 87102 \\ Richard L. Beauheim \\ Geohydrology Department \\ Sandia National Laboratories \\ Albuquerque, New Mexico 87185-1324
}

\begin{abstract}
Room $Q$ is a 109-m-long cylindrical excavation in the Salado Formation at the Waste Isolation Pilot Plant (WIPP) site. Fifteen boreholes were drilled and instrumented around Room $Q$ so that tests could be conducted to determine the effects of room excavation on the hydraulic properties of the surrounding evaporite rocks. Pressure-buildup and pressure-pulse tests were conducted in all of the boreholes before Room $Q$ was mined. The data sets from only eight of the boreholes are adequate for parameter estimation, and five of those are of poor quality. Constant-pressure flow tests and pressure-buildup tests were conducted after Room $Q$ was mined, producing eleven interpretable data sets, including two of poor quality. Pre-mining transmissivities interpreted from the three good-quality data sets ranged from $1 \times 10^{-15}$ to $5 \times 10^{-14} \mathrm{~m}^{2} / \mathrm{s}$ (permeability-thickness products of $2 \times 10^{-22}$ to $9 \times 10^{-21} \mathrm{~m}^{3}$ ) for test intervals ranging in length from 0.85 to $1.37 \mathrm{~m}$. Pre-mining average permeabilities, which can be considered representative of undisturbed, far-field conditions, were $6 \times 10^{-20}$ and $8 \times 10^{-20} \mathrm{~m}^{2}$ for anhydrite, and $3 \times 10^{-22} \mathrm{~m}^{2}$ for halite. Post-mining transmissivities interpreted from the good-quality data sets ranged from $1 \times 10^{-16}$ to $3 \times 10^{-13}$ $\mathrm{m}^{2} / \mathrm{s}$ (permeability-thickness products of $2 \times 10^{-23}$ to $5 \times 10^{-20} \mathrm{~m}^{3}$ ). Post-mining average permeabilities for anhydrite ranged from $8 \times 10^{-20}$ to $1 \times 10^{-19} \mathrm{~m}^{2}$. These values are thought to have been only slightly, if at all, affected by excavation of Room $Q$. Post-mining average permeabilities for halite ranged from $2 \times 10^{-23}$ to $5 \times 10^{-20} \mathrm{~m}^{2}$, and are thought to reflect varying degrees of excavation response. Pore pressures decreased by several $\mathrm{MPa}$ after mining at all boreholes for which reliable pre- and post-mining comparisons are possible, except for one borehole at which no change was observed. The changes in hydraulic properties and pore pressures that were observed can be attributed to one or a combination of three processes: stress reduction, changes in pore connectivity, and flow towards Room $Q$. The effects of the three processes cannot be individually quantified with the available data.
\end{abstract}




\section{ACKNOWLEDGEMENTS}

The authors wish to thank Lee Jensen and Susan Howarth for their efforts in bringing the Room Q test data together under difficult circumstances. The critical reviews of Jim Butler and Kurt Larson have contributed significantly to this report. Rick Bower's assistance with preparation of the final manuscript is also greatly appreciated. 


\section{CONTENTS}

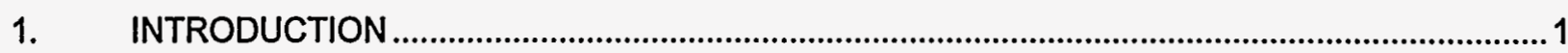

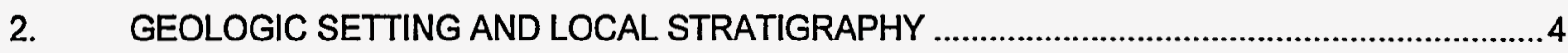

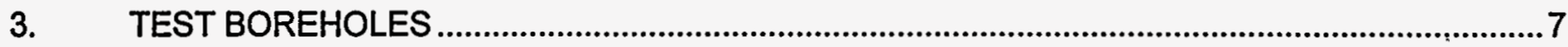

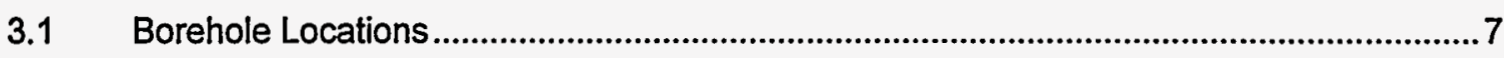

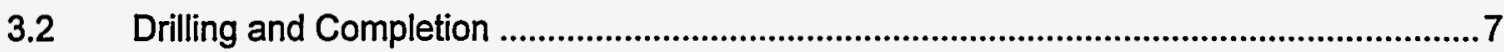

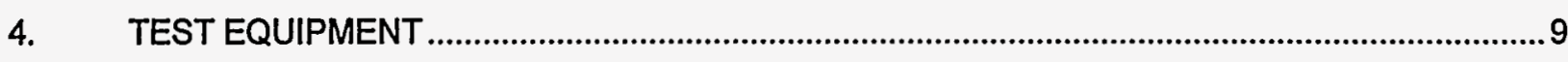

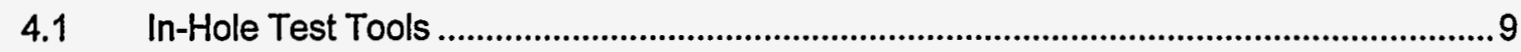

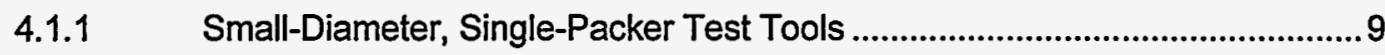

4.1.2 Small-Diameter, Dual-Packer Test Tools ....................................................10

4.1.3 Large-Diameter, Dual-Packer Test Tools..................................................... 10

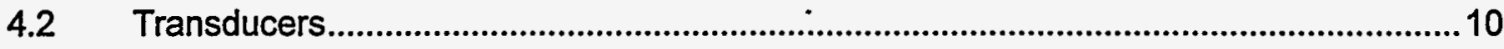

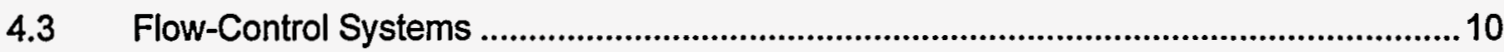

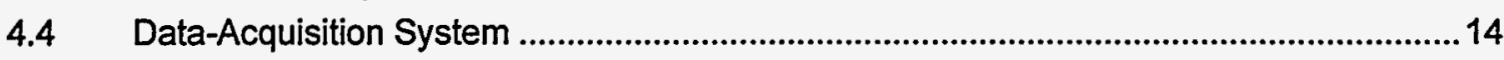

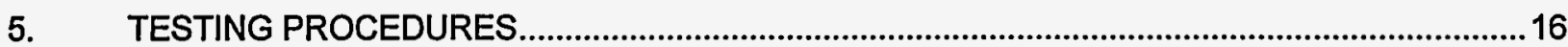

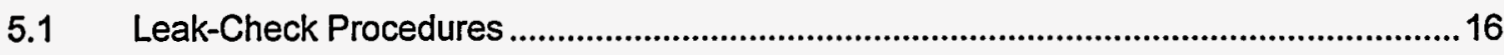

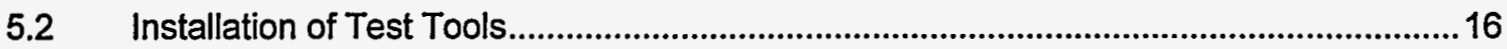

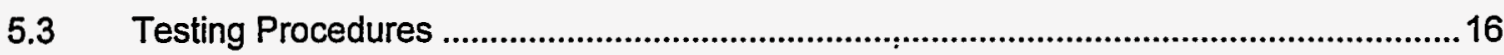

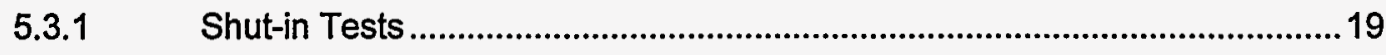

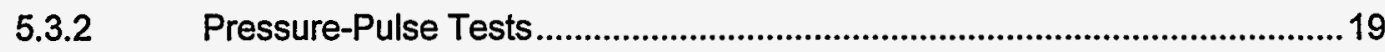

5.3.3 Constant-Pressure Flow Tests .............................................................. 19

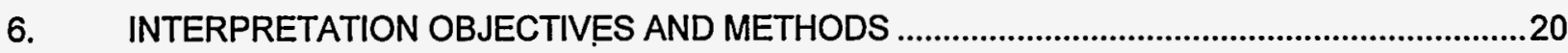

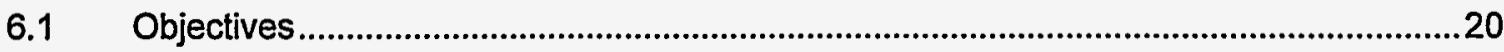

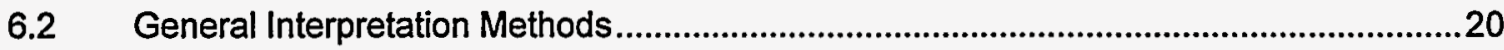

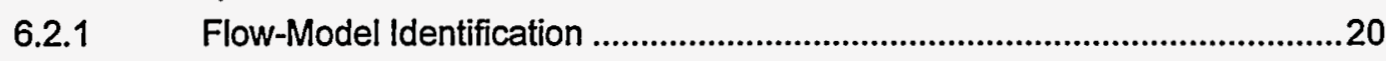

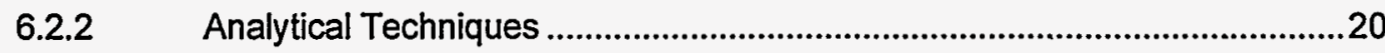

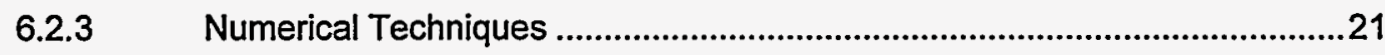

6.3 Treatment of Borehole Geometry .............................................................................21

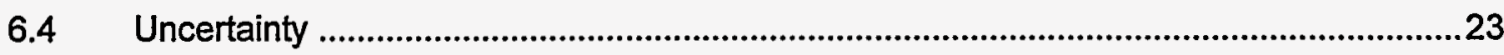

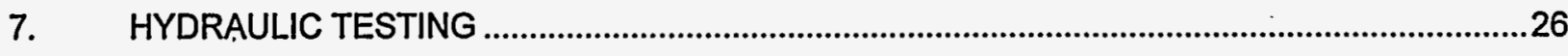

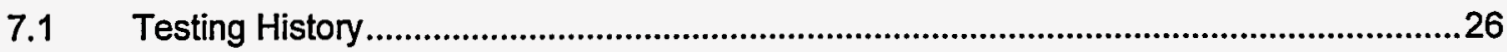

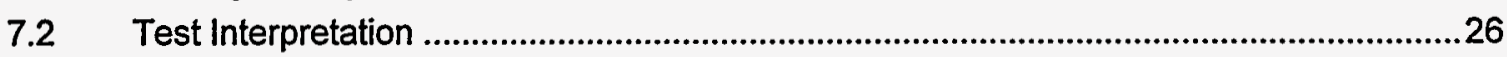

7.2.1 QPP01

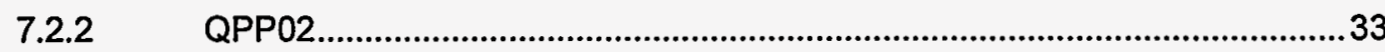

7.2.3 QPP03

7.2.4 QPP04 


\section{CONTENTS (Continued)}

Q $7.2 .5 \quad$ QPP05

7.2.6 QPP11

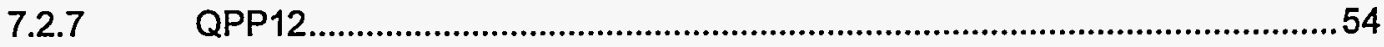

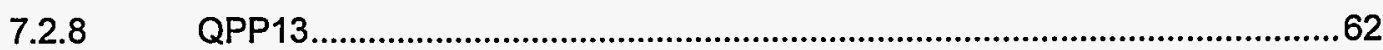

7.2.9 QPP14

7.2.10 QPP15

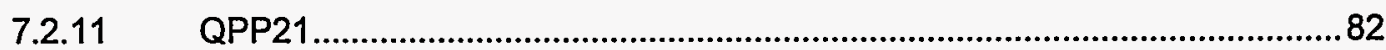

7.2.12 QPP22

7.2.13 QPP23

7.2.14 QPP24

7.2.15 QPP25

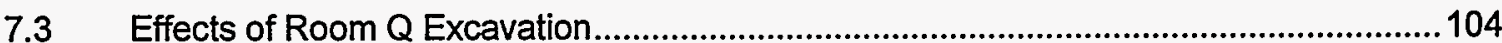

8. MECHANISMS AND PROCESSES AFFECTING SALADO PROPERTIES AROUND

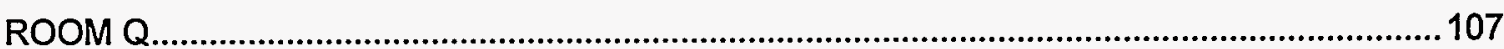

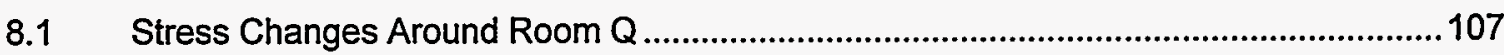

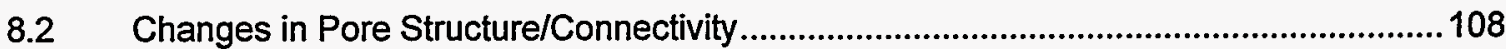

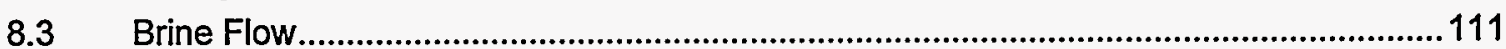

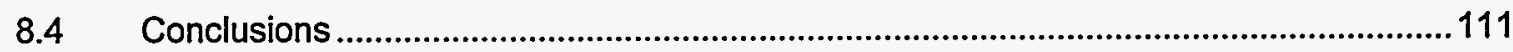

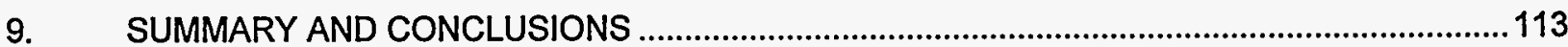

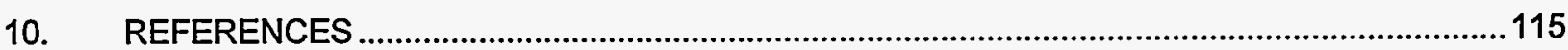

APPENDIX A: $\quad$ Plots of Packer Pressures During Testing .........................................................117

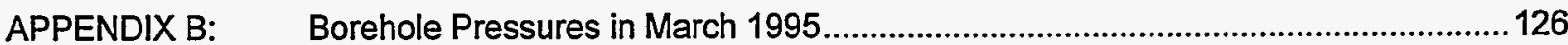




\section{Figures}

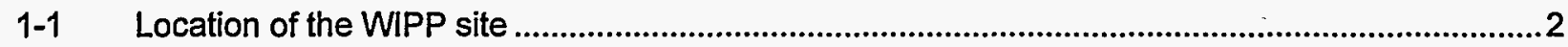

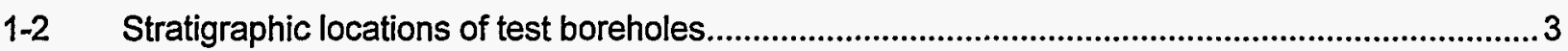

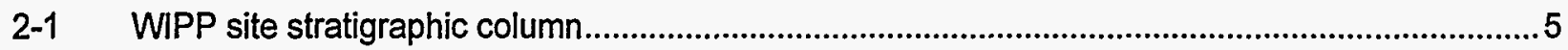

2-2 Detailed stratigraphy near the WIPP underground facility ..........................................................6

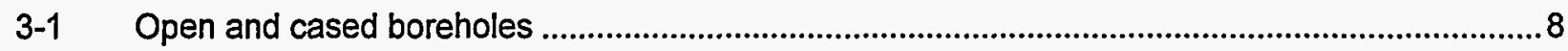

4-1 Small-diameter single-packer test tool ......................................................................................11

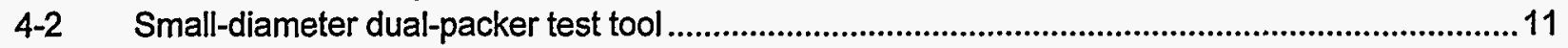

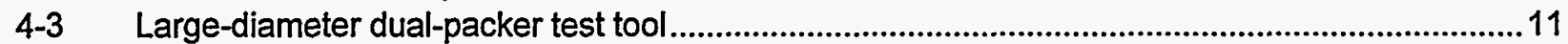

4-4 Packer-inflation and brine-management system for large-diameter tools .................................... 12

4-5 Packer-inflation and brine-management system for small-diameter tools..................................13

4-6 Brine flow and measurement system for small-diameter tools ............................................... 15

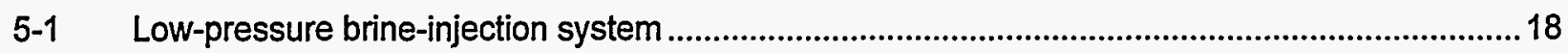

6-1 Diagnostic plot for flow-model identification ...............................................................................21

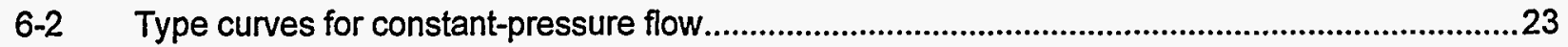

7-1 QPP01 test-zone pressure

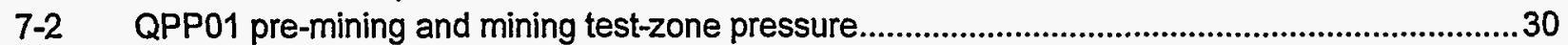

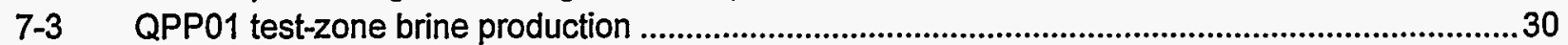

7-4 Horner plot of the QPP01 pre-mining test-zone pressure .............................................................31

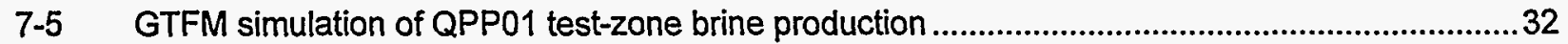

7-6 GTFM simulation of QPP01 post-mining test-zone pressure ................................................32

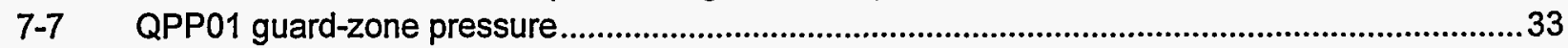

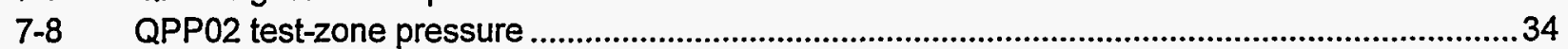

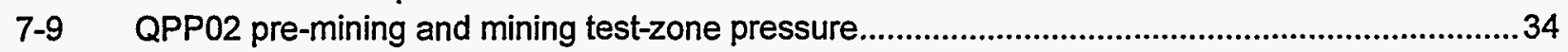

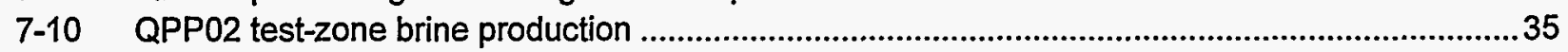

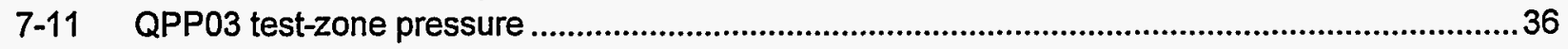

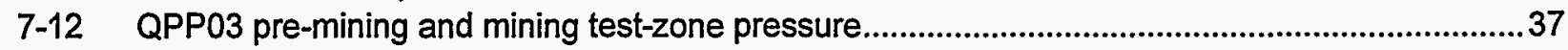

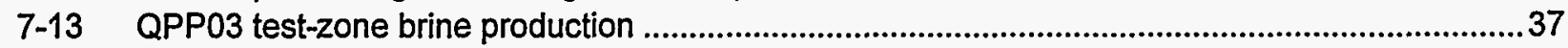

7-14 GTFM simulation of QPP03 post-mining test-zone pressure .....................................................38

7-15 GTFM simulation of QPP03 test-zone brine production ...............................................................39

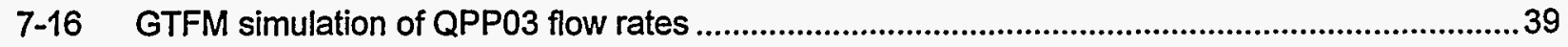

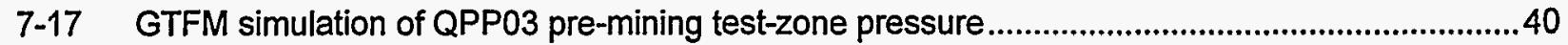

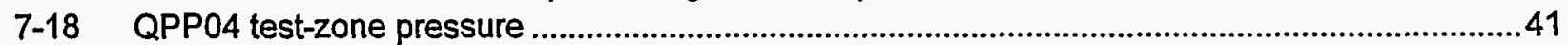

7-19 QPP04 pre-mining and mining test-zone pressure.............................................................42

7-20 Horner plot of the QPP04 pre-mining test-zone pressure ......................................................42

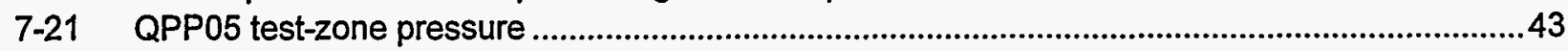

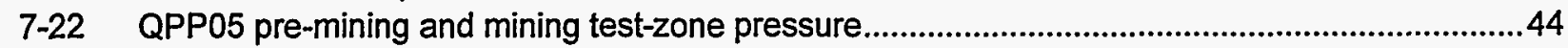

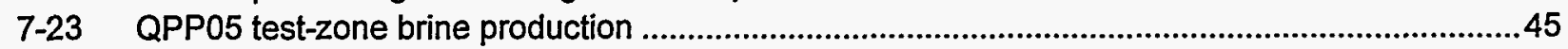

7-24 GTFM simulation of QPP05 pre-mining test-zone pressure.....................................................45

7-25 GTFM simulation of QPP05 post-flow-test pressure ..................................................................46

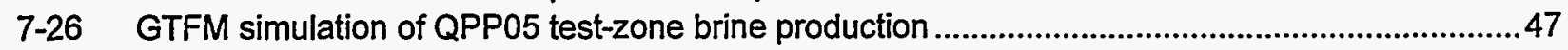

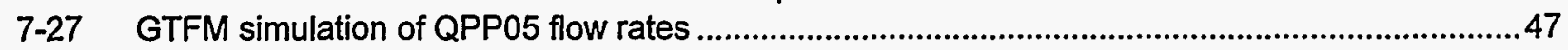




\section{Figures (Continued)}

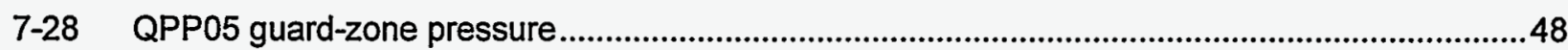

7-29 QPP05 pre-mining and mining guard-zone pressure .........................................................49

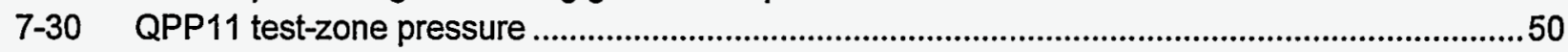

7-31 QPP11 pre-mining and mining test-zone pressure .................................................................50

7-32 GTFM simulation of QPP11 pre-mining test-zone pressure ..................................................51

7-33 Horner plot of the QPP11 post-mining test-zone pressure .................................................52

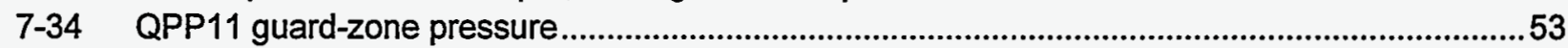

7-35 Horner plot of the QPP11 post-mining guard-zone pressure ....................................................53

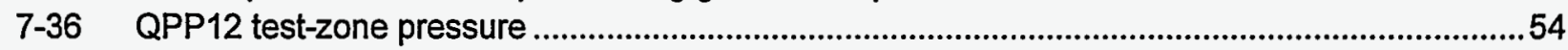

7-37 QPP12 pre-mining and mining test-zone pressure ...............................................................55

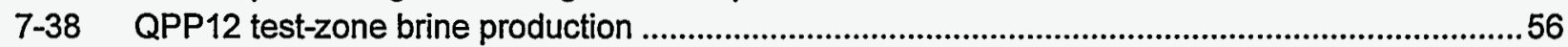

7-39 Type-curve match of the QPP12 flow rates........................................................................56

$7-40$ Interpret/2 type-curve match of the QPP12 post-flow-test pressure buildup ................................57

7-41 Interpret/2 Horner superposition match of the QPP12 post-flow-test pressure buildup ................57

7-42 IInterpret/2 simulation of the QPP12 constant-pressure flow test and pressure buildup...............58

7-43 GTFM simulation of the QPP12 test-zone brine production .......................................................59

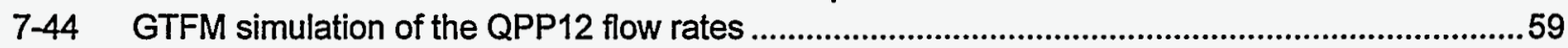

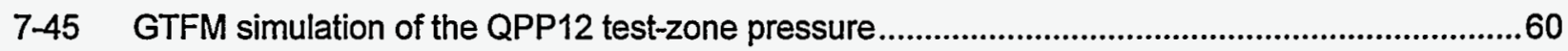

7-46 GTFM Horner simulation of the QPP12 post-flow-test pressure buildup.....................................60

7-47 GTFM simulation of the QPP12 pre-mining test-zone pressure ............................................61

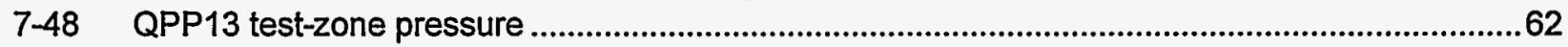

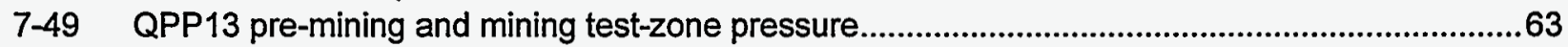

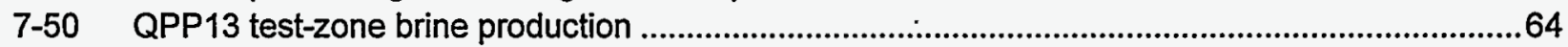

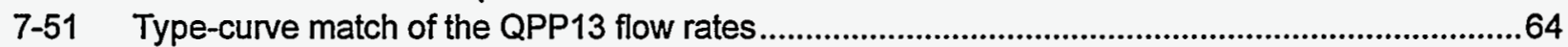

7-52 Interpret/2 type-curve match of the QPP13 post-flow-test pressure buildup ................................65

7-53 Interpret/2 Horner superposition match of the QPP13 post-flow-test pressure buildup ...............65

7-54 Interpret/2 simulation of the QPP13 constant-pressure flow test and pressure buildup...............66

7-55 GTFM simulation of the QPP13 pre-mining test-zone pressure ..................................................67

7-56 GTFM simulation of the QPP13 post-mining test-zone pressure .............................................67

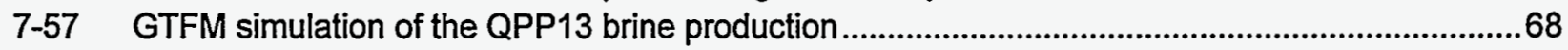

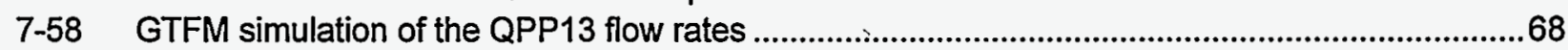

7-59 GTFM Horner simulation of the QPP13 post-flow-test pressure buildup....................................69

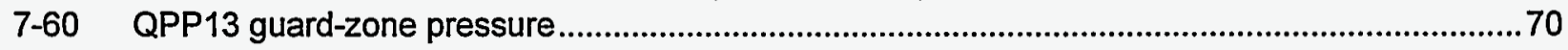

7-61 Horner plot of the QPP13 pre-mining guard-zone pressure .................................................70

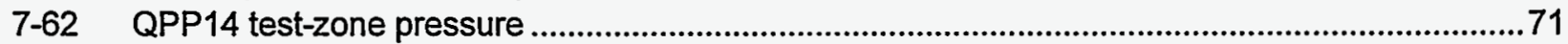

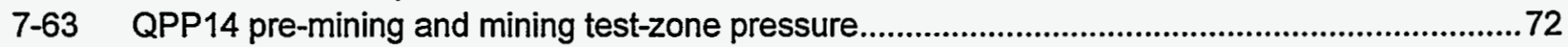

7-64 GTFM simulation of the QPP14 pre-mining test-zone pressure ...................................................73

7-65 GTFM simulation of the QPP14 post-mining test-zone pressure .............................................74

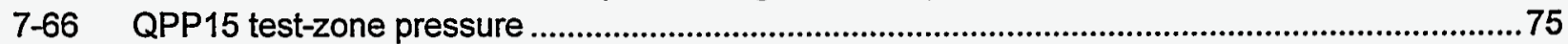

7-67 QPP15 pre-mining and mining test-zone pressure .....................................................................75

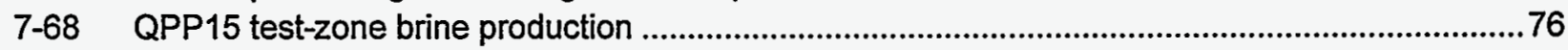

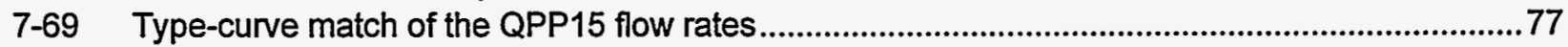

7-70 Interpret/2 type-curve match of the QPP15 post-flow-test pressure buildup ................................77

7-71 Interpret/2 Horner superposition match of the QPP15 post-flow-test pressure buildup ................78

7-72 Interpret/2 simulation of the QPP15 post-flow-test pressure buildup ..........................................78

7-73 GTFM simulation of the QPP15 post-mining test-zone pressure ..............................................79

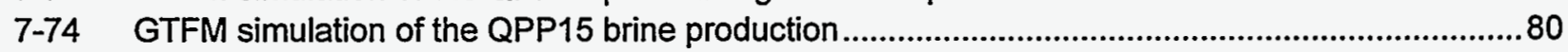




\section{Figures (Continued)}

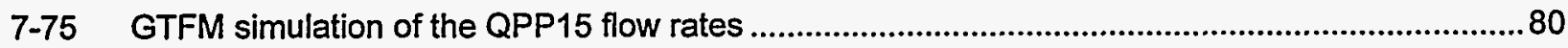

7-76 GTFM simulation of the QPP15 pre-mining test-zone pressure .................................................81

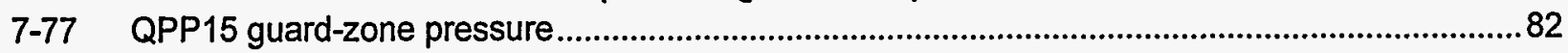

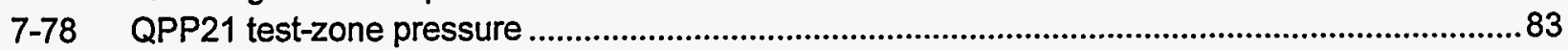

7-79 QPP21 pre-mining and mining test-zone pressure....................................................................84

7-80 GTFM simulation of the QPP21 pre-mining test-zone pressure ....................................................85

7-81 GTFM simulation of the QPP21 post-mining test-zone pressure ...............................................85

7-82 GTFM Horner simulation of the QPP21 post-flow-test pressure buildup......................................86

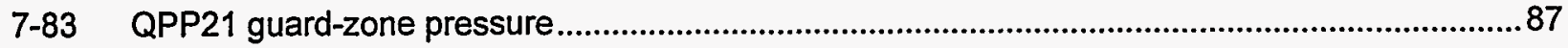

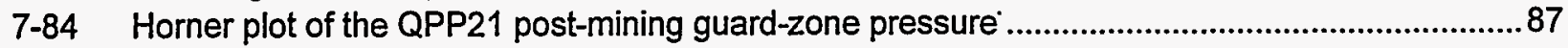

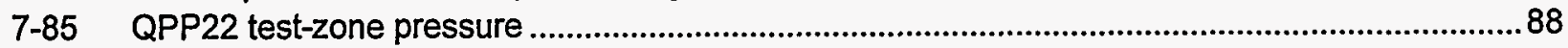

7-86 QPP22 pre-mining and mining test-zone pressure.....................................................................89

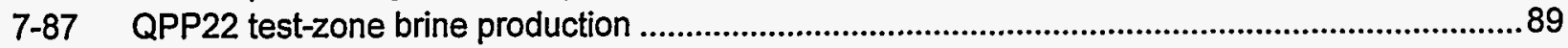

7-88 GTFM simulation of the QPP22 post-mining test-zone pressure ...............................................90

7-89 GTFM simulation of the QPP22 test-zone brine production .........................................................91

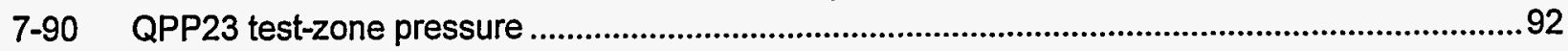

7-91 QPP23 pre-mining and mining test-zone pressure ...................................................................92

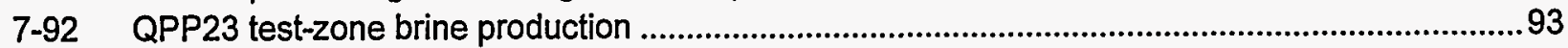

7-93 GTFM simulation of the QPP23 test-zone brine production .......................................................94

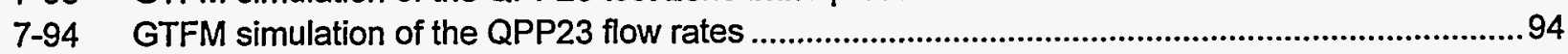

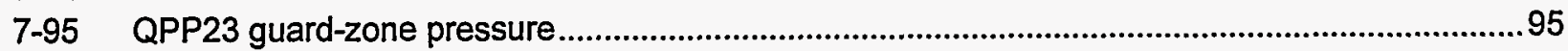

7-96 Horner plot of the QPP23 pre-mining guard-zone pressure ........................................................96

7-97 Horner plot of the QPP23 post-mining guard-zone pressure .....................................................96

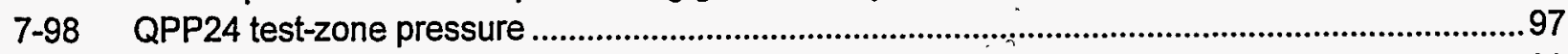

7-99 QPP24 pre-mining and mining test-zone pressure .................................................................98

7-100 QPP25 test-zone pressure ..........................................................................................................99

7-101 QPP25 pre-mining and mining test-zone pressure .....................................................................99

7-102 QPP25 test-zone brine production .........................................................................................100

7-103 GTFM simulation of the QPP25 post-mining test-zone pressure ...............................................101

7-104 GTFM simulation of the QPP25 test-zone brine production .......................................................101

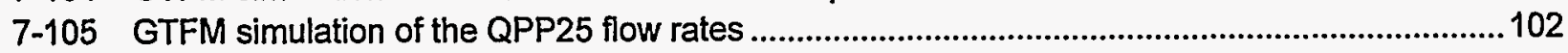

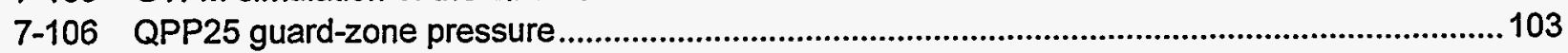

7-107 Horner plot of the QPP25 pre-mining guard-zone pressure ................................................... 103

8-1 Simulated mean stresses at the QPP0x borehole positions....................................................108

8-2 Simulated mean stresses at the QPP1x borehole positions.....................................................109

8-3 Simulated mean stresses at the QPP2x borehole positions......................................................109

8-4 Mean stresses and interpreted formation pore pressures around Room $Q$.............................110 


\section{Tables}

5-1 As-Built Test-Tool Configurations (after Jensen et al., 1993) .................................................... 17

6-1 Summary of Test-Zone-Compressibility Measurements .......................................................25

7-1 GTFM Analysis Results for the Pre-Mining Period .................................................................2

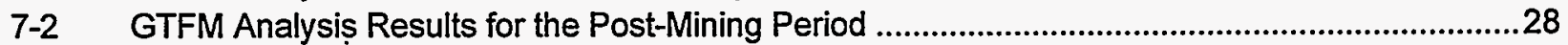

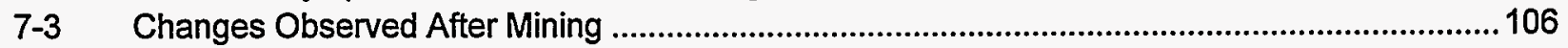

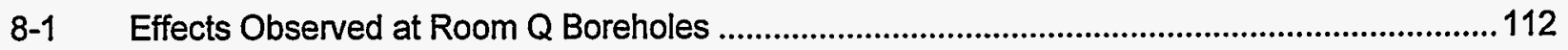




\section{INTRODUCTION}

This report presents interpretations of hydraulic tests conducted in 15 boreholes around Room $Q$ at the Waste Isolation Pilot Plant (WIPP) site in southeastern New Mexico (Figure 1-1). The WIPP is a U.S. Department of Energy research and development facility designed to demonstrate safe disposal of transuranic wastes from the nation's defense programs. The WIPP disposal horizon is located in the lower portion of the Permian Salado Formation, a 600-m-thick sequence of bedded evaporites. Room $Q$ is a 109 -m-long excavation, circular in cross section with a nominal diameter of $2.9 \mathrm{~m}$. An integrated set of experiments was planned and conducted in and around Room $Q$ to define mechanisms and properties affecting brine flow from the Salado Formation to excavations (Nowak, 1989).

For one set of experiments, boreholes were drilled before Room $Q$ was excavated to create three lines comprising five holes each vertically above, vertically below, and horizontally north of the centerline of the room (Figure 1-2). All of the boreholes terminate $22.9 \mathrm{~m}$ along the length of the room in a plane normal to the axis of the room. In each of the three arrays, the boreholes were designed to terminate at distances of approximately $2.4,3.3,4.6,7.6$, and $13.7 \mathrm{~m}$ from the centerline of the room. The purpose of the 15 boreholes around Room $Q$ was to allow permeability and porepressure measurements to be made before and after the room was excavated. The testing program to obtain those measurements was designed and performed by S-Cubed of La Jolla, California, in consultation with Sandia National Laboratories, Albuquerque, New Mexico.

Hydraulic testing was performed in the boreholes around Room $Q$ to provide quantitative estimates of the hydraulic properties controlling brine flow through the Salado Formation, and to determine how those properties are affected by nearby excavations. The specific objectives of the tests were:

To determine the permeabilities and pore pressures of different strata before they were disturbed by the excavation of Room $Q$, and

To determine how the permeabilities and pore pressures of the strata around Room $Q$ were affected by the excavation, both as a function of radial distance from the room and as a function of time.

This report discusses testing performed between April 1989 and June 1992. The testing program for the 15 boreholes consisted of initial pressure-buildup periods and pressure-pulse tests before Room $Q$ was mined, and pressure-buildup periods, constant-pressure flow tests, and pressurebuildup tests after Room $Q$ was mined. The stratigraphic intervals tested included halite (both pure and impure) and anhydrite (with associated clay seams). Preliminary interpretations of the tests were presented by Howarth et al. (1991). 


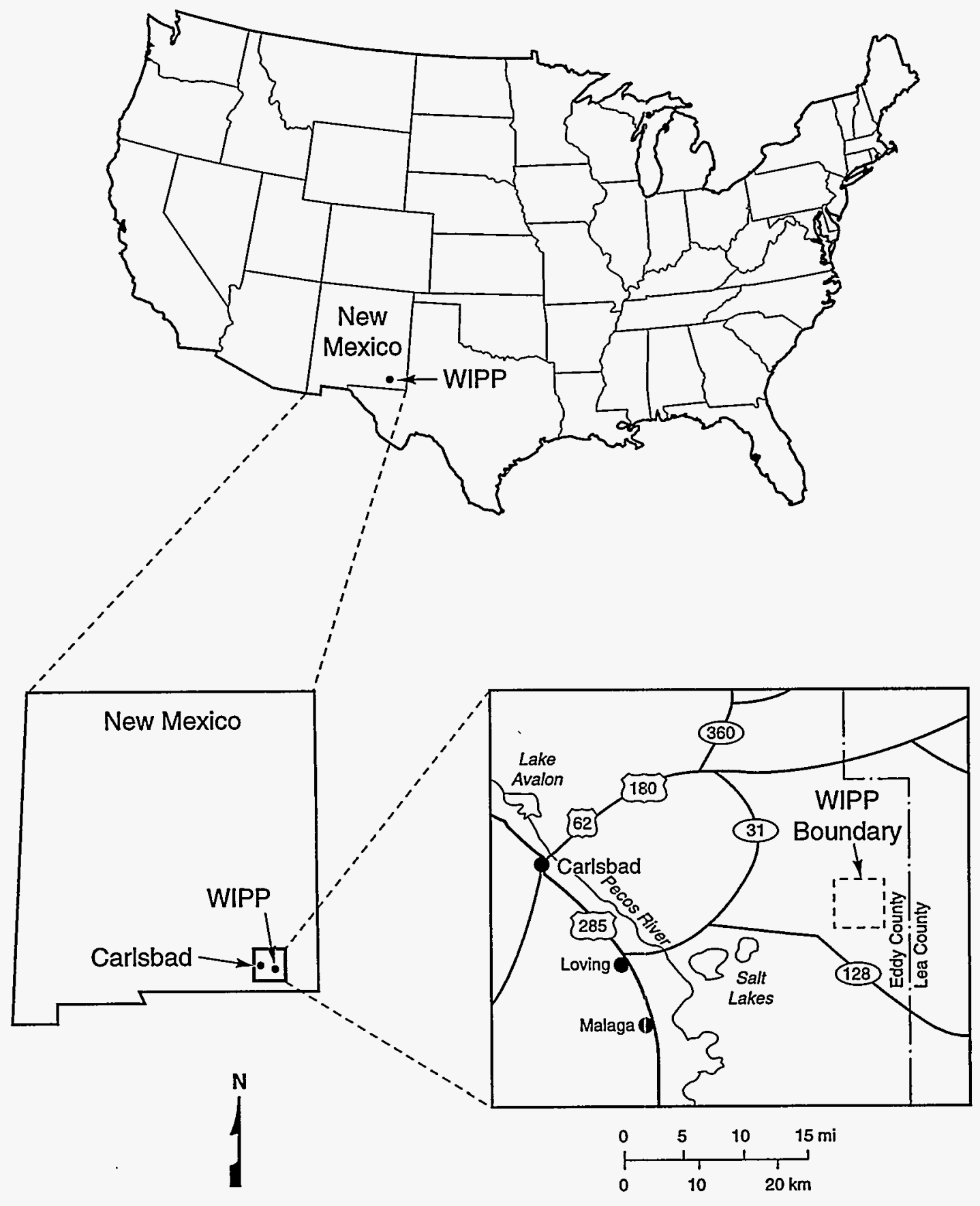

TRI-6330-3-5

Figure 1-1. Location of the WIPP site. 


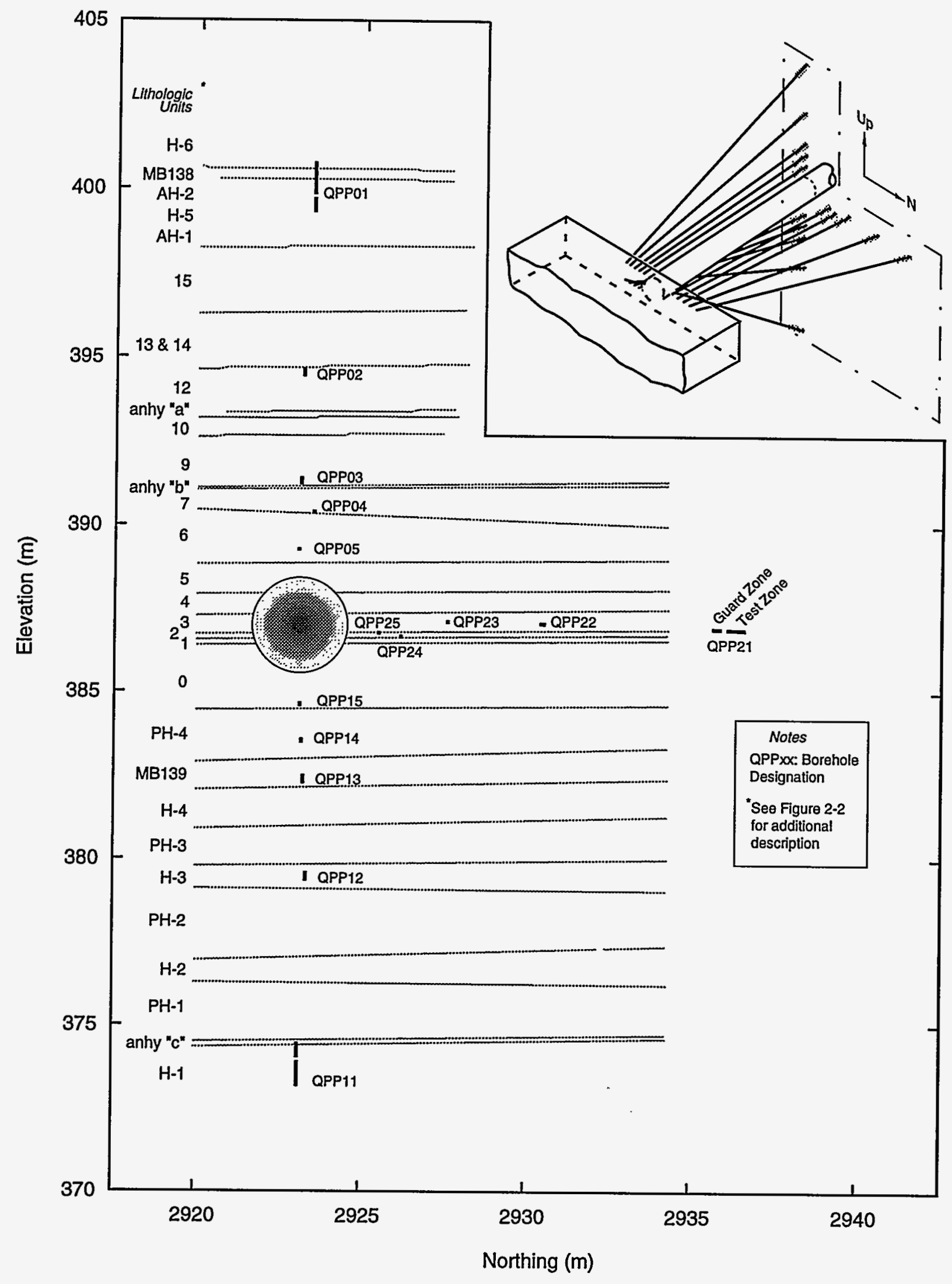

TRI-6119-233-2

Figure 1-2. Stratigraphic locations of test boreholes. 


\section{GEOLOGIC SETTING AND LOCAL STRATIGRAPHY}

The WIPP is located in the northern part of the Delaware Basin in southeastern New Mexico. WIPP-site geologic investigation have concentrated on the upper seven formations typically found in that part of the Delaware Basin. These are, in ascending order, the Bell Canyon Formation, the Castile Formation, the Salado Formation, the Rustler Formation, the Dewey Lake Redbeds, the Dockum Group, and the Gatuna Formation (Figure 2-1). All of these formations are of Permian age except for the Dockum Group, which is of Triassic age, and the Gatuña, which is a Quaternary deposit.

The WIPP underground facility lies in the lower part of the Salado Formation at an approximate depth of $655 \mathrm{~m}$ below ground surface. The Salado Formation is approximately $600 \mathrm{~m}$ thick at the WIPP site and is composed largely of halite, with minor amounts of interspersed clay and polyhalite. The Salado also contains numerous interbeds of anhydrite, polyhalite, clay, and siltstone. Many of these interbeds are traceable over much of the Delaware Basin. Jones et al. (1960) designated 45 of the anhydrite and/or polyhalite interbeds as "Marker Beds", and numbered these "Marker Beds" from 100 to 144, with numbers increasing downward. The WIPP facility horizon (the stratigraphic location of the underground excavations) lies between Marker Beds 138 and 139.
A typical stratigraphic section of the Salado Formation in the vicinity of the WIPP underground facility, adapted from Westinghouse (1989), is shown in Figure 2-2. Deal et al. (1989) present a detailed description of stratigraphic units that correlate throughout most of the underground facility. The description includes a 41.2-m interval of the Salado, centered approximately at the stratigraphic midpoint of the excavations. This description delineates 16 "map units", numbered 0 to 15 , and 23 other units. The majority of the units are composed primarily of halite and are distinguished principally on the basis of differing clay and polyhalite contents. The halite units lacking map unit designations are identified by $\mathrm{H}$ (pure halite), AH (argillaceous halite), or $\mathrm{PH}$ (polyhalitic halite) prefixes followed by a number representing that unit's position with respect to the base of the sequence, which was arbitrarily defined as the halite unit immediately underlying anhydrite " $\mathrm{c}$ " and clay B. For example, $\mathrm{AH}-4$ is the fourth argillaceous halite unit above the base of the sequence. The remainder of the units are anhydrite interbeds. such as Marker Beds 138 and 139. Thinner anhydrite interbeds and a number of the more continuous clay seams have also been given letter designations (e.g., anhydrite "a", clay B) to facilitate consistent referencing. These units are shown on Figure 2-2. The stratigraphic positions of Room $Q$ and the surrounding test boreholes are shown in Figure 1-2. 


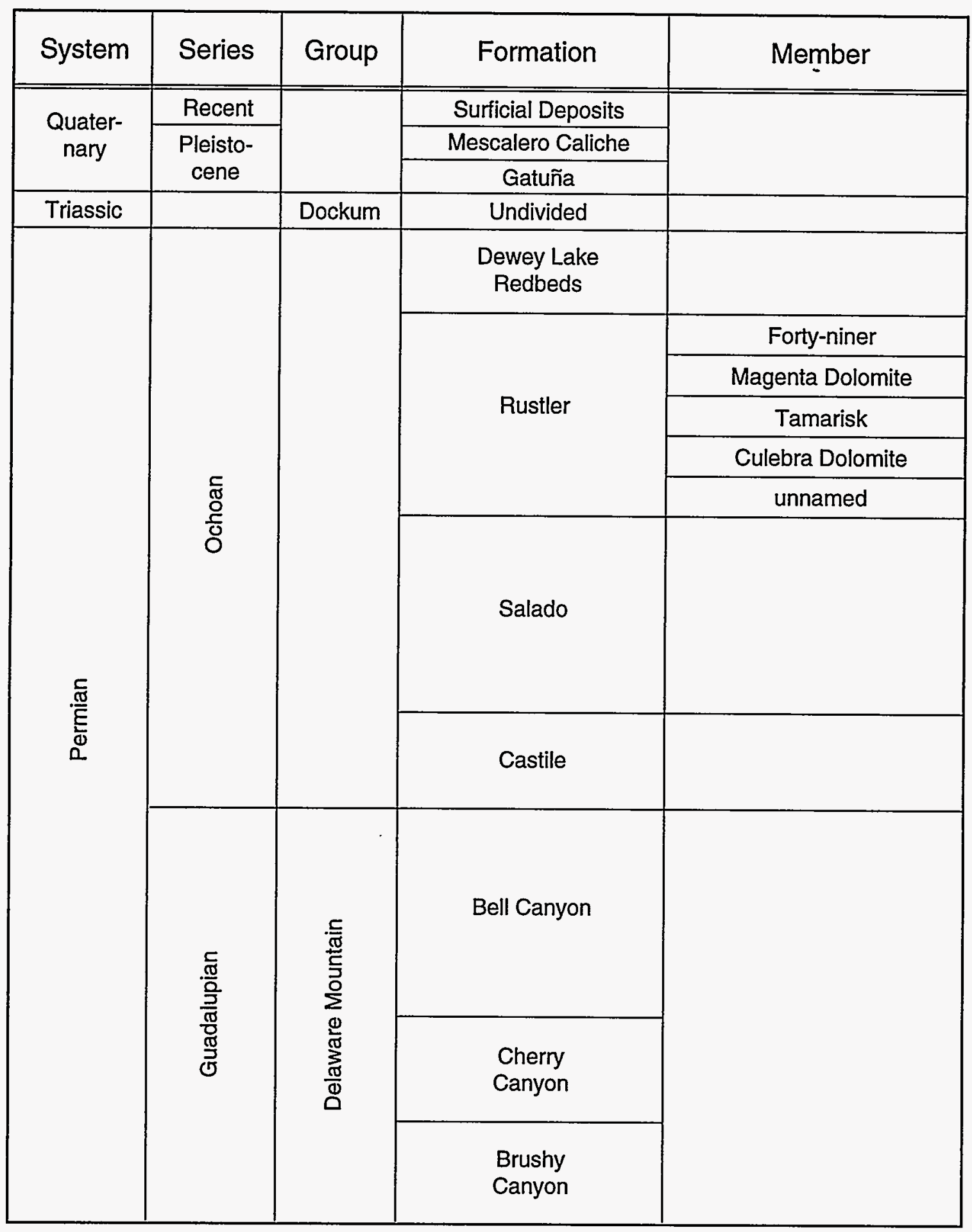

TRI-6330-89-6

Figure 2-1. WIPP site stratigraphic column. 


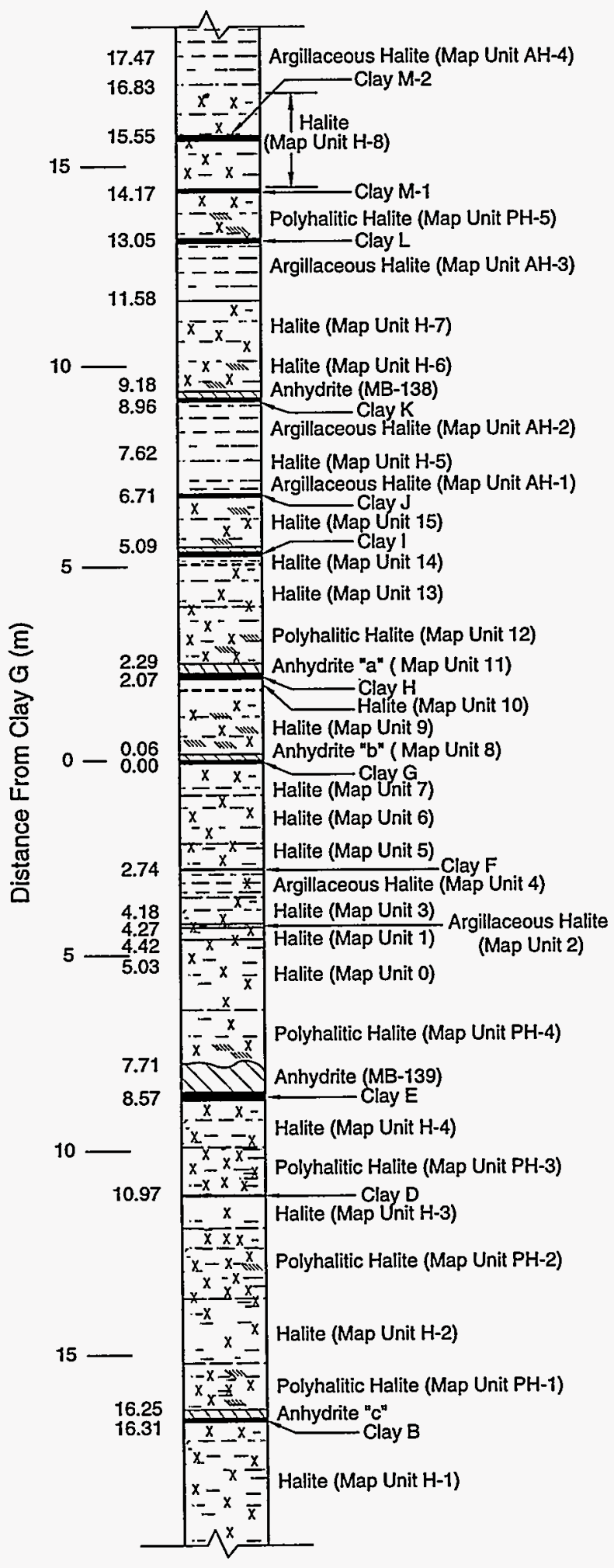

\begin{tabular}{|c|c|c|c|}
\hline \multicolumn{2}{|c|}{ Rock Type } & \multicolumn{2}{|c|}{ Accessory Constituents } \\
\hline & Halite & $\begin{array}{|ll|}x & x \\
x & x \\
\end{array}$ & Polyhalite \\
\hline & Anhydrite & & $\begin{array}{l}\text { Clay Seam } \\
>0.6 \mathrm{~cm} \text { Thick }\end{array}$ \\
\hline$E$ & $\begin{array}{l}\text { Polyhalitic } \\
\text { Halite }\end{array}$ & 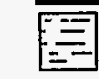 & $\begin{array}{l}\text { Argillaceous } \\
\text { Material }\end{array}$ \\
\hline$=$ & $\begin{array}{l}\text { Argillaceous } \\
\text { Halite }\end{array}$ & 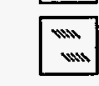 & $\begin{array}{l}\text { Anhydrite } \\
\text { Stringers }\end{array}$ \\
\hline
\end{tabular}

Lithologic Contacts

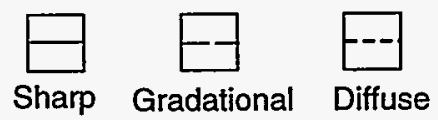

Notes:

1. Distances in meters are measured from the base of anhydrite " $b$ " (Clay $G$ ) and are averaged from representative corehole logs, shaft and test-room mapping. Actual distance and unit thicknesses may vary locally from those shown.

2. Descriptions of units are based on corehole data, shaft mapping and visual inspection of exposures in underground drifts and rooms.

Adapted from Westinghouse (1989) and Deal et al. (1989) 


\section{TEST BOREHOLES}

Fifteen boreholes were drilled and completed into the west face of the Room $Q$ instrumentation alcove between February 7 and March 23, 1989. Twelve boreholes were lined and grouted to isolate test regions within the formation. The three boreholes furthest from the planned centerline of Room $Q$ remained unlined to accommodate large-diameter test tools.

\subsection{Borehole Locations}

Figure 1-2 shows two- and threedimensional perspectives of the locations of the fifteen test boreholes relative to the instrumentation alcove. Test boreholes QPP01 through QPP05 are sloped upward and terminate in a vertical line above Room Q, boreholes QPP11 through QPP15 are sloped downward and terminate in a vertical line below Room Q, and boreholes QPP21 through QPP25 fan out to the north from Room $Q$ and are nearly horizontal. The borehole collars are located on the west face of the instrumentation alcove. The test boreholes extend approximately $23 \mathrm{~m}$ into the formation, with test regions approximately $2 \mathrm{~m}$ in length.

\subsection{Drilling and Completion}

The Room $Q$ boreholes were drilled with a Diamec 230 dual-column mounted rotary drill.
Each borehole was drilled with a nominal diameter of $10.2 \mathrm{~cm}$ to the depth designated for the start of test region. Boreholes QPP01, QPP11, and QPP21, the large-diameter boreholes, were drilled to the end of their designed test regions at a 10.2-cm diameter. These three boreholes were not cased, but remained open over their entire lengths. The twelve remaining boreholes were designed to accept small-diameter $(3.5-\mathrm{cm})$ test tools. Steel pipe casing was grouted in place along the $10.2-\mathrm{cm}$ lengths of these boreholes prior to advancing the small-diameter $(3.8-\mathrm{cm})$ test regions. Each pipe was cut to fit the specific length of each hole and fitted with a welded flange collar. A PVC cap was permanently attached to the downhole casing end to serve as a centering device and to prevent grout and debris from filling the pipe during insertion and later grouting of the pipe in the hole. These caps were then drilled through as the small-diameter test regions were advanced.

All boreholes with the exception of QPP05 were destructively drilled using plug bits. Borehole QPP05 was cored, but significant core fragmentation prevented recovery of competent core. Therefore, no stratigraphic information was obtained during drilling. Figure 3-1 shows the two types of holes created for the tests. A detailed discussion of drilling and completion methods is provided in Jensen et al. (1993). 


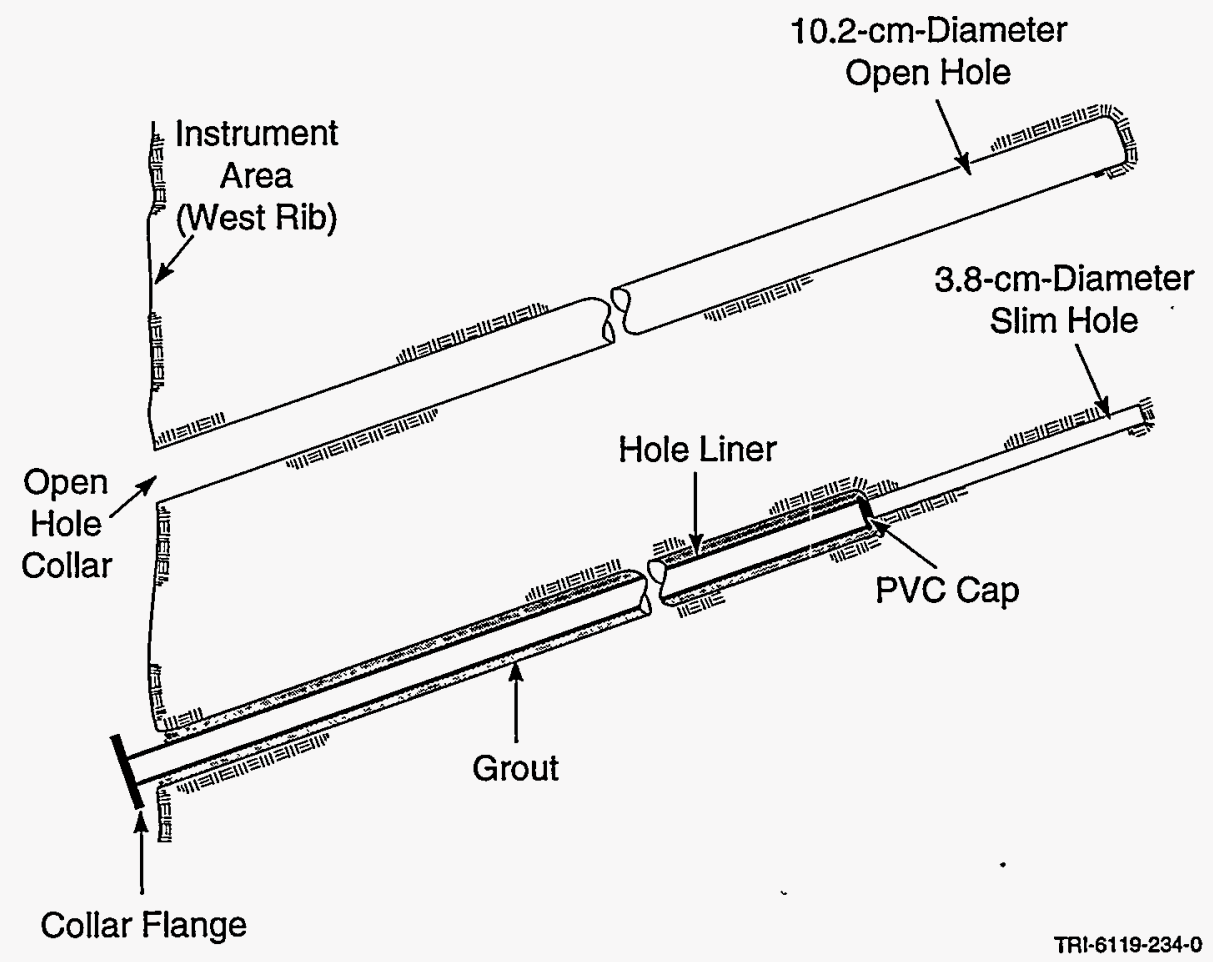

Figure 3-1. Open and cased boreholes. 


\section{TEST EQUIPMENT}

This section describes the instrumentation used to conduct tests in the boreholes around Room $Q$. Test equipment included in-hole test tools, transducers, a flow-control system, and a data-acquisition system (DAS). Pertinent equipment calibration methods and additional test equipment details are discussed in detail in Jensen et al. (1993).

\subsection{In-Hole Test Tools}

Three test-tool configurations were used in the Room $Q$ borehole tests: small-diameter, single-packer test tools; small-diameter, dualpacker test tools; and large-diameter, dual-packer test tools. All test tools used sliding-end packers designed and built specifically for the testing program by TAM International of Houston, Texas. The test tools were utilized to isolate test zones located in the bottoms of the individual boreholes. The dual-packer test tools provided isolated "guard" zones in addition to the test zones. Test and guard-zone pressures were monitored by transducers connected to the isolated zones through 1/16-inch stainless steel tubing. Packerinflation and operating pressures were monitored by transducers attached to the packer-inflation lines.

Each of the fifteen test tools had devices to measure borehdole closure attached to the bottom of the packer assembly. Two types of closuremeasurement devices were used: hydraulically actuated, opposing-button closure gauges in the small-diameter boreholes; and mechanically actuated, opposing-plate gauges in the largediameter boreholes. Both devices used linear variable-differential transformers (LVDTs) to measure changes in borehole diameter. In general, the closure devices failed to perform as designed and the data provided by them are considered unreliable. Jensen et al. (1993) provide a thorough discussion of closuremeasurement devices.

Temperatures in the test zones associated with the large-diameter test tools were measured by thermocouples attached to the test tool. The thermocouples were factory calibrated and no additional calibration was performed at the WIPP calibration laboratory.

The test tools were mounted on hollow mandrels through which stainless steel tubing and wiring passed, connecting the closure gauges, packers, test zones, and guard zones with the transducers and instruments in the instrumentation alcove outside of Room Q. Injection and vent ports to the test and guard zones enabled technicians to apply specified pressures to each of the isolated zones.

\subsubsection{Small-Diameter, Single-Packer Test Tools}

Small-diameter, single-packer test tools were used for testing in the six QPPX2 (QPP02, QPP12, and QPP22) and QPPX4 boreholes around Room Q. The single-packer test tools isolated single zones (test zones) within the boreholes (Figure 4-1). They included single $3.5-\mathrm{cm}$ outside-diameter sliding-end packers mounted on hollow mandrels. The packers had 36-cm-long, inflatable natural rubber elements. When inflated in a 3.8-cm-diameter borehole, the packers provided seal lengths of approximately 32 $\mathrm{cm}$. The downhole sections of the test tools had outside diameters of $3.5 \mathrm{~cm}$. 


\subsubsection{Small-Diameter, Dual-Packer Test Tools}

Small-diameter, dual-packer test tools were used for testing in the six QPPx3 and QPP 55 boreholes around Room $Q$. The test tools used two $3.5-\mathrm{cm}$ outside-diameter, opposed, slidingend packers mounted on a hollow mandrel (Figure 4-2). Each packer had two 36-cm-long, inflatable natural rubber elements that provided seal lengths of about $33 \mathrm{~cm}$ in a $3.8-\mathrm{cm}$-diameter borehole. The downhole sections of the test tools had outside diameters of $3.5 \mathrm{~cm}$. When inflated, the dual packers isolated a guard zone and a test zone. Each dual-packer test tool was equipped with ports which connected the test zone, guard zone, and packers to the control panel. A single electrical bundle contained a wire used to transmit electrical signals from the closure gauges and thermocouples.

\subsubsection{Large-Diameter, Dual-Packer Test Tools}

Large-diameter, dual-packer test tools were used in the three QPPX1 boreholes around Room Q. These dual-packer test tools held two sliding-end, $8.9-\mathrm{cm}$ outside-diameter inflatable packers mounted on $4.8-\mathrm{cm}$ outside-diameter hollow mandrels. The packers were oriented with the fixed ends toward the bottoms of the boreholes. The packers had two 46-cm-long inflatable synthetic and natural rubber elements. When inflated, these packers provided seal lengths of about $41 \mathrm{~cm}$ in 10.2-cm-diameter holes. The dual-packer tools isolated guard zones and test zones. Each dual-packer test tool was equipped with ports to connect the test zone, guard zone, and packers to the control panel. A single electrical bundle contained a wire used to transmit electrical signals from the closure gauges and thermocouples. Figure 4-3 shows the largediameter, dual-packer test tool.

\subsection{Transducers}

Zone pressures and packer pressures were measured using strain-gauge transducers located in the instrument alcove. For test and guard zones, Foxboro/ICT model 1225-16S-K54, 0-200 psi transducers accurate to \pm 1 psi over the rated pressure range were used. Packer pressures were monitored using Data Instruments model SA, 0-3000 psig pressure transducers accurate to \pm 30 psi over their rated pressure range. The transducers were calibrated before testing began and after testing was completed. No calibrations were performed during testing to avoid disrupting the tests. See Jensen et al. (1993) for pre-test calibration information.

\subsection{Flow-Control Systems}

Two separate brine-monitoring and management systems were used in the borehole hydraulic tests. Both of these systems were actuated by compressed nitrogen. Packer inflation, brine monitoring, and brine management (inflow or outflow) were accomplished through control panels and a network of control valves located in the instrumentation alcove. Figure 4-4 is a schematic representation of the brine system used with the large-diameter test tools. Figure 4-5 shows the packer-inflation and brine-management systems used with the small-diameter test tools.

The brine-measuring device used during constant-pressure flow tests for the large-diameter boreholes was based on an electronic flow meter 


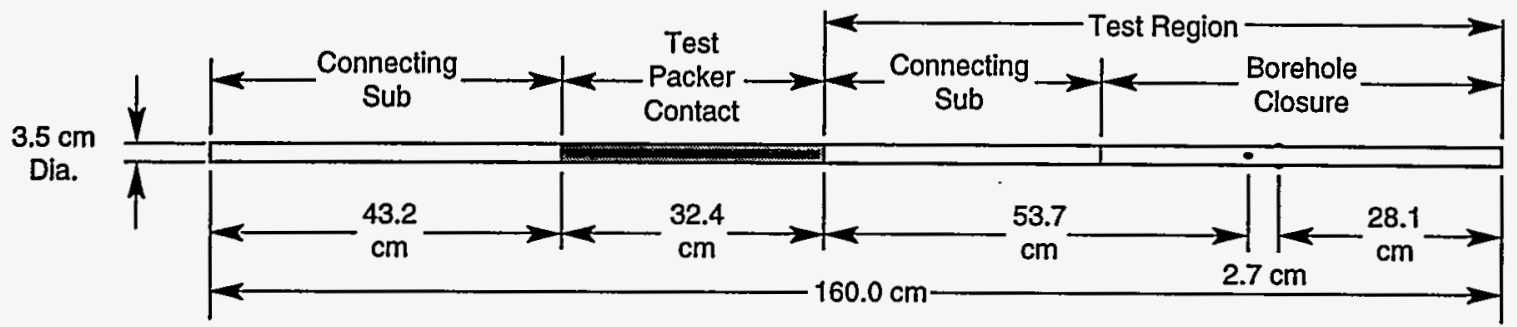

TRI-6119-240-0

Figure 4-1. Small-diameter single-packer test tool.

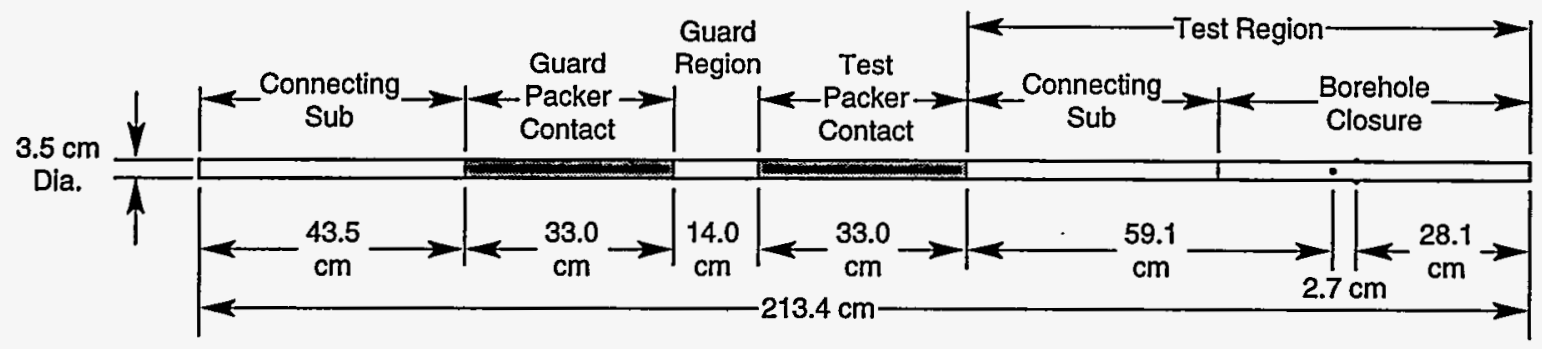

TRI-6119-240-0

Figure 4-2. Small-diameter dual-packer test tool.

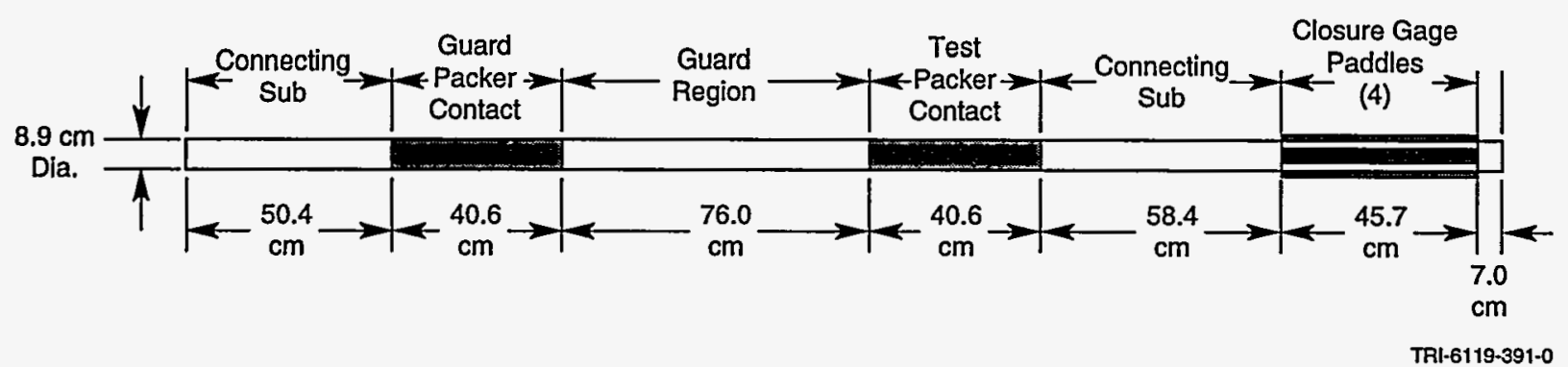

Figure 4-3. Large-diameter dual-packer test tool. 


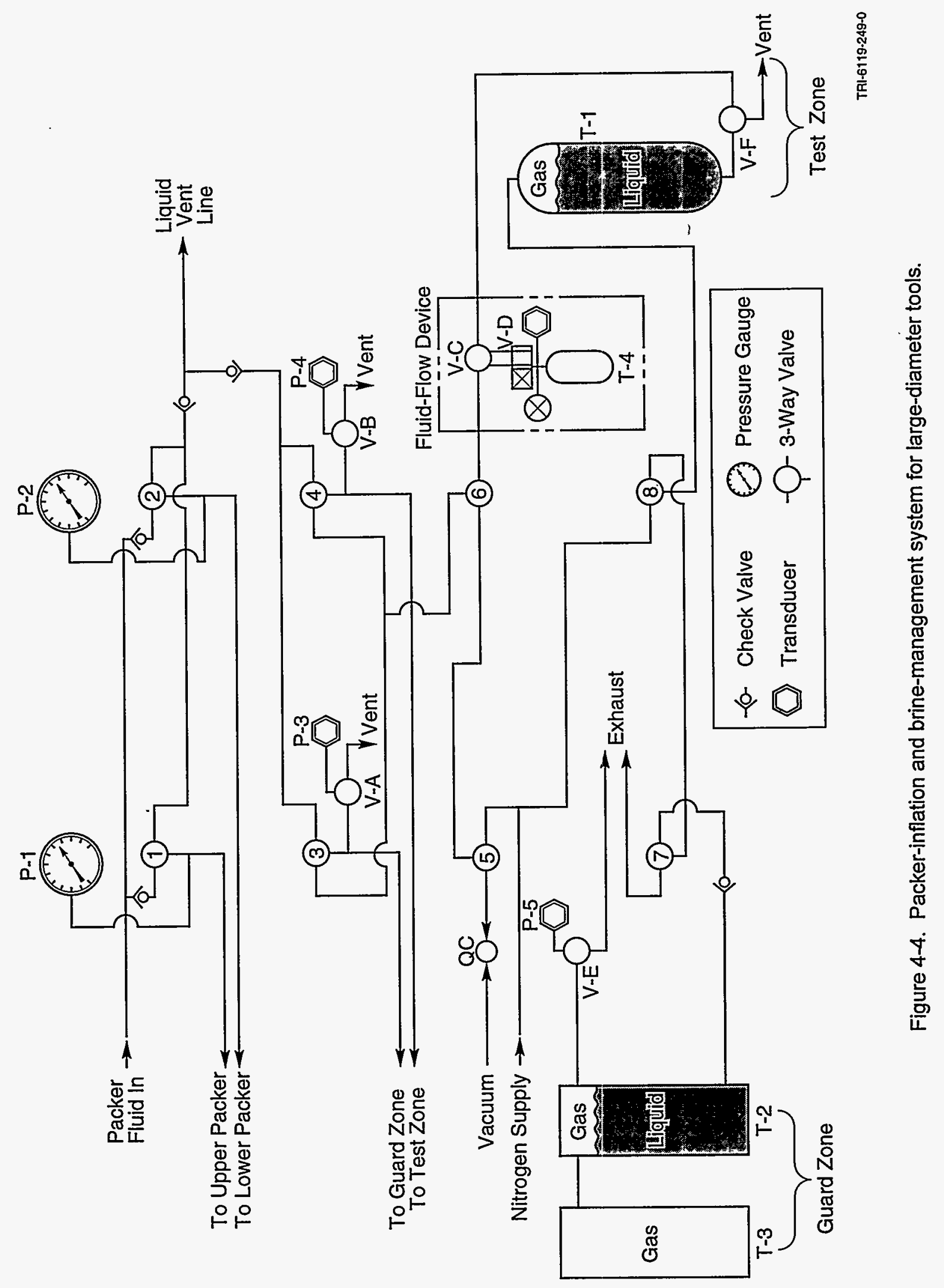




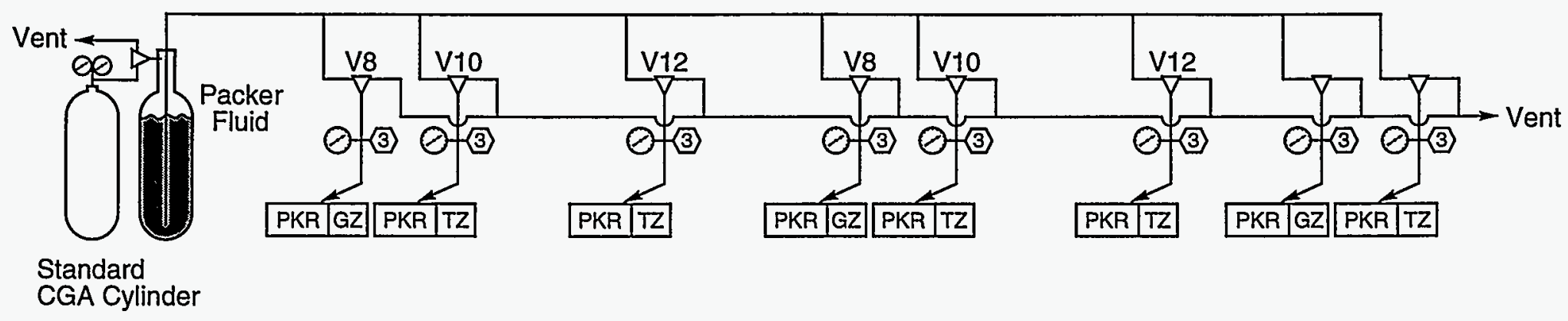

Brine Supply $(3 \mathrm{~L})$

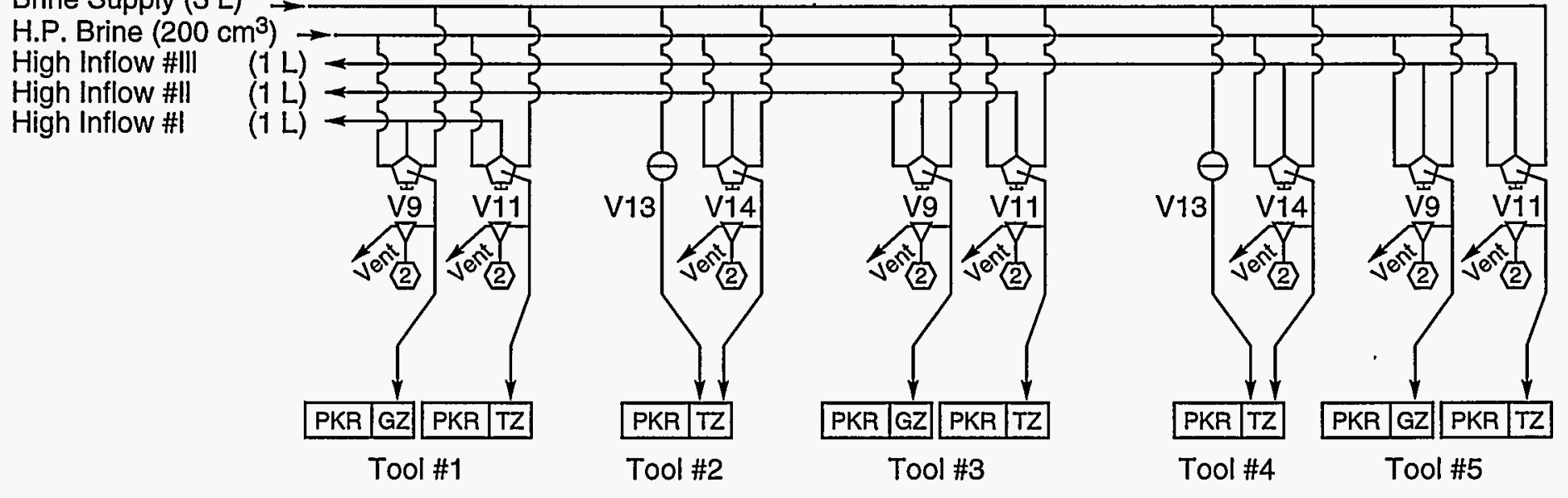

\begin{tabular}{|llll|}
\hline PKR & Packer & $\ominus$ 2-Way Valve & (2) 2000-psi Transducer \\
\hline $\mathrm{GZ}$ & Guard Zone & $\nabla$ 3-Way Valve & $(3)$ 3000-psi Transducer \\
\hline $\mathrm{TZ}$ & Test Zone & $\square$ 5-Way Valve & $\bigcirc$ 3000-psi Gauge \\
\hline
\end{tabular}

Figure 4-5. Packer-inflation and brine-management system for small-diameter tools. 
connected to a nitrogen reservoir to maintain the test-zone pressure at a constant value. Brine volumes injected into or withdrawn from the smalldiameter test zones under constant pressure were measured by monitoring the pressure differential between a brine reservoir and a reference reservoir with Sensotek AD111 AP differentialpressure transmitters. To accomplish this pressure monitoring, each of the small-diameter test-tool control panels was equipped with three stainless steel tubes of the same diameter and length. One tube provided the reservoir for injecting or collecting brine from the test zone; one tube was used as a buffer for the gas-head supply; and one tube was filled with a measured volume of brine, to serve as a reference volume. Because the three tubes were the same diameter and length, any brine change in the reservoir tube could be directly related and compared to the known brine volume in the reference tube. Volume changes between the two tubes were monitored using a differential pressure gauge located between the bottom of the reservoir tube and the reference tube. Both sides of the gauge were equivalently influenced by the injection/withdrawal pressure head supplied by the nitrogen through the buffer tube, thereby preserving the direct relationship of brine column weight between the reservoir and reference tubes. Figure 4-6 illustrates the configuration of the stainless steel tubes and differential pressure transmitter used to control and measure brine flow to and from the small-diameter test tools.

During constant-pressure flow tests, the test interval pressure should ideally remain constant. However, examination of the pressure data revealed that the pressure response for the small-diameter test tools was a "sawtooth" pattern (see, for example, Figure 7-11). The reason for this pattern is that as fluid flowed into the collection reservoir, the nitrogen in the head space and in the buffer tube compressed with a corresponding pressure increase. The sudden pressure drop resulted from draining the fluid in the collection reservoir. This problem could have been avoided had the nitrogen reservoir been of sufficiently greater volume compared to the fluid-collection reservoir.

\subsection{Data-Acquisition System}

A computer-controlled DAS monitored the progress of the tests and recorded output from the transducers, thermocouples, and LVDTs. The DAS contained a line conditioner, power supplies, a digital voltmeter, and a microcomputer to control test progress and to store and process data. The DAS was designed to accept and condition signals from the variety of sensors and instruments used in the tests. The DAS consisted of a Leading Edge computer using Labtech Notebook software to monitor the data. All pressure, flow, and closure data were transmitted to the computer using HANZON 4000-series 20-channel (16 input and 4 output) data loggers. The Leading Edge computer failed on October 18, 1991 and was replaced with a Texas Microsystems B-386 S/16 on January 15, 1992 , which was used until testing ended in June 1992.

All data were recorded on the system's hard disk and were periodically down-loaded onto floppy diskettes. Data file lengths were limited to a period of seven days. The DAS allowed technicians to view preselected parameters in real time on the system's monitor. This capability provided assistance to technicians in performing test set-up procedures or interpretation. Jensen et al. (1993) provide more information on the DAS, its operation, and its capabilities. 


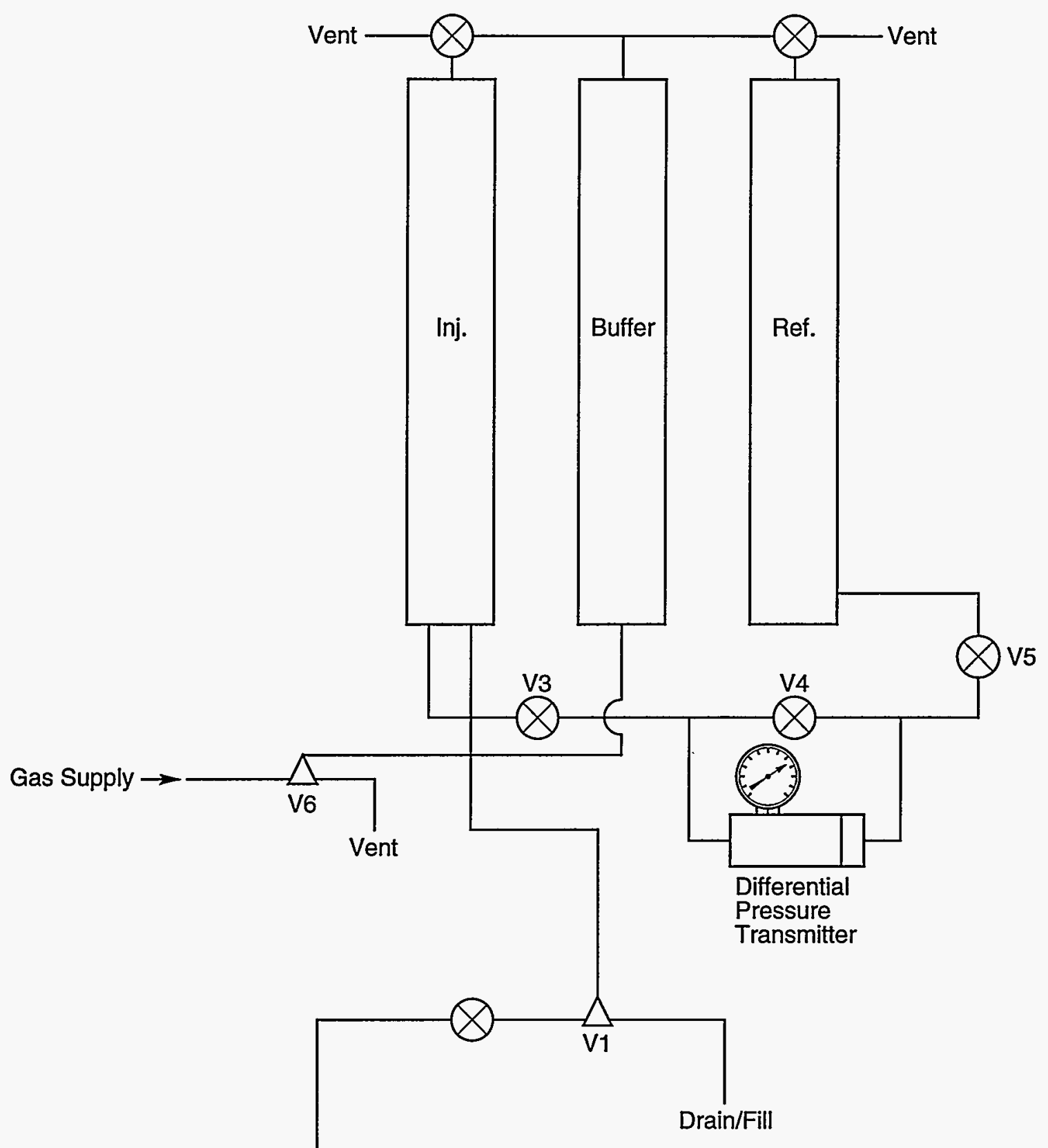

To Manifold

$$
\begin{aligned}
& \bigotimes \text { 2-Way Valve } \\
& \triangle \text { 3-Way Valve }
\end{aligned}
$$

TRl-6119-251-0

Figure 4-6. Brine flow and measurement system for small-diameter tools. 


\section{TESTING PROCEDURES}

This section presents system leak-check procedures, test-tool-installation procedures, and testing procedures used for the tesiting around Room Q. Additional details regarding installation and test-initiation procedures are discussed in Jensen et al. (1993).

\subsection{Leak-Check Procedures}

Prior to test-tool installation, system leak testing was performed on the test tools and the flow and packer-inflation manifolds. The systems were leak tested by installing each test tool in a length of sealed steel tubing and pressurizing the system. Leak integrity of the flow and packercontrol manifolds was evaluated by pressurizing the manifolds with 'compressed nitrogen and then monitoring for any pressure decay using a transducer. After the flow and packer-control leak check and a packer-pressure-adjustment period, the test and guard zones were each pressurized to approximately 3.5 MPa and monitored for evidence of leaks. Fittings and/or tubing were tightened or replaced to eliminate all leaks detected.

\subsection{Installation of Test Tools}

As discussed in Section 3, the twelve boreholes closest to Room $Q$ were cased soon after drilling. However, the test regions in all fifteen boreholes remained open to atmospheric pressure for up to two months before test-tool installation. Prior to test-tool installation, the boreholes were cleaned and calipers were run into the boreholes to verify that the borehole diameters were large enough to accommodate the test tools.

Borehole preparation prior to test-tool installation consisted of blowing compressed air into the boreholes to remove rock fragments and dust, squaring off the ends of the test regions within each borehole, and swabbing the horizontal or downward-sloping boreholes to remove brine. During these preparation activities, technicians noted a substantial volume of mud and/or clay at the end of the QPP01 test region. Therefore, an $86.3-\mathrm{cm}$ extension was added to the end of the QPP01 test tool to position the closure gauges and test-zone packer along competent borehole wall. Three different test-tool configurations were installed in the boreholes: six small-diameter, single-packer tools; six small-diameter, dualpacker tools; and three large-diameter, dualpacker tools. Summary information on the test-tool configuration for each borehole is given in Table 5-1.

A brine-injection system was used to inject brine into the test and guard zones following testtool emplacement. The system consisted of a brine reservoir and a low pressure gas supply regulated at $0.068 \mathrm{MPa}$. Using the low-pressure gas supply and selecting the proper control valve for each tool, the test zones were filled with brine, displacing trapped air through vent lines. After the test zones were filled with brine, the control valves were closed. In the dual-packer test-tool systems, the packers that isolated the test zones from the guard zones were inflated after the test zone and guard zone had been filled with brine. Figure $5-1$ is a schematic representation of the low-pressure brine-injection system.

\subsection{Testing Procedures}

Three types of hydraulic tests were performed to provide data that could be interpreted to quantify the pre- and post-mining hydraulic properties of the formation surrounding Room Q: 
Table 5-1. As-Built Test-Tool Configurations (after Jensen et al., 1993)

\begin{tabular}{|c|c|c|c|c|c|c|c|c|c|}
\hline $\begin{array}{l}\text { Tool/Hole } \\
\text { Number }\end{array}$ & $\begin{array}{c}\text { Radial } \\
\text { Dist. } \\
\text { from Q } \\
\text { Axis } \\
(\mathrm{m})\end{array}$ & $\begin{array}{l}\text { Hole } \\
\text { Diam. } \\
\text { (cm) }\end{array}$ & $\begin{array}{l}\text { Tool } \\
\text { Type }\end{array}$ & $\begin{array}{l}\text { Tool } \\
\text { Diam. } \\
(\mathrm{cm})\end{array}$ & $\begin{array}{l}\text { Test- } \\
\text { Zone } \\
\text { Length } \\
(\mathrm{cm})\end{array}$ & $\begin{array}{l}\text { Test- } \\
\text { Zone } \\
\text { Vol. } \\
\left(\mathrm{cm}^{3}\right)\end{array}$ & $\begin{array}{l}\text { Guard- } \\
\text { Zone } \\
\text { Length } \\
(\mathrm{cm})\end{array}$ & $\begin{array}{c}\text { Guard- } \\
\text { Zone } \\
\text { Vol. } \\
\left(\mathrm{cm}^{3}\right)\end{array}$ & $\begin{array}{l}\text { Install } \\
\text { Date }\end{array}$ \\
\hline QPP01 & 13.73 & 10.16 & DP & 8.89 & 188 & 5100 & 76 & 2000 & $5 / 7 / 89$ \\
\hline QPP02 & 7.63 & 3.81 & SP & 3.49 & 85 & 290 & - & - & $4 / 24 / 89$ \\
\hline QPP03 & 4.36 & 3.81 & DP & 3.49 & 90 & 300 & 14 & 135 & $4 / 24 / 89$ \\
\hline QPP04 & 3.38 & 3.81 & SP & 3.49 & 85 & 290 & - & - & $4 / 24 / 89$ \\
\hline QPP05 & 2.28 & 3.81 & DP & 3.49 & 90 & 300 & 14 & 135 & $4 / 24 / 89$ \\
\hline QPP11 & 13.77 & 10.16 & DP & 8.89 & 135 & 6000 & 76 & 2000 & $5 / 6 / 89$ \\
\hline QPP12 & 7.63 & 3.81 & SP & 3.49 & 85 & 290 & - & - & $4 / 19 / 89$ \\
\hline QPP13 & 4.72 & 3.81 & DP & 3.49 & 90 & 300 & 14 & 135 & $4 / 19 / 89$ \\
\hline QPP14 & 3.50 & 3.81 & SP & 3.49 & 85 & 290 & - & - & $4 / 19 / 89$ \\
\hline QPP15 & 2.41 & 3.81 & DP & 3.49 & 90 & 300 & 14 & 135 & $4 / 19 / 89$ \\
\hline QPP21 & 13.44 & 10.16 & $D P^{\circ}$ & 8.89 & 136 & 6100 & 76 & 2000 & $5 / 8 / 89$ \\
\hline QPP22 & 7.39 & 3.81 & SP & 3.49 & 85 & 290 & - & - & $4 / 23 / 89$ \\
\hline QPP23 & 4.49 & 3.81 & DP & 3.49 & 90 & 300 & 14 & 135 & $4 / 23 / 89$ \\
\hline QPP24 & 3.05 & 3.81 & SP & 3.49 & 85 & 290 & - & - & $4 / 23 / 89$ \\
\hline QPP25 & 2.41 & 3.81 & DP & 3.49 & 90 & 300 & 14 & 135 & $4 / 23 / 89$ \\
\hline
\end{tabular}

* $\mathrm{DP}=$ double packer $\mathrm{SP}=$ single packer

Notes:

1) Test-zone length is the distance between the hole end and the borehole contact of the deepest packer.

2) Test- and guard-zone volumes include the volumes of the connecting lines.

3) Guard-zone length is the distance between packer borehole contacts.

4) Elevation of the Room $Q$ axis is $387.02 \mathrm{~m}$ above mean sea level at test location.

5) Install dates refer to the time when tool installation was complete. 


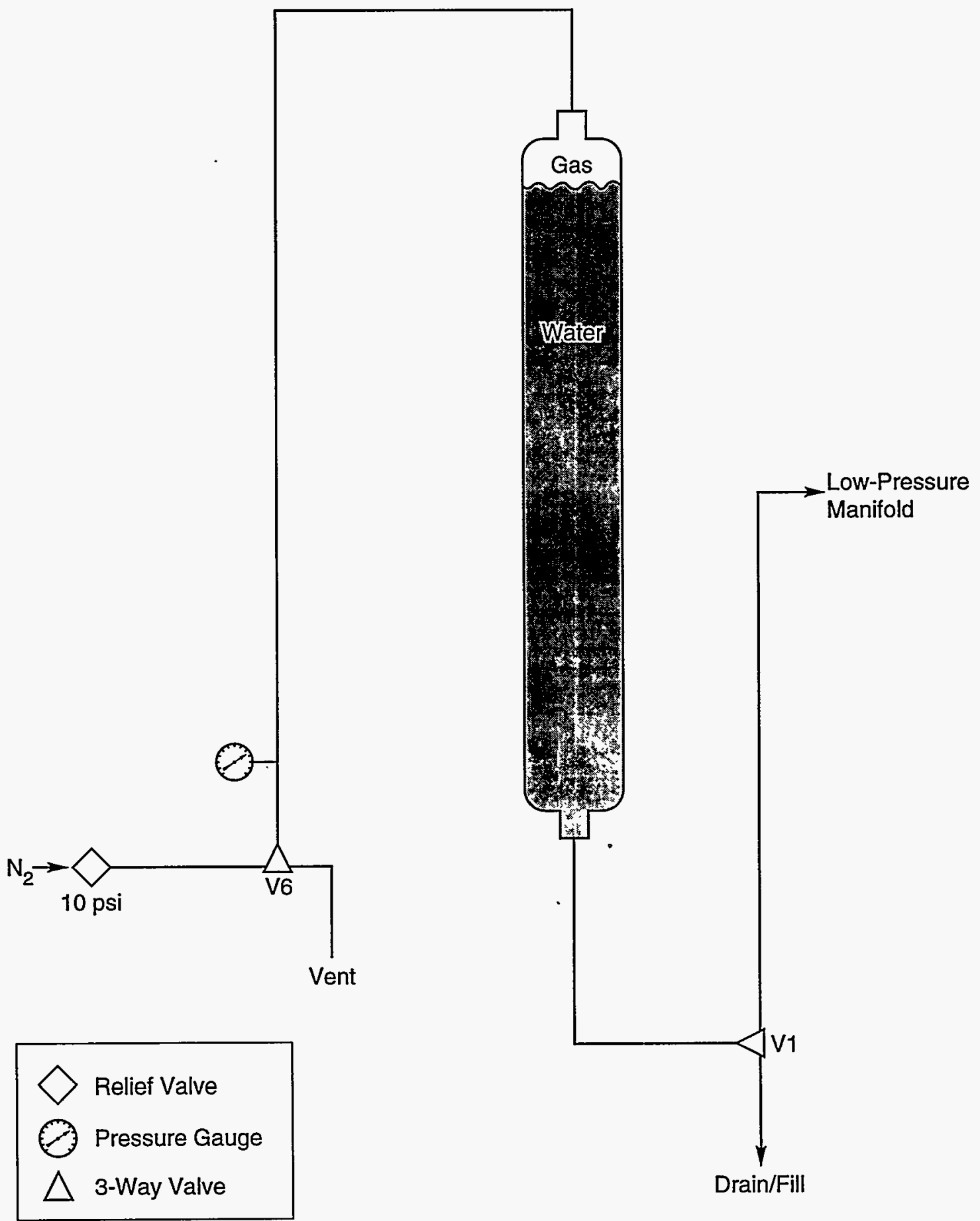

TRI-6119-248-0

Figure 5-1. Low-pressure brine-injection system. 
shut-in tests; pressure-pulse tests; and constantpressure flow tests.

\subsubsection{Shut-in Tests}

Shut-in (or pressure-buildup) tests were used to initialize testing in the boreholes and as a final test event following constant-pressure flow testing. A shut-in test is performed by closing the valves which connect the test interval to either atmospheric pressure or the flow-control system. These periods of pressure buildup should ideally continue until the borehole pressure reaches the ambient formation pore pressure. However, because of the low transmissivities of the tested strata, equilibrium pressures could not be reached in the boreholes in the time between the initial shut-in and the mining of Room $Q$, and still leave time to perform pre-mining permeability tests. Therefore, the initial shut-in tests were terminated prematurely to allow other testing to proceed.

\subsubsection{Pressure-Pulse Tests}

For a pressure-pulse test, the test-zone pressure is instantaneously reduced or increased by venting fluid from or injecting fluid into the zone. The volume of injected or withdrawn fluid should be recorded for calculation of test-zone compressibility. Immediately following the test-zone pressure reduction or increase, the shut-in valve is closed and the test-zone pressure is allowed to reequilibrate with the pore pressure in the surrounding rock.

\subsubsection{Constant-Pressure Flow Tests}

In low-transmissivity environments, flow tests performed at constant pressure are preferred over constant-rate flow tests because: 1) constant test pressures are operationally much easier to maintain than very low constant flow rates, and 2) constant-pressure tests are not as affected by wellbore storage as constant-rate tests, which simplifies test analysis.

Constant-pressure flow tests were initiated in the boreholes surrounding Room $Q$ by pressurizing the flow-control panels to predetermined operational pressures and then opening the valves between the test zones and flow panels. During the 150-day duration of the flow tests, both the test-interval pressures and the volumes of fluid drained from or injected into the test intervals were measured. The brine-collection reservoirs had to be drained periodically during the flow tests, which resulted in the small pressure drops observed during some of the flow tests. At the conclusion of the constant-pressure flow tests, the valves between the test zones and flow panels were closed, initiating pressure-buildup (shut-in) tests. 


\section{INTERPRETATION OBJECTIVES AND METHODS}

\subsection{Objectives}

The purpose of hydraulic testing around Room $Q$ was to characterize the hydraulic properties (transmissivity, storativity, and initial formation pressure) of the evaporite units before and after mining. The configuration of the borehole arrays was designed to investigate how changes in the stress field around Room $Q$ would affect the hydraulic properties of the evaporite units as functions of distance and direction from the room.

\subsection{General Interpretation Methods}

Analysis of hydraulic test data is an inverse problem where the system response is known but the conceptual flow model and hydraulic parameters of the responding medium are unknown. The hydraulic tests performed in the boreholes around Room $Q$ have been interpreted using a combination of analytical and numerical methods. All of the methods used, however, assume that hydraulic properties are not changing during a test. Interpretation of the pressure responses observed during and after the mining of Room $Q$ might be better performed using a numerical model capable of coupling the geomechanical responses to mining with the hydraulic responses to the testing, but no such model was available.

\subsubsection{Flow-Model Identification}

Correct application of analytical and numerical analysis methods to hydraulic-test data requires that the conceptual flow model that most closely represents the observed formationpressure or flow-rate response be identified. Flow- model identification is facilitated by the construction of diagnostic plots (Bourdet et al., $1989)$ that delineate three primary flow regimes (Figure 6-1). Early-time or near-wellbore flow regimes include wellbore storage, skin (increased or decreased permeability in the immediate vicinity of the wellbore), and fracture flow. Middle-time regimes or system responses reflect homogeneous, heterogeneous, composite, fracture, double-porosity, and/or partial-penetration conditions. Late-time responses show either infiniteacting behavior or bounded behavior. Common types of boundaries are linear no-flow and constant-pressure boundaries, and circular no-flow and constant-pressure boundaries. The flow model active during the early-, middle-, and latetime flow regimes for each test was identified by the characteristic shape of the pressure derivative on the diagnostic plot. Horne (1990) provides a detailed discussion of the use of the pressure derivative for flow-model identification, and provides examples of various flow models for visual comparison to actual data.

\subsubsection{Analytical Techniques}

Analytical solutions exist for the three types of hydraulic tests that were performed in the Room $Q$ boreholes. Pressure-pulse tests (also referred to as "shut-in", "modified", or "pressurized" slug tests) can be interpreted using type curves developed from an analytical solution by Bredehoeft and Papadopulos (1980). The analytical solution for changing flow rate during a constant-pressure test was developed by Jacob and Lohman (1952). Gringarten et al. (1979) presented a solution for the shut-in period following constant-rate and variable-rate events. All of the analytical techniques estimate transmissivity by 


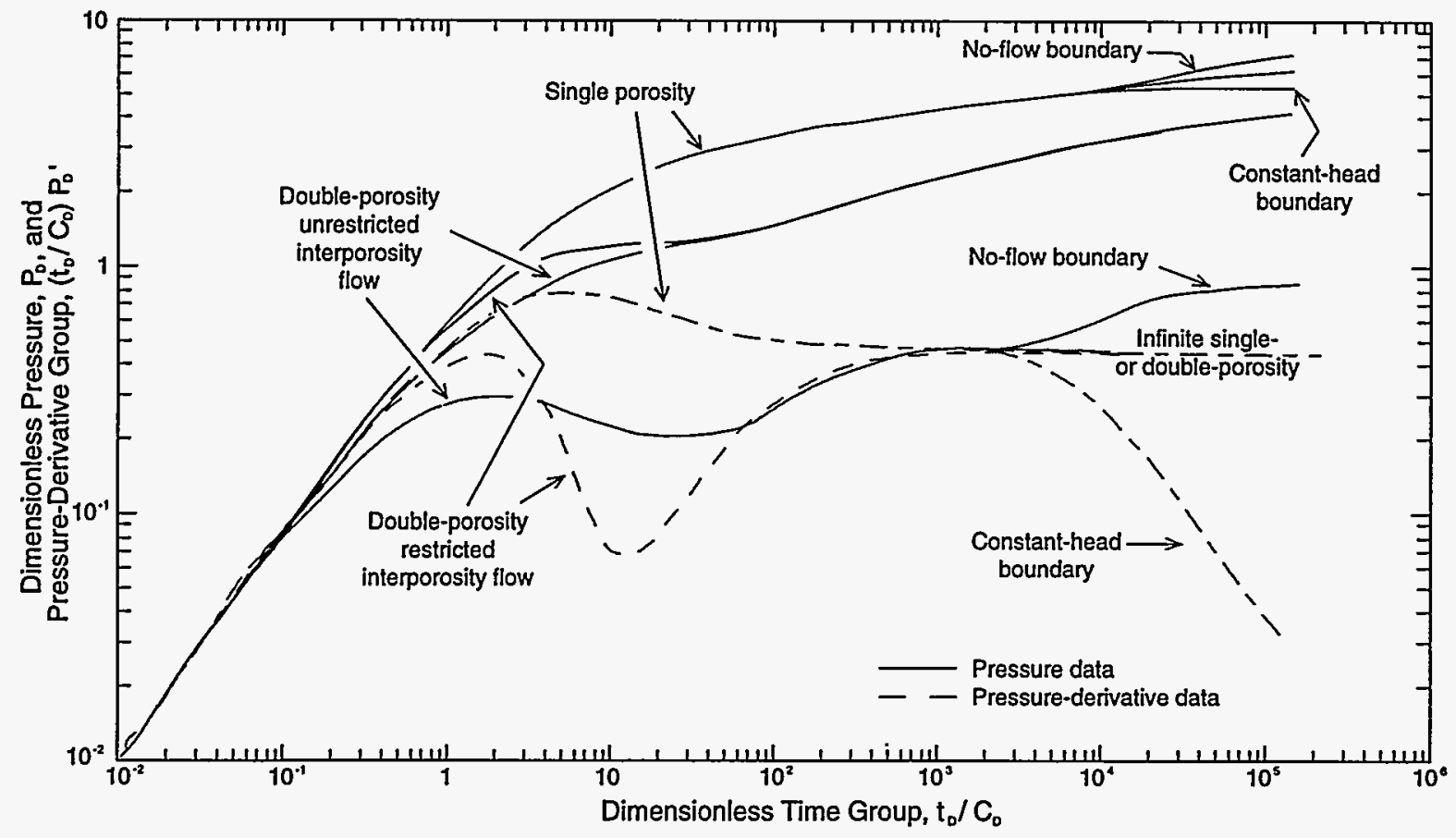

TRI-6115-379-0

Figure 6-1. Diagnostic plot for flow-model identification.

using a match point and substitution of a dimensionless variable. For a detailed discussion of analytical techniques, see Beauheim et al. (1993).

\subsubsection{Numerical Techniques}

Analytical techniques are useful tools for estimating transmissivity and sometimes storativity from individual test sequences. However, they do not account for transient conditions which may exist prior to a test sequence. The numerical wellbore simulator GTFM (Graph Theoretic Field Model; Pickens et al., 1987) was designed specifically for interpretation of sequential test events under nonideal conditions. The advantage of this approach for low-permeability formations is that the effects of lingering pressure transients, temperature effects, and changing wellbore storage are accounted for in the interpretation. The results are a parameter set that is consistent for an entire sequence of test events.

\subsection{Treatment of Borehole Geometry}

The test interpretations presented in this report were performed assuming radial flow towards the test boreholes. Considering that all of the boreholes were drilled at acute angles to the subhorizontal bedding and that in some cases the tested intervals did not span the full thicknesses of particular layers, flow to the boreholes could have had radial, elliptical, or spherical components, depending upon the anisotropy in permeability of the tested strata. Anisotropy in permeability can be caused by a number of factors, including vertical heterogeneity, fracturing, and the presence of 
tabular minerals, such as clays, which tend to allow flow parallel to their long axes more readily than flow parallel to their short axes.

No quantitative information is available concerning anisotropy in evaporites. Our macroscopic examination of WIPP core, however, has led to the following qualitative observations. Neither pure nor polyhalitic halite contains structures or other features that would lead to preferential permeability in any consistent direction. Pure and polyhalitic halite may, therefore, be considered isotropic. Argillaceous halite contains bedded clay seams and/or stringers that might impart a preferential permeability parallel to bedding. The clay itself may, in fact, be the most permeable component of the rock. Argillaceous halite, therefore, is probably anisotropic with vertical permeability lower than horizontal permeability. Anhydrite interbeds commonly contain subhorizontal, bedding-plane fractures (Borns, 1985). Video logging of boreholes in the WIPP facility has shown these bedding-plane fractures to be the primary, if not exclusive, source of brine coming from the interbeds. Anhydrite interbeds, therefore, probably have horizontal permeabilities that are higher than vertical permeabilities due to fracture orientation.

Beauheim et al. (1993) reviewed literature pertaining to the influences of borehole slant and anisotropy on hydraulic-test responses. They also performed a numerical modeling study to evaluate the accuracy of applying standard radial-flow solutions and an idealized equivalent-verticalborehole geometry to interpret hydraulic tests in slanted boreholes completely penetrating a permeable layer. The idealized equivalent vertical borehole consisted of a borehole with a length equal to the vertical thickness of the tested strata and a diameter equal to the average of the major and minor axes of the ellipse formed by the intersection of the slanted borehole and a horizontal plane. They concluded that for borehole slants up to $75^{\circ}$ from vertical (the maximum slant they investigated) and for horizontal-to-vertical permeability ratios of at least 10 , tests could be interpreted with little error using the equivalentvertical-borehole geometry. Thus, the tests of anhydrite layers conducted in boreholes QPP01, QPP03, and QPP13 can probably be interpreted reliably using the equivalent-vertical-borehole approach.

The other borehole tests were conducted in halite or polyhalitic halite layers that extended above, and below the isolated test intervals. Because the boreholes were not cored or otherwise logged, the clay contents of these layers are uncertain. If the tested strata were isotropic and thick relative to the vertical extent of the test interval, three flow regimes could be evident during a hydraulic test: an early cylindrical- (radial-) flow period, a transition period, and a late spherical-flow period (Tang, 1988). Doe (1991) presented analytical solutions for the variations in flow rates during constant-pressure flow tests for radial and spherical flow conditions. By presenting the solutions in terms of dimensionless flow rate versus dimensionless flow time, Doe graphed loglog "type curves" (Figure 6-2). Formation hydraulic parameters and the nature of the flow regime can be identified by matching test data to one of the type curves. The data from the flow tests in QPP12, QPP13, and QPP15 were interpreted through type-curve matching.

A distinguishing feature of spherical flow as opposed to radial flow is the stabilization at late time of pressure in the case of constant-rate production, or of rate in the case of constantpressure production. If a radial-flow model is inappropriately applied to spherical-flow data, the late-time data will appear to reflect the presence of some heterogeneity, such as a constant-pressure boundary or an increase in permeability. All of the 


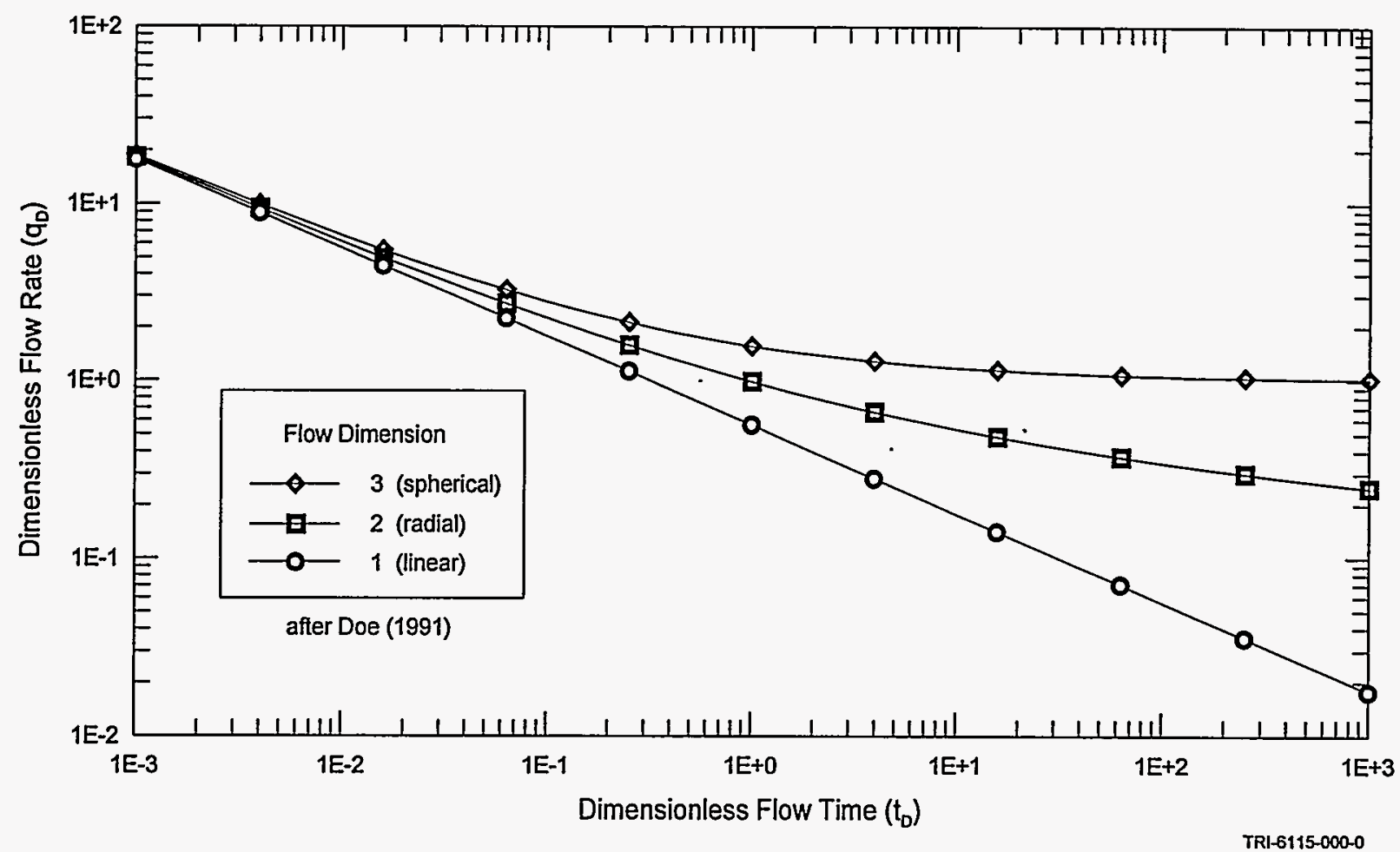

Figure 6-2. Type curves for constant-pressure flow.

tests that could be interpreted were interpreted with the radial-flow numerical model GTFM. No indications of spherical flow were evident in any of the tests, although the quality of the data may, in some instances, have masked such effects.

\subsection{Uncertainty}

Reliable interpretation of the hydraulic tests conducted around Room $Q$ is hampered by numerous uncertainties relating to the specific strata that were tested, the effects being measured, effects or properties that were not measured, and the limitations of the analytical/ numerical techniques used in test interpretation.

Of the 15 boreholes around Room $Q$, only QPP05 was cored and that core was too broken to $\log$ (Jensen et al., 1993). The other 14 . boreholes were drilled with plug bits. As a result, no direct identification of the stratigraphic units within the borehole test intervals could be made. The stratigraphic positions of the test intervals presented in Figure 1-2 were extrapolated, with a correction for the regional dip, from the information obtained from four boreholes, two cored straight up and two cored straight down, in the instrumentation alcove immediately adjacent to Room Q. As shown in Figure 1-2, most of the test-interval positions are close to extrapolated map-unit contacts. The uncertainty in the extrapolated stratigraphy is such that most of the test intervals could actually lie in units above or below those indicated on Figure 1-2. The results of video logging of borehole QPP15 in 1993 revealed that its test-zone position closely corresponds to the position given on Figure 1-2.

Another source of uncertainty in test interpretation relates to the different processes or effects that occurred during the tests. Ideally, the 
pressure changes measured during the tests would have been caused solely by the responses of the perfectly isolated test intervals and the surrounding formation. In fact, the observed pressure changes were also affected by changes in packer-inflation pressures and hence volumes, by borehole deformation, by movement of the test tools, and, in some cases, by apparent leaks around the packers or through other parts of the test apparatus. The effects of these non-ideal conditions are discussed in relation to specific tests in Section 7.

Interpretation of transmissivity from pressure-pulse tests relies on knowledge of the aggregate compressibility of everything contained within a test zone (Neuzil, 1982). If the test-zone compressibility is unknown, only the ratio of transmissivity to test-zone compressibility can be determined. Thus, uncertainty in test-zone compressibility translates linearly to uncertainty in transmissivity. Test-zone compressibilities were measured in ten of the Room $Q$ boreholes in May 1989 and ranged from $1.0 \times 10^{-9}$ to $1.7 \times 10^{-8} \mathrm{~Pa}^{-1}$ (Table 6-1). Repeated measurements in eight of the boreholes differed by factors between 1.3 and 4.6. These measurements provide an initial basis for the estimation of transmissivity from the pressure-pulse tests conducted in the ten boreholes. However, Beauheim et al. (1993) showed that test-zone compressibilities are often pressure-dependent, with higher test-zone compressibilities observed at lower pressures. No data are available with which to evaluate the pressure-dependence of test-zone compressibilities in the Room $Q$ boreholes, decreasing confidence in our estimates of transmissivity.

Storativities interpreted from single-hole test data are inherently uncertain because storativity is inversely correlated with the square of the effective borehole radius used in hydraulic-test interpretation. Effective borehole radius depends, in part, on the presence or absence of an increased or decreased permeability "skin" around a borehole, and quantitative information on borehole skins is rarely available.

Comparison of pre- and post-mining tests performed in some of the boreholes around Room $Q$ showed clear indications that geomechanical responses to the mining affected hydraulic properties and pore pressures (see Sections 7 and 8). The analytical and numerical techniques used to interpret the tests, however, could not account for geomechanical effects directly. Insofar as the geomechanical responses occurred rapidly after mining and did not continue to change hydraulic properties, the interpretations of hydraulic tests performed months to years later should be little affected. Initial pore-pressure conditions for the post-mining tests, however, must be considered uncertain. 
Table 6-1. Summary of Test-Zone-Compressibility Measurements

\begin{tabular}{|c|c|c|c|c|c|}
\hline Borehole & $\begin{array}{c}\text { Initial } \\
\text { Pressure } \\
\text { (MPa) }\end{array}$ & $\begin{array}{c}\text { Final } \\
\text { Pressure } \\
\text { (MPa) }\end{array}$ & $\begin{array}{c}\text { Volume } \\
\text { Produced } \\
\left(\mathrm{cm}^{3}\right)\end{array}$ & $\begin{array}{l}\text { Zone Fluid } \\
\text { Volume } \\
\left(\mathrm{cm}^{3}\right)\end{array}$ & $\begin{array}{c}\text { Zone } \\
\text { Compressibility } \\
\left(\mathrm{Pa}^{-1}\right)\end{array}$ \\
\hline \multirow[t]{3}{*}{ QPP02 } & 0.94 & 0.46 & 0.9 & 290 & $6.5 \times 10^{-9}$ \\
\hline & 0.94 & 0.46 & 1.3 & 290 & $9.3 \times 10^{-9}$ \\
\hline & 0.46 & 0.94 & -0.5 & 290 & $3.6 \times 10^{-9}$ \\
\hline \multirow[t]{3}{*}{ QPP04 } & 3.39 & 0.51 & 2.2 & 290 & $2.6 \times 10^{-9}$ \\
\hline & 3.39 & 0.51 & 2.6 & 290 & $3.1 \times 10^{-9}$ \\
\hline & 0.51 & 3.26 & -1.5 & 290 & $1.9 \times 10^{-9}$ \\
\hline \multirow[t]{3}{*}{ QPP05 } & 2.12 & 0.5 & 2.7 & 300 & $5.6 \times 10^{-9}$ \\
\hline & 2.12 & 0.5 & 4.6 & 300 & $9.5 \times 10^{-9}$ \\
\hline & 0.5 & 2.1 & -1.4 & 300 & $2.9 \times 10^{-9}$ \\
\hline QPP11 & 1.17 & 0.11 & 6.5 & 6000 & $1.0 \times 10^{-9}$ \\
\hline \multirow[t]{2}{*}{ QPP14 } & 4.87 & 0.24 & 1.8 & 290 & $1.3 \times 10^{-9}$ \\
\hline & 0.24 & 4.77 & -2.8 & 290 & $2.1 \times 10^{-9}$ \\
\hline \multirow[t]{3}{*}{ QPP15 } & 4.96 & 0.09 & 5.4 & 300 & $3.7 \times 10^{-9}$ \\
\hline & 4.96 & 0.09 & 25.0 & 300 & $1.7 \times 10^{-8}$ \\
\hline & 0.09 & 4.96 & -6.7 & 300 & $4.6 \times 10^{-9}$ \\
\hline QPP21 & 2.04 & 0.09 & 23.0 & 6000 & $2.0 \times 10^{-9}$ \\
\hline \multirow[t]{3}{*}{ QPP22 } & 6.17 & 0.43 & 5.4 & 290 & $3.2 \times 10^{-9}$ \\
\hline & 6.17 & 0.43 & 7.2 & 290 & $4.3 \times 10^{-9}$ \\
\hline & 0.43 & 6.03 & -5.4 & 290 & $3.3 \times 10^{-9}$ \\
\hline \multirow[t]{3}{*}{ QPP23 } & 1.85 & 0.44 & 9.0 & 300 & $2.1 \times 10^{-9}$ \\
\hline & 1.85 & 0.44 & 1.9 & 300 & $4.5 \times 10^{-9}$ \\
\hline & 0.44 & 1.85 & -2.0 & 300 & $4.7 \times 10^{-9}$ \\
\hline \multirow[t]{3}{*}{ QPP25 } & 5.53 & 0.53 & 1.8 & 300 & $1.2 \times 10^{-9}$ \\
\hline & 5.53 & 0.53 & 5.6 & 300 & $3.7 \times 10^{-9}$ \\
\hline & 0.53 & 5.4 & -2.3 & 300 & $1.6 \times 10^{-9}$ \\
\hline
\end{tabular}




\section{HYDRAULIC TESTING}

\subsection{Testing History}

Test tools were installed in the Room $Q$ boreholes and test intervals were shut-in between April 25 and May 8, 1989 (1989 Calendar days 115 and 128). In most intervals, the pressures were increased to about $0.7 \mathrm{MPa}$ by injecting brine shortly after shut-in. Over the next several weeks, various tool and/or pressure readjustments were performed in different boreholes as discussed in the Operational Log presented by Jensen et al. (1993). On May 18 and 19, 1989 (1989 Calendar days 138 and 139), test-zone compressibility measurements were made in the test intervals of all boreholes except for QPP01, QPP03, QPP12, QPP13, and QPP24 to check for trapped air (Table 6-1). On May 31, 1989 (1989 Calendar day 151), pressure-pulse tests were initiated in all test intervals. Pulse-injection tests were performed in the test intervals in which pressures were less than $5 \mathrm{MPa}$ (QPP02, QPP04, QPP05, QPP11, QPP12, QPP14, QPP15, and QPP21) while pulsewithdrawal tests were performed in the test intervals in which pressures were greater than 5 MPa (QPP01, QPP03, QPP13, QPP22, QPP23, QPP24, and QPP25) (Table 6-1). The test durations were constrained by the schedule established for the mining of Room $Q$ which, for contractual reasons, could not be modified.

On July 12, 1989 (1989 Calendar day 193), the test and guard zones in the nine boreholes that would be closest to Room $Q$ were opened in preparation for mining. This was done to prevent hydraulic fracturing of the rock, which was considered possible if the mining of Room $Q$ reduced the stress on the rock below the fluid pressures in the boreholes. The mining occurred between July 12 and August 8, 1989 (1989 Calendar days 193 to 220), with the plane containing the test intervals being passed on July 24, 1989 (1989 Calendar day 205). All of the open test intervals were shut-in on July 26, 1989 (1989 Calendar day 207), except for that in QPP23, which was shut-in on August 8,1989. The mining was performed in one pass using a Robbins Hard Rock Tunnel Boring Machine to cut a 2.9-m-diameter cylindrical opening.

On February 21, 1990 (1989 Calendar day 417 ), flow tests were initiated in all test intervals except for those in QPP22 and the QPPx4 boreholes. In QPP22, a pulse-withdrawal test was initiated on February 21, 1990, and a flow test was initiated on May 3, 1990 (1989 Calendar day 488). The flow tests were intended to be conducted at constant pressures but, in most cases, the testinterval pressures increased during the tests as brine flowed into the brine accumulators, compressing the gas buffers contained therein (see Section 4.3). The brine accumulators were also drained as necessary during the tests, introducing additional pressure fluctuations: Most of the flow tests were terminated on July 18, 1990 (1989 Calendar day 564) after 147 days of flow.

Pressure-buildup tests were conducted after the flow tests were terminated and the test intervals were shut-in. These tests involved nothing more than simple monitoring of the testinterval pressures. In most cases, the pressurebuildup tests continued past the end of the current reporting period (June 8, 1992).

\subsection{Test Interpretation}

Interpretations of the tests performed in each hole are presented below. Tables 7-1 and 7-2 summarize the results. 
Table 7-1. GTFM Analysis Results for the Pre-Mining Period.

\begin{tabular}{|c|c|c|c|c|c|c|c|c|c|}
\hline Borehole & Zone & $\begin{array}{c}\text { Map } \\
\text { Unit(s) }\end{array}$ & $\begin{array}{c}\text { Transmissivity } \\
\left(\mathrm{m}^{2} / \mathrm{s}\right)\end{array}$ & $\begin{array}{l}\text { Permeability- } \\
\text { Thickness } \\
\left(\mathrm{m}^{3}\right)^{\star}\end{array}$ & Storativity & $\begin{array}{c}\text { Average } \\
\text { Hydraulic } \\
\text { Conductivity } \\
(\mathrm{m} / \mathrm{s})\end{array}$ & $\begin{array}{c}\text { Average } \\
\text { Permeability } \\
\left(\mathrm{m}^{2}\right)\end{array}$ & $\begin{array}{c}\text { Specific } \\
\text { Storage } \\
\left(\mathrm{m}^{-1}\right)\end{array}$ & $\begin{array}{c}\text { Pore } \\
\text { Pressure } \\
\text { (MPa) }\end{array}$ \\
\hline QPP03 & Test & anhy. "b" & $2.6 \times 10^{-14}$ & $4.5 \times 10^{-21}$ & $2.0 \times 10^{-7}$ & $4.3 \times 10^{-13}$ & $7.6 \times 10^{-20}$ & $3.3 \times 10^{-6}$ & 12.9 \\
\hline QPP04 & Test & 6,7 & NA & NA & NA & NA & NA & NA & 9.0 \\
\hline QPP11 & Test & $\mathrm{H}-1$ & $\left(\leq 2.1 \times 10^{-18}\right)$ & $\left(\leq 3.7 \times 10^{-24}\right)$ & $\left(2.7 \times 10^{-6}\right)$ & $\left(\leq 1.6 \times 10^{-15}\right)$ & $\left(\leq 2.7 \times 10^{-22}\right)$ & $\left(2.0 \times 10^{-6}\right)$ & $(\geq 5.5)$ \\
\hline QPP12 & Test & $\mathrm{H}-3$ & $1.3 \times 10^{-15}$ & $2.3 \times 10^{-22}$ & $2.1 \times 10^{-6}$ & $2.7 \times 10^{-22}$ & $1.3 \times 10^{-15}$ & $2.5 \times 10^{-6}$ & 9.6 \\
\hline QPP13 & Test & MB139 & $5.1 \times 10^{-14}$ & $8.9 \times 10^{-21}$ & $6.6 \times 10^{-8}$ & $3.4 \times 10^{-13}$ & $6.0 \times 10^{-20}$ & $4.4 \times 10^{-7}$ & 12.4 \\
\hline QPP13 & Guard & MB139 & NA & NA & NA & NA & NA & NA & 11.0 \\
\hline QPP23 & Guard & 3 & NA & NA & NA & NA & NA & NA & 9.8 \\
\hline QPP24 & Test & 2 & NA & NA & NA & NA & NA & NA & $>9$ \\
\hline QPP25 & Test & 2,3 & NA & NA & NA & NA & NA & NA & $>7.5$ \\
\hline QPP25 & Guard & 2,3 & NA & NA & NA & NA & NA & NA & 9.4 \\
\hline
\end{tabular}

* Conversion from transmissivity to permeability-thickness uses brine density of $1220 \mathrm{~kg} / \mathrm{m}^{3}$ (Deal et al., 1989), viscosity of $2.1 \mathrm{cp}$ (McTigue, 1993), and gravitational acceleration of $9.7917 \mathrm{~m} / \mathrm{s}^{2}$ (Barrows et al., 1983).

NA - data inadequate for parameter estimation.

() - parentheses indicate high relative uncertainty. 
Table 7-2. GTFM Analysis Results for the Post-Mining Period.

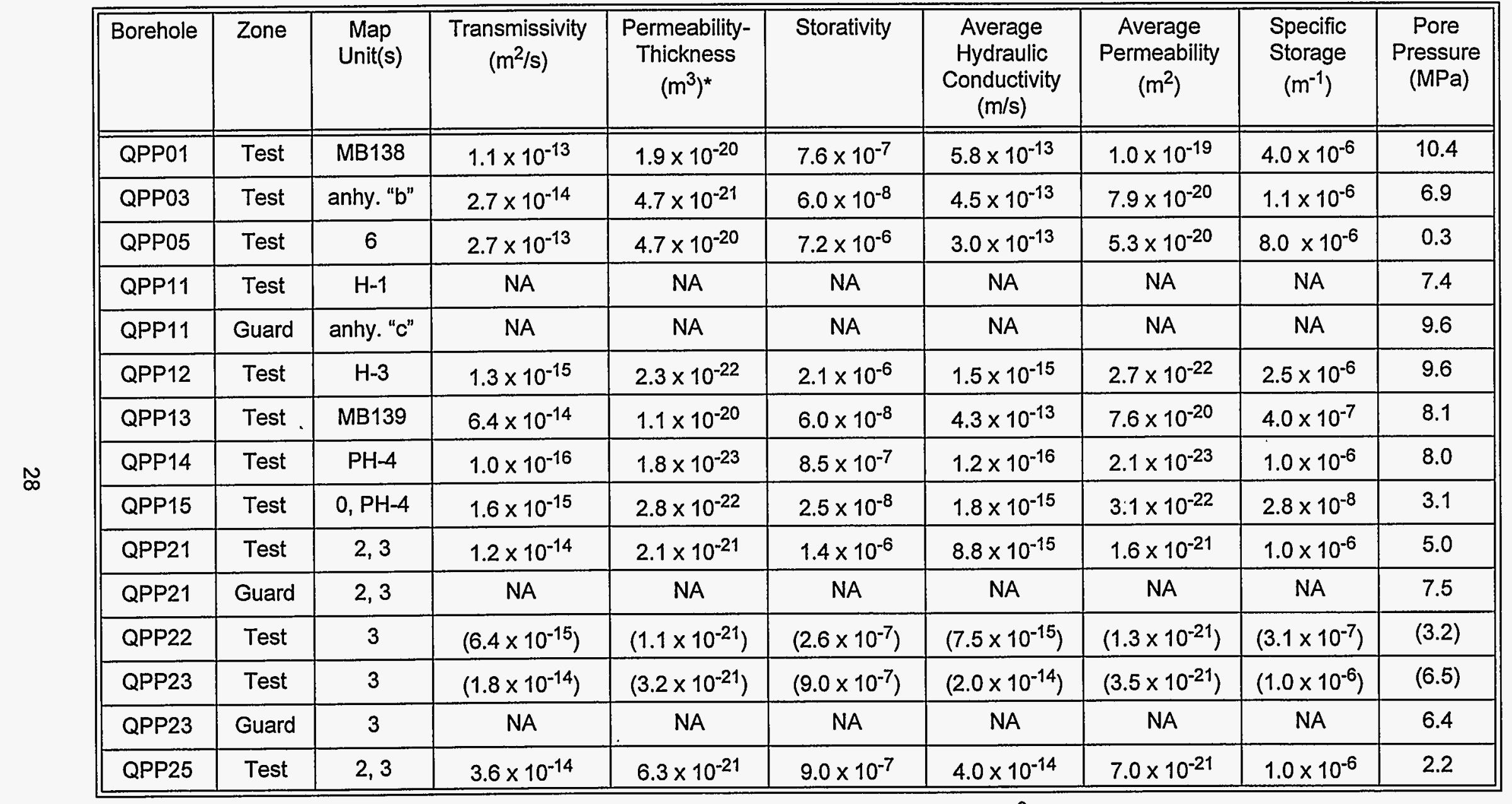

* Conversion from transmissivity to permeability-thickness uses brine density of $1220 \mathrm{~kg} / \mathrm{m}^{3}$ (Deal et al., 1989), viscosity of $2.1 \mathrm{cp}$ (McTigue, 1993), and gravitational acceleration of $9.7917 \mathrm{~m} / \mathrm{s}^{2}$ (Barrows et al., 1983).

NA - data inadequate for parameter estimation.

() - parentheses indicate high relative uncertainty. 


\subsubsection{QPP01}

According to survey information, the test zone in borehole QPP01 extends from the upper part of map unit AH-2 completely through Marker Bed 1.38 into map unit H-6 (Figure 1-2). The guard zone is contained entirely within map unit $\mathrm{AH}-2$. Deal et al. (1989) report that AH-2 is composed of halite with up to $5 \%$ clay, Marker Bed 138 is anhydrite, and $H-6$ is halite containing up to $3 \%$ polyhalite.

\subsubsection{Test Zone.}

The complete pressure record from the QPP01 test zone is shown in Figure 7-1. The premining pressure record is shown in Figure 7-2. The brine-inflow data are shown in Figure 7-3. During the flow test, the test-zone pressure was intended to be maintained at about $0.9 \mathrm{MPa}$ by the gas "cushion" in the brine accumulator so that flow could occur under constant-pressure conditions. Instead, the test-zone pressure increased to about $7.4 \mathrm{MPa}$ as the accumulator filled over the next 54 days (perhaps because the brine accumulator initially contained too much brine and, therefore, too little gas). After the brine accumulator was drained on April 30, 1990 (1989 Calendar day $485)$, the test-zone pressure increased less rapidly as brine flow continued because of the larger volume of gas available in the accumulator. A total of about $2000 \mathrm{~cm}^{3}$ of brine was collected during the 143-day flow test.

The anomalous pressure fluctuations observed during the QPP01 testing restricted the amount of interpretation that could be performed. Interpretive approaches based on analytical solutions could not be used at all, and numerical simulations using GTFM were limited to specific periods during the testing sequence. Figure $7-4$ shows a Horner plot of the late-time pre-mining data. The initial formation pressure was estimated

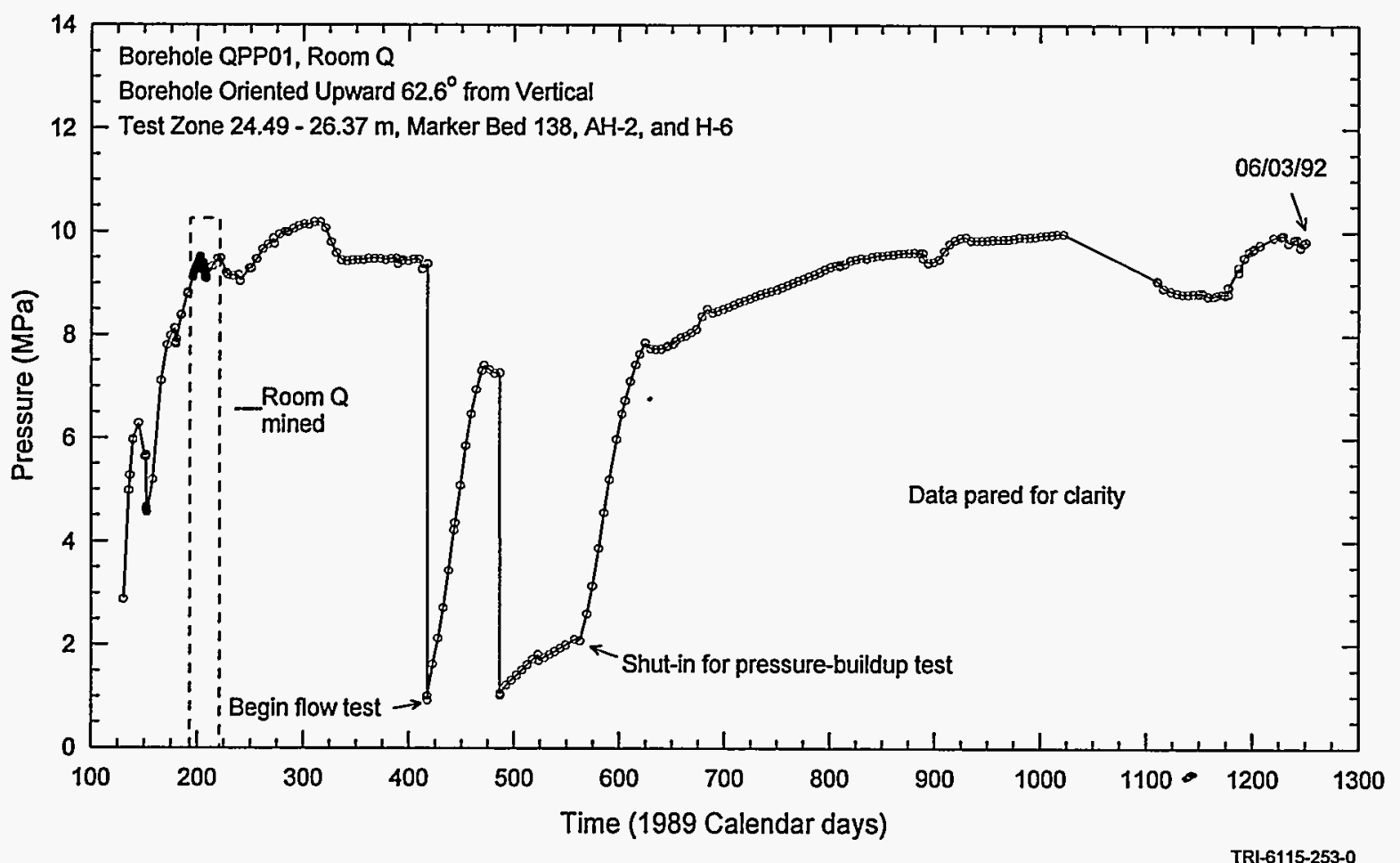

Figure 7-1. QPP01 test-zone pressure.. 


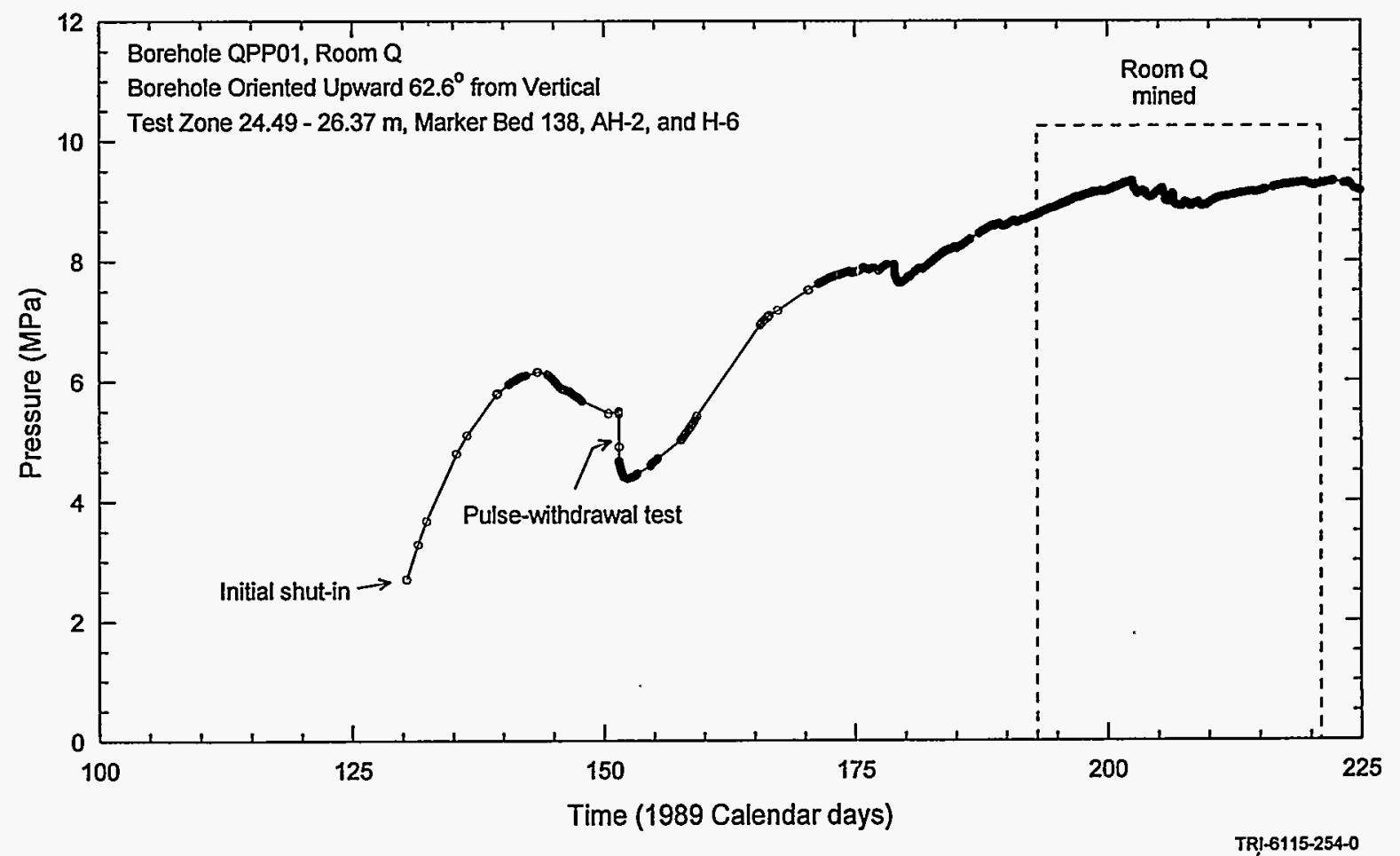

Figure 7-2. QPP01 pre-mining and mining test-zone pressure.

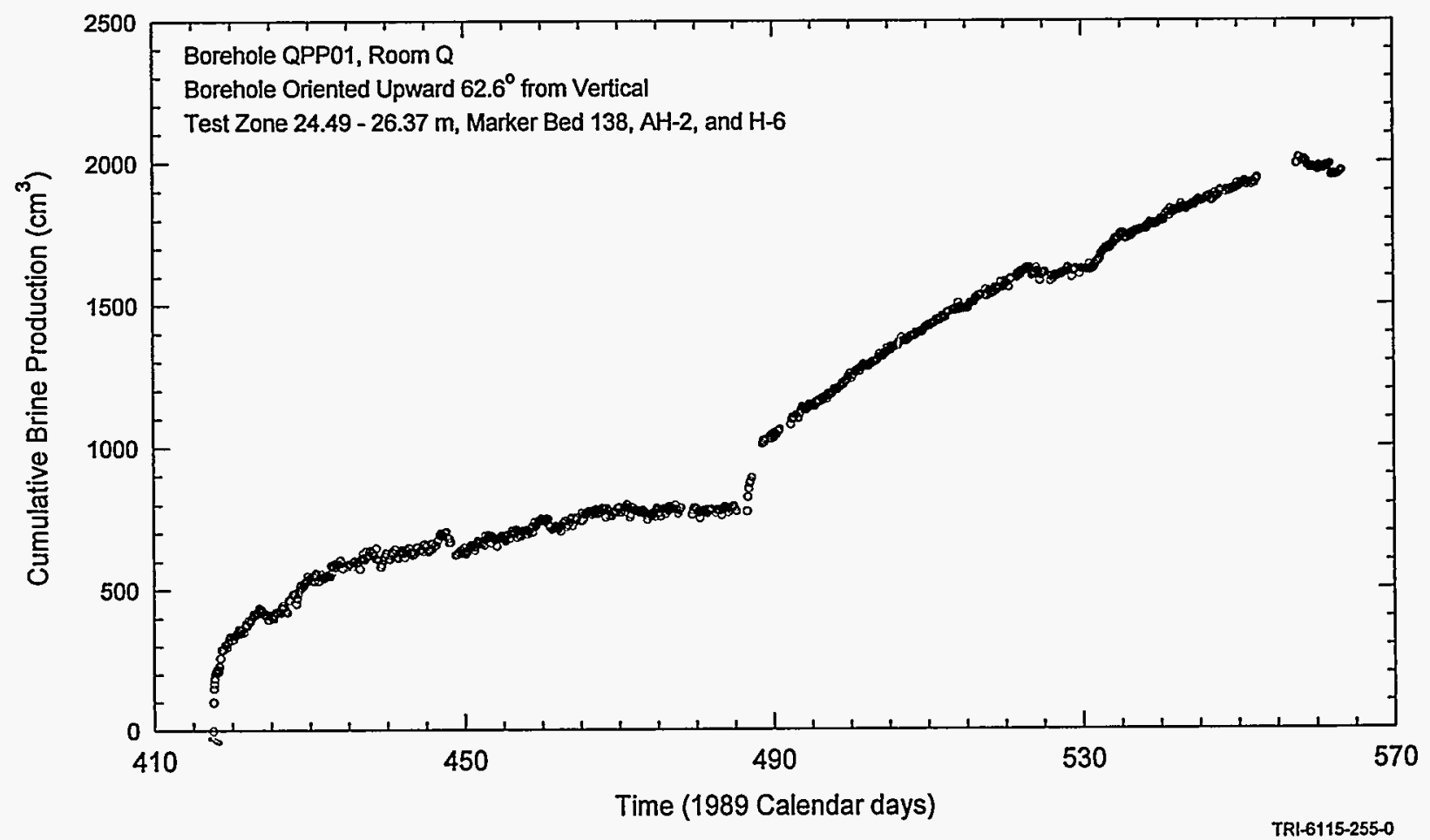

Figure 7-3. QPP01 test-zone brine production. 


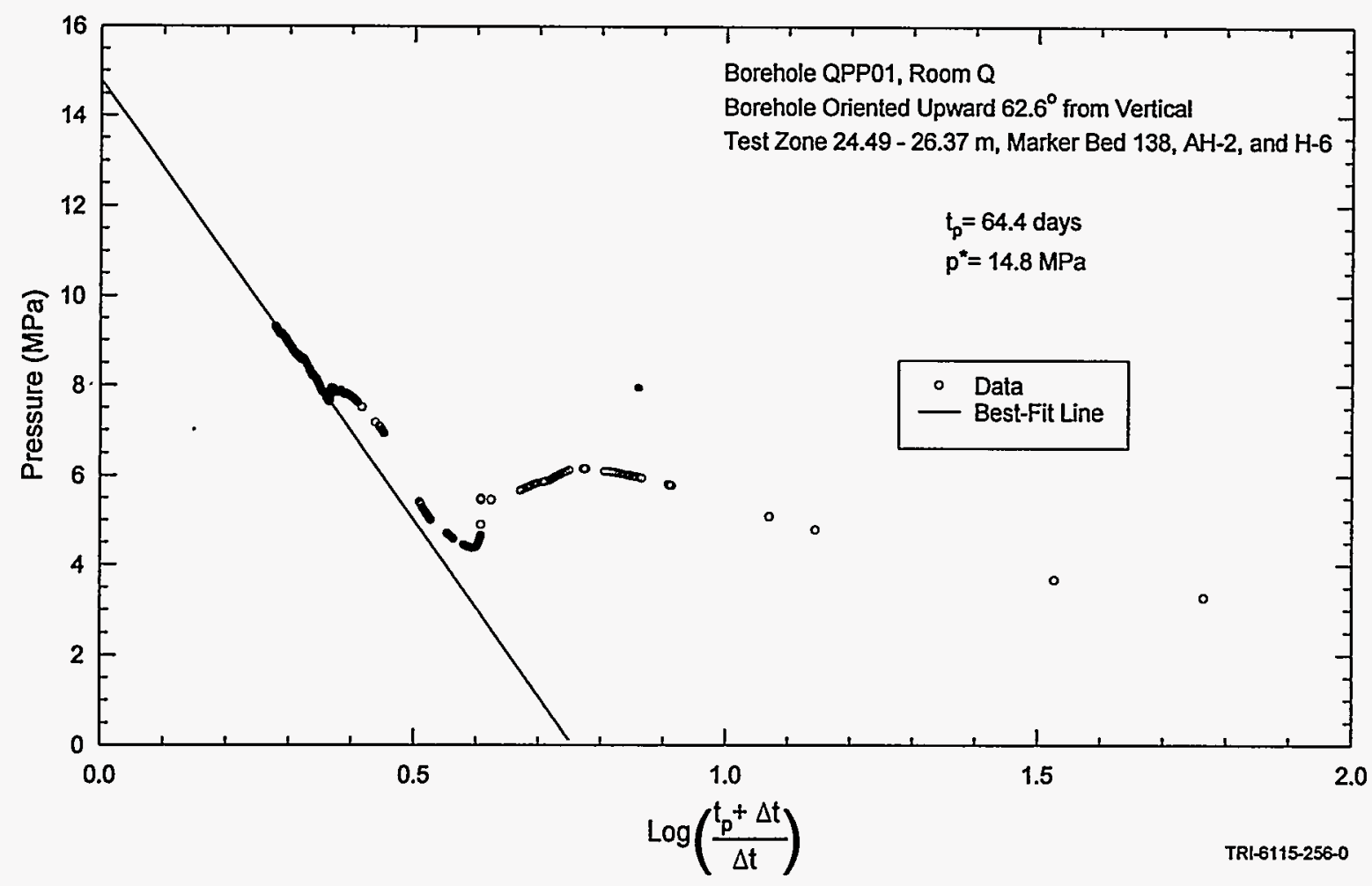

Figure 7-4. Horner plot of the QPP01 pre-mining test-zone pressure.

to be 14.8 MPa. No GTFM interpretation could be performed of the initial pressure-buildup response before Room $Q$ was mined to confirm the initial pressure estimate, or of the post-mining pressure response preceding the flow test.

The brine production during the flow test was simulated by including the entire sequence of pressures in the borehole from drilling up to and including the flow test as a specified-pressure history sequence in the simulation. The best-fit simulation of the brine production is shown in Figure 7-5. The specified parameters for this simulation were an equivalent-vertical-borehole radius of $8.1 \mathrm{~cm}$ and a test-zone fluid volume of $5100 \mathrm{~cm}^{3}$. The fitted parameters were a transmissivity of $1.1 \times 10^{-13} \mathrm{~m}^{2} / \mathrm{s}$ (permeabilitythickness product of $1.9 \times 10^{-20} \mathrm{~m}^{3}$ ), a storativity of $7.6 \times 10^{-7}$, a formation pore pressure of $10.4 \mathrm{MPa}$, and a test-zone compressibility of $5.0 \times 10^{-9} \mathrm{~Pa}^{-1}$.
Figure 7-6 shows how the simulation using these parameters matches the pressure buildup following the flow test. The first 14 days of the buildup were treated as a specified-pressure history sequence because the increasing rate of pressure buildup during this period could not be matched using a constant value of test-zone compressibility and no data were available with which to define a relationship between test-zone pressure and compressibility. The simulation matches the remainder of the pressure buildup reasonably well, given the anomalous pressure fluctuations that occurred and could not be included in the simulation.

\subsubsection{Guard Zone.}

The complete pressure record from the QPP01 guard zone is shown in Figure 7-7. The 


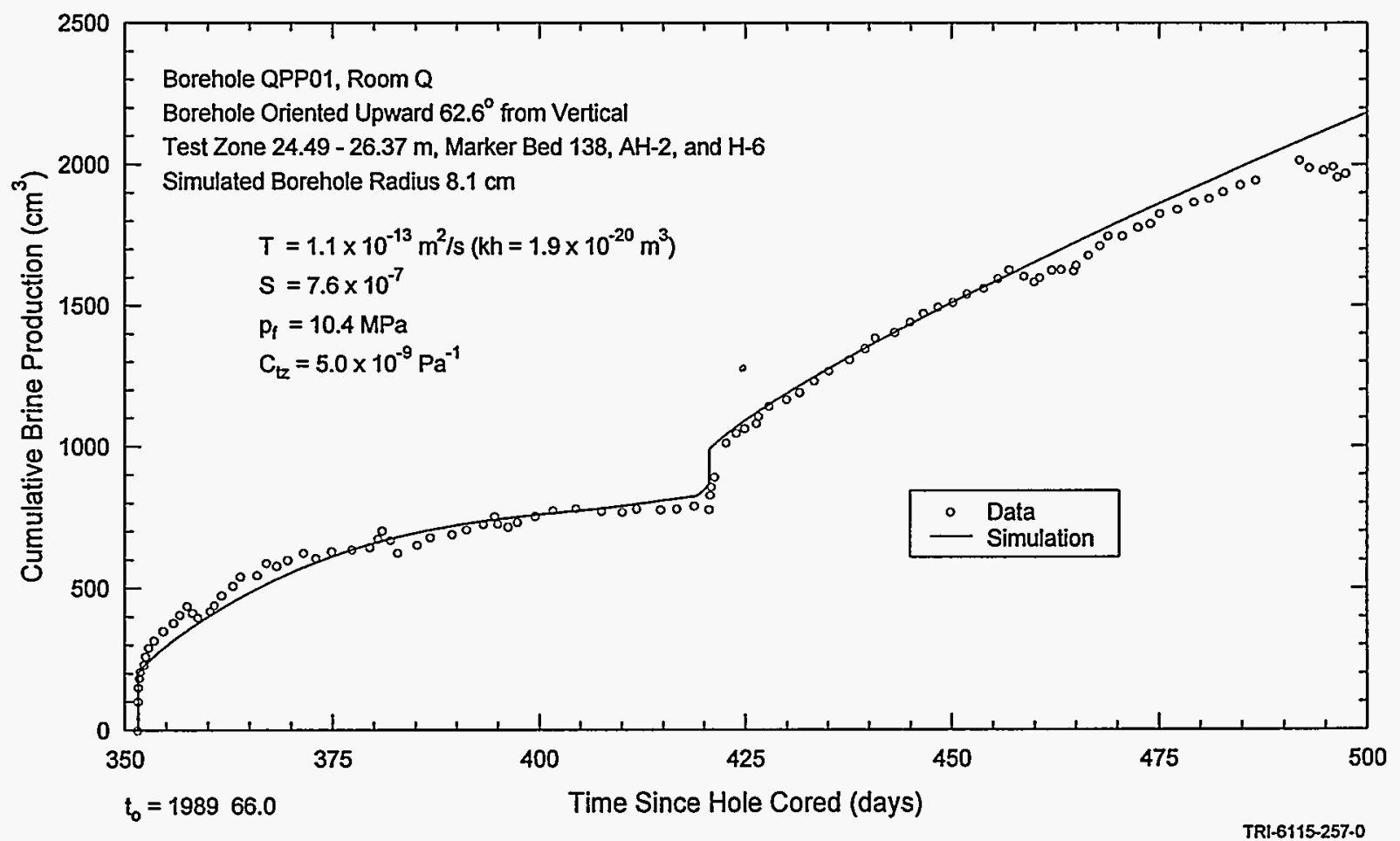

Figure 7-5. GTFM simulation of QPP01 test-zone brine production.

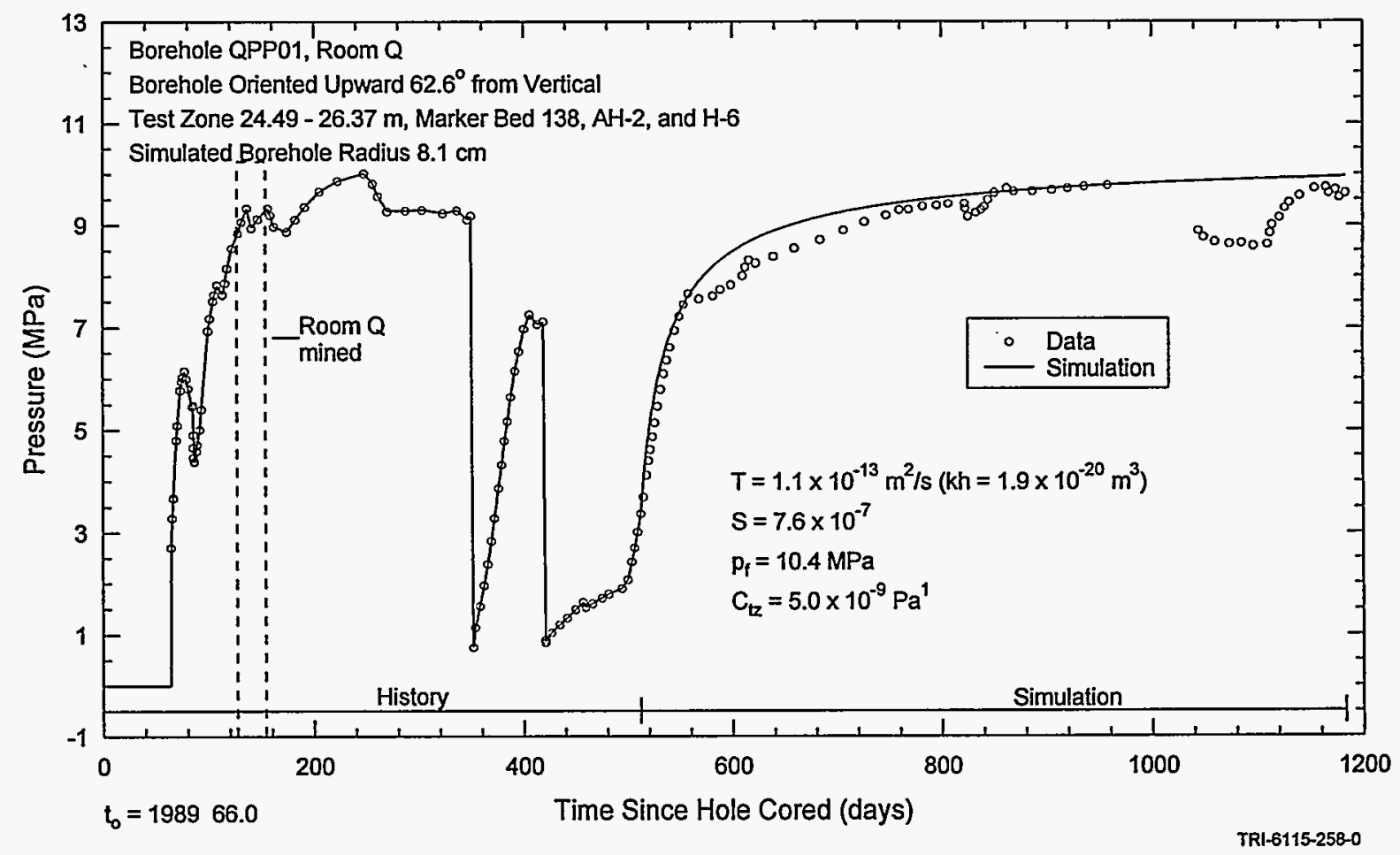

Figure 7-6. GTFM simulation of QPP01 post-mining test-zone pressure. 


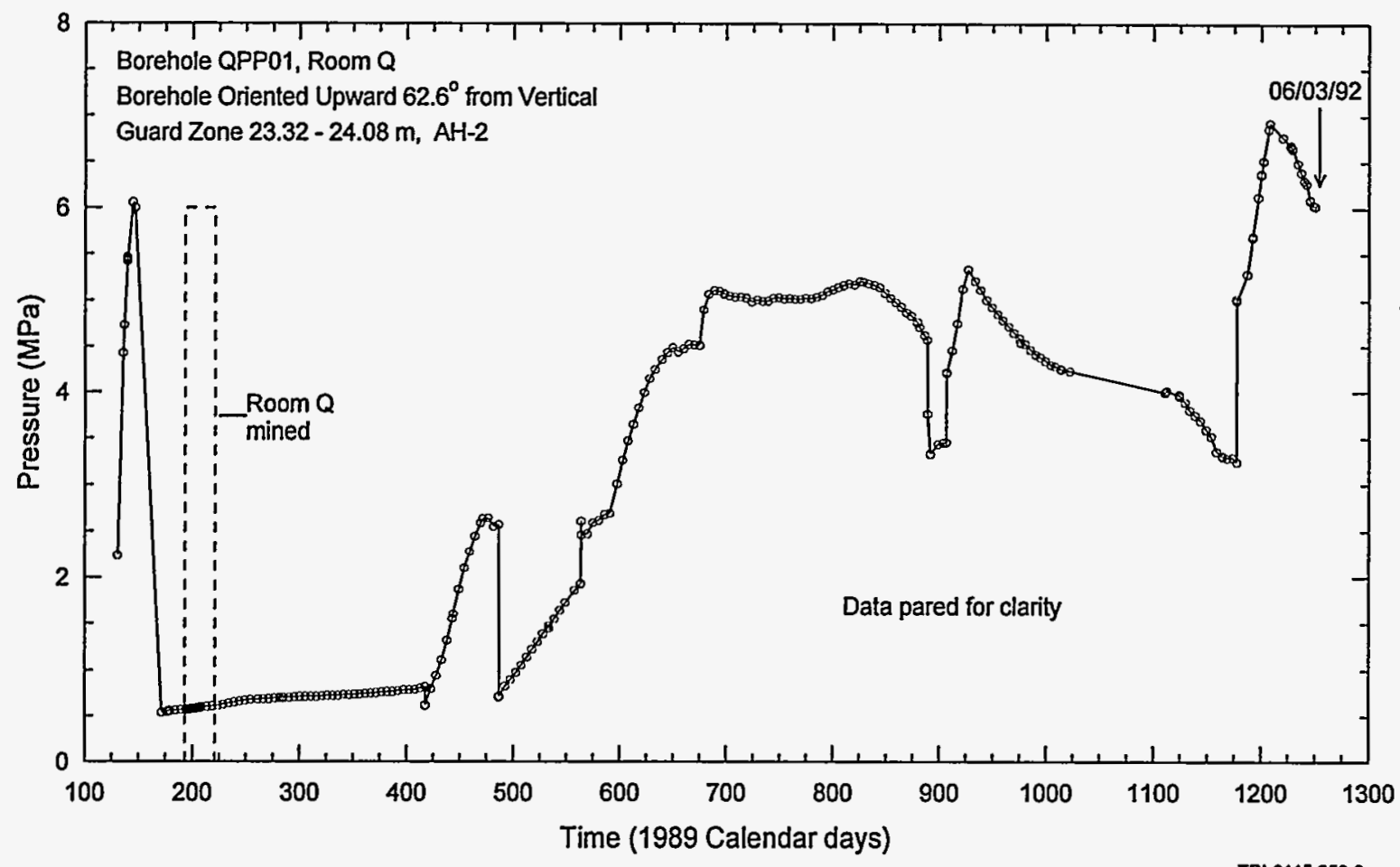

Figure 7-7. QPP01 guard-zone pressure.

guard-zone pressure response was limited by low inflation pressure of the guard-zone packer (see Figure A-1). No estimate of the AH-2 pore pressure can be made because the guard-zone pressure was so strongly influenced by changes in the packer pressure.

\subsubsection{Summary.}

The QPP01 test-zone responses are thought to reflect primarily the properties of Marker Bed 138, with insignificant contributions from map units $\mathrm{AH}-2$ and $\mathrm{H}-6$. Krieg (1984) reports that the average thickness of Marker Bed 138 at 20 locations throughout the WIPP underground facility is $0.19 \mathrm{~m}$. Assuming that the transmissivity of $1.1 \mathrm{x}$ $10^{-13} \mathrm{~m}^{2} / \mathrm{s}$ is distributed uniformly over a $0.19-\mathrm{m}$ thickness in QPP01, the average hydraulic conductivity of Marker Bed 138 would be about $6 \times$ $10^{-13} \mathrm{~m} / \mathrm{s}$ (permeability of about $1 \times 10^{-19} \mathrm{~m}^{2}$ ). The average specific storage of Marker Bed 138 would be about $4 \times 10^{-6} \mathrm{~m}^{-1}$. The estimated pore pressure in the QPP01 test zone decreased from 14.8 to $10.4 \mathrm{MPa}$ after mining. No information was obtained from the guard zone.

\subsubsection{QPP02}

The survey data indicate that the QPP02 test zone includes the upper part of map unit 12 and the lower part of map unit 13. According to Deal et al. (1989), map unit 12 consists of halite with up to $3 \%$ polyhalite and map unit 13 is halite with up to $3 \%$ clay and less than $1 \%$ polyhalite. The contact between the two units is gradational.

The complete pressure record from the QPP02 test interval is shown in Figure 7-8. Before the mining of Room $Q$, the pore pressure in QPP02 appeared to be about $1 \mathrm{MPa}$ (Figure 7-9). Mining caused episodic pressure increases followed by decays. After mining, inconsistent pressure 


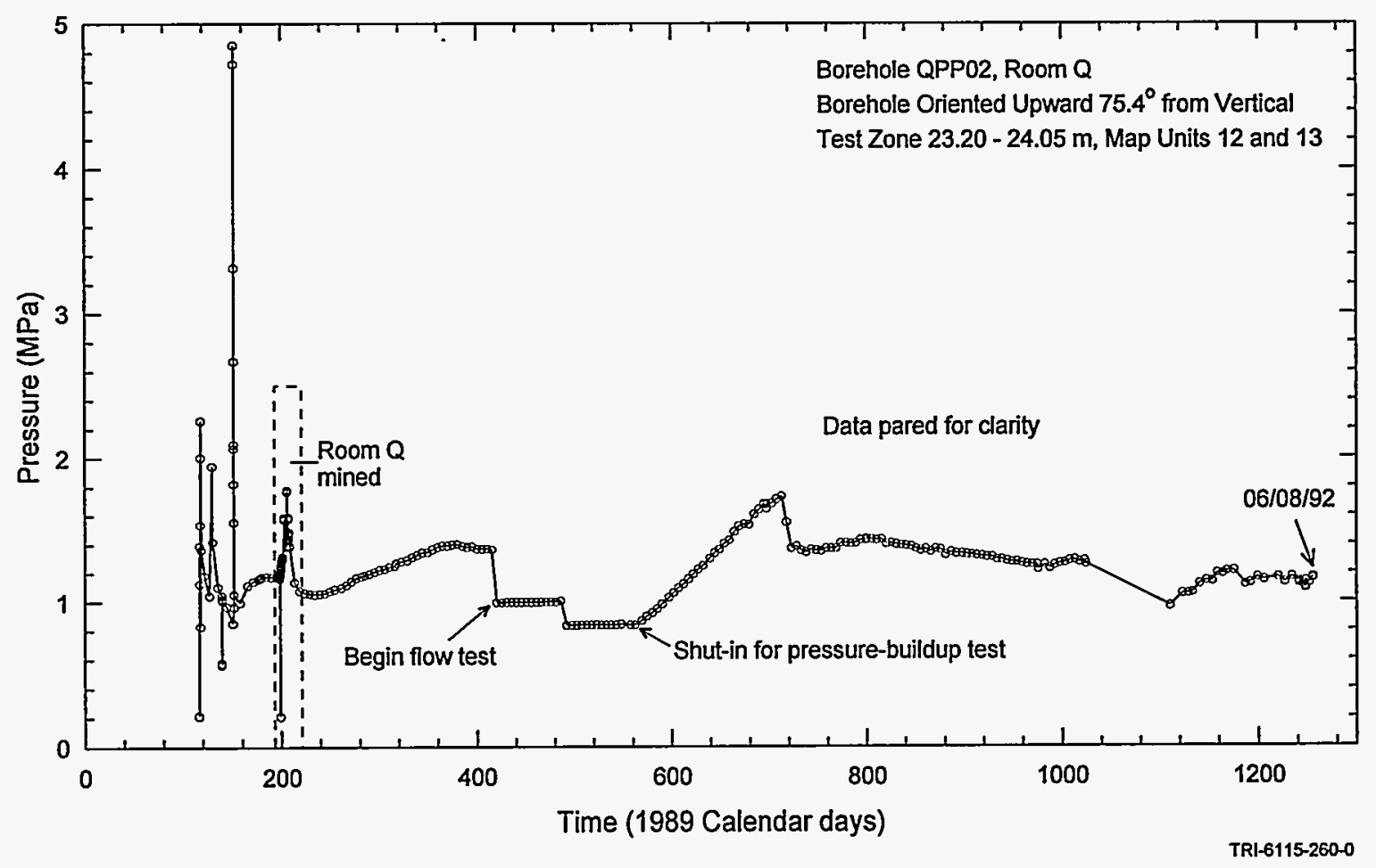

Figure 7-8. QPP02 test-zone pressure.

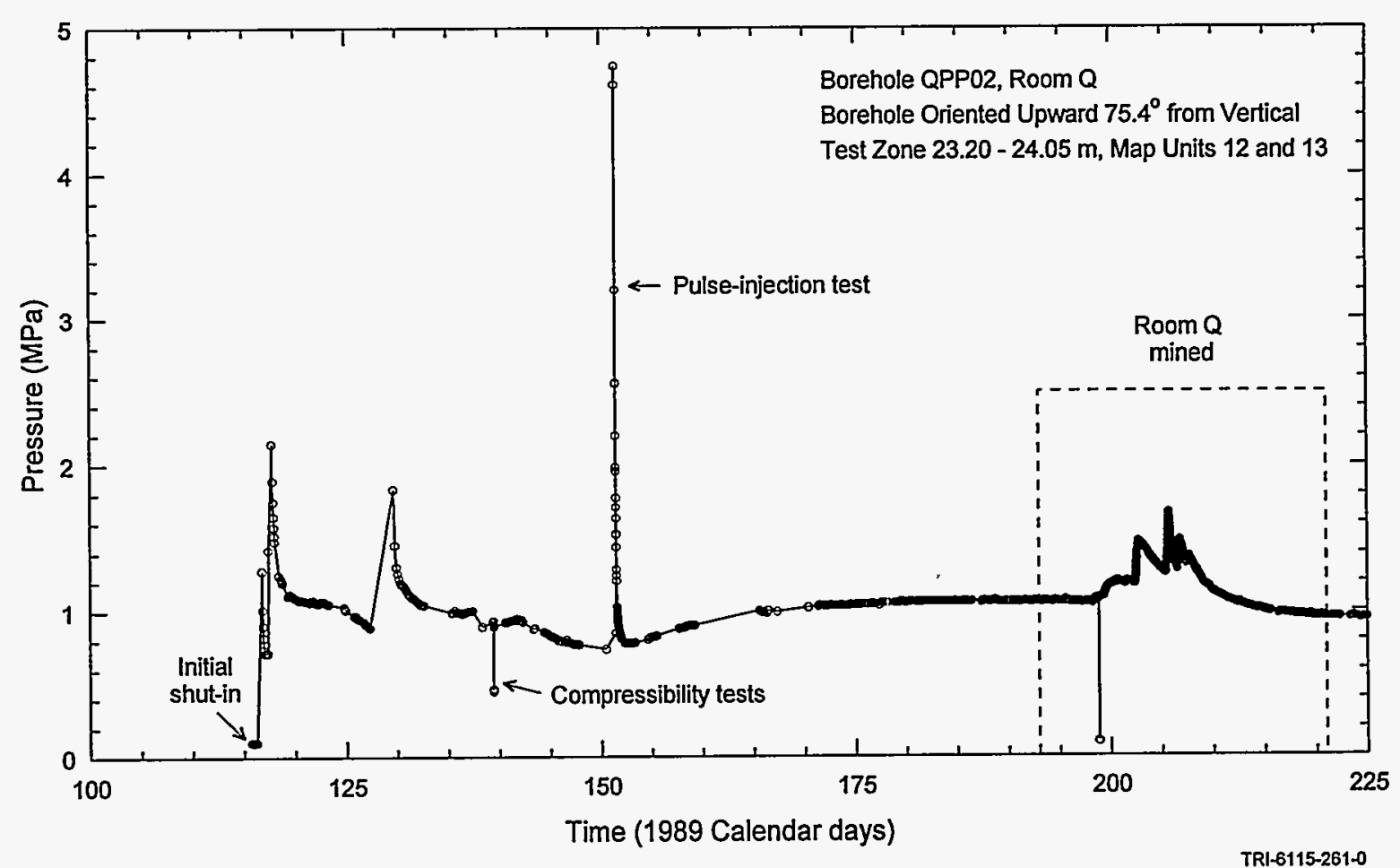

Figure 7-9. QPP02 pre-mining and mining test-zone pressure. 
behavior was observed, including both slow and abrupt reversals in pressure trends for no known reasons (e.g., 1989 Calendar days 380 and 715). Because the reasons for the anomalous pressure fluctuations are unknown, the overall pressure response observed in QPP02 is considered uninterpretable.

The total measured brine production during the 147-day flow test (Figure 7-10) in QPP02 was only slightly over $3 \mathrm{~cm}^{3}$. The brine production cannot be simulated reliably without knowledge of the far-field formation pore pressure and the pressure distribution existing around the borehole at the time the test began. In addition, too little brine was produced to have confidence that formation production, and not other factors such as borehole closure, was the sole source of the brine. Therefore, no interpretation has been made to determine characteristic hydraulic parameters from the data obtained from borehole QPP02. The packer pressure during the testing is shown in Figure A-2.

\subsubsection{QPP03}

The test-zone packer in QPP03 never functioned, causing the actual test interval to extend from the end of the guard-zone packer to the end of the borehole, a length of $1.37 \mathrm{~m}$. Jensen et al. (1993) report that this interval lies entirely within the lower part of map unit 9 , one of the purest halite units near the WIPP facility horizon (Deal et al., 1989). However, video logging of the borehole after testing was completed revealed that anhydrite " $b$ " was also included in the test interval. Previous testing of map unit 9 at other locations has shown it to have an unmeasurably low permeability (Beauheim et al., 1991; Finley et

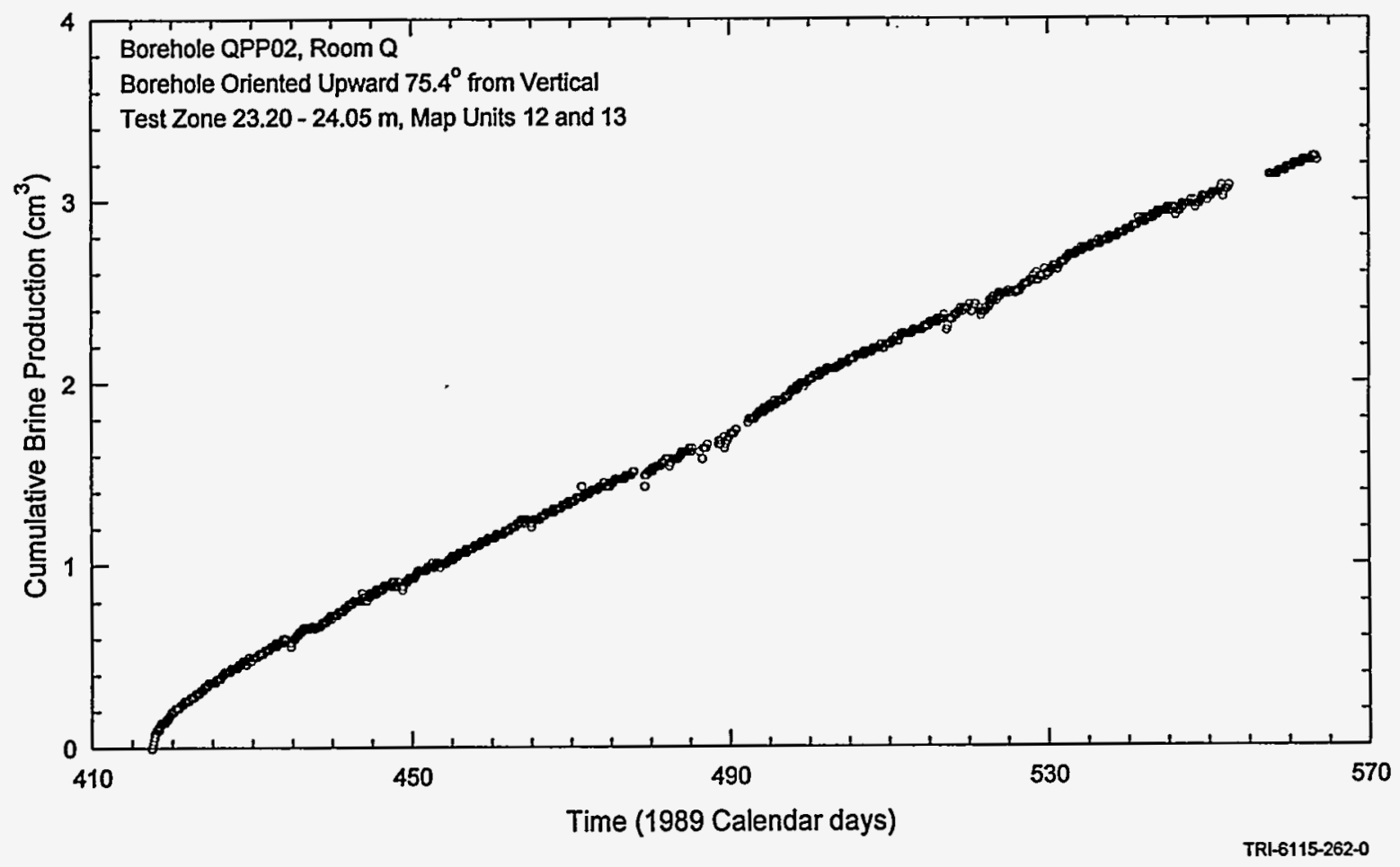

Figure 7-10. QPP02 test-zone brine production. 
al., 1992). Therefore, the pressure and flow responses observed in QPP03 are believed to be representative of anhydrite "b" only.

The complete pressure record from the QPP03 tests is shown in Figure 7-11. The pressure record before and during mining of Room $Q$ is shown in Figure 7-12. Brine accumulation during the flow test is illustrated in Figure 7-13. After the flow test was terminated on June 4, 1990 (1989 Calendar day 520 ), the test tool was removed from the borehole. On June 7, 1990 (1989 Calendar day 523), a similar test tool was set in the borehole with the new test-zone packer placed at the position of the former guard-zone packer in order to maintain the same test-interval length. After the new test tool was installed, the test region was filled with nitrogen and shut-in. The high compressibility of gas relative to that of brine as well as the pressure-dependence of gas compressibility are responsible for the initially slow but increasing rate of pressure buildup in the test zone following the tool replacement (Figure 7-11). The data from both the pre- and post-mining hydraulic tests conducted in QPPO3 are interpretable.

Numerical Interpretation. The formation pore pressure of anhydrite " $b$ " in QPP03 appeared to be much lower following the mining of Room $Q$ than it had been before mining (Figure 7-11). Therefore, the pre- and post-mining periods were simulated independently with GTFM to evaluate the change in pore pressure. The pre-mining simulation included the initial 33-day period during which the borehole was at atmospheric pressure as a specified-pressure history sequence. The pre-mining period was ignored completely and the pressures in QPP03 during the mining of Room $Q$ and during the flow test were treated as specifiedpressure history sequences in the post-mining simulation.

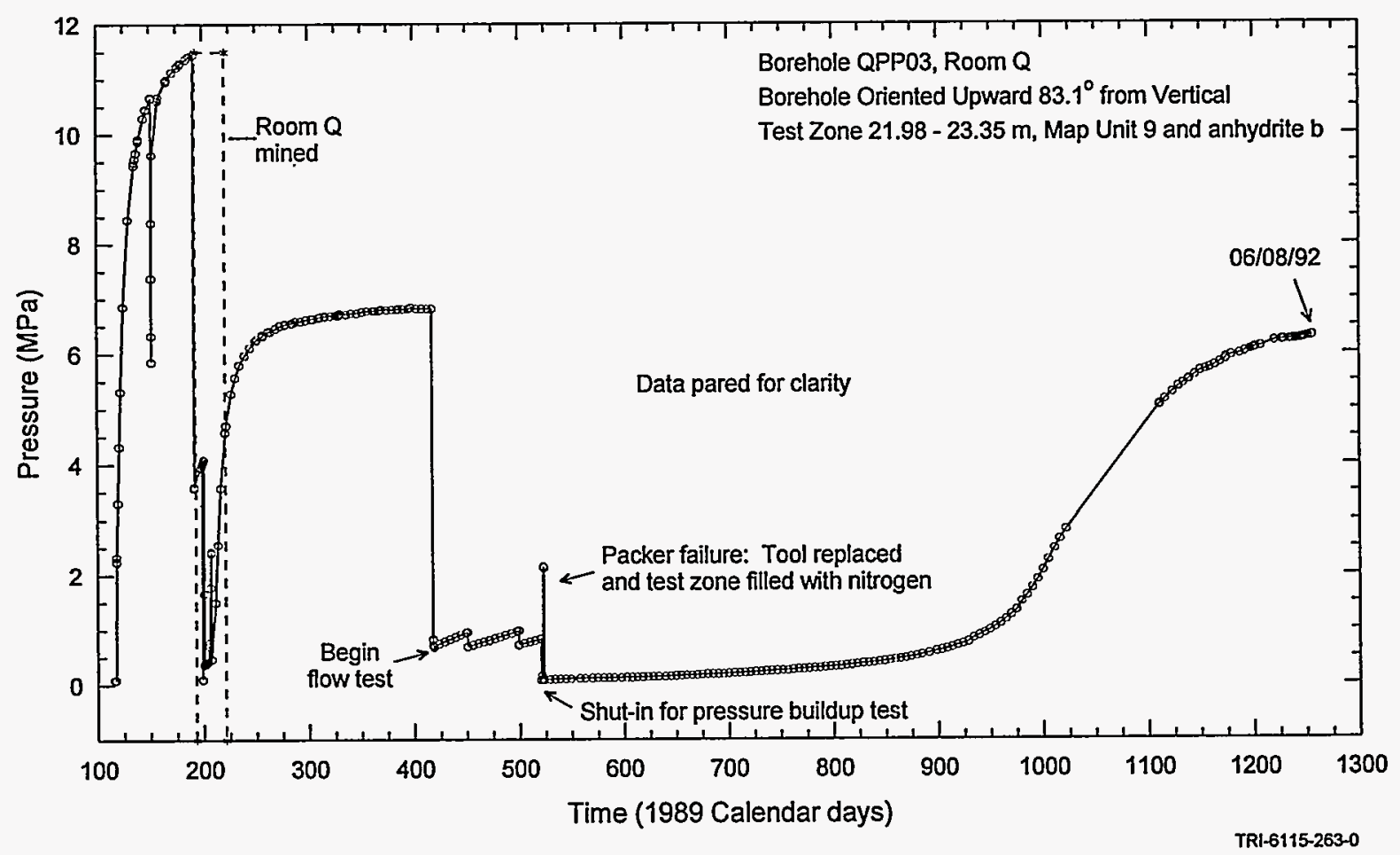

Figure 7-11. QPP03 test-zone pressure. 


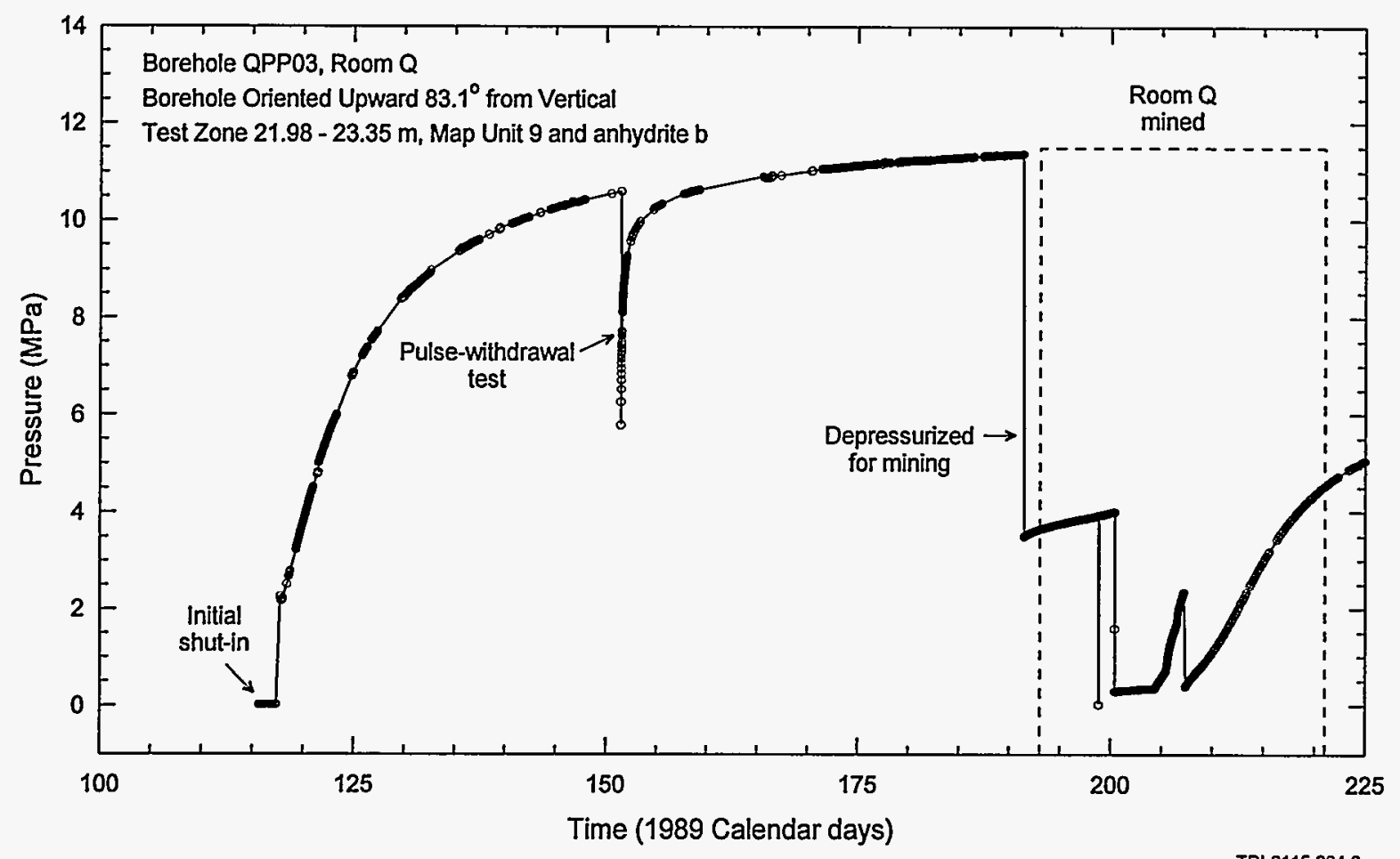

Figure 7-12. QPP03 pre-mining and mining test-zone pressure.

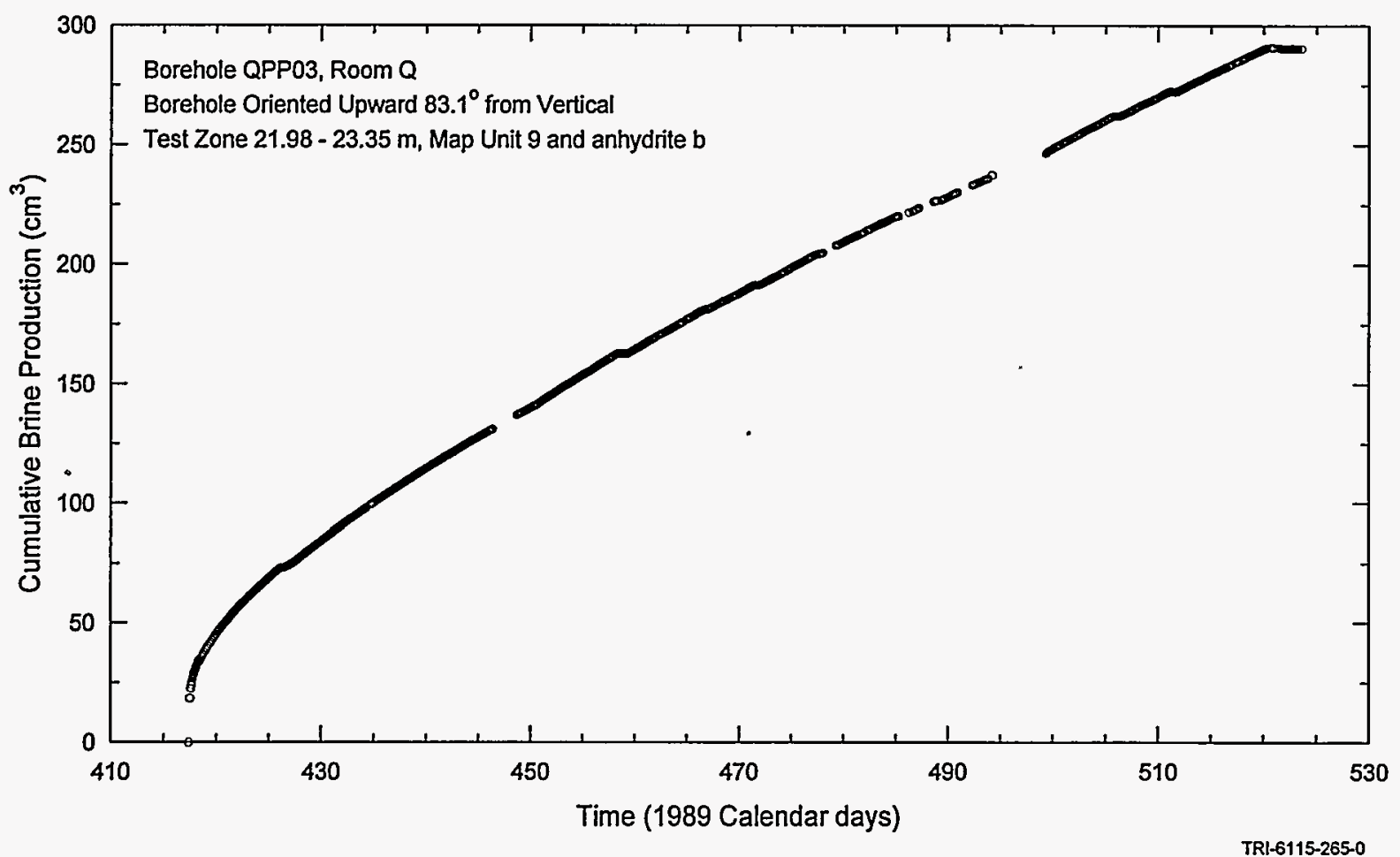

Figure 7-13. QPP03 test-zone brine production. 
No information on test-zone compressibility is available for QPP03. Therefore, the initial focus of test interpretation was to match data unaffected by test-zone compressibility, the brine production during the flow test. After preliminary estimates of transmissivity and storativity were obtained from the flow-test data, the post-mining pressure responses were simulated using testzone compressibility as a fitting parameter in place of transmissivity. Final parameter estimates were obtained by simultaneously matching both the flow and pressure responses. Attempts were then made to match the pre-mining pressure response using the parameters determined from the postmining analysis, varying only formation pore pressure and test-zone compressibility.

Figures 7-14, 7-15, and 7-16 show the best-fit GTFM simulations of the post-mining pressure response, cumulative fluid production, and flow-rate data, respectively. Pressures during the mining of Room $Q$ were included in the simulation as a specified-pressure history sequence. The observed and simulated flow rates (Figure 7-16) are in close agreement for the duration of the flow test with the exception of the first measured flow rate, which is anomalously high due to expansion of the test-zone fluid and tool compliance in response to the initial pressure drop. The close match of the simulated flow rate to that measured provides confidence that the hydraulic properties of the formation and near-borehole region are reliably represented in the model. The specified parameters used in the simulations were an equivalent-vertical-borehole radius of $8.9 \mathrm{~cm}$ and a test-zone fluid volume of $495 \mathrm{~cm}^{3}$. The fitted parameters were: skin transmissivity of $5.4 \times 10^{-14}$ $\mathrm{m}^{2} / \mathrm{s}$ (permeability-thickness of $9.5 \times 10^{-21} \mathrm{~m}^{3}$ ), skin storativity of $6.8 \times 10^{-8}$, radial skin thickness of $0.07 \mathrm{~m}$, formation transmissivity of $2.7 \times 10^{-14} \mathrm{~m}^{2} / \mathrm{s}$ (permeability-thickness of $4.7 \times 10^{-21} \mathrm{~m}^{3}$ ), a storativity of $6.0 \times 10^{-8}$, a formation pore pressure of $6.9 \mathrm{MPa}$, and a test-zone compressibility of $5.0 \mathrm{x}$ $10^{-9} \mathrm{~Pa}^{-1}$ until the end of the flow test. The effect

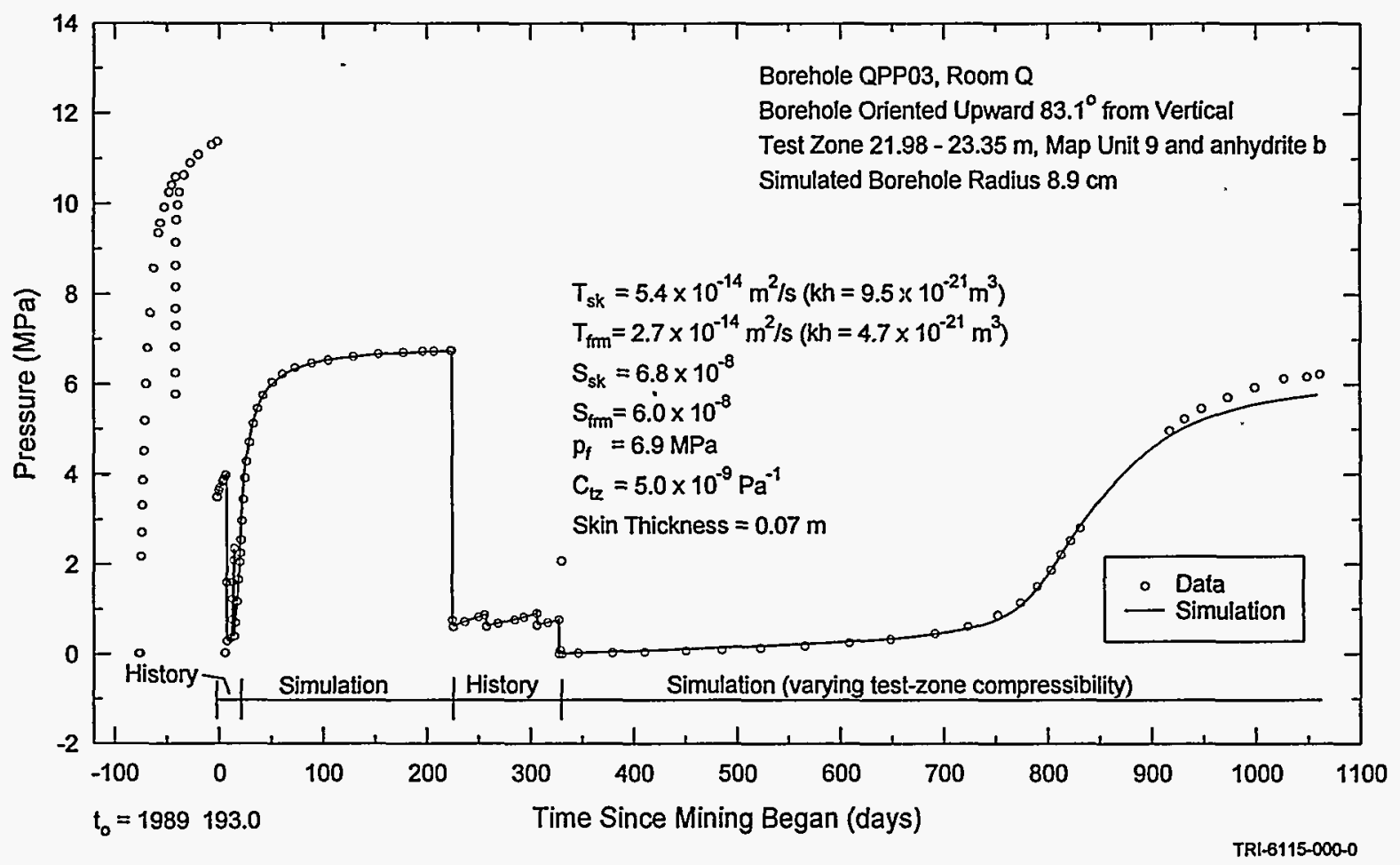

Figure 7-14. GTFM simulation of QPP03 post-mining test-zone pressure. 


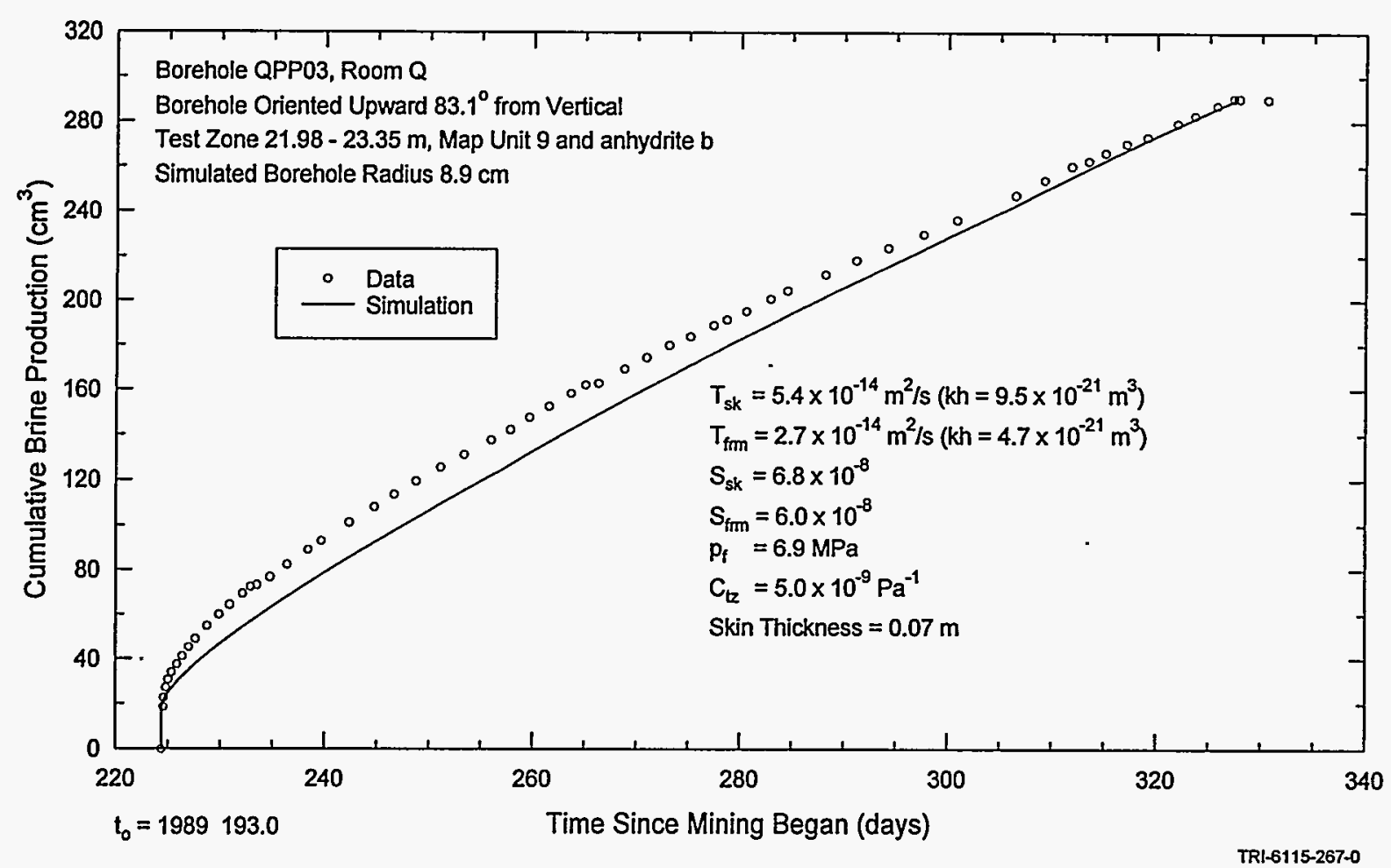

Figure 7-15. GTFM simulation of QPP03 test-zone brine production.

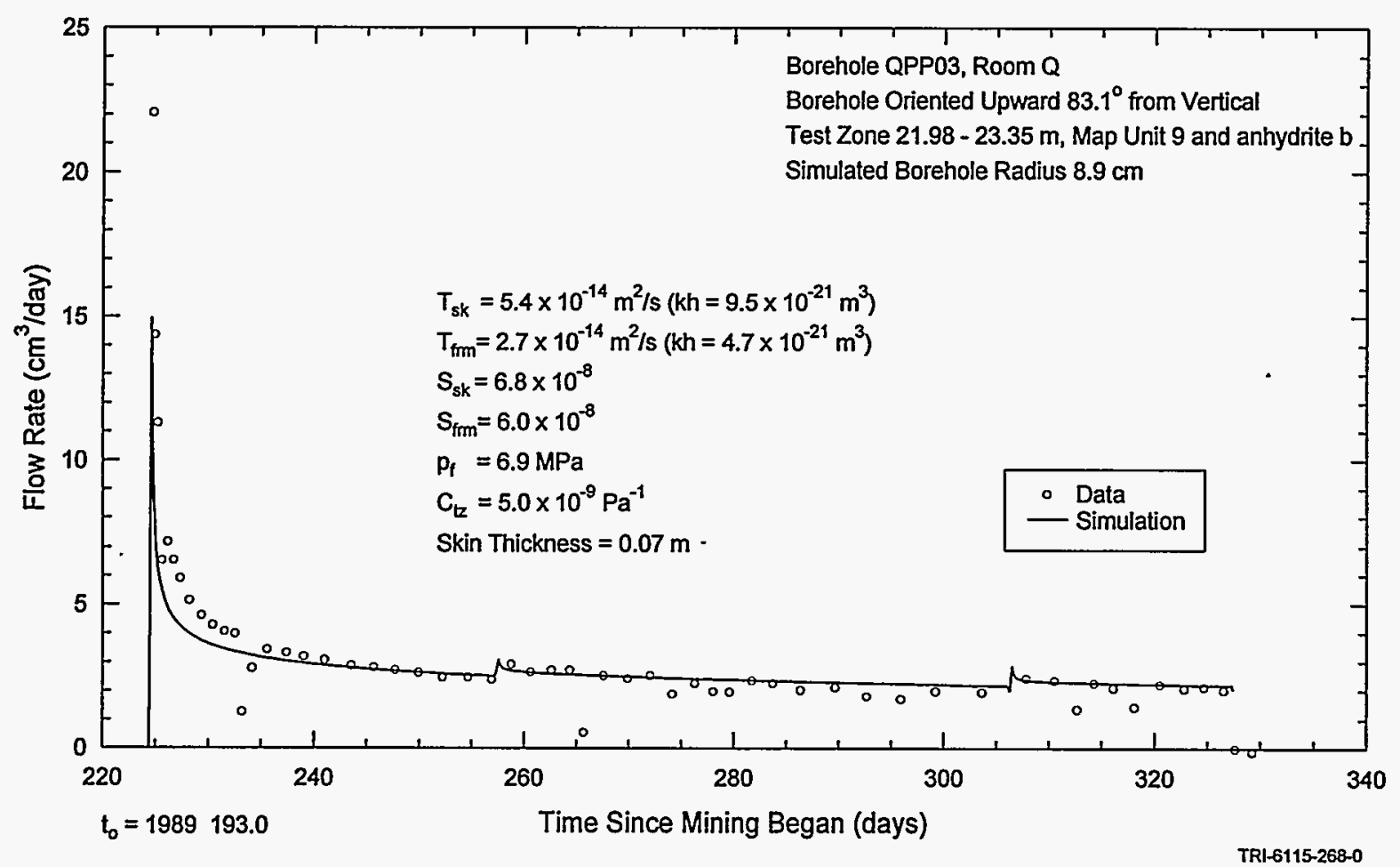

Figure 7-16. GTFM simulation of QPPO3 flow rates. 
of the gas-filled test zone during the post-flow pressure-buildup test was incorporated in the simulation by varying the test-zone compressibility as the inverse of the test-zone pressure during the buildup period.

Figure 7-17 shows the best-fit GTFM simulation of the QPP03 pressure response preceding the mining of Room $Q$. The same skin parameter values were used in this simulation as in the post-mining simulations along with a formation transmissivity of $2.6 \times 10^{-14} \mathrm{~m}^{2} / \mathrm{s}$ (permeabilitythickness of $4.5 \times 10^{-21} \mathrm{~m}^{3}$ ), a storativity of $2.0 \times$ $10^{-7}$, a formation pore pressure of $12.9 \mathrm{MPa}$, and a test-zone compressibility of $1.0 \times 10^{-9} \mathrm{~Pa}^{-1}$. The pressure buildup after the test zone was first shutin was not matched as well as the pulse-withdrawal test by the simulation. The actual pressure buildup occurred more slowly than simulated, probably because of pressure-dependent test-zone compressibility. Beauheim et al. (1993) demonstrated decreasing test-zone compressibility as test-zone pressure increased for test tools similar to those used in the Room $Q$ boreholes.

Summary. The numerical interpretations of the QPP03 hydraulic tests provided a formation transmissivity estimate of $2.6 \times 10^{-14}$ to $2.7 \times 10^{-14}$ $\mathrm{m}^{2} / \mathrm{s}$. The estimated storativity from the numerical simulations is $6 \times 10^{-8}$ to $2 \times 10^{-7}$. Estimated formation pore pressures are $12.9 \mathrm{MPa}$ prior to the mining of Room $Q$ and $6.9 \mathrm{MPa}$ following the mining of Room $Q$. Estimated test-zone compressibilities range from $1 \times 10^{-9}$ to $5 \times 10^{-9}$ $\mathrm{Pa}^{-1}$, within the range established from measurements in other boreholes (Table 6-1). The simulations also indicated the possible presence of a 7-cm-thick skin around the QPP03 borehole with a transmissivity twice that of the surrounding formation.

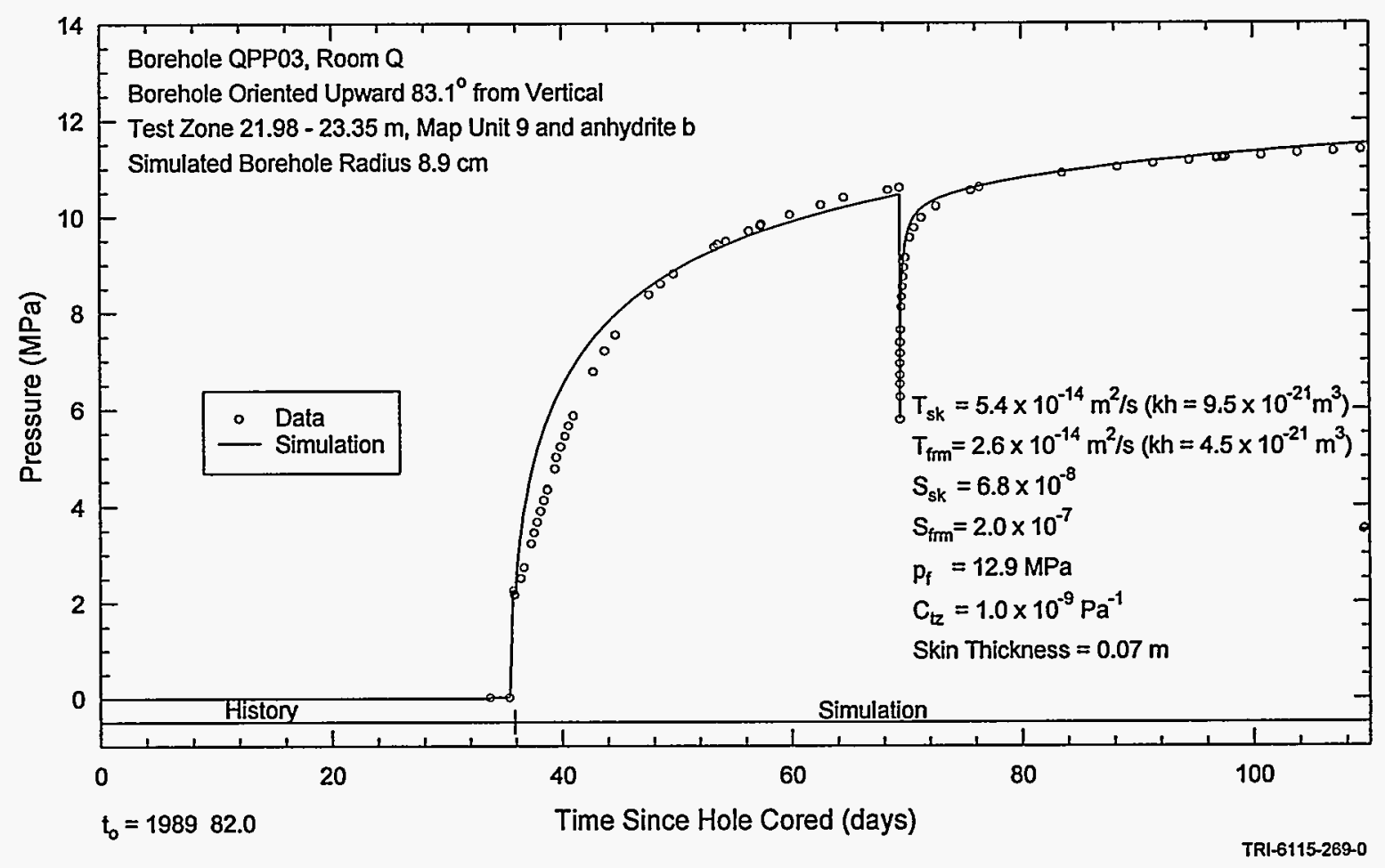

Figure 7-17. GTFM simulation of QPP03 pre-mining test-zone pressure. 
Krieg (1984) reports that the average thickness of anhydrite "b" at 18 locations throughout the WIPP underground facility is $0.06 \mathrm{~m}$. Assuming that transmissivity is distributed uniformly over a $0.06-\mathrm{m}$ thickness in QPP03, the average pre-mining hydraulic conductivity of anhydrite "b" would be about $4.3 \times 10^{-13} \mathrm{~m} / \mathrm{s}$ (permeability of about $7.6 \times 10^{-20} \mathrm{~m}^{2}$ ) and the average post-mining hydraulic conductivity would be about $4.5 \times 10^{-13} \mathrm{~m} / \mathrm{s}$ (permeability of about 7.9 $\times 10^{-20} \mathrm{~m}^{2}$ ). The average pre-mining specific storage of anhydrite "b" would be about $3.3 \times 10^{-6}$ $\mathrm{m}^{-1}$, and the average post-mining specific storage would be approximately $1.0 \times 10^{-6} \mathrm{~m}^{-1}$. These differences between pre- and post-mining conditions are within the experimental uncertainty of the measurements.

\subsubsection{QPP04}

The survey data indicate the test zone of borehole QPP04 is located near the contact of map unit 6 and map unit 7. Map unit 6 is a relatively pure halite unit typically containing $<0.5 \%$ clay and polyhalite, and map unit 7 is also a relatively pure halite usually containing $<1 \%$ clay and polyhalite (Deal et al., 1989). The contact of map units 6 and 7 is gradational.

The complete pressure record from the QPP04 tests is shown in Figure 7-18. Data collected before and during mining are shown in Figure 7-19. The pressure responses observed in the QPP04 test zone are not considered to be interpretable. A Horner plot of the pre-mining data indicates an initial formation pressure of about 9 $\mathrm{MPa}$ (Figure 7-20). After the mining, the pressure seemed to be restricted at about $6.5 \mathrm{MPa}$ until January 3, 1990 (1989 Calendar day 368), when it suddenly began to decrease. No consistent pressure behavior was observed after that time even though the interval remained shut-in and no problems were encountered maintaining pressure in the packer (see Figure A-4).

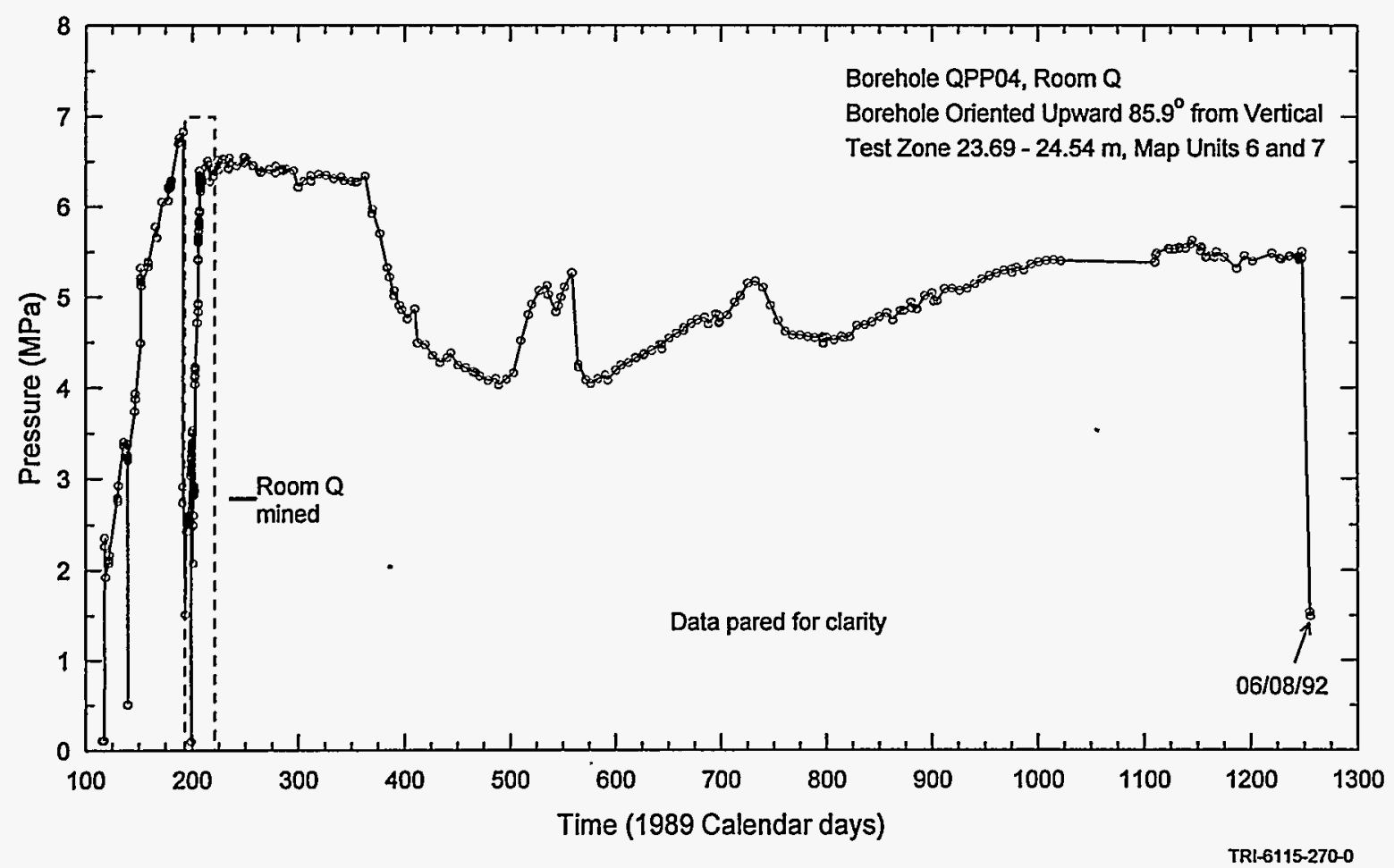

Figure 7-18. QPP04 test-zone pressure. 


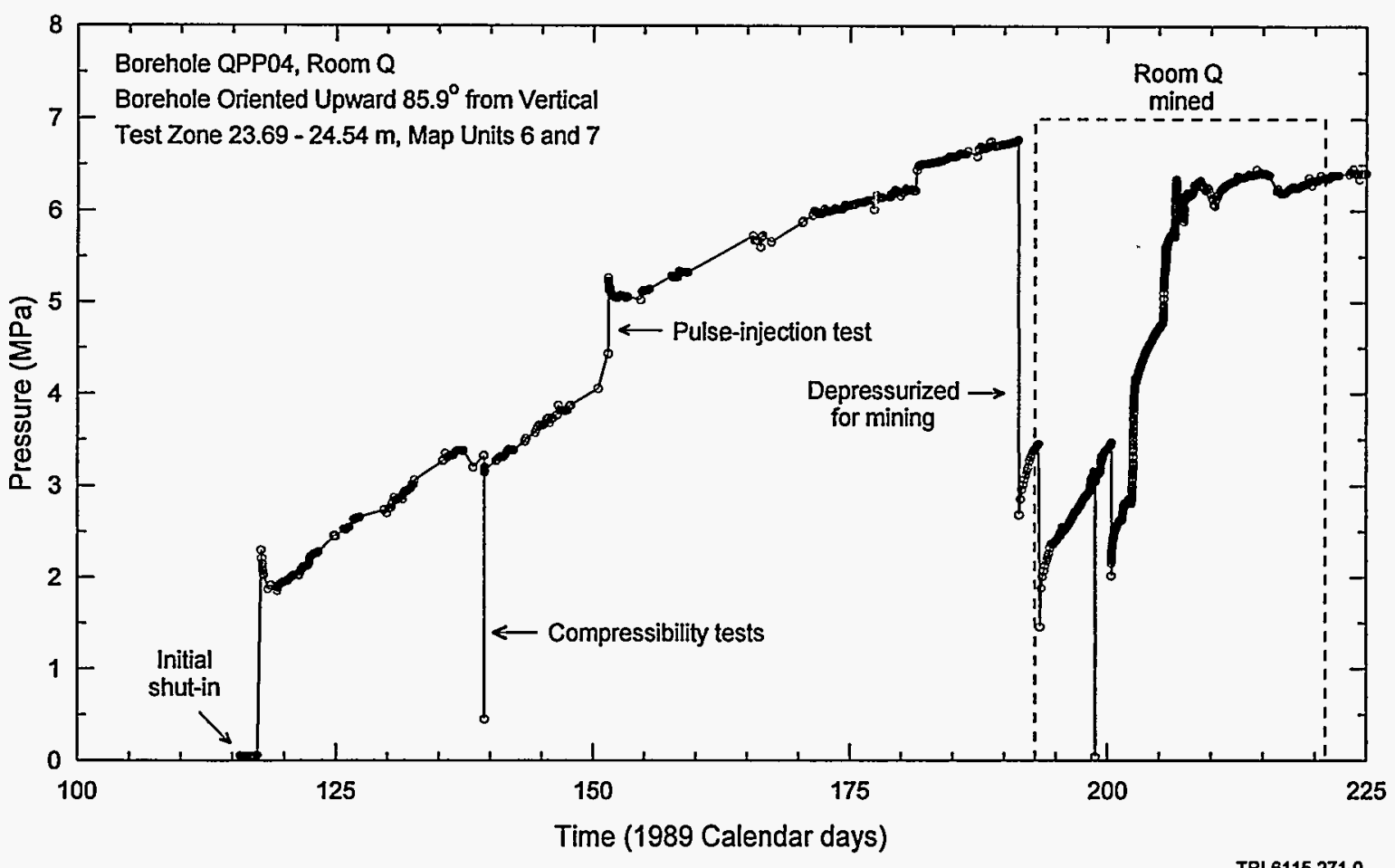

Figure 7-19. QPP04 pre-mining and mining test-zone pressure.

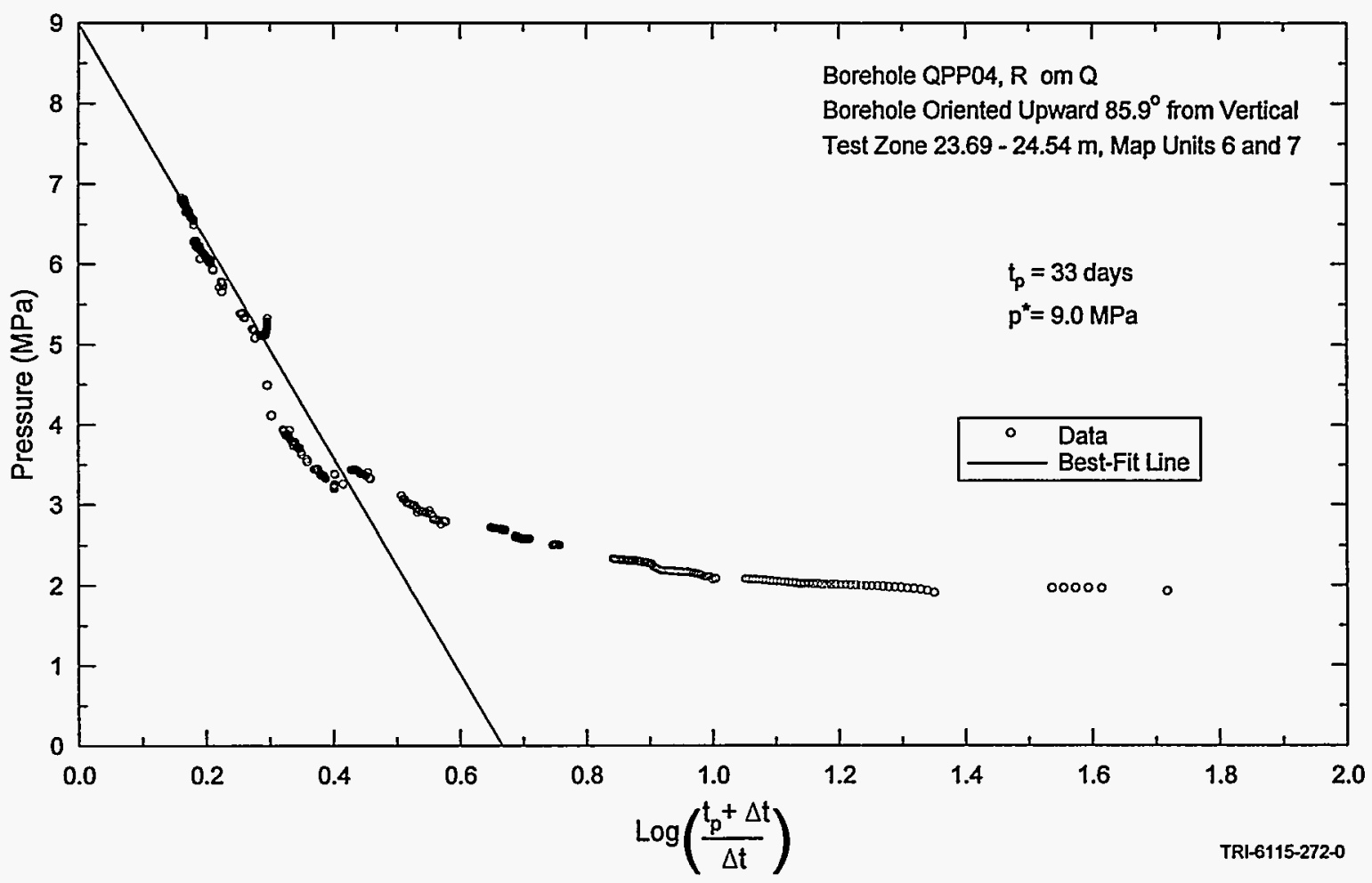

Figure 7-20. Horner plot of the QPP04 prè-mining test-zone pressure. 
The changes in the pressure behavior observed in QPP04 may reflect mining-induced changes in the rock mass. The QPP04 test interval is within $1.6 \mathrm{~m}$ of the Room $\mathrm{Q}$ excavation. The apparent restriction in the pressure in QPP04 after mining may indicate that a "check-valve-like" fracture connection was created between the borehole and Room Q. The abrupt decrease in pressure beginning January 3, 1990 and the increase in pressure beginning May 16, 1990 (1989 Calendar day 501) may indicate further discrete readjustments of the rock mass. The steady increase in the packer-inflation pressure during the monitoring period (Figure A-4) must reflect compression of the packer element by the rock.

\subsubsection{QPP05}

The survey data indicate that both the test and guard zones in borehole QPP05 lie within map unit 6. Deal et al. (1989) describe map unit 6 as consisting primarily of halite, with less than $0.5 \%$ clay and polyhalite.

\subsubsection{Test Zone.}

The complete pressure record from the QPP05 test zone is shown in Figure 7-21. Prior to the mining of Room $Q$, the pressure in the QPP05 test interval showed no clear trend. The pressure was increased by fluid injection twice, on April 27, 1989 and May 31, 1989 (Calendar days 117 and 151; Figure 7-22). After each increase, the pressure initially decreased by a few tenths of an $\mathrm{MPa}$, probably because of compliance effects, and then appeared to stabilize, first at about $2.1 \mathrm{MPa}$ and then at about 4.8 MPa. These apparent pressure stabilizations at arbitrary and different pressures probably reflect extremely low permeability, perhaps coupled with high test-zone compressibility. After the excavation of Room $Q$,

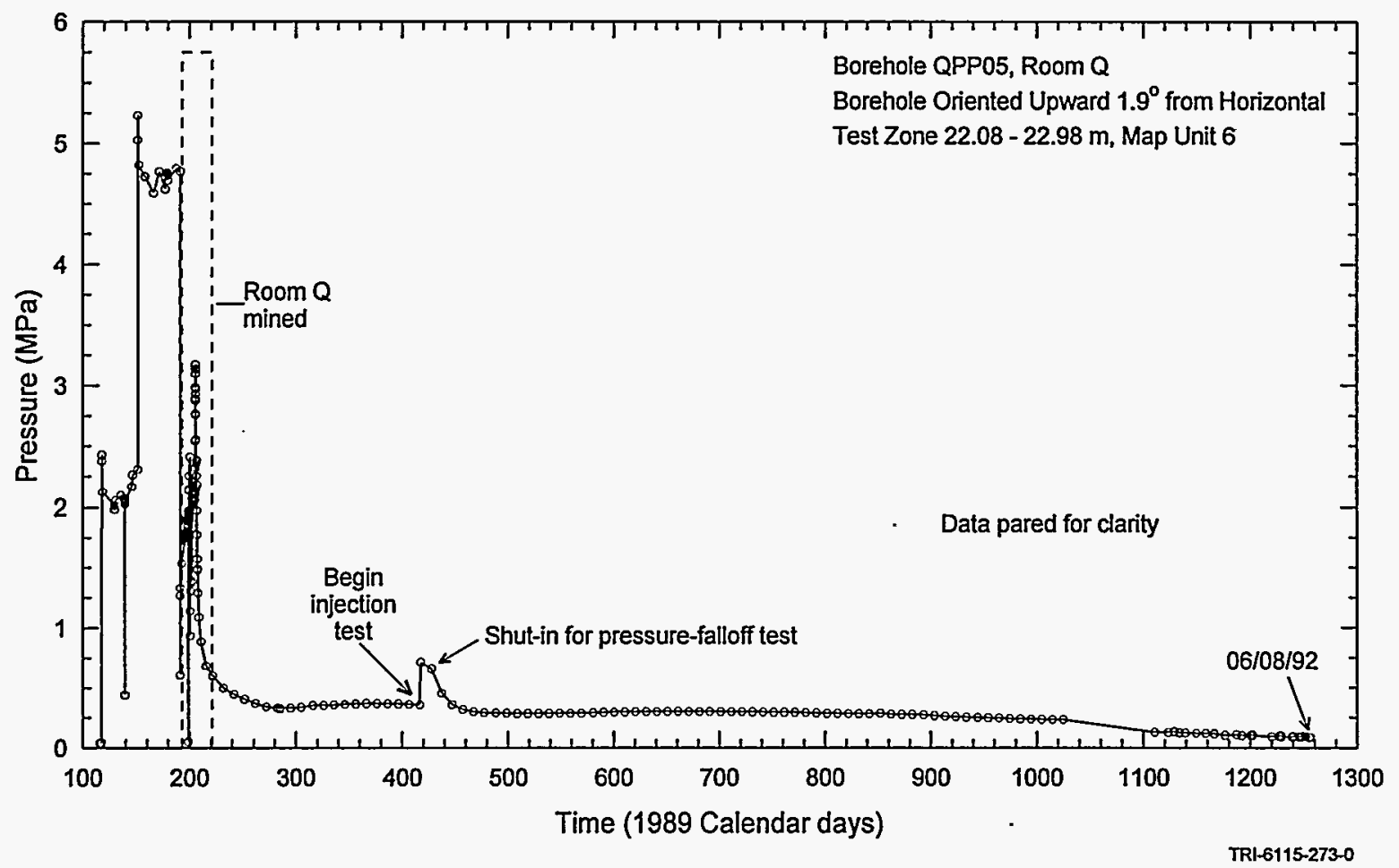

Figure 7-21. QPP05 test-zone pressure. 


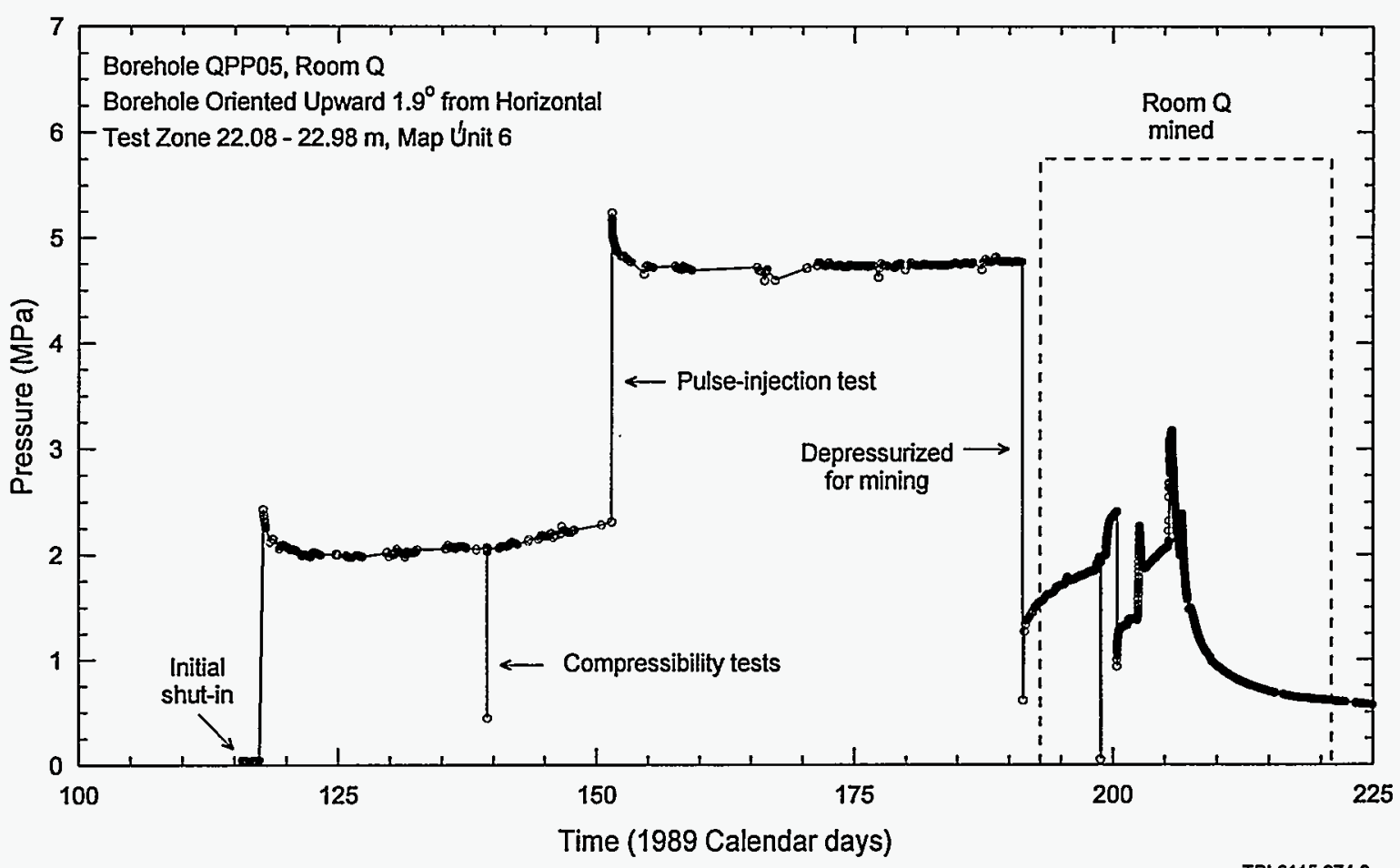

Figure 7-22. QPP05 pre-mining and mining test-zone pressure.

which passed within about $0.5 \mathrm{~m}$ of the QPP05 test interval, the test interval would no longer hold pressures of these magnitudes. The test interval was shut-in at a pressure of about $1.5 \mathrm{MPa}$ on July 26, 1989 (Calendar day 207), two days after the excavation had passed by the test interval. Within eight days, the test-interval pressure had decreased to about $0.7 \mathrm{MPa}$. The pressure then decreased slowly to about $0.3 \mathrm{MPa}$ over the following 70 days, where it remained for the next 130 days until the flow test was started.

For the flow test, the test zone was connected to a brine accumulator pressurized to about $0.71 \mathrm{MPa}$. By the time the test was terminated 15 days later, about $27 \mathrm{~cm}^{3}$ of brine had flowed from the accumulator into the formation (Figure 7-23). The pressure in the accumulator decreased to about $0.65 \mathrm{MPa}$ during the test.

Inflation pressures in the two packers in borehole QPP05 (Figure A-5) increased steadily after the mining of Room $Q$, as was the case with the packer in QPP04 (Figure A-4). These increases must reflect compression of the packer elements by the rock.

Figure 7-24 shows a GTFM simulation of the pressure data from the two fluid-injection events preceding the mining of Room $Q$. The initial pressure decreases observed when the test zone was shut-in after each injection could not be matched using a homogeneous system. Therefore, a thin skin of higher permeability was added to the model. The specified parameters for the simulation were a borehole radius of $1.9 \mathrm{~cm}$, a test-zone fluid volume of $300 \mathrm{~cm}^{3}$, and a test-zone compressibility of $6 \times 10^{-9} \mathrm{~Pa}^{-1}$ (the average of the values presented in Table 6-1 for QPP05). The fitted parameters were a skin transmissivity of $1.4 \mathrm{x}$ $10^{-15} \mathrm{~m}^{2} / \mathrm{s}$ (permeability-thickness of $2.4 \times 10^{-22}$ $\mathrm{m}^{3}$ ), skin storativity of $4.5 \times 10^{-6}$, skin thickness of $0.87 \mathrm{~cm}$, formation transmissivity of $5.8 \times 10^{-18}$ $\mathrm{m}^{2} / \mathrm{s}$ (permeability-thickness of $1.0 \times 10^{-24} \mathrm{~m}^{3}$ ), 


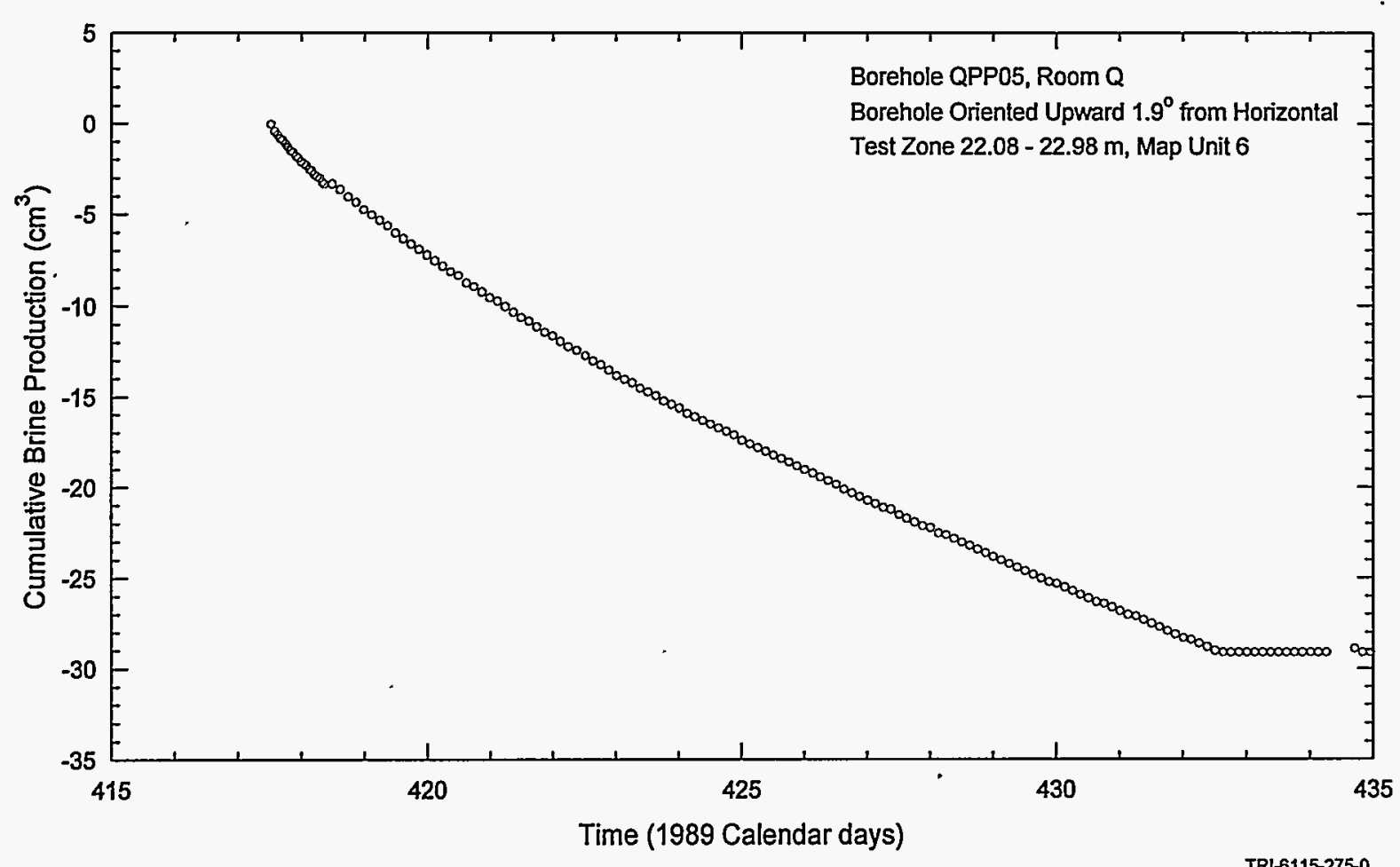

Figure 7-23. QPP05 test-zone brine production.

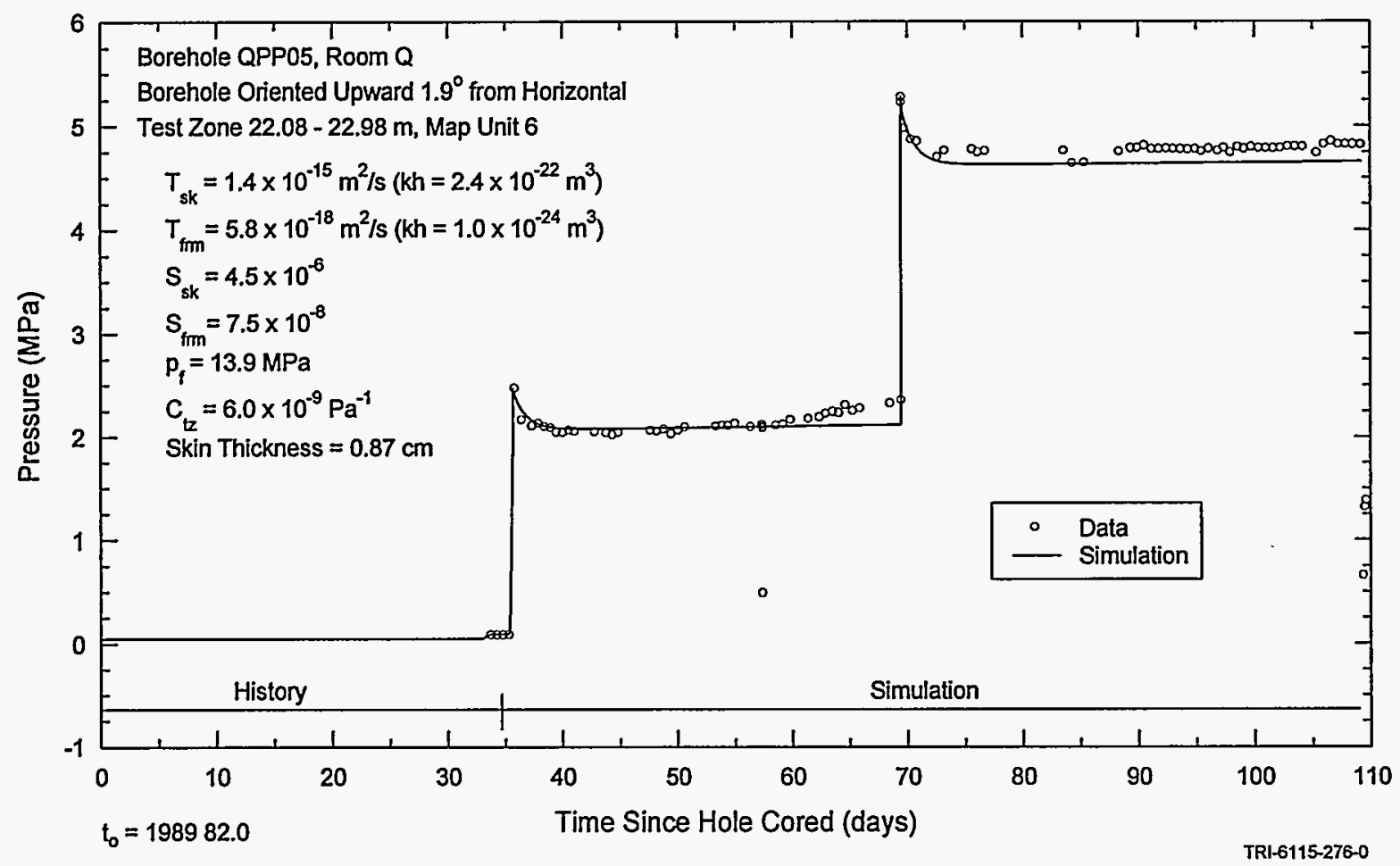

Figure 7-24. GTFM simulation of QPP05 pre-mining test-zone pressure. 
formation storativity of $7.5 \times 10^{-8}$, and formation pore pressure of $13.9 \mathrm{MPa}$. The simulation shown in Figure 7-24 cannot be considered definitive because no knowledge of the actual formation pore pressure is available; the use of $13.9 \mathrm{MPa}$ in the simulation provided an optimized fit, but cannot be verified with the available data. The sole purpose of presenting this simulation is to provide an indication of how low the transmissivity of the QPP05 test zone would need to be to produce the observed pressure responses.

The flow test and pressure-falloff test conducted after the mining of Room $Q$ were also simulated using GTFM. Simulations of the pressure data, cumulative brine injection, and brine-injection rate data are shown in Figures 7-25, 7-26, and 7-27, respectively. The simulation shown in Figure 7-25 matches the pressure data well for about the first 450 days after the flow test began, until the observed pressure began to decrease. The brine injection and rate data are well matched by the simulations. The simulations used the same values of borehole radius, test-zone fluid volume, and test-zone compressibility as the pre-mining simulation shown in Figure 7-24. Transmissivity was increased by almost five orders of magnitude, to $2.7 \times 10^{-13} \mathrm{~m}^{2} / \mathrm{s}$ (permeabilitythickness of $4.7 \times 10^{-20} \mathrm{~m}^{3}$ ), the formation storativity was increased by two orders of magnitude to $7.2 \times 10^{-6}$, and formation pore pressure was decreased to $0.28 \mathrm{MPa}$ from the premining values. No borehole skin was used in the post-mining simulation. The formation parameters used to match the data measured during the postmining time period should be used with caution because the test and guard zones were in hydraulic communication.

\subsubsection{Guard Zone.}

The complete pressure record from the QPP05 guard zone is shown in Figure 7-28.

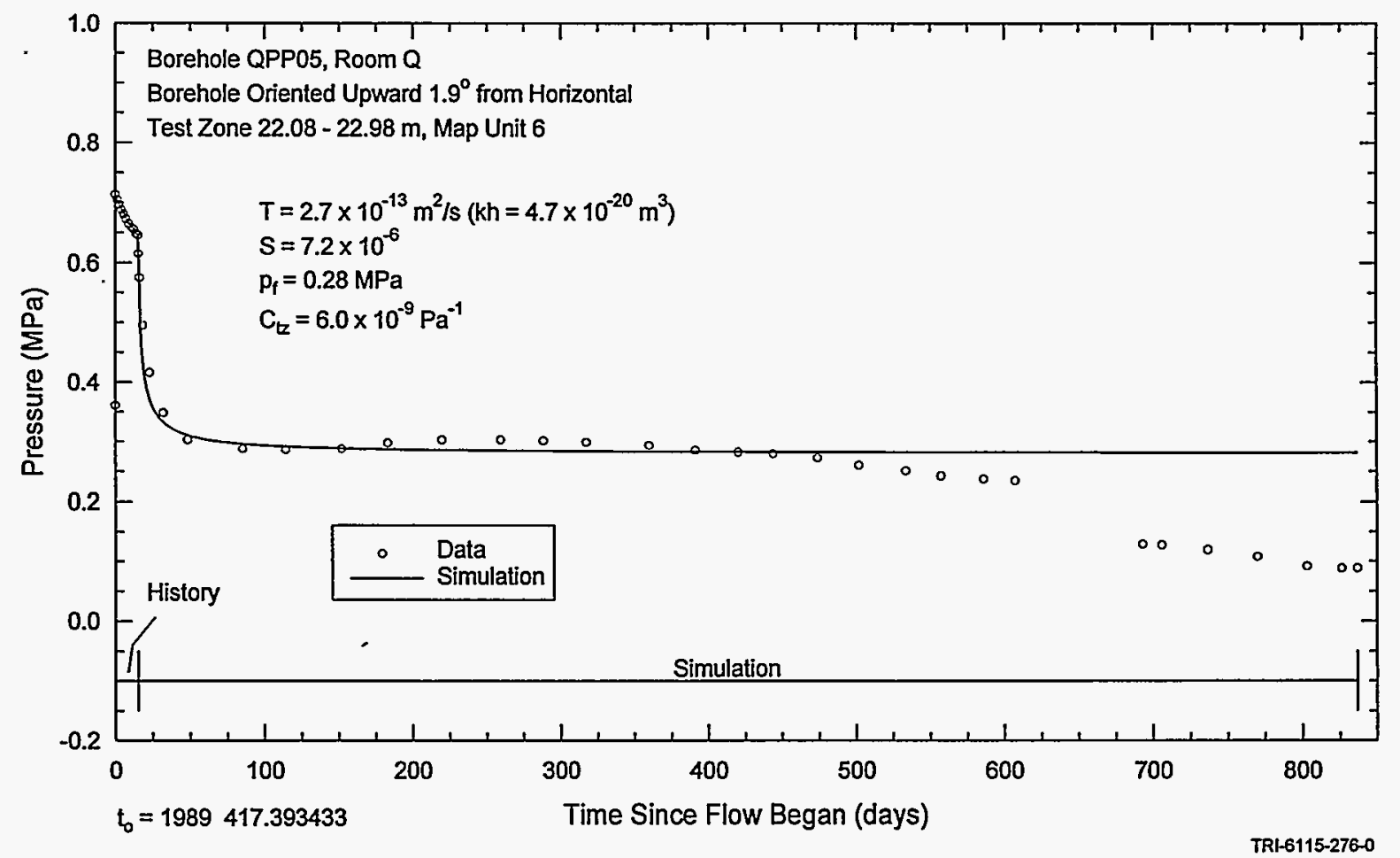

Figure 7-25. GTFM simulation of QPP05 post-flow-test pressure. 


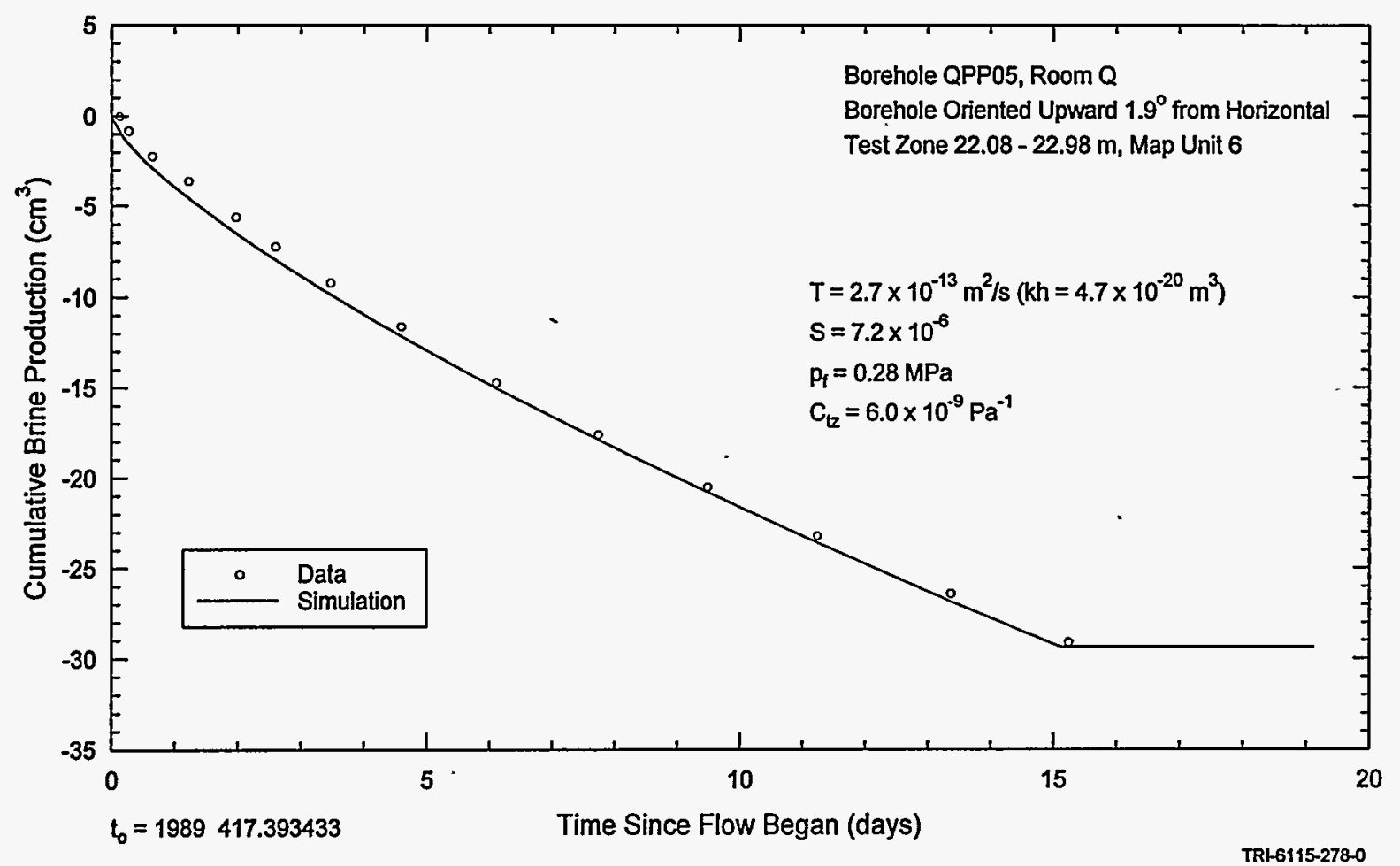

Figure 7-26. GTFM simulation of QPP05 test-zone brine production.

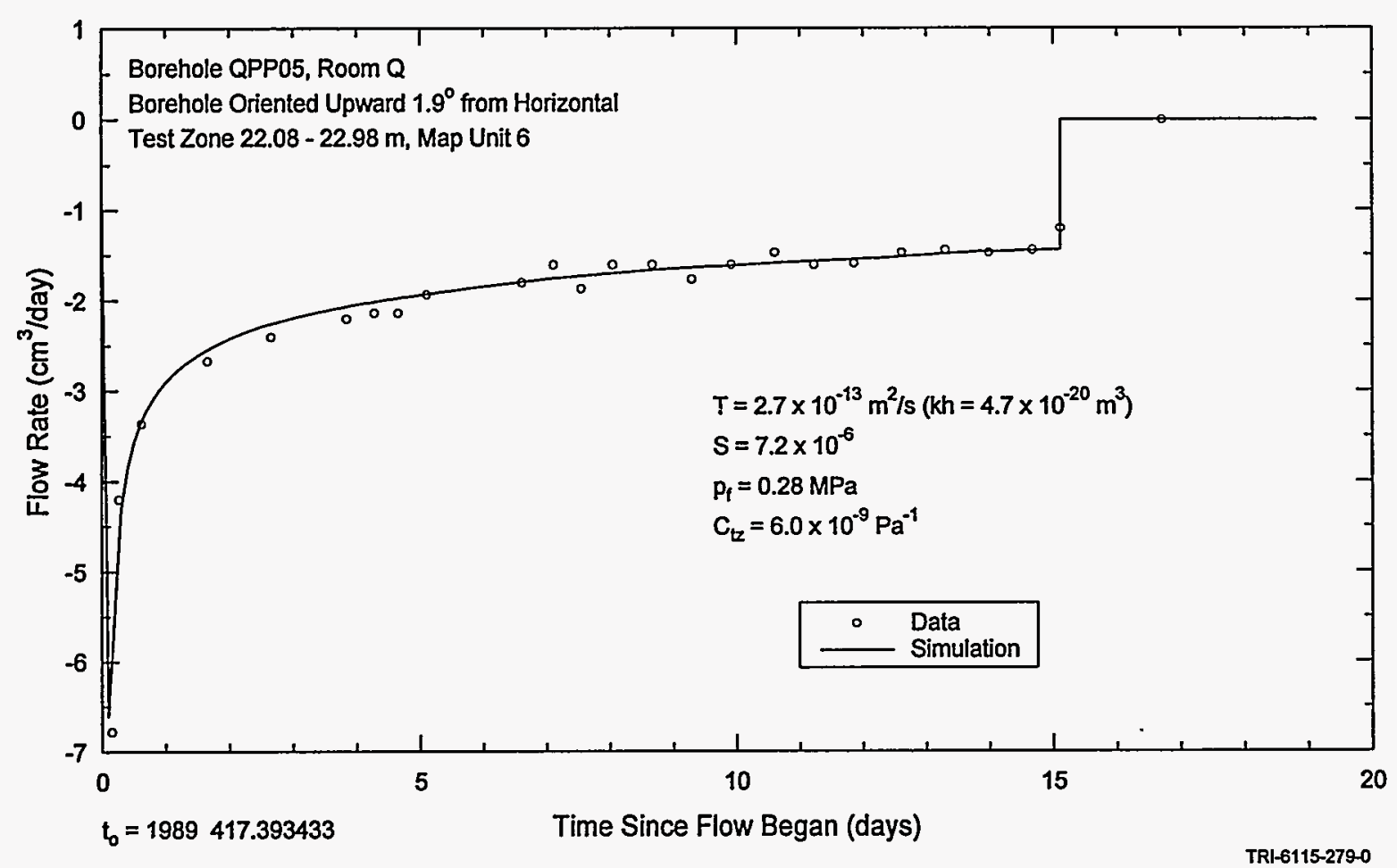

Figure 7-27. GTFM simulation of QPP05 flow rates. 


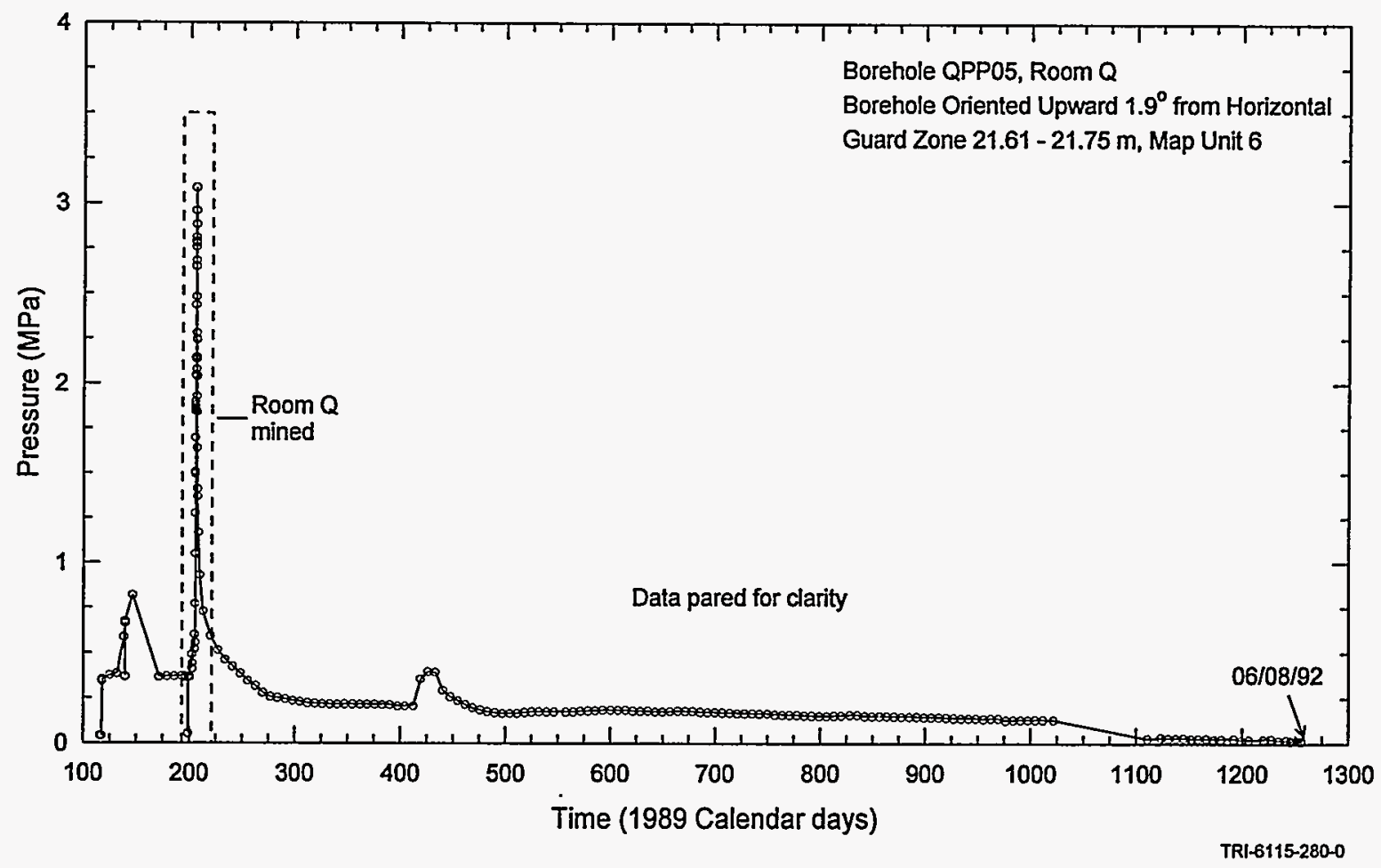

Figure 7-28. QPP05 guard-zone pressure.

Before Room $Q$ was mined, no interactions were evident between pressures in the QPP05 test and guard zones (compare Figures 7-22 and 7-29). Since mining progressed past QPP05 on July 24 , 1989 (1989 Calendar day 205), however, the test and guard zones have been in clear hydraulic communication. During the constant-head test in the test zone, the guard-zone pressure also increased, further confirming the communication of the zones.

\subsubsection{Summary.}

Interpretation of the pre-mining data from the QPP05 test zone is highly uncertain. If the interpreted transmissivity was uniformly distributed over the $0.90-\mathrm{m}$ length of the test zone, the average pre-mining hydraulic conductivity was approximately $6.4 \times 10^{-18} \mathrm{~m} / \mathrm{s}$ (permeability of $1.1 \mathrm{X}$ $10^{-24} \mathrm{~m}^{2}$ ). The average pre-mining specific storage was $8.3 \times 10^{-8} \mathrm{~m}^{-1}$. The parameter values interpreted from the post-mining data are believed to be more reliable than the pre-mining values. The average post-mining hydraulic conductivity was approximately $3.0 \times 10^{-13} \mathrm{~m} / \mathrm{s}$ (permeability of $5.3 \times 10^{-20} \mathrm{~m}^{2}$ ), and the average specific storage was $8.0 \times 10^{-6} \mathrm{~m}^{-1}$. Regardless of the uncertainty in the pre-mining values, the test-zone transmissivity clearly increased by several orders of magnitude after mining.

The pre- and post-mining pressure behavior of QPP05 reflects its proximity to Room Q. Prior to mining, the test- and guard-zone pressures reacted independently and the test zone was able to maintain high pressures. In the postmining period, the test and guard zones were in hydraulic communication and both zones were at low pressures ( $<0.5 \mathrm{MPa}$ ). Chester (Appendix B) reports that in March 1995, the pressure in the test and guard zones was $0.5 \mathrm{MPa}$, further confirming the connection of the zones and the low-pressure regime. The probable cause for the hydraulic 


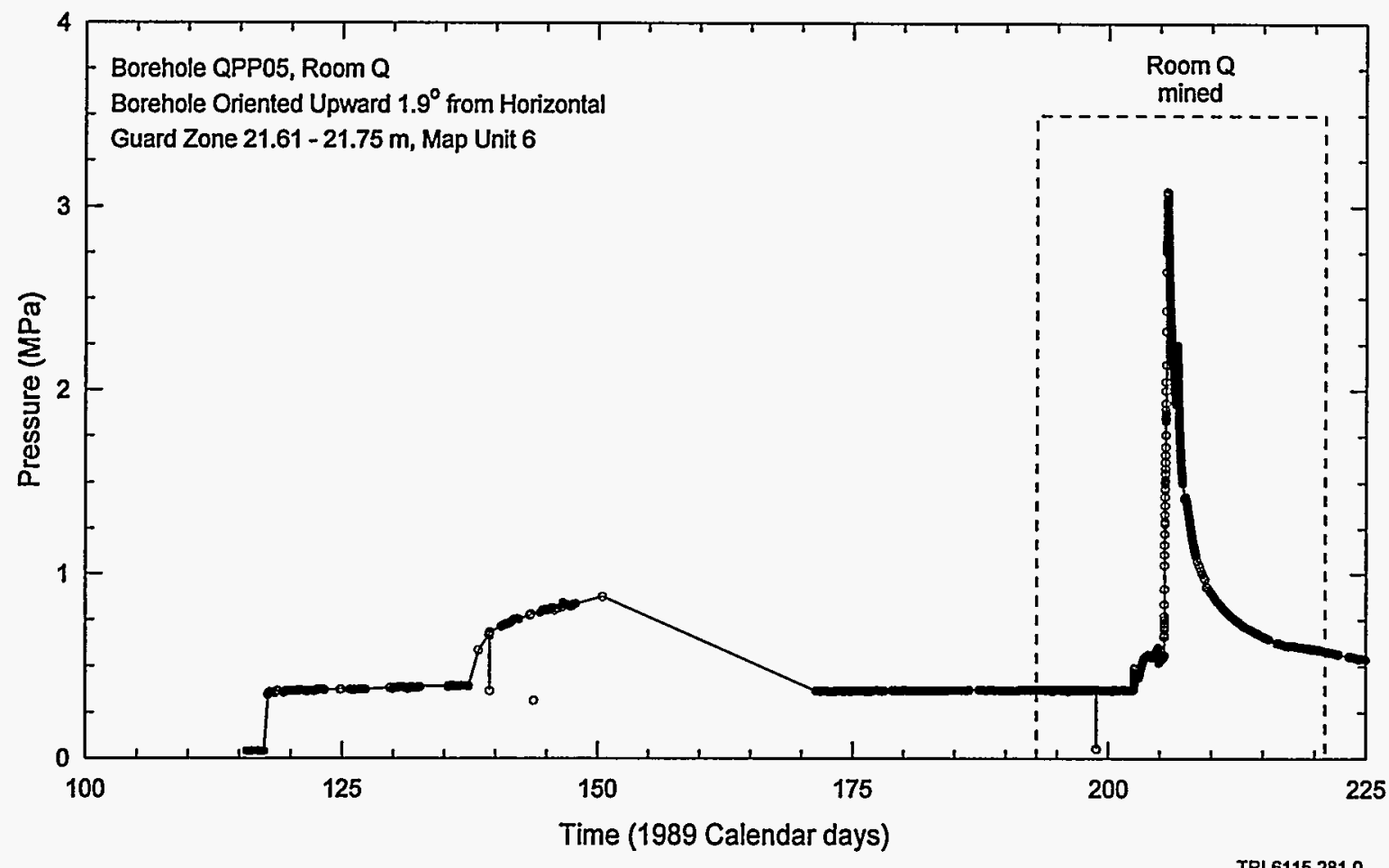

Figure 7-29. QPP05 pre-mining and mining guard-zone pressure.

communication and the low-pressure regime was the formation of a disturbed rock zone (DRZ) in the vicinity of Room $Q$.

\subsubsection{QPP11}

The survey data indicate that the QPP11 test zone is located in map unit $\mathrm{H}-1$. According to Deal et al. (1989), map unit $\mathrm{H}-1$ is primarily halite, but locally contains up to $3 \%$ clay as well as up to $1 \%$ polyhalite. The guard zone of QPP11 lies both in map unit $\mathrm{H}-1$ and anhydrite "c".

\subsubsection{Test Zone.}

The complete pressure record from the QPP11 test zone is shown in Figure 7-30. No clear trends were evident in the test-zone pressure data before the mining of Room Q (Figure 7-31). Pressure increases of 0.1 to $0.2 \mathrm{MPa}$ were noted over approximately 10-day periods immediately after the test zone was first shut-in and after test-zonecompressibility measurements. After the pre-mining pulse injection, however, the test-zone pressure stabilized at about 3.6 MPa. The pressure began to increase after the mining of Room $Q$ began, and the rate of pressure increase accelerated after mining passed the QPP11 testzone. By the start of the flow test on February 21, 1990 (1989 Calendar day 417), the test-zone pressure had reached almost $5.2 \mathrm{MPa}$ (Figure 7-30). During the flow test, the test-zone pressure decreased from the design pressure of about $0.95 \mathrm{MPa}$ to $0.25 \mathrm{MPa}$, apparently because of a leak in the flow system. Because of the leak, the data from the brine accumulator are not considered to be reliable. The rate of pressure increase following the flow test increased for approximately the first 200 days of the pressure-buildup test, probably reflecting a pressure-dependent test-zone compressibility. By the end of the monitoring period (June 3, 1992), the test-zone pressure had reached only $3.7 \mathrm{MPa}$. 


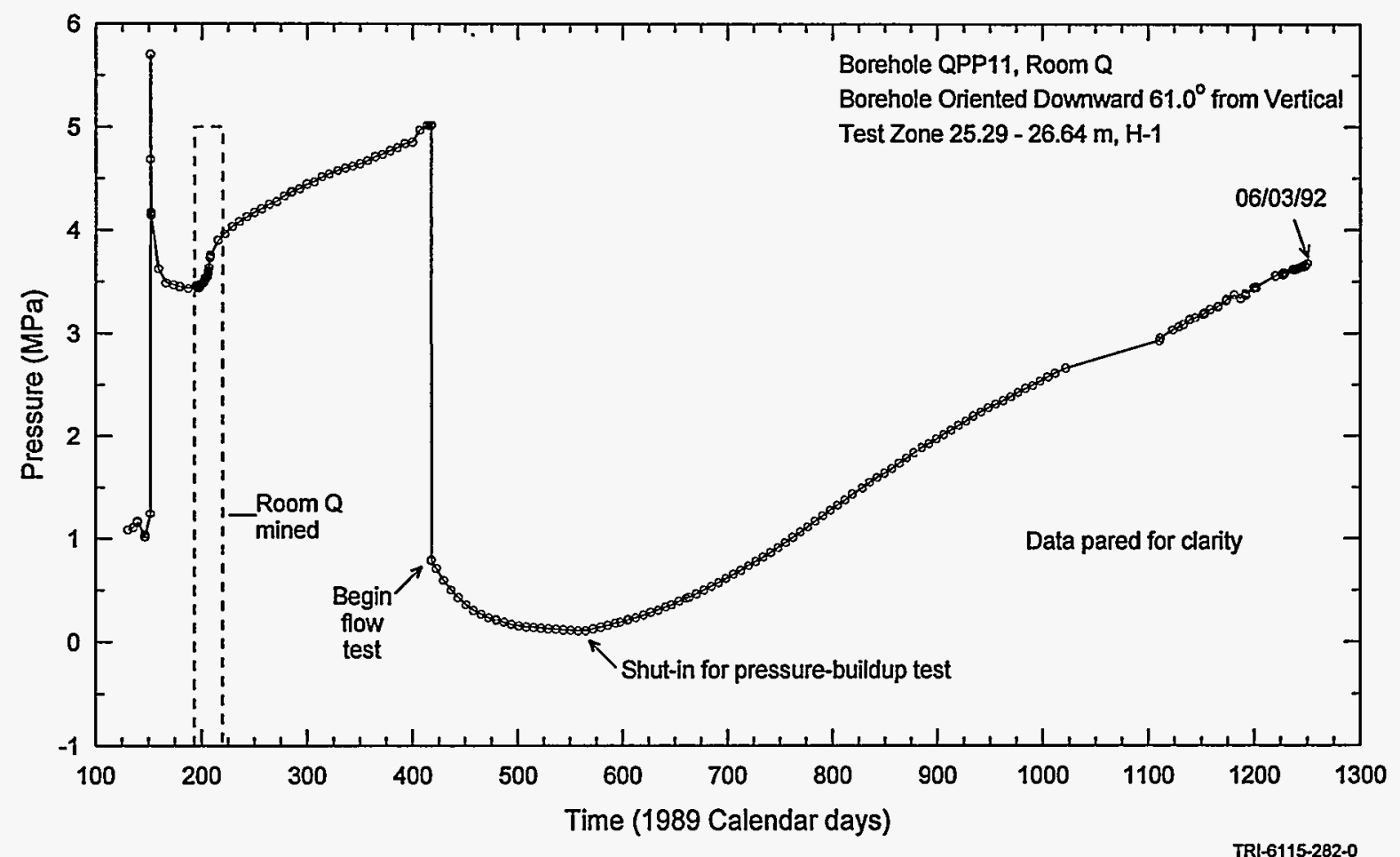

Figure 7-30. QPP11 test-zone pressure.

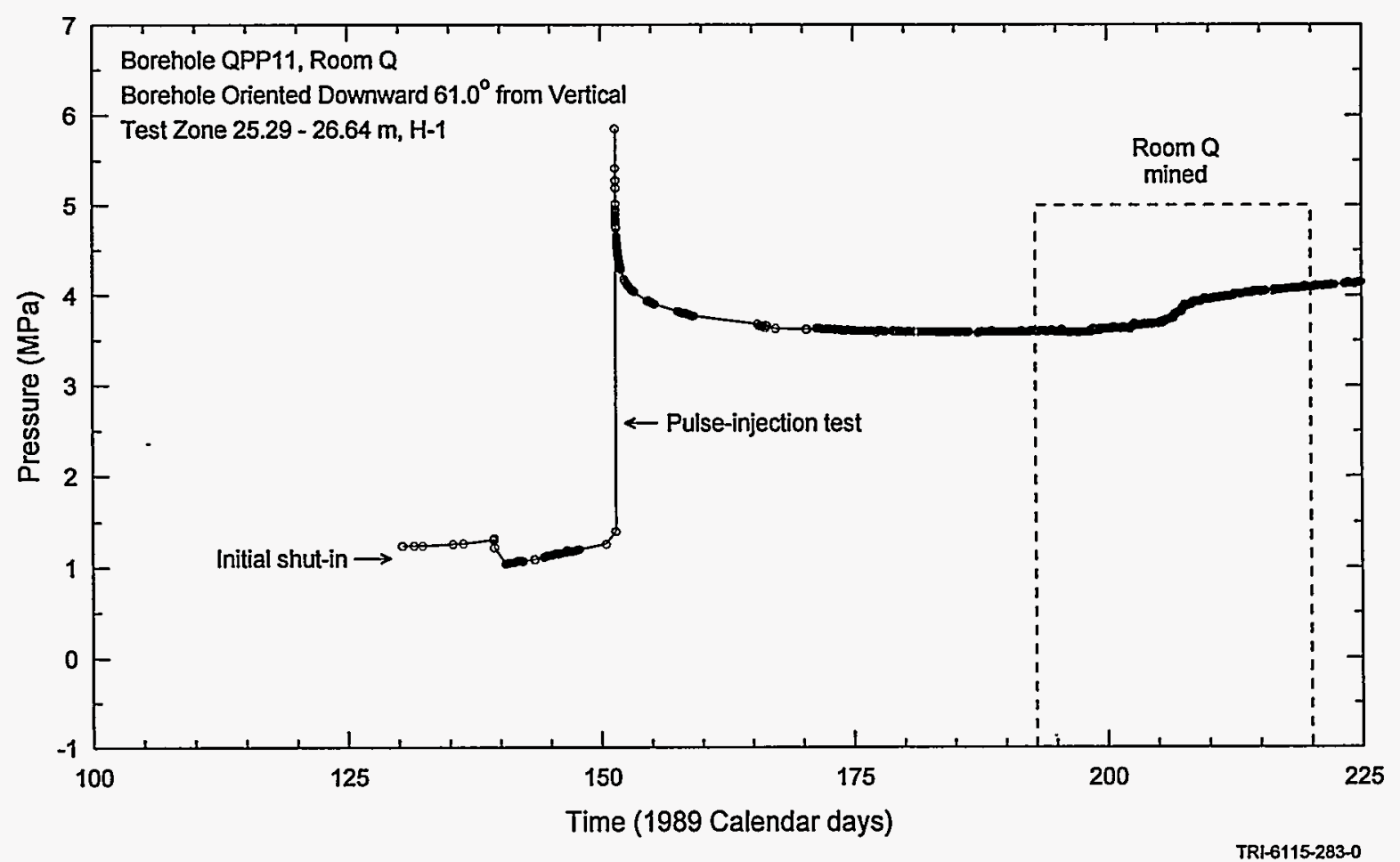

Figure 7-31. QPP11 pre-mining and mining test-zone pressure. 
The only portion of the QPP11 tests that could be interpreted was the pre-mining pulseinjection test. The test-zone compressibility was measured before mining to be $1.0 \times 10^{-9} \mathrm{~Pa}^{-1}$. Figure 7-32 displays the simulated response of the pre-mining pulse-injection test. The specified parameters for the GTFM simulation were a borehole radius of $0.077 \mathrm{~m}$, a test-zone fluid volume of $6000 \mathrm{~cm}^{3}$, a test-zone compressibility of $1 \times 10^{-9} \mathrm{~Pa}^{-1}$, and a pore pressure of $5.5 \mathrm{MPa}$. The rapid early time pressure recovery could only be simulated with the addition of a finite-thickness skin of greater permeability than the formation. The fitted parameters were a skin transmissivity of $1.3 \mathrm{x}$ $10^{-13} \mathrm{~m}^{2} / \mathrm{s}$ (permeability thickness of $2.3 \times 10^{-20}$ $\mathrm{m}^{3}$ ), formation transmissivity of $2.1 \times 10^{-15} \mathrm{~m}^{2} / \mathrm{s}$ (permeability-thickness of $3.7 \times 10^{-22} \mathrm{~m}^{3}$ ), skin storativity of $2.2 \times 10^{-6}$, formation storativity of $2.7 \times$ $10^{-6}$, and skin thickness of $2.3 \mathrm{~cm}$. The simulation shown in Figure 7-32 is non-unique because the pre-mining pore pressure could not be estimated with the available data. The value used in the simulation, 5.5 $\mathrm{MPa}$, is lower than is believed reasonable for pre-mining conditions. Similar fits to that shown in Figure 7-32 could probably be obtained by simultaneously decreasing the transmissivity and increasing the pore pressure. The purpose of presenting this simulation is to provide an indication of how low the transmissivity would need to be to produce the observed pressure response.

None of the post-mining test events could be interpreted because no data are available to constrain the analysis. The increase in pressure that occurred after the mining of Room $Q$ cannot be interpreted without understanding its cause. The flow test cannot be interpreted because of the lack of reliable flow data. Similarly, the pressurebuildup test cannot be interpreted without knowledge of the preceding flow rates. Lack of knowledge of the test-zone compressibility during the pressure-buildup test would also preclude unique determination of permeability.

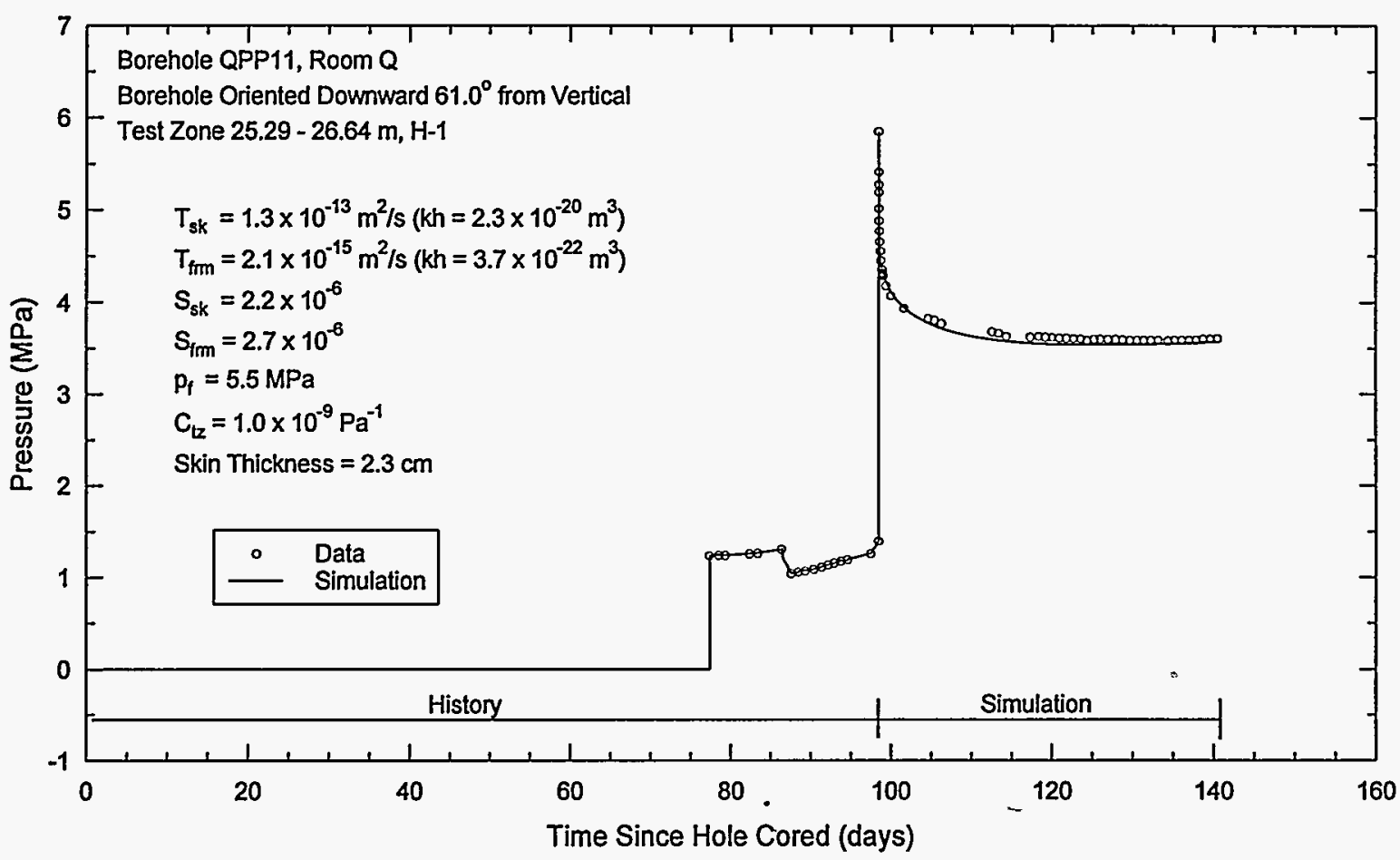

Figure 7-32. GTFM simulation of QPP11 pre-mining test-zone pressure. 
The only information that was obtained from the post-mining QPP11 test-zone data is an estimate of the post-mining formation pore pressure. Figure $7-33$ is a Horner plot of the pressure-buildup data following the flow test. Extrapolating the pressure trend to infinite time (1.0 on the time axis) provides an estimated pore pressure of $7.4 \mathrm{MPa}$.

\subsubsection{Guard Zone.}

The complete pressure record from the QPP11 guard zone is shown in Figure 7-34. The QPP11 guard zone was opened for flow at atmospheric pressure from June 20, 1989 to February 21, 1990 (1989 Calendar days 171 to 417). No reliable flow data were collected during this time. At the end of the flow test, the guardzone pressure was increased to about $0.9 \mathrm{MPa}$ and shut-in. A Horner plot of the ensuing pressure buildup is shown in Figure 7-35. The formation pore pressure indicated by the Horner plot is about $9.6 \mathrm{MPa}$.

\subsubsection{Summary.}

The numerical simulation of the pre-mining pulse-injection test revealed that the early-time rapid pressure decay could be modeled by including a 2.3-cm-thick skin of higher transmissivity $\left(1.3 \times 10^{-13} \mathrm{~m}^{2} / \mathrm{s}\right)$ around the borehole and using a formation transmissivity of $2.1 \times 10^{-15} \mathrm{~m}^{2} / \mathrm{s}$. If transmissivity is uniformly distributed along the 1.35-m length of the QPP11 test zone, the average pre-mining hydraulic conductivity was approximately $1.6 \times 10^{-15} \mathrm{~m} / \mathrm{s}$ (permeability of $2.7 \times 10^{-22} \mathrm{~m}^{2}$ ). The average specific storage was $2.0 \times 10^{-6} \mathrm{~m}^{-1}$. The formation pore pressure used in the simulation, 5.5 $\mathrm{MPa}$, was chosen arbitrarily and is probably lower than the

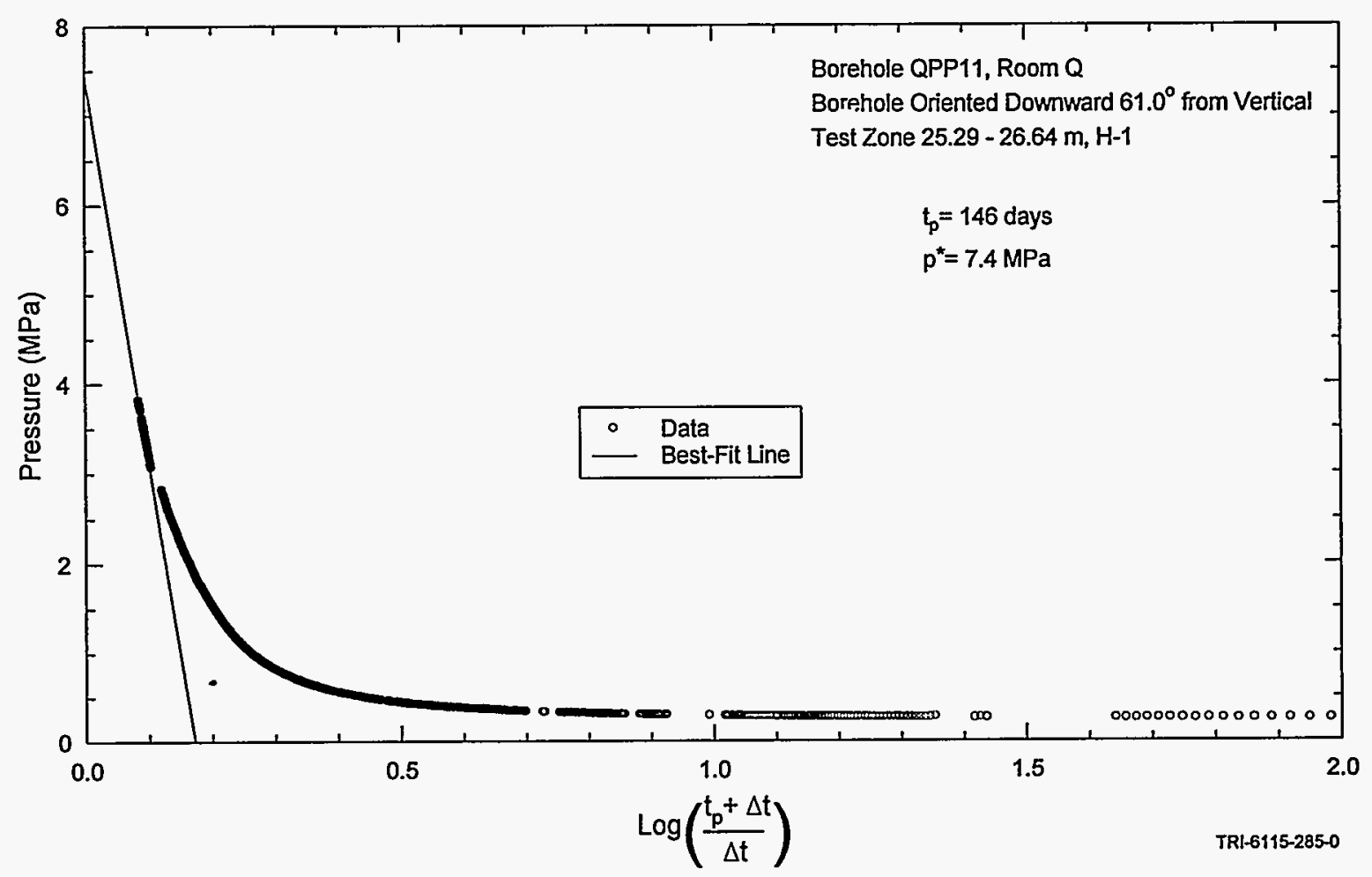

Figure 7-33. Horner plot of the QPP11 post-mining test-zone pressure. 


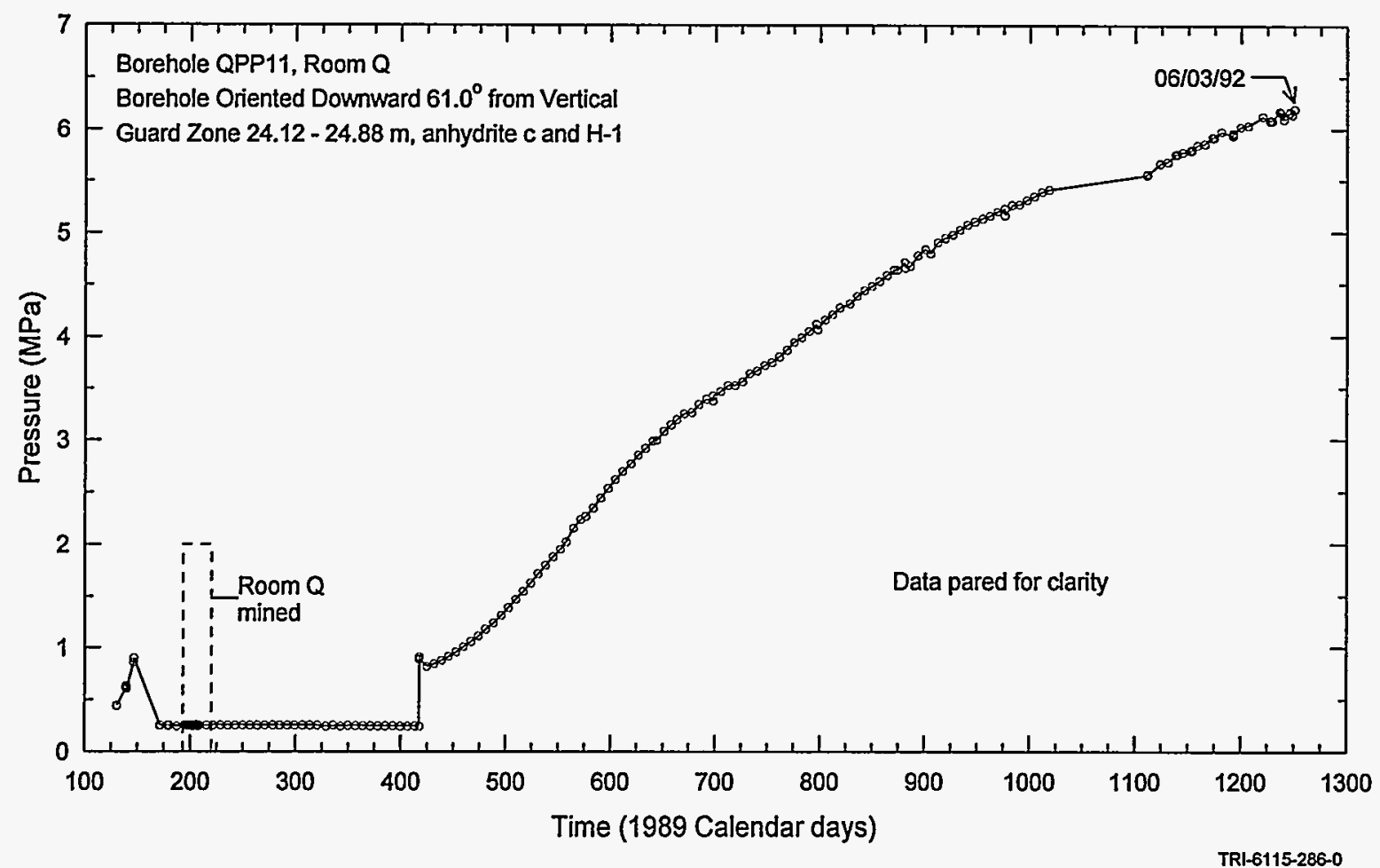

Figure 7-34. QPP11 guard-zone pressure.

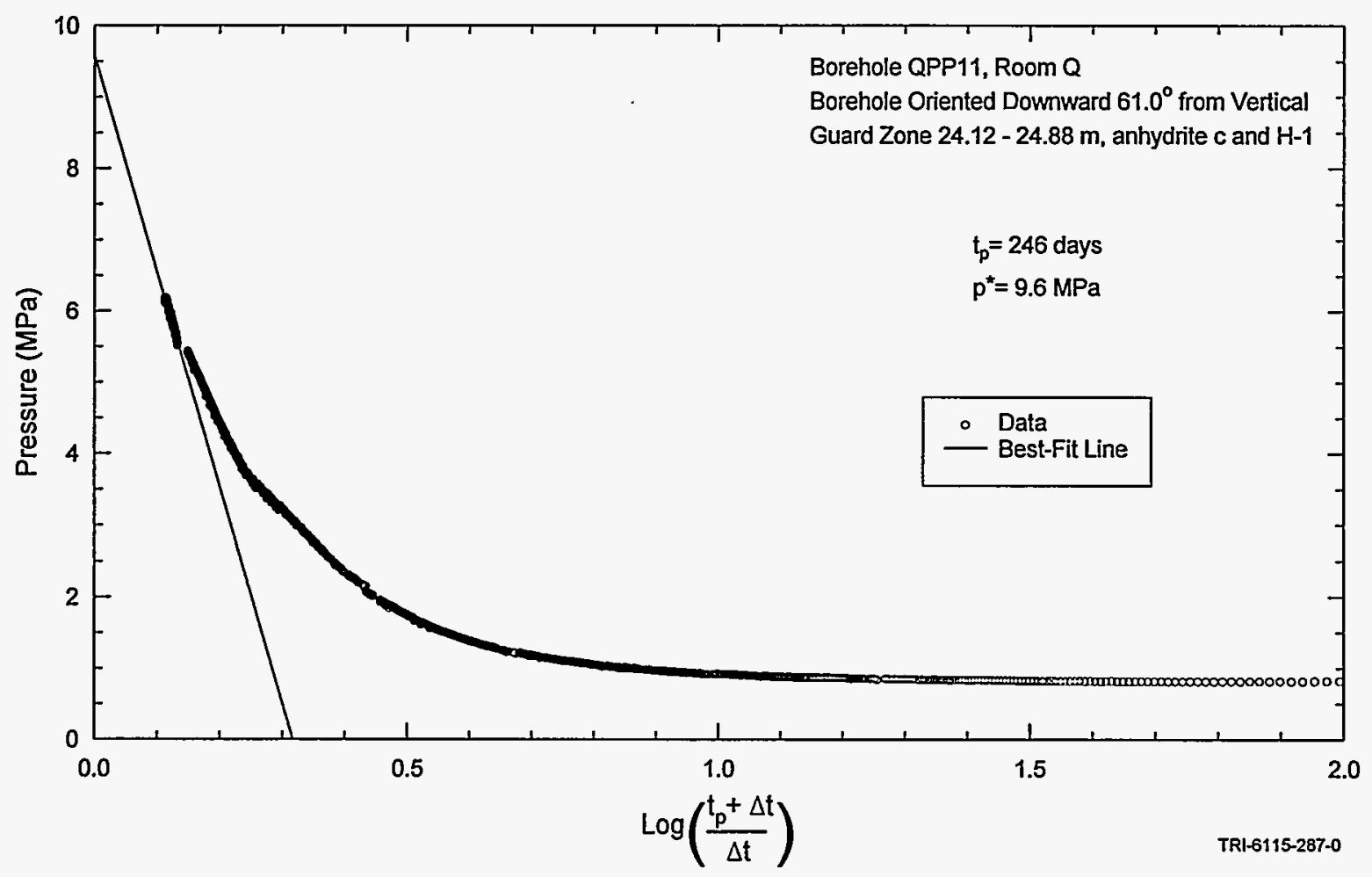

Figure 7-35. Horner plot of the QPP11 post-mining guard-zone pressure. 
actual pre-mining pore pressure. In that case, the interpreted transmissivity is probably an overestimate.

The only information that can be obtained from the post-mining tests conducted in borehole QPP11 is estimates of the post-mining formation pore pressures in the test and guard zones. The pore pressure at the test-zone horizon appears to be about 7.4 MPa, while that at the guard-zone horizon appears to be about $9.6 \mathrm{MPa}$. The reason for the difference in pressures is uncertain. The vertical separation between the test and guard zones is only about $0.20 \mathrm{~m}$, but the guard zone contains anhydrite " $\mathrm{c}$ " which could have had an initial post-mining pore pressure higher than that of map unit $\mathrm{H}-1$ because anhydrite and halite may respond differently to stress changes associated with mining (see Section 8). Presumably, the difference between the test-zone and guard-zone pore pressures would dissipate with time due to flow from the anhydrite into the halite.
Both the test and guard zones in borehole QPP11 are good candidates for future tests. Our inability to obtain quantitative information on permeability from the post-mining tests already conducted stems from the failure to measure flow rates and test-zone compressibility rather than from anomalies in the observed pressure responses. These measurement deficiencies could be easily corrected in future tests.

\subsubsection{QPP12}

The survey data indicate that the QPP12 test zone is within map unit $\mathrm{H}-3$, a halite unit that typically contains less than $1 \%$ clay and/or polyhalite (Deal et al., 1989).

The complete pressure record from the QPP12 test zone is shown in Figure 7-36. The mining of Room $Q$ caused oscillations in the testzone pressure of a few tenths of an MPa, but did

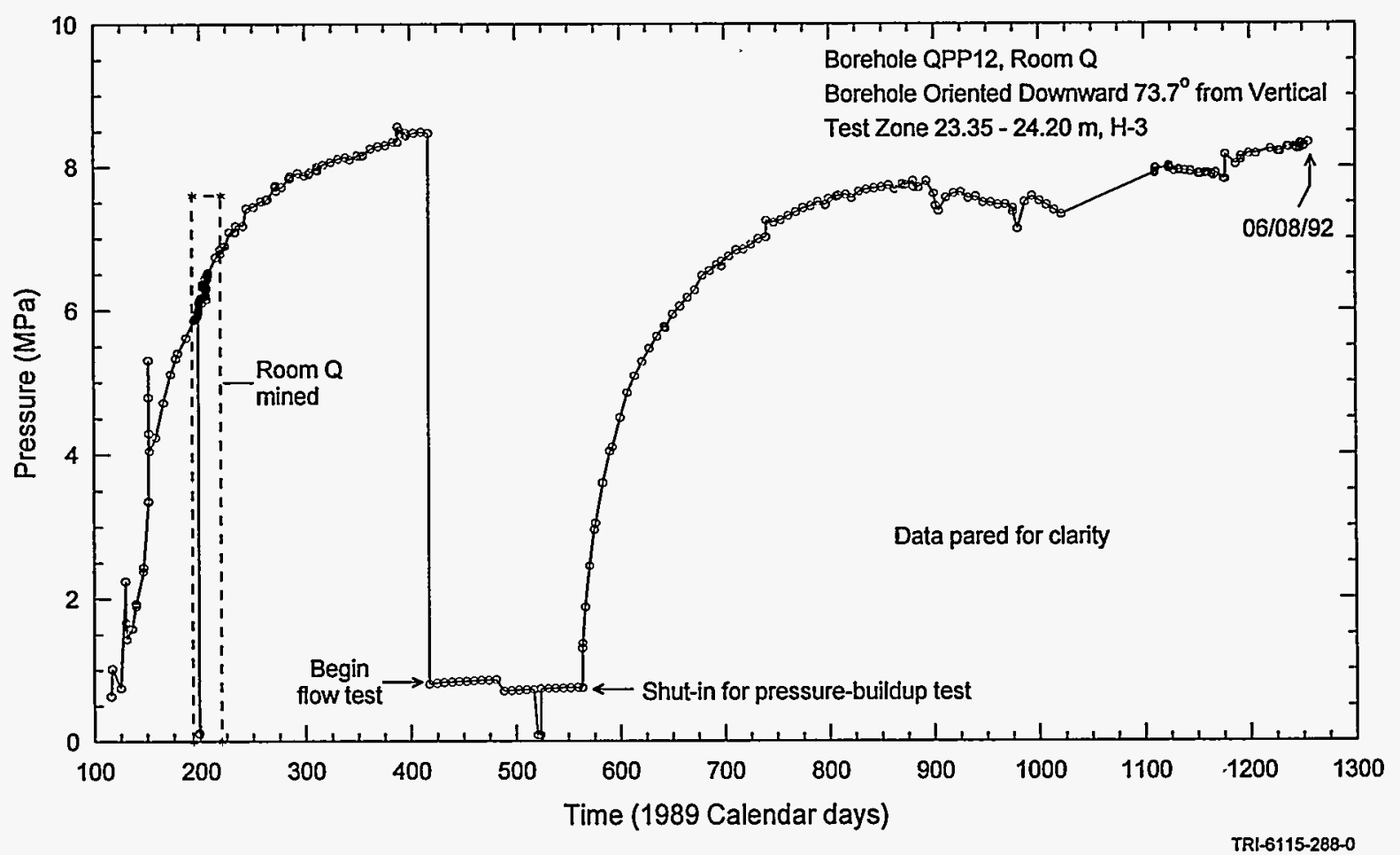

Figure 7-36. QPP12 test-zone pressure. 
not appear to have a long-term effect (Figure 7-37). Brine accumulation during the flow test is illustrated in Figure 7-38. The data quality from QPP12 was generally good until June 18, 1991 (1989 Calendar day 899), when the test-zone packer began to lose pressure (Figure A-7). After that date, both the test-zone and packer pressures showed evidence of leaks.

The data from both the pre- and postmining hydraulic tests conducted in QPP12 are interpretable. The flow-rate data from the flow test were analyzed using the type curves of Doe (1991), the pressure-buildup data were analyzed using the Interpret/2 well-test interpretation code, and the entire testing sequence was simulated using GTFM.

Analytical Interpretations. Figure 7-39 shows the best-fit match of the QPP12 flow-rate data to the constant-pressure flow type curves of Doe (1991). The late-time data match the radial- flow type curve well, while the early-time data fall above the type curve. Assuming that the pressure differential between the borehole and the surrounding formation was about $8.5 \mathrm{MPa}$, the type-curve match provides a transmissivity estimate of $7.6 \times 10^{-16} \mathrm{~m}^{2} / \mathrm{s}$ (permeabilitythickness of $1.3 \times 10^{-22} \mathrm{~m}^{3}$ ).

For analysis of the pressure-buildup test using Interpret/2, the constant-pressure flow test was divided into 52 separate flow periods having constant rates ranging from 2.36 to $0.20 \mathrm{~cm}^{3} /$ day. Figures 7-40,7-41, and 7-42 show excellent log$\log$, Horner, and linear-linear matches, respectively, between the pressure-buildup test data and Interpret/2 simulations. The parameters used for the simulations are a transmissivity of 7.5 $\times 10^{-16} \mathrm{~m}^{2} / \mathrm{s}$ (permeability-thickness of $1.3 \times 10^{-22}$ $\mathrm{m}^{3}$ ), a formation pore pressure of $9.25 \mathrm{MPa}$, a wellbore-storage coefficient of $0.67 \mathrm{~cm}^{3} / \mathrm{MPa}$ (corresponding to a test-zone compressibility of 2.3 $\left.\times 10^{-9} \mathrm{~Pa}^{-1}\right)$, and a wellbore skin factor of -0.09 .

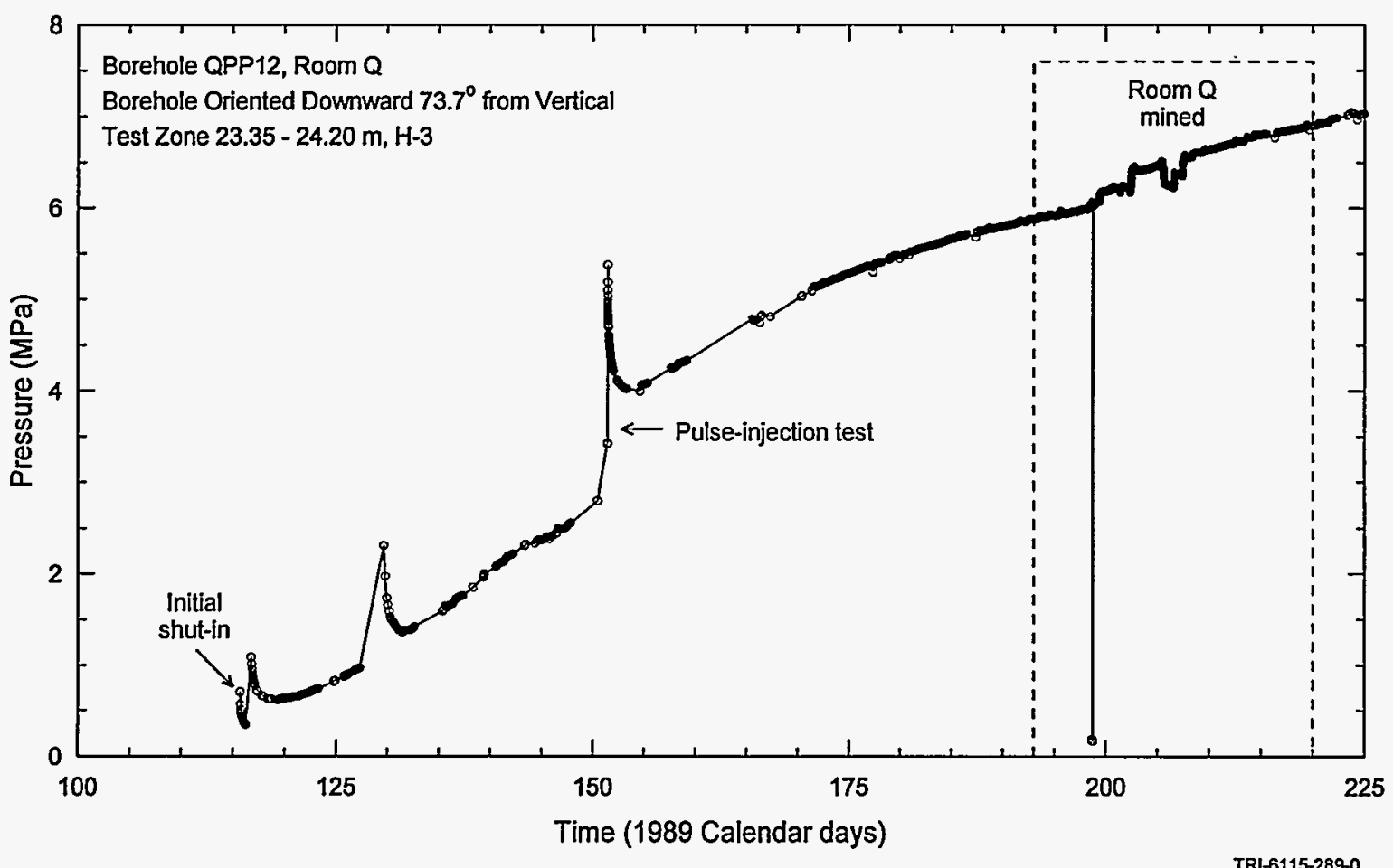

Figure 7-37. QPP12 pre-mining and mining test-zone pressure. 


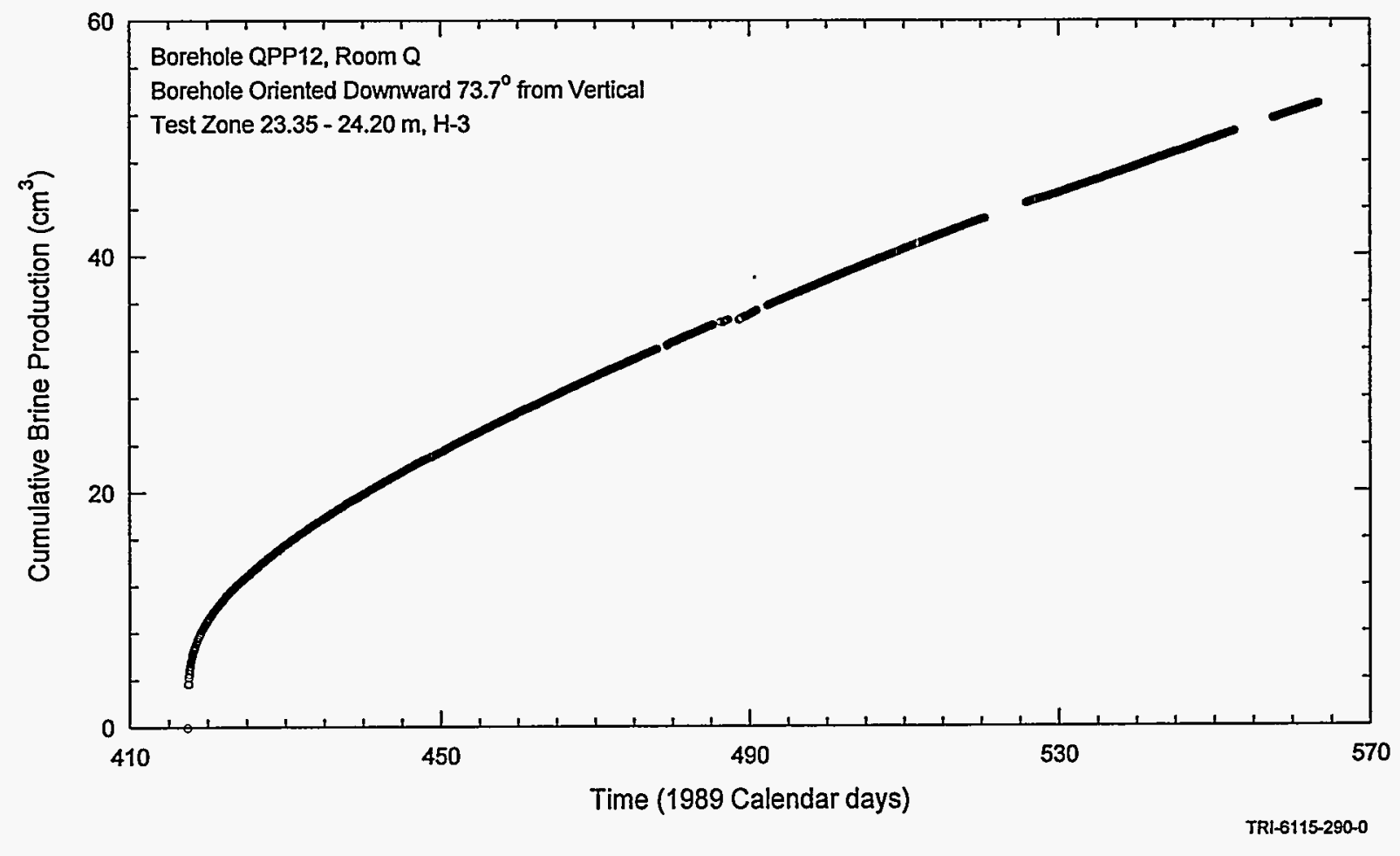

Figure 7-38. QPP12 test-zone brine production.

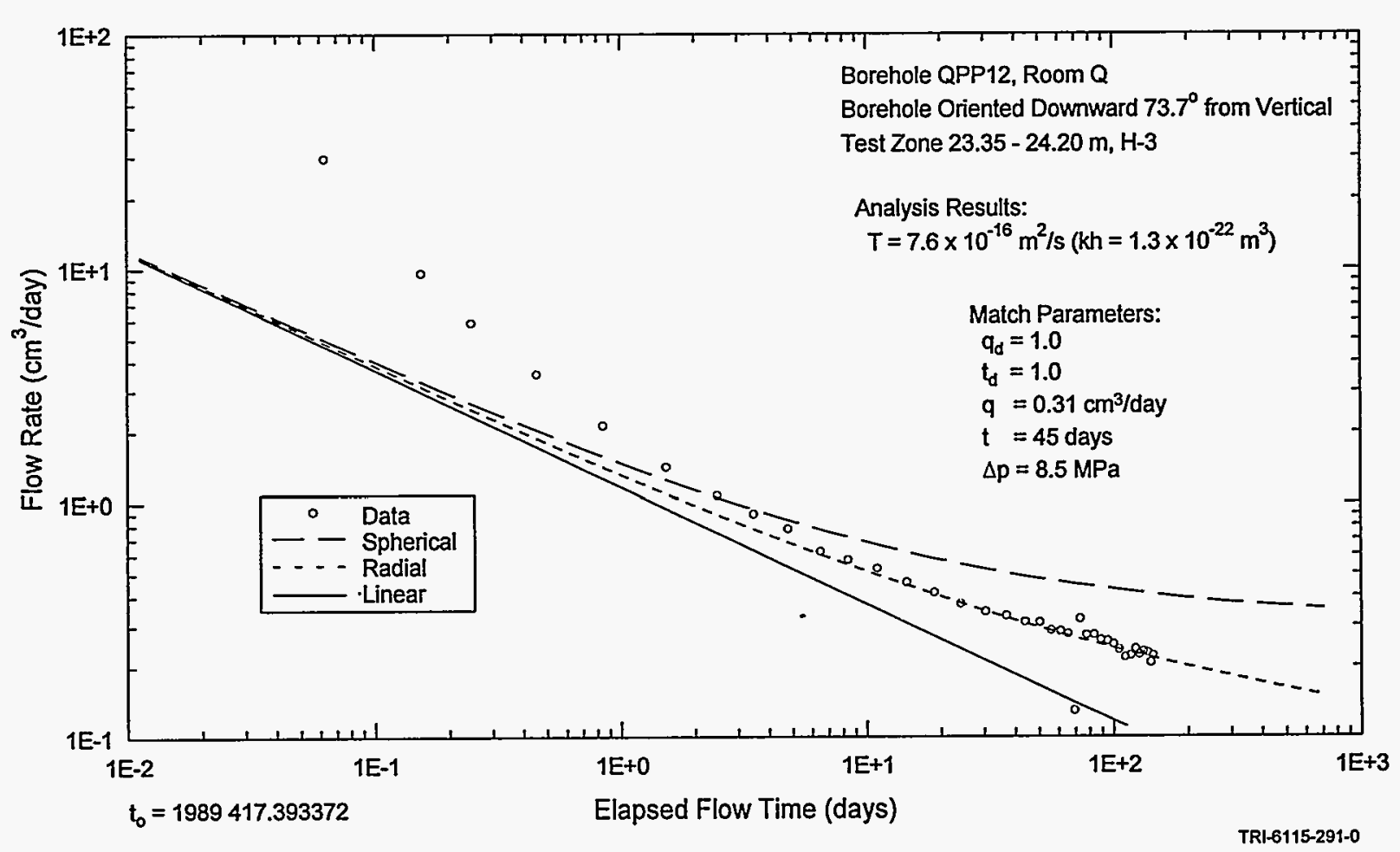

Figure 7-39. Type-curve match of the QPP12 flow rates. 


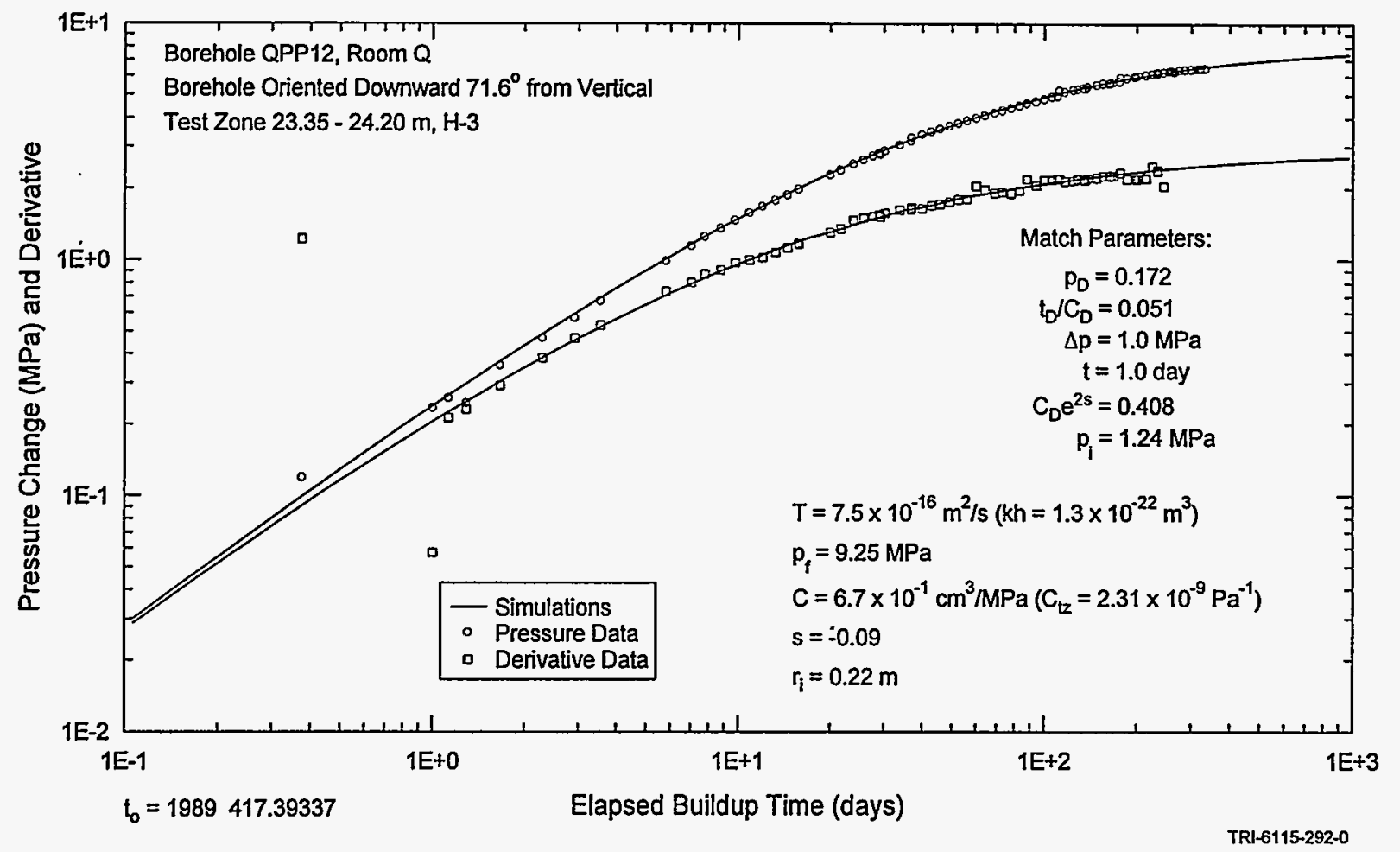

Figure 7-40. Interpret/2 type-curve match of the QPP12 post-flow-test pressure buildup.

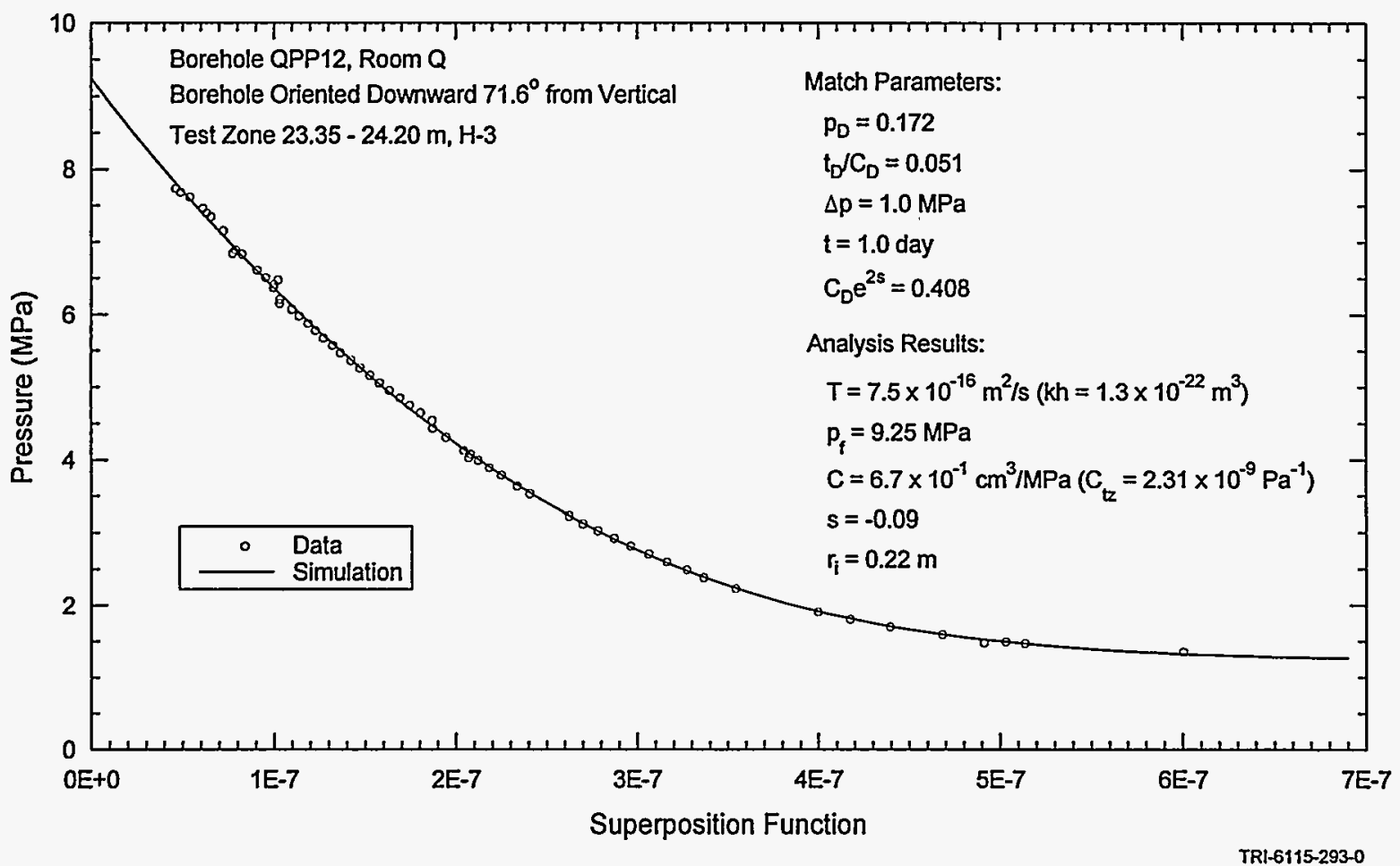

Figure 7-41. Interpret/2 Horner superposition match of the QPP12 post-flow-test pressure buildup. 


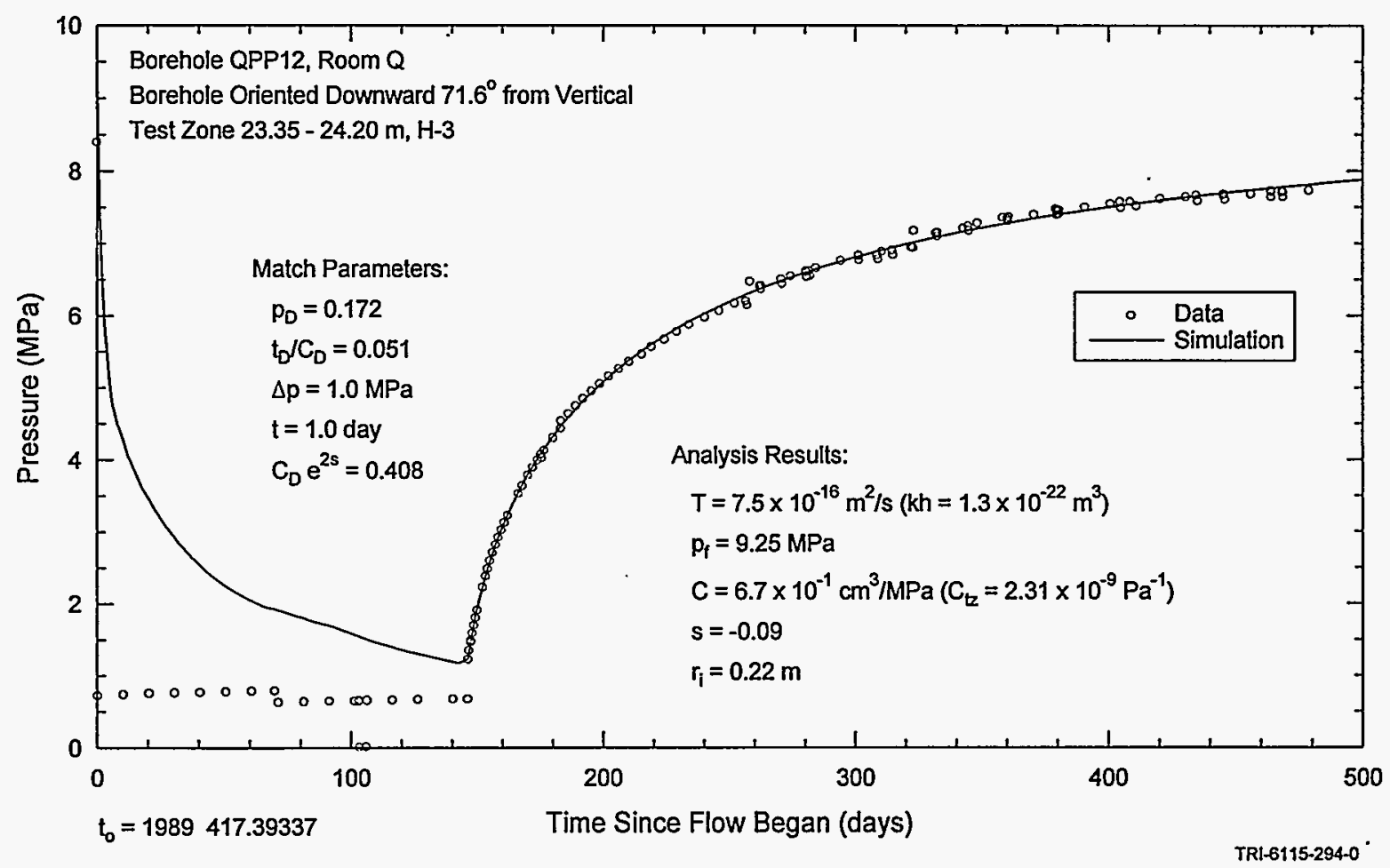

Figure 7-42. Interpret/2 simulation of the QPP12 constant-pressure flow test and pressure buildup.

Numerical Interpretations. The only value of the test-zone compressibility available for QPP12 was calculated using the volume of fluid and initial pressure drop associated with the flow test, $1.67 \times 10^{-9} \mathrm{~Pa}^{-1}$. This value of test-zone compressibility was used for the numerical simulations. Subsequent attempts to match the flow data (volume and rate) and pressure data simultaneously provided final values of transmissivity, storativity, and formation pore pressure. The pressure-buildup period preceding mining was simulated using a variable test-zone compressibility. Although test-zone compressibility was not measured at different pressures, a generic data set was generated based on the discussion presented in Beauheim et al. (1993).

A number of periods were included in the GTFM simulations as specified-pressure history events. These included: the initial 60-day period after drilling during which the borehole was at atmospheric pressure; several-day periods following the first three test-zone packer-pressure increases (April 25, May 9, and May 31, 1989) when compliance effects dominated the pressure responses; the period of the constant-pressure flow test; and a three-day period from June 4 to 7 , 1990 (1989 Calendar days 520 to 523) when the test tool was removed from the hole. Packerpressure increases during the final pressurebuildup test were treated as pressure-pulse events.

Figures $7-43$ and $7-44$ show the best-fit GTFM simulations for the brine-inflow volume and rates during the flow test, respectively. Figure 7-45 shows the best-fit simulation of the post-mining pressure data. Figure 7-46 shows a Horner plot of the buildup-test data and simulation. Figure 7-47 shows the simulation of the pre-mining pressure data. The pre-mining period was simulated using a variable test-zone compressibility. Because of the lack of information regarding test-zone compressibility during this period, the parameters carry a higher uncertainty. All five plots represent 


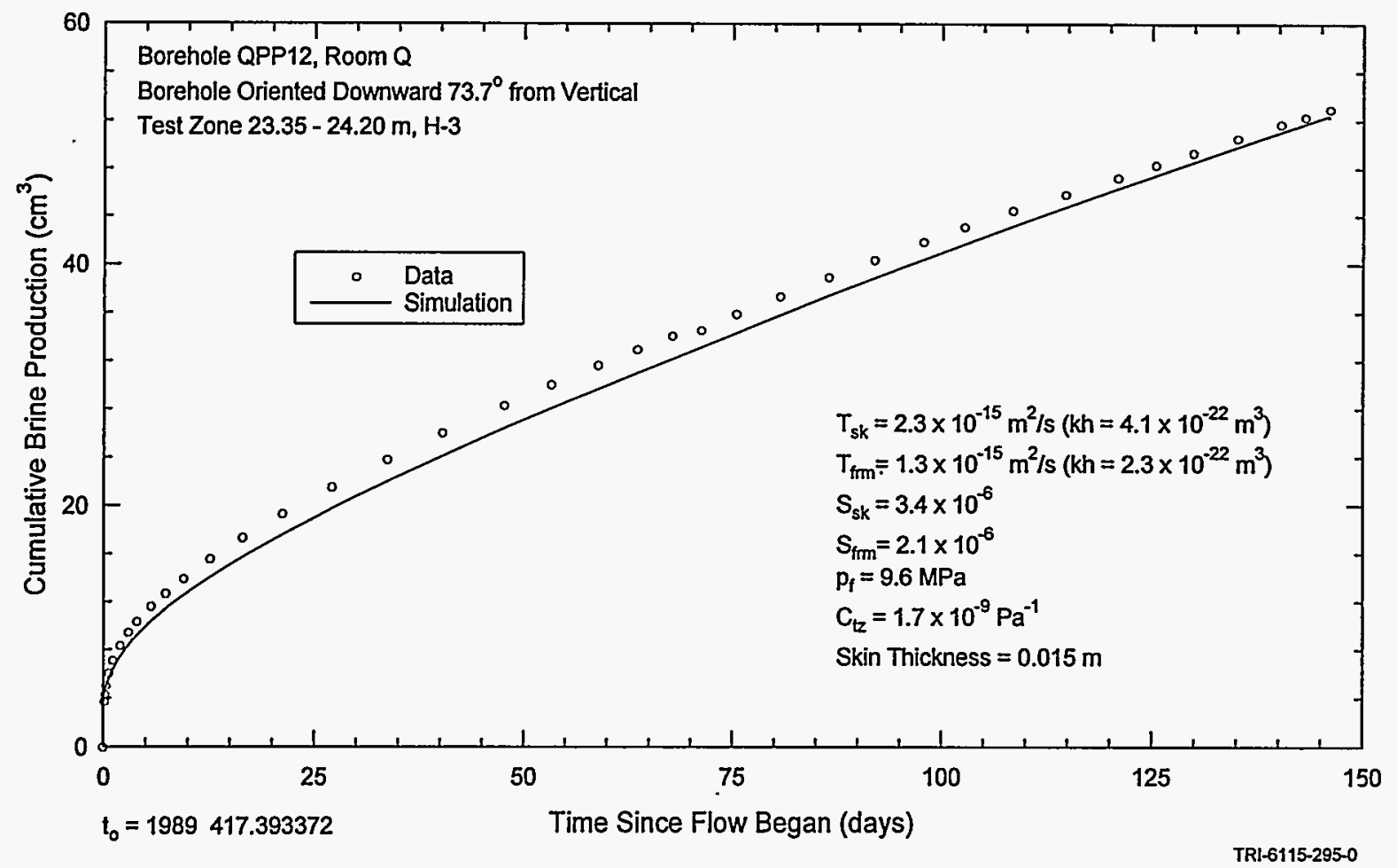

Figure 7-43. GTFM simulation of QPP12 test-zone brine production.

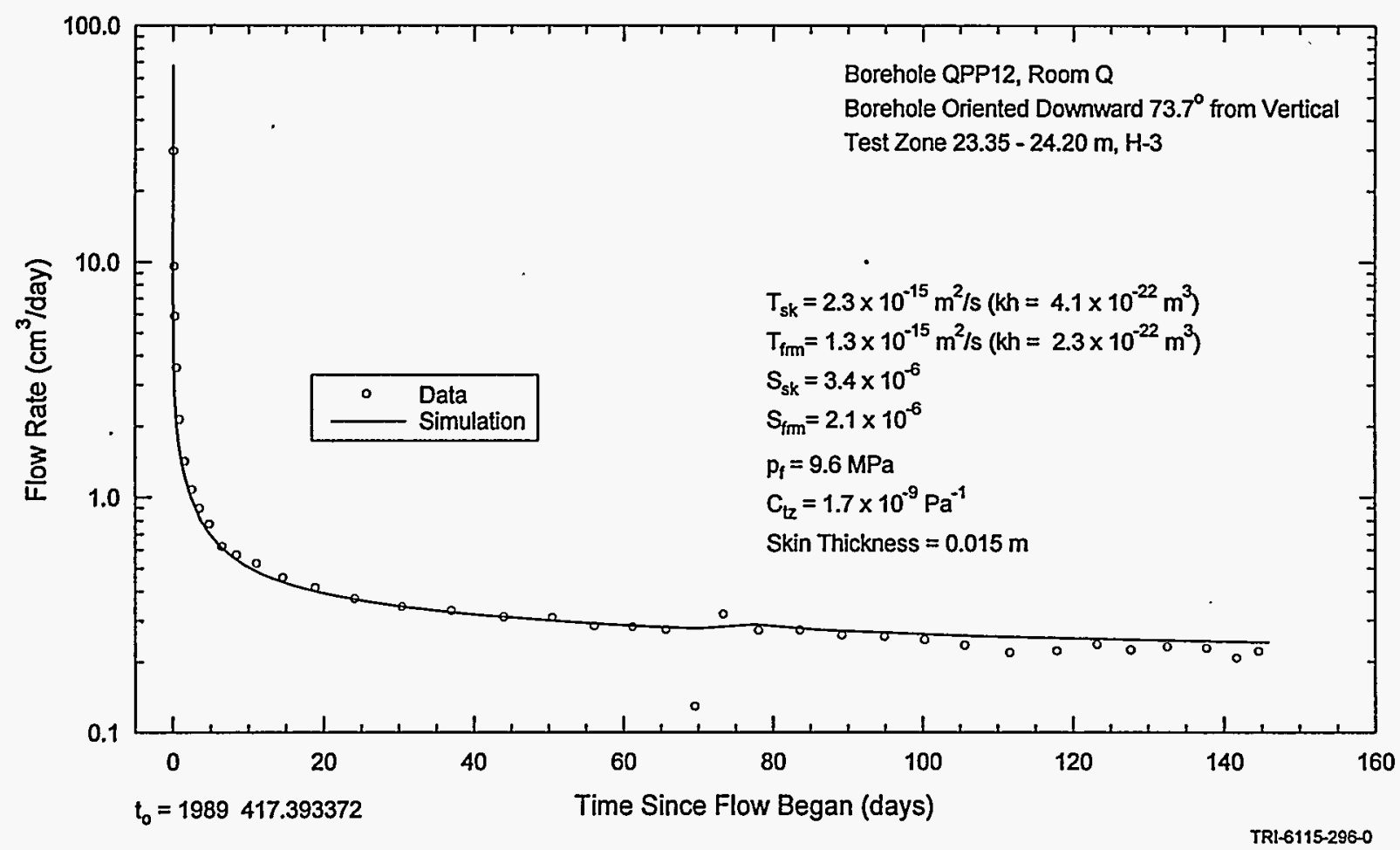

Figure 7-44. GTFM simulation of the QPP12 flow rates. 


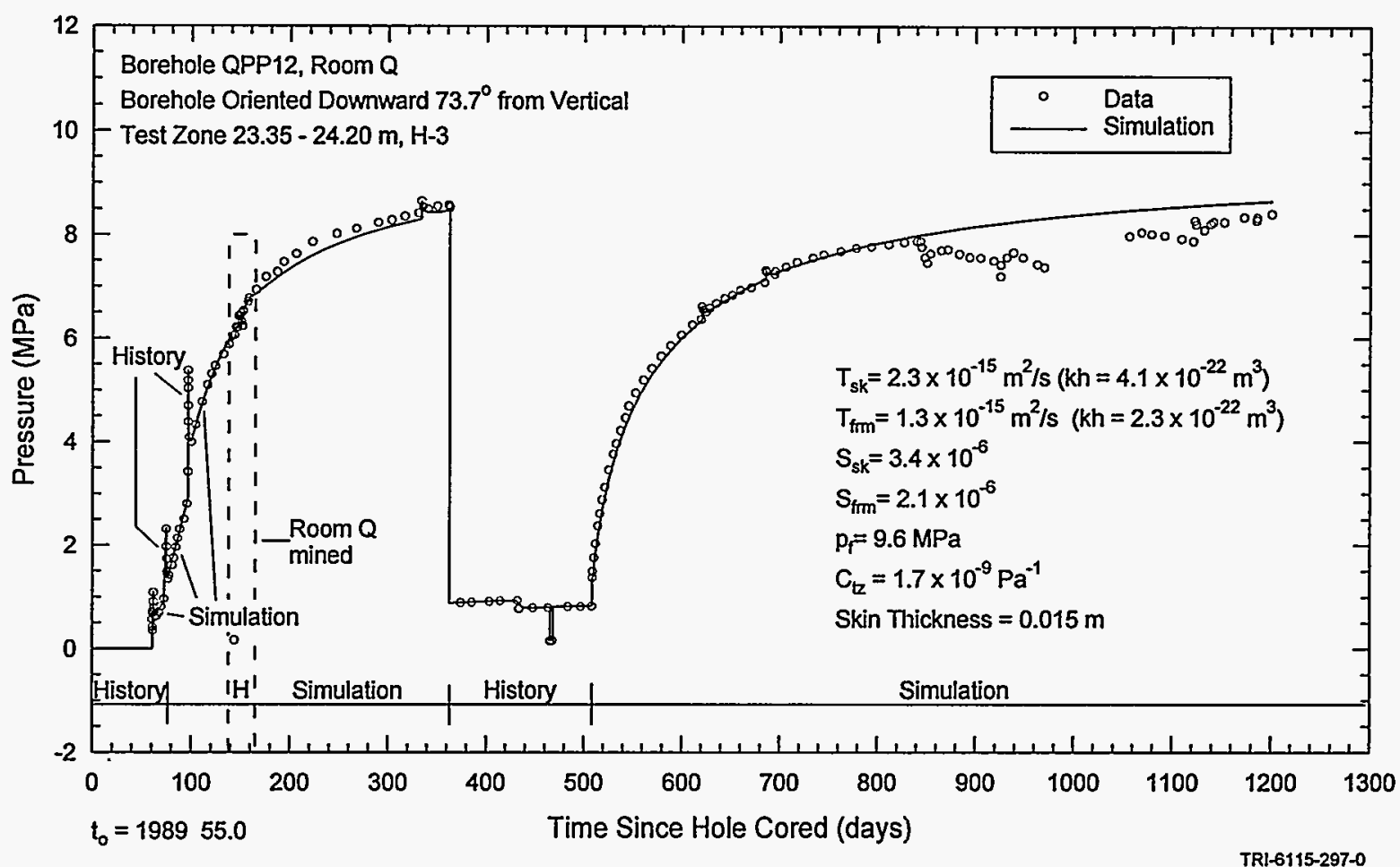

Figure 7-45. GTFM simulation of the QPP12 test-zone pressure.

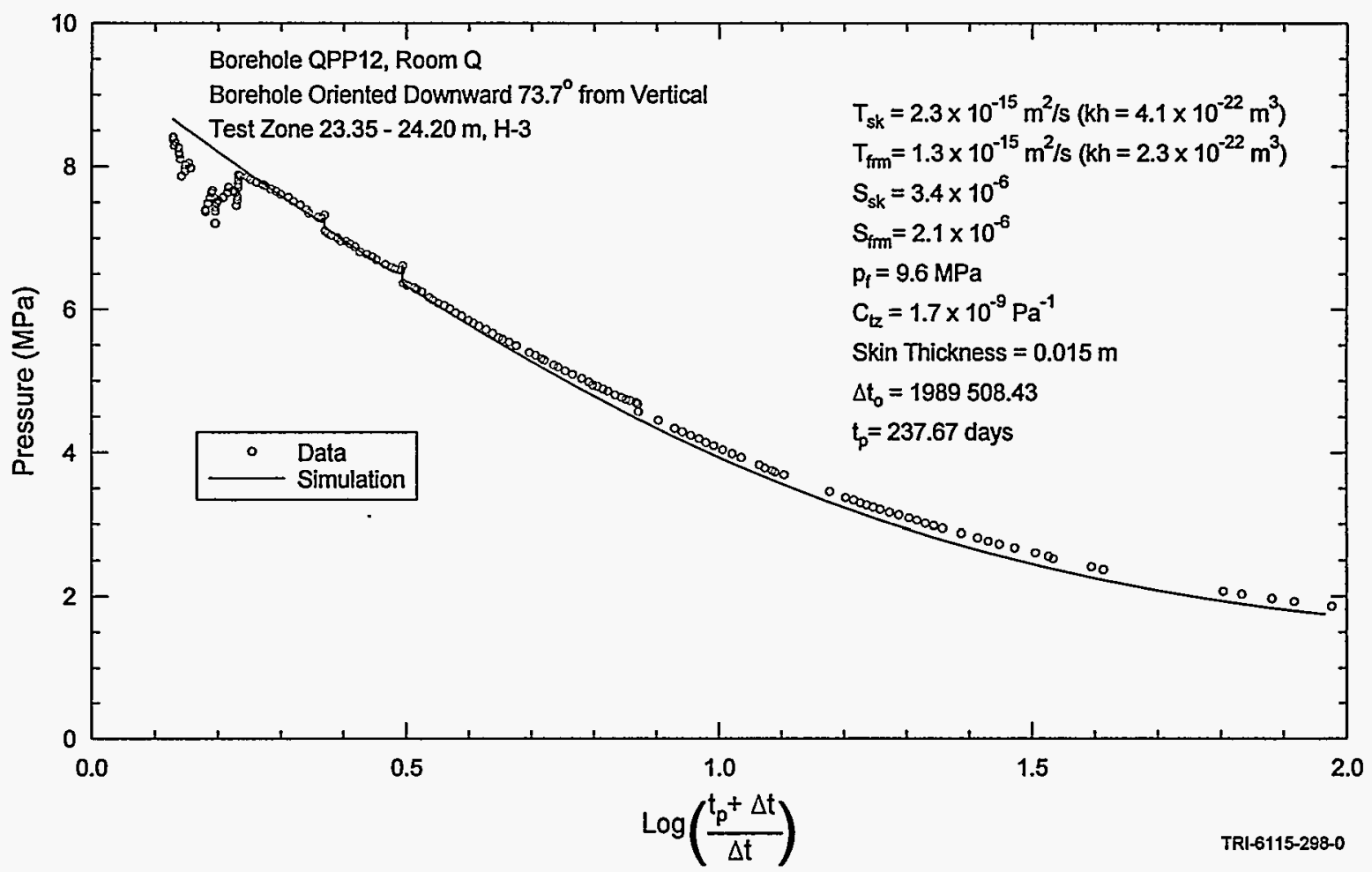

Figure 7-46. GTFM Horner simulation of the QPP12 post-flow-test pressure buildup. 


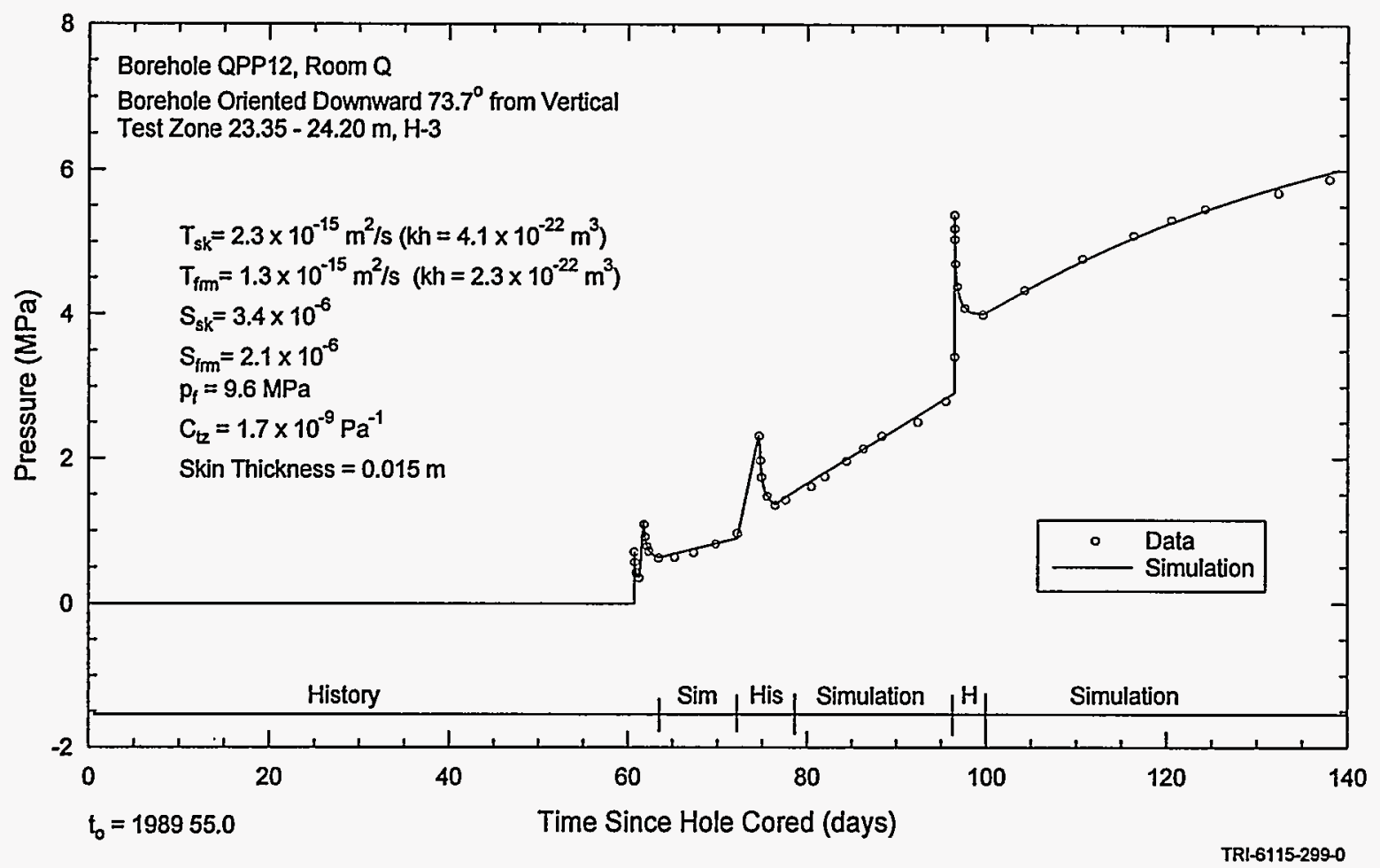

Figure 7-47. GTFM simulation of the QPP12 pre-mining test-zone pressure.

output from a single simulation that included $a$ thin skin around the borehole. The specified parameters used in the simulation were a borehole radius of $1.9 \mathrm{~cm}$, test-zone fluid volume of 290 $\mathrm{cm}^{3}$, and test-zone compressibility of $1.67 \times 10^{-9}$ $\mathrm{Pa}^{-1}$ (for the post-mining simulation). The fitted parameters were a skin thickness of $1.5 \mathrm{~cm}$, a skin transmissivity of $2.3 \times 10^{-15} \mathrm{~m}^{2} / \mathrm{s}$ (permeabilitythickness of $4.1 \times 10^{-22} \mathrm{~m}^{3}$ ), a skin storativity of 3.4 $\times 10^{-6}$, a formation transmissivity of $1.3 \times 10^{-15}$ $\mathrm{m}^{2} / \mathrm{s}$ (permeability-thickness of $2.3 \times 10^{-22} \mathrm{~m}^{3}$ ), a formation storativity of $2.1 \times 10^{-6}$, and a formation pore pressure of $9.6 \mathrm{MPa}$.

Summary. All of the QPP12 test data were well matched by radial-flow models. Despite the borehole being oriented about $16^{\circ}$ below horizontal, no partial-penetration or other non- radial-flow effects were observed. The analytical and numerical interpretations of the QPP12 tests provided estimates of formation transmissivity ranging from $7.5 \times 10^{-16}$ to $1.3 \times 10^{-15} \mathrm{~m}^{2} / \mathrm{s}$ (permeability-thicknesses of $1.3 \times 10^{-22}$ to $2.3 \times$ $10^{-22} \mathrm{~m}^{3}$ ), estimates of formation-pore pressure of 9.25 to $9.6 \mathrm{MPa}$, and a dimensionless skin factor of -0.26 to -0.09 . The formation storativity estimated from the numerical simulations of the flow and buildup tests was $2.1 \times 10^{-6}$.

If the transmissivity and storativity of the QPP12 test zone were distributed uniformly over its $0.85-\mathrm{m}$ length, the average hydraulic conductivity would range from about $8.8 \times 10^{-16}$ to $1.5 \times 10^{-15} \mathrm{~m} / \mathrm{s}$ (permeability of $1.5 \times 10^{-22}$ to $2.7 \times$ $10^{-22} \mathrm{~m}^{2}$ ) and the average specific storage would be $2.5 \times 10^{-6} \mathrm{~m}^{-1}$. 


\subsubsection{QPP13}

Video logging revealed that the guard zone and most of the test zone in borehole QPP13 lie in Marker Bed 139 (MB139). MB139 is an anhydrite interbed, typically about $0.9 \mathrm{~m}$ thick, that lies 1 to 2 $\mathrm{m}$ below the floor of the waste-disposal rooms in the WIPP underground facility. The total vertical thickness of MB139 that could have been contained in the QPP13 test and guard zones (and behind the intervening packer) is less than $0.23 \mathrm{~m}$. The lower few centimeters of the test zone penetrate map unit $\mathrm{H}-4$, a coarsely crystalline halite unit containing $\leq 1 \%$ polyhalite and/or clay (Deal et al., 1989).

\subsubsection{Test Zone.}

The complete record of pressures observed in the QPP13 test zone is shown in Figure 7-48. The pre-mining pressure record is shown in Figure 7-49. The anomalous pressure recovery after the pulse withdrawal on 1989 Calendar day 151 was probably caused by communication with the guard zone (through the formation) which was depressurized sometime between day 150 and day 171 . Before mining began, the test-zone pressure was released to prevent a potential blow out as mining operations passed the test zone. Figure 7-49 shows that mining caused some pressure fluctuations in the test zone. We suspect that the pressure decrease at 1989 Calendar day 202 was caused by a deliberate release of the test-zone pressure, but no documentation of that event has been found. Following the mining of Room $Q$, both the testzone and guard-zone packer pressures were repeatedly increased and on occasion decreased; this information was poorly documented.

On February 21, 1990 (1989 Calendar day 417), a flow test was initiated by reducing the testzone pressure from 7.72 to $0.73 \mathrm{MPa}$. The

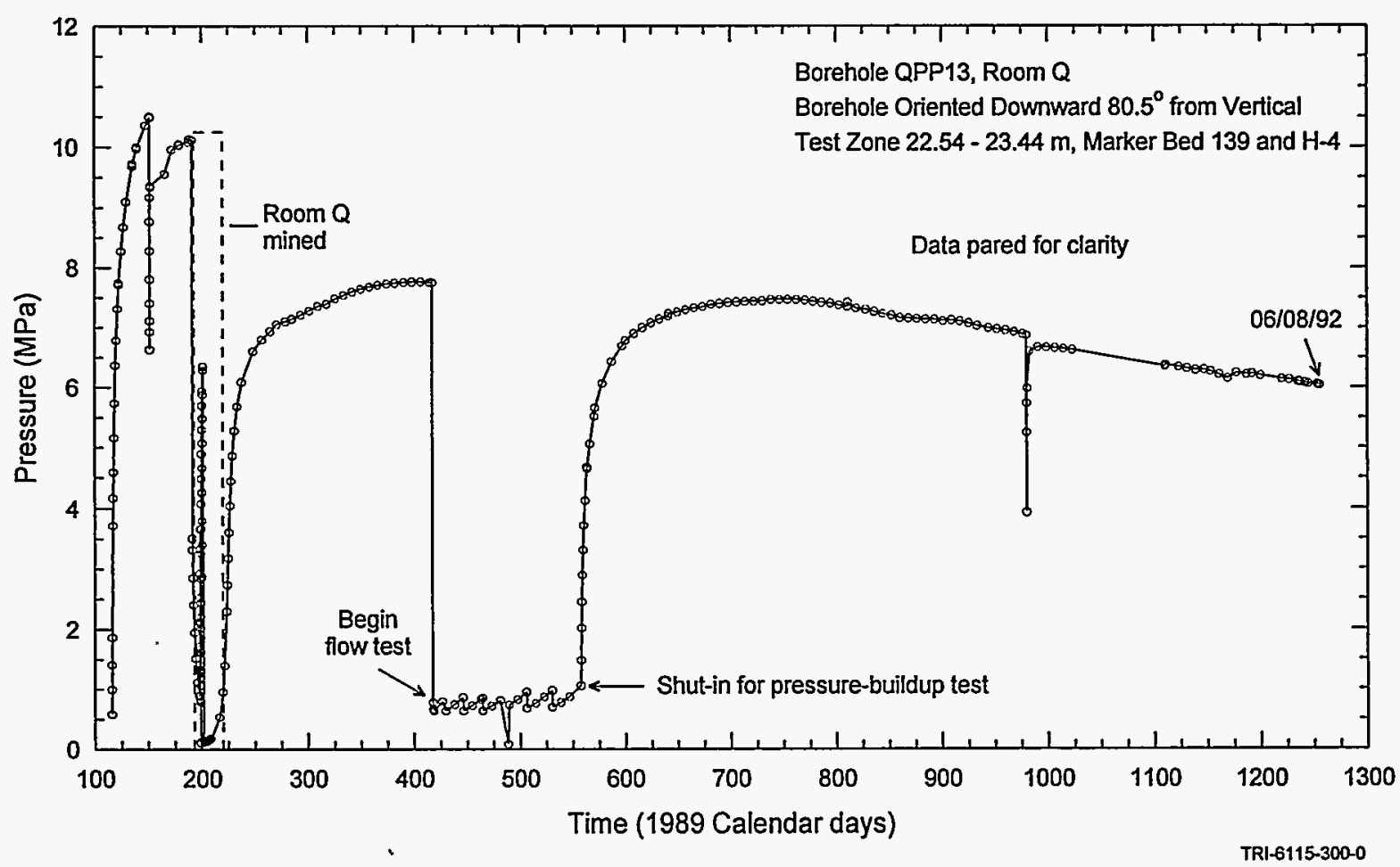

Figure 7-48. QPP13 test-zone pressure. 


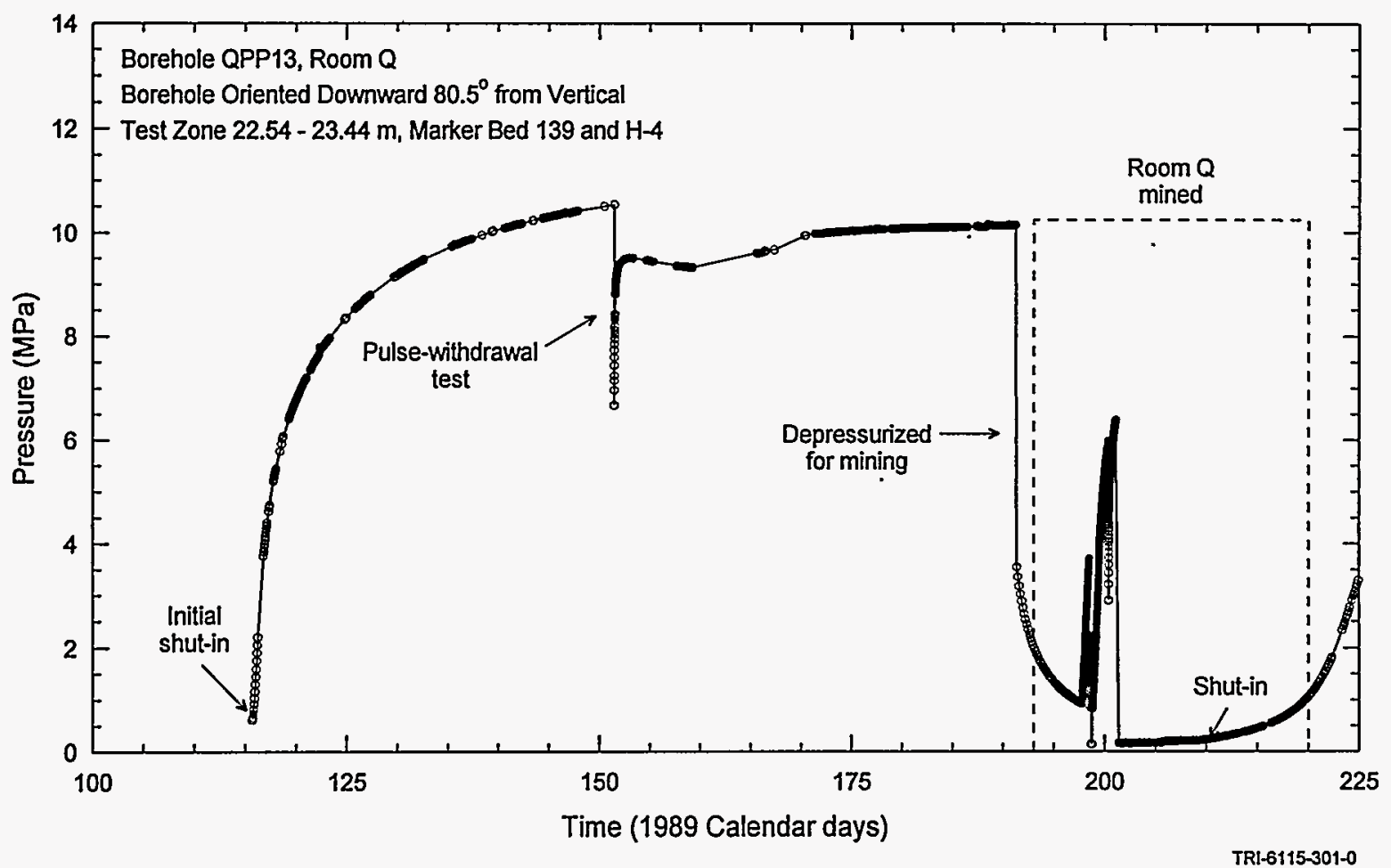

Figure 7-49. QPP13 pre-mining and mining test-zone pressure.

cumulative brine volume produced is shown in Figure 7-50. Brine-inflow volumes were captured in a brine accumulator located in the Instrumentation Area. The brine accumulator was partially filled and then drained on six separate occasions during the 147-day flow test. A total of about $720 \mathrm{~cm}^{3}$ of brine was recovered during the flow period. On May 6, 1990 (1989 Calendar day 491), the test tool was removed temporarily to disassemble the borehole diameter gauges. The flow test was terminated on July 18, 1990 (1989 Calendar day 564) by shutting in the test zone, thereby initiating a pressure-buildup test.

The decreasing pressure trend observed in the late-time data of the pressure recovery following the flow test was probably caused by equipment problems and not changes in the formation properties. Chester (Appendix B) reports that the pressure in the test zone on March 10, 1995, after the test tool and packers had been refurbished, was $6.6 \mathrm{MPa}$, which is higher than the
$6 \mathrm{MPa}$ meașured on June 8,1992 shown on Figure 7-48.

Analytical Interpretations. Type-curve analysis was performed on the flow-test data. Figure 7-51 shows the best-fit match of flow-rate data to the constant-pressure flow type-curves of Doe (1991). The match to the radial-flow type curve provides a transmissivity estimate of $4.3 \times$ $10^{-14} \mathrm{~m}^{2} / \mathrm{s}$ (permeability-thickness of $7.6 \times 10^{-21}$ $\left.\mathrm{m}^{3}\right)$.

For analysis of the pressure-buildup test using Interpret/2, the constant-pressure flow test was divided into 53 separate flow periods having constant rates ranging from $16.8 \mathrm{~cm}^{3} /$ day to 4.58 $\mathrm{cm}^{3} /$ day. The best fit obtained between log-log pressure and pressure-derivative type curves and the pressure-buildup data is shown in Figure 7-52. The best Horner match is shown in Figure 7-53, and the best linear-linear match is shown in Figure 7-54. All of these matches provided the same estimated 


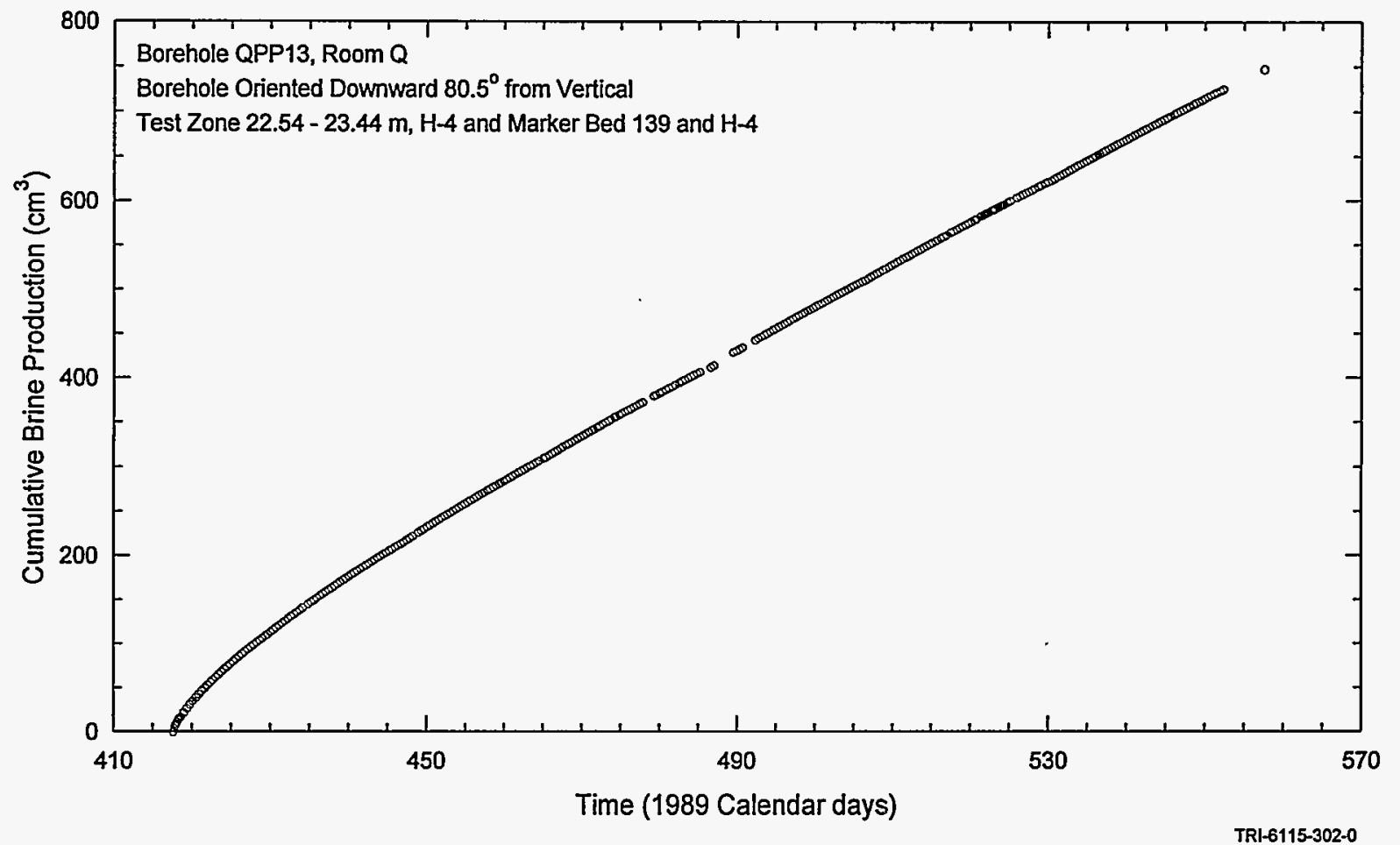

Figure 7-50. QPP13 test-zone brine production.

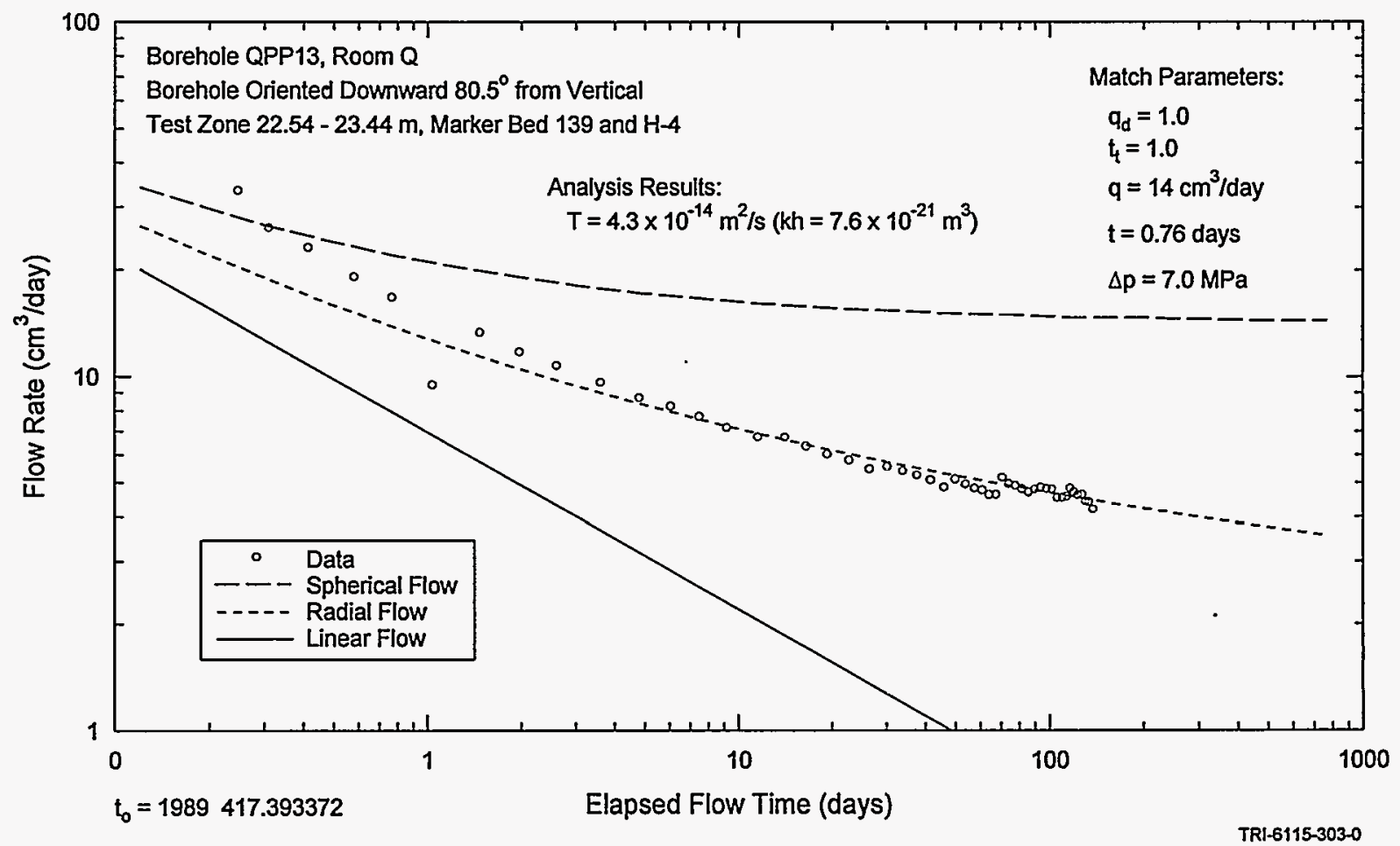

Figure 7-51. Type-curve match of the QPP13 flow rates. 


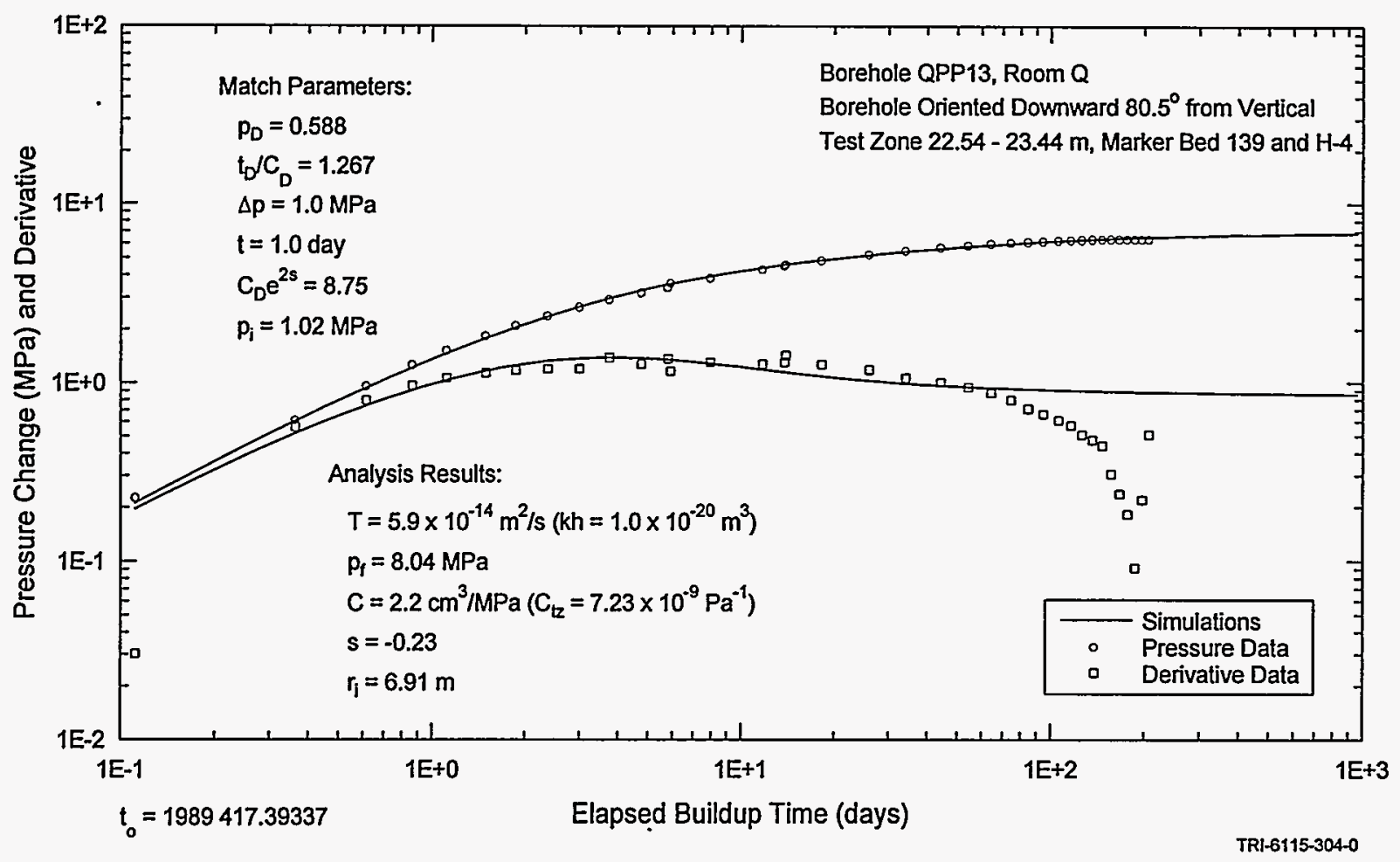

Figure 7-52. Interpret/2 type-curve match of the QPP13 post-flow-test pressure buildup.

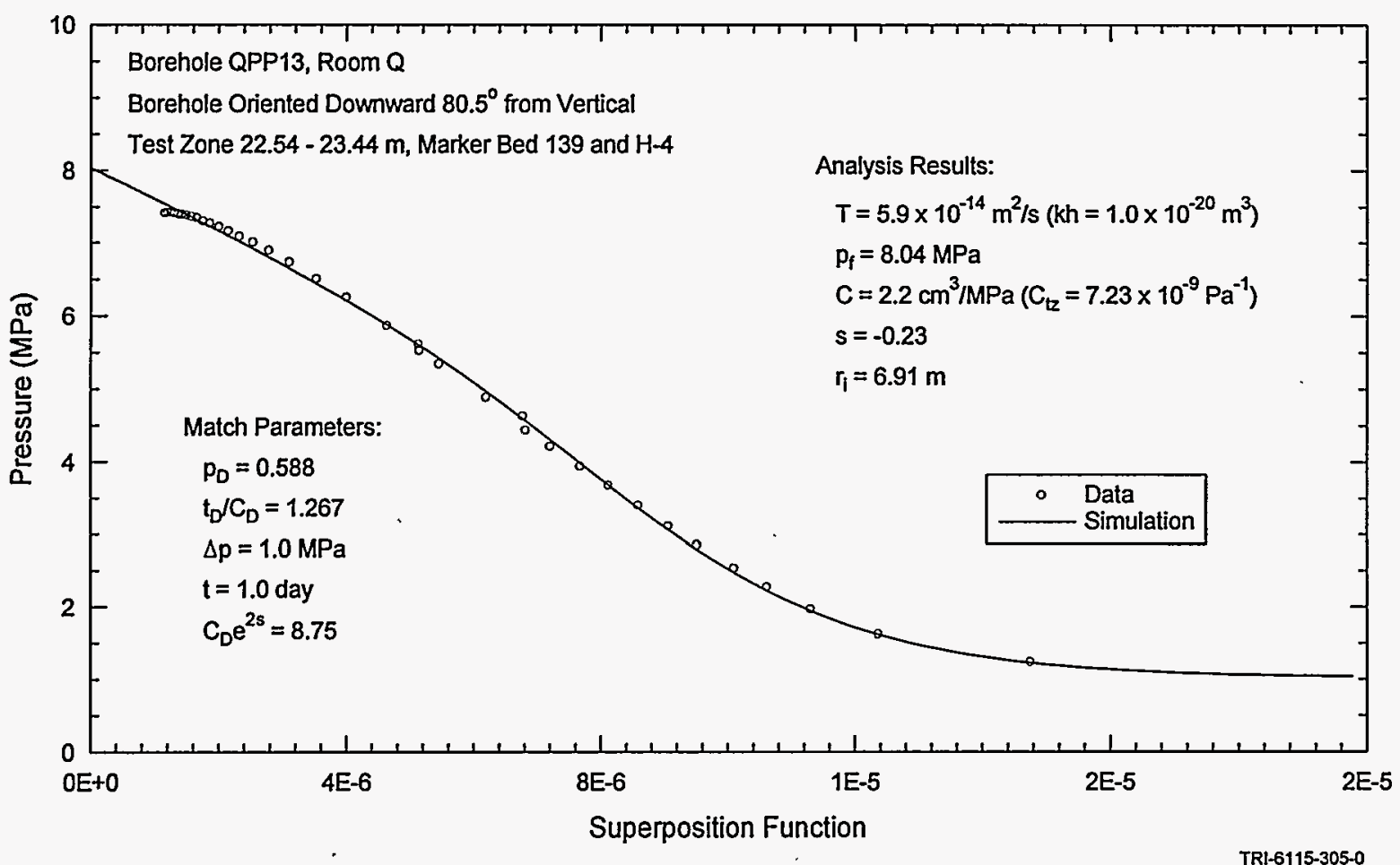

Figure 7-53. Interpret/2 Horner superposition match of the QPP13 post-flow-test pressure buildup. 


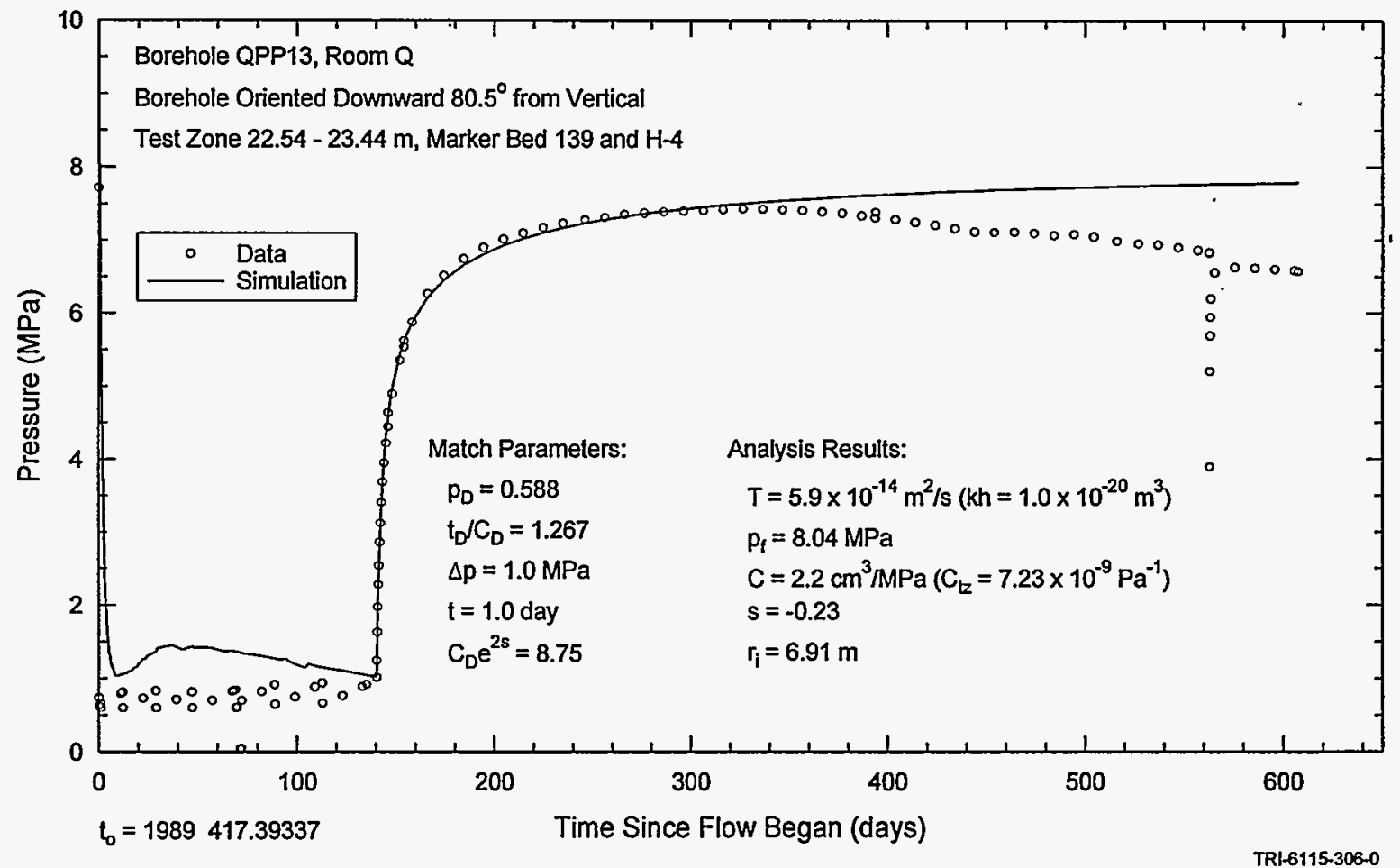

Figure 7-54. Interpret/2 simulation of the QPP13 constant-pressure flow test and pressure buildup.

parameters: a transmissivity of $5.9 \times 10^{-14} \mathrm{~m}^{2} / \mathrm{s}$ (permeability-thickness of $1.0 \times 10^{-20} \mathrm{~m}^{3}$ ), a formation pore pressure of $8.04 \mathrm{MPa}$, a wellborestorage coefficient of $2.2 \mathrm{~cm}^{3} / \mathrm{MPa}$ (corresponding to a test-zone compressibility of $\left.7.23 \times 10^{-9} \mathrm{~Pa}^{-1}\right)$, and a wellbore skin factor of -0.23 .

\section{Numerical Interpretations. ' The} significant difference in estimated formation pore pressures prior to and following the mining of Room $Q$ required that two GTFM simulations (offset relative to the initiation of the mining of Room $Q$ ) be used. The QPP13 testing was preceded by a 60 -day period during which the borehole was at atmospheric pressure. This openborehole period was included in the first GTFM simulation as a specified-pressure history sequence. A short period beginning with the initiation of the mining of Room $Q$ and the pressure history during the flow test were included in the second GTFM simulation as specified-pressure history sequences.
Figure 7-55 shows the best-fit GTFM simulation for the buildup preceding the mining of Room Q. The specified parameters for this simulation were a borehole radius of $6.7 \mathrm{~cm}$ and a test-zone fluid volume of $300 \mathrm{~cm}^{3}$. The fitted parameters were a transmissivity of $5.1 \times 10^{-14}$ $\mathrm{m}^{2} / \mathrm{s}$ (permeability-thickness of $8.9 \times 10^{-21} \mathrm{~m}^{3}$ ), a storativity of $6.6 \times 10^{-8}$, a formation pore pressure of $12.4 \mathrm{MPa}$, and a test-zone compressibility of 4.0 $\times 10^{-9} \mathrm{~Pa}^{-1}$.

Figures 7-56, 7-57, and 7-58 show the best-fit GTFM 'simulations for the test-zone pressure following the mining of Room $Q$, the brine-inflow volume, and the brine-inflow rate, respectively. Figure 7-59 shows the best-fit Horner plot of the buildup-test data. The four simulations were generated using the same specified and fitted parameters. The parameters used to obtain the fits are similar to the parameters used to match the pre-mining data, with the exception of the formation pore pressure. The specified 


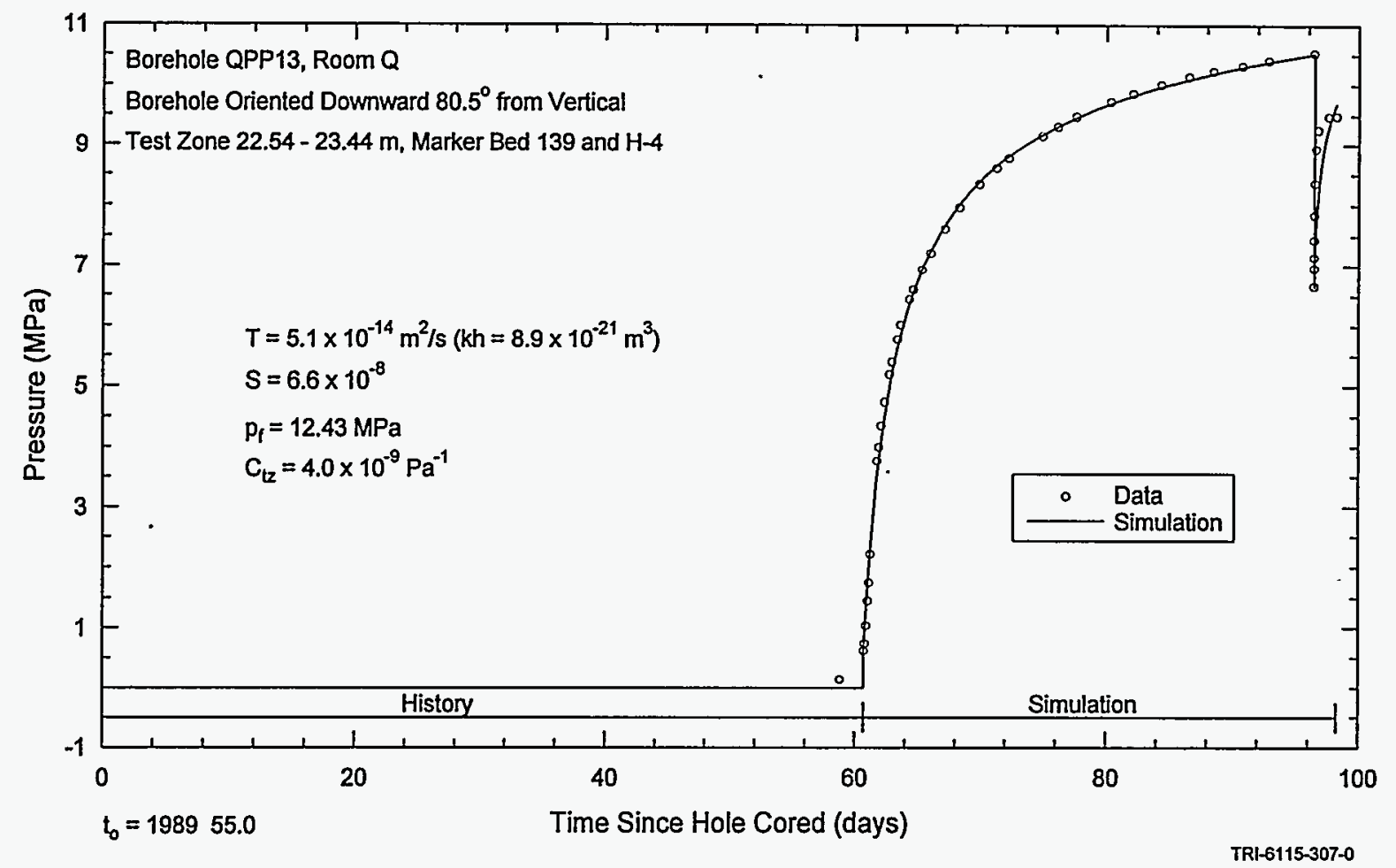

Figure 7-55. GTFM simulation of the QPP13 pre-mining test-zone pressure.

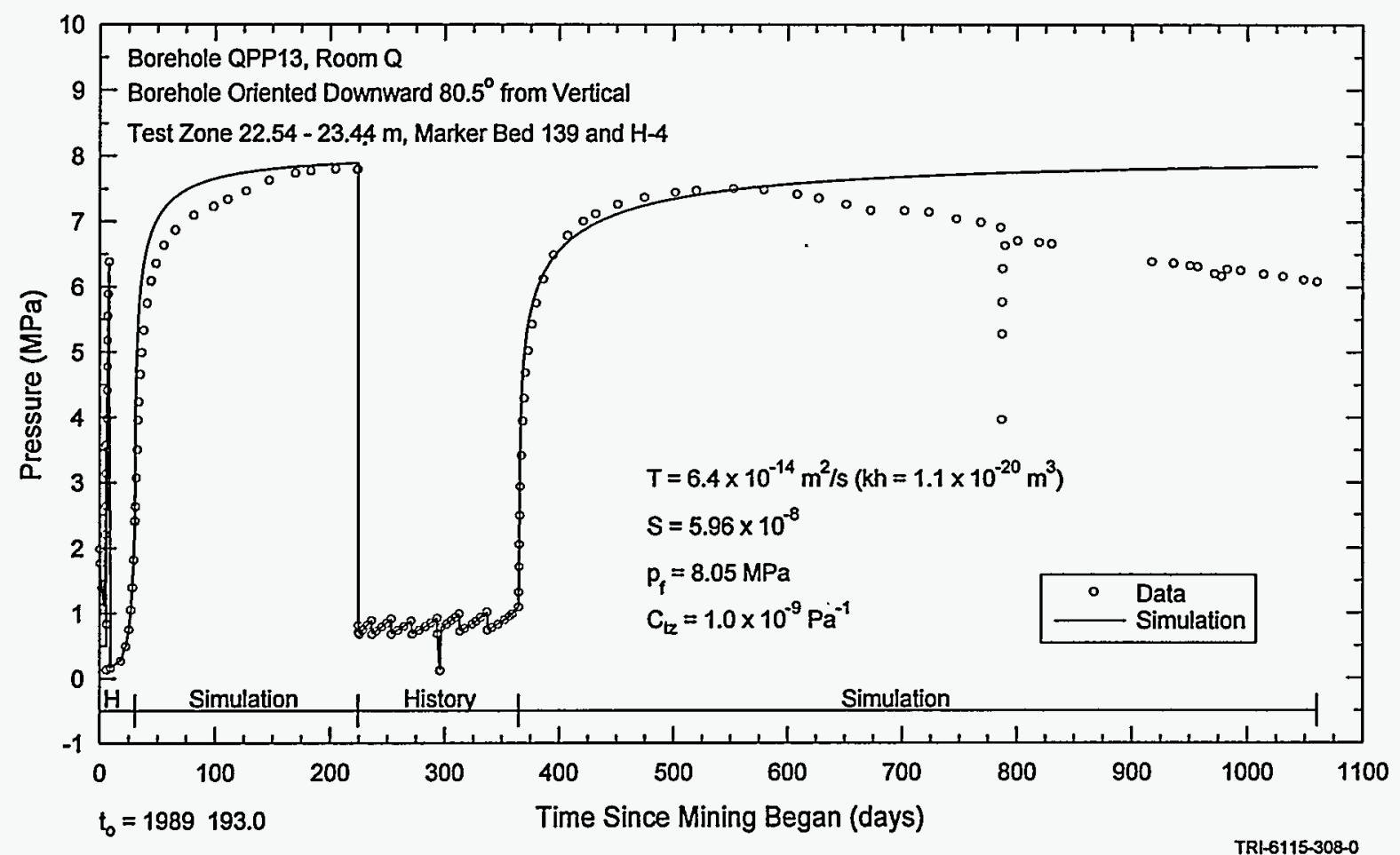

Figure 7-56. GTFM simulation of the QPP13 post-mining test-zone pressure 


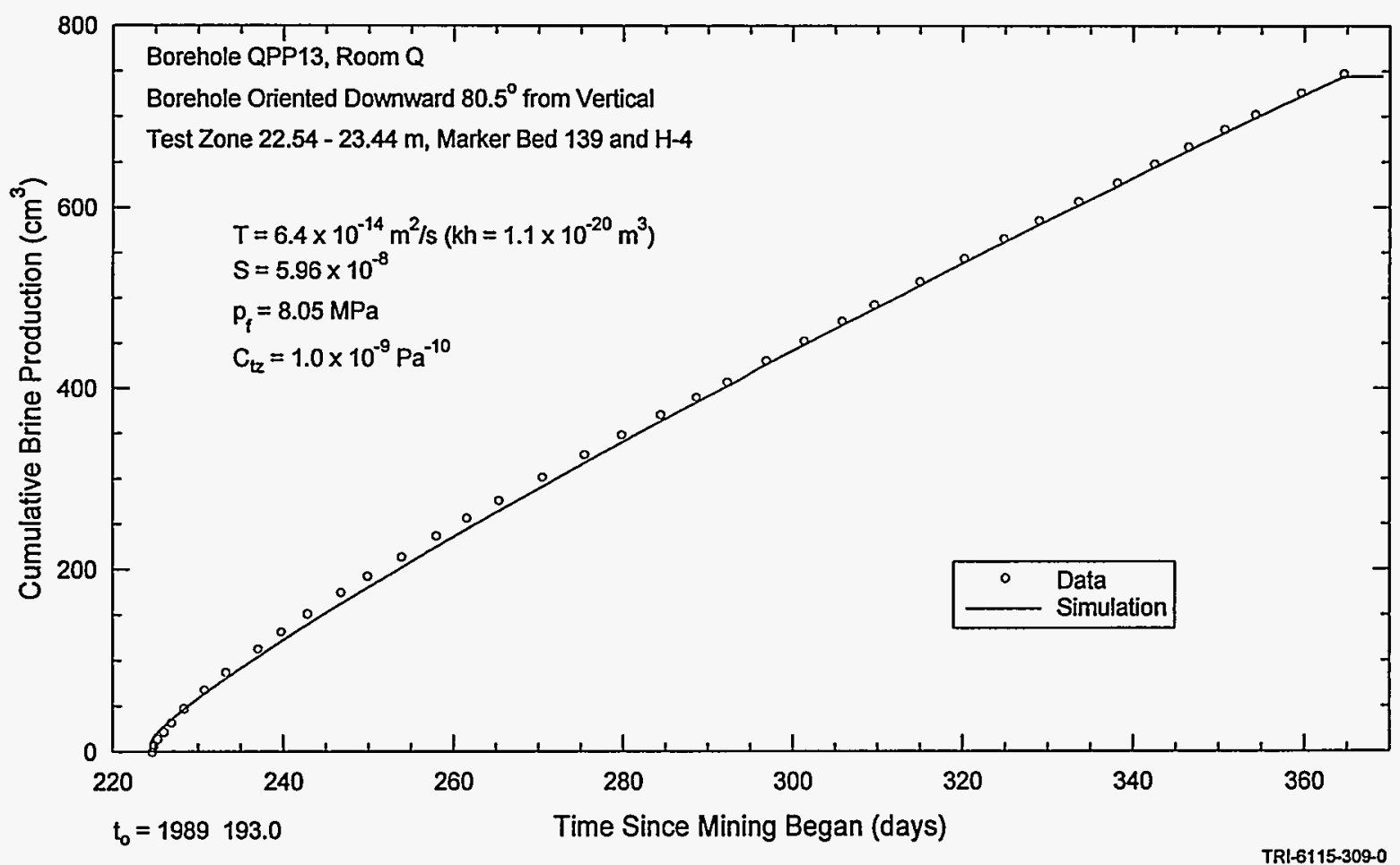

Figure 7-57. GTFM simulation of the QPP13 brine production.

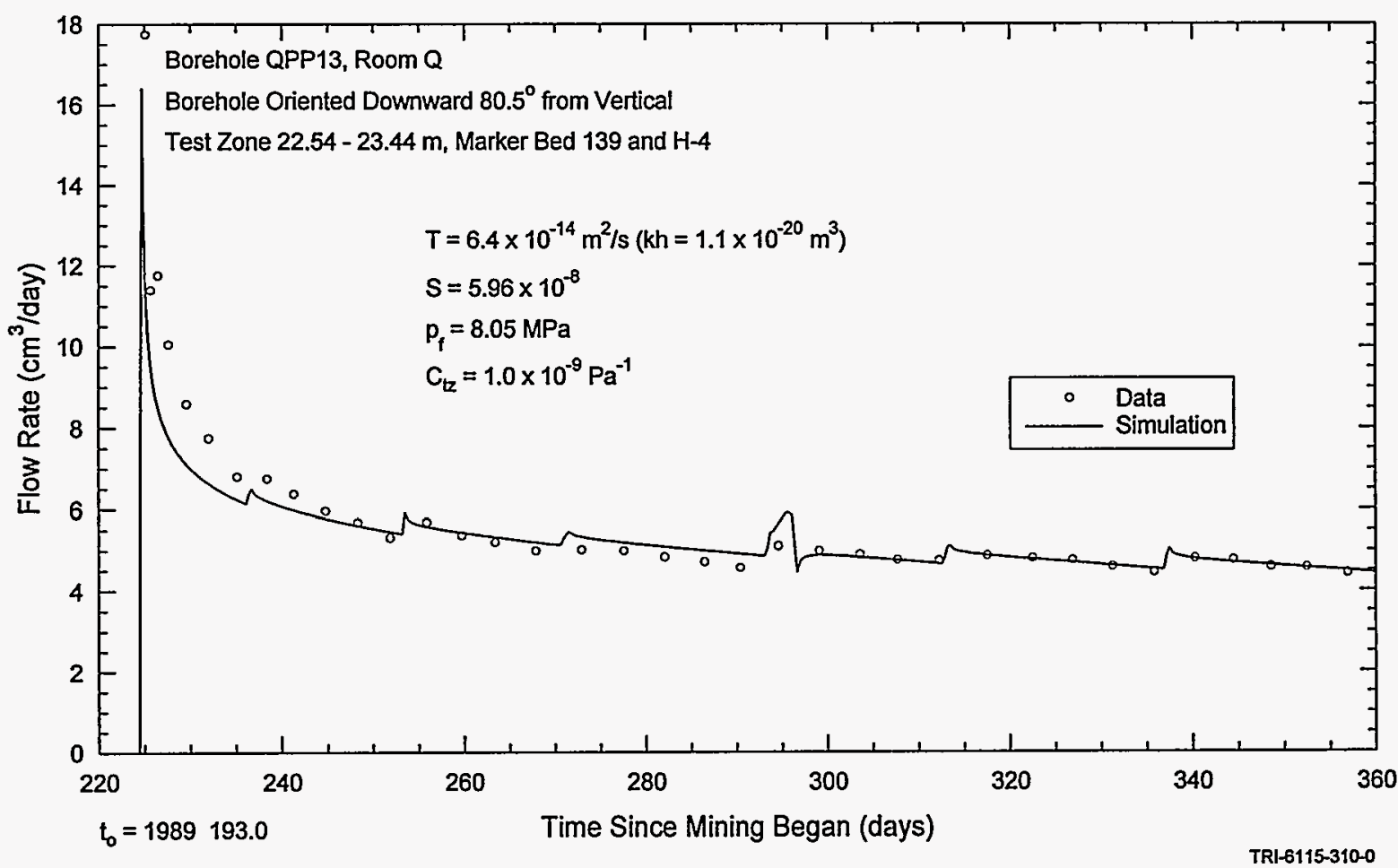

Figure 7-58. GTFM simulation of the QPP13 flow rates. 


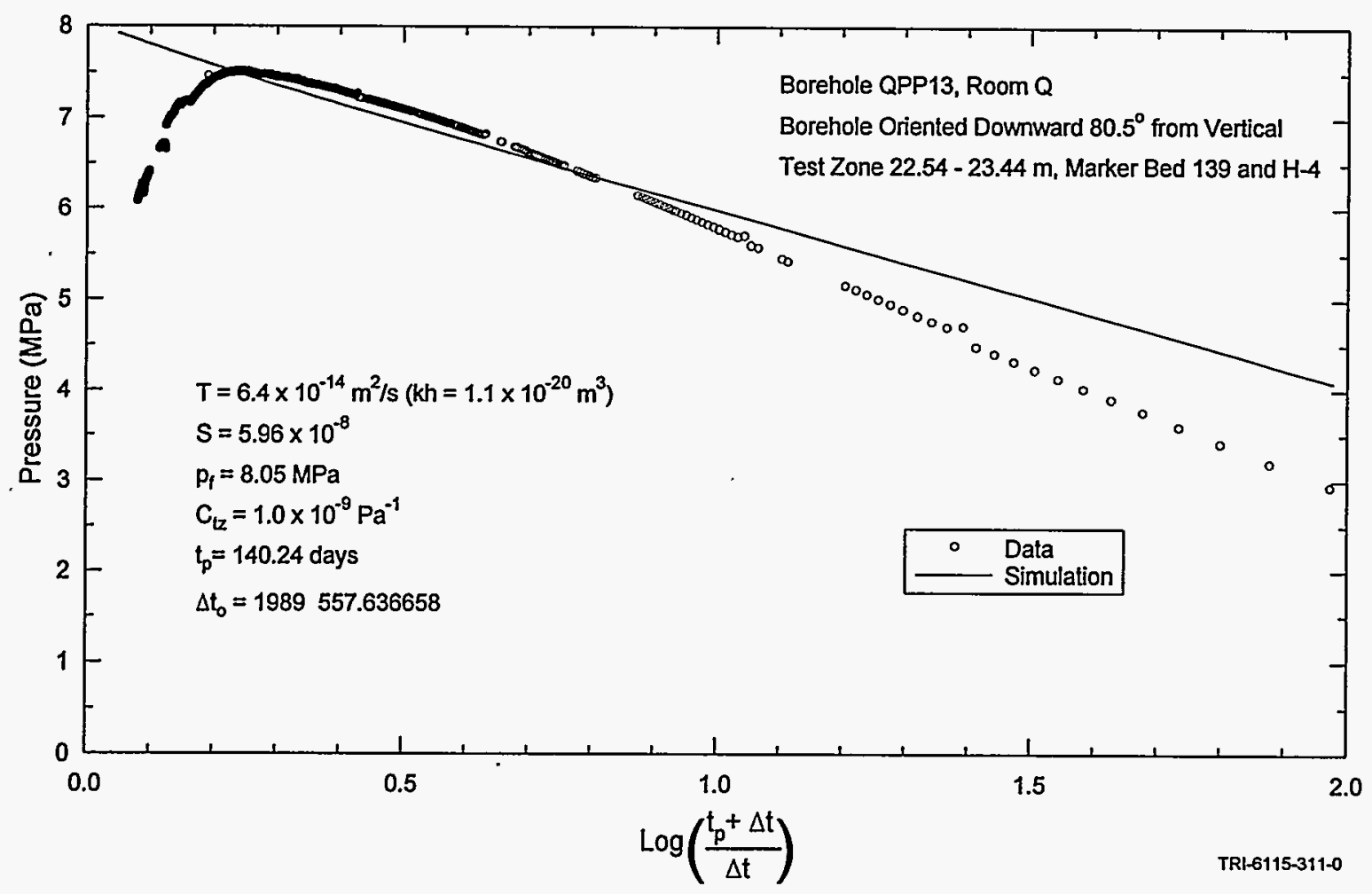

Figure 7-59. GTFM Horner simulation of the QPP13 post-flow-test pressure buildup.

parameters were a borehole radius of $6.7 \mathrm{~cm}$ and a test-zone fluid volume of $300 \mathrm{~cm}^{3}$. The fitted parameters were a transmissivity of $6.4 \times 10^{-14}$ $\mathrm{m}^{2} / \mathrm{s}$ (permeability-thickness of $1.1 \times 10^{-20} \mathrm{~m}^{3}$ ), a storativity of $6.0 \times 10^{-8}$, a formation pore pressure of $8.05 \mathrm{MPa}$, and a test-zone compressibility of 1.0 $\times 10^{-9} \mathrm{~Pa}^{-1}$.

\subsubsection{Guard Zone.}

The complete pressure record from the QPP13 guard zone is shown in Figure 7-60. The pre-mining pore pressure built up to a level higher than what was observed during the post-mining period. Figure 7-61 is a Horner plot of the pre-mining pressure data showing an extrapolated formation pore pressure of $11 \mathrm{MPa}$. After mining, numerous fluctuations were observed in the guard-zone pressure data that correlate with losses in guardzone packer pressures and reinflations of the packer (Figure A-8). The post-mining pressure data display a decreasing trend similar to that of the test-zone data of the same period. This trend is believed to be an artifact related to difficulties in maintaining pressure in the guard-zone packer because Chester (Appendix B) reports that the observed pressure was higher on March 10, 1995 after the test tool and packers were removed, refurbished, and reinstalled.

\subsubsection{Summary.}

Both the test zone and guard zone displayed high pre-mining pore pressures, 12.4 $\mathrm{MPa}$ and $11 \mathrm{MPa}$, respectively. In the post-mining period, the test- and guard-zone pressures rose to over $7 \mathrm{MPa}$ before beginning long-term declines to about $6 \mathrm{MPa}$. Pressures of 6.6 and $6.4 \mathrm{MPa}$ were observed in the test zone and guard zone, respectively, after the test tool and packers were refurbished, suggesting that the declining pressure trends were an artifact of equipment problems rather than a true formation response. 


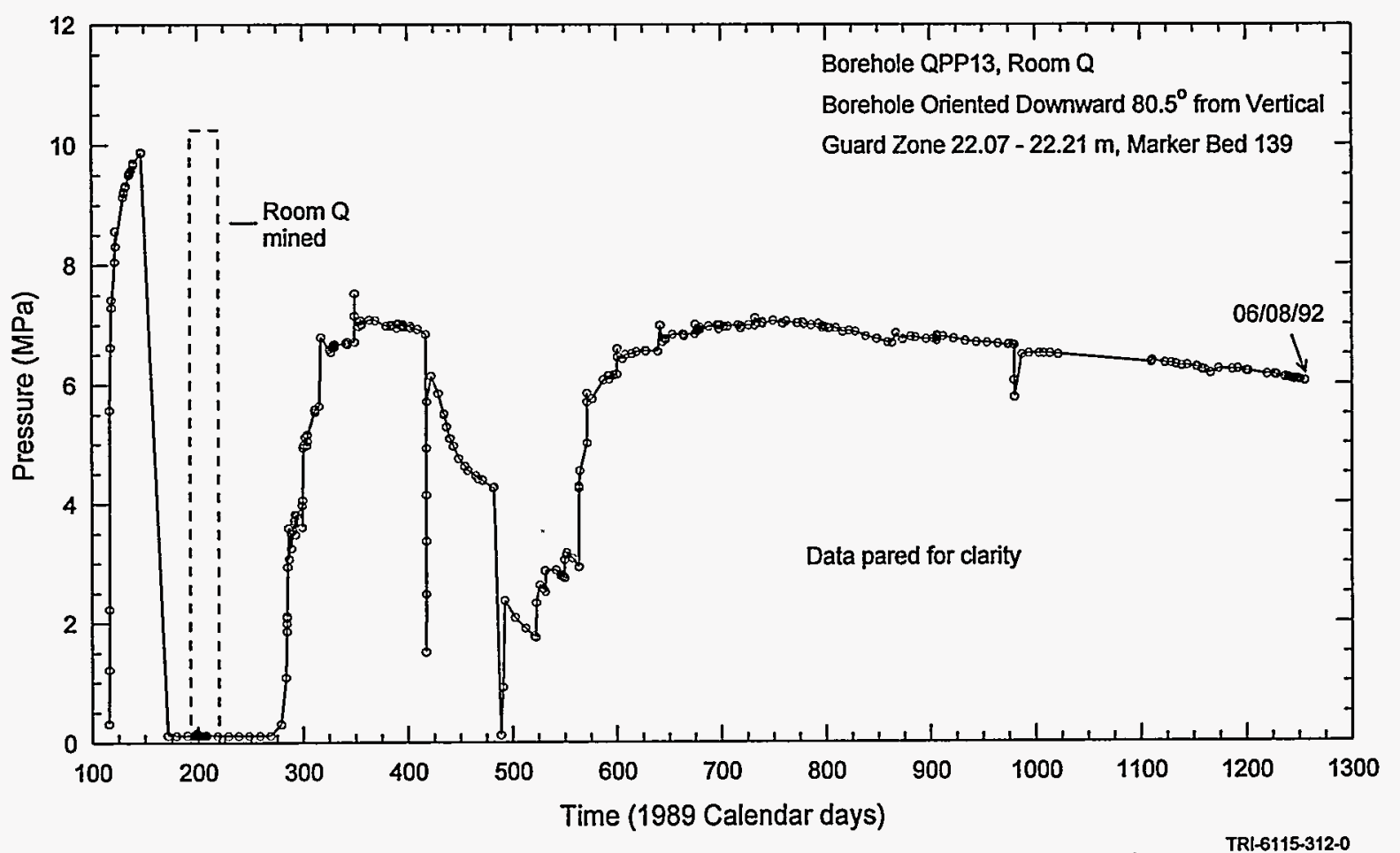

Figure 7-60. QPP13 guard-zone pressure.

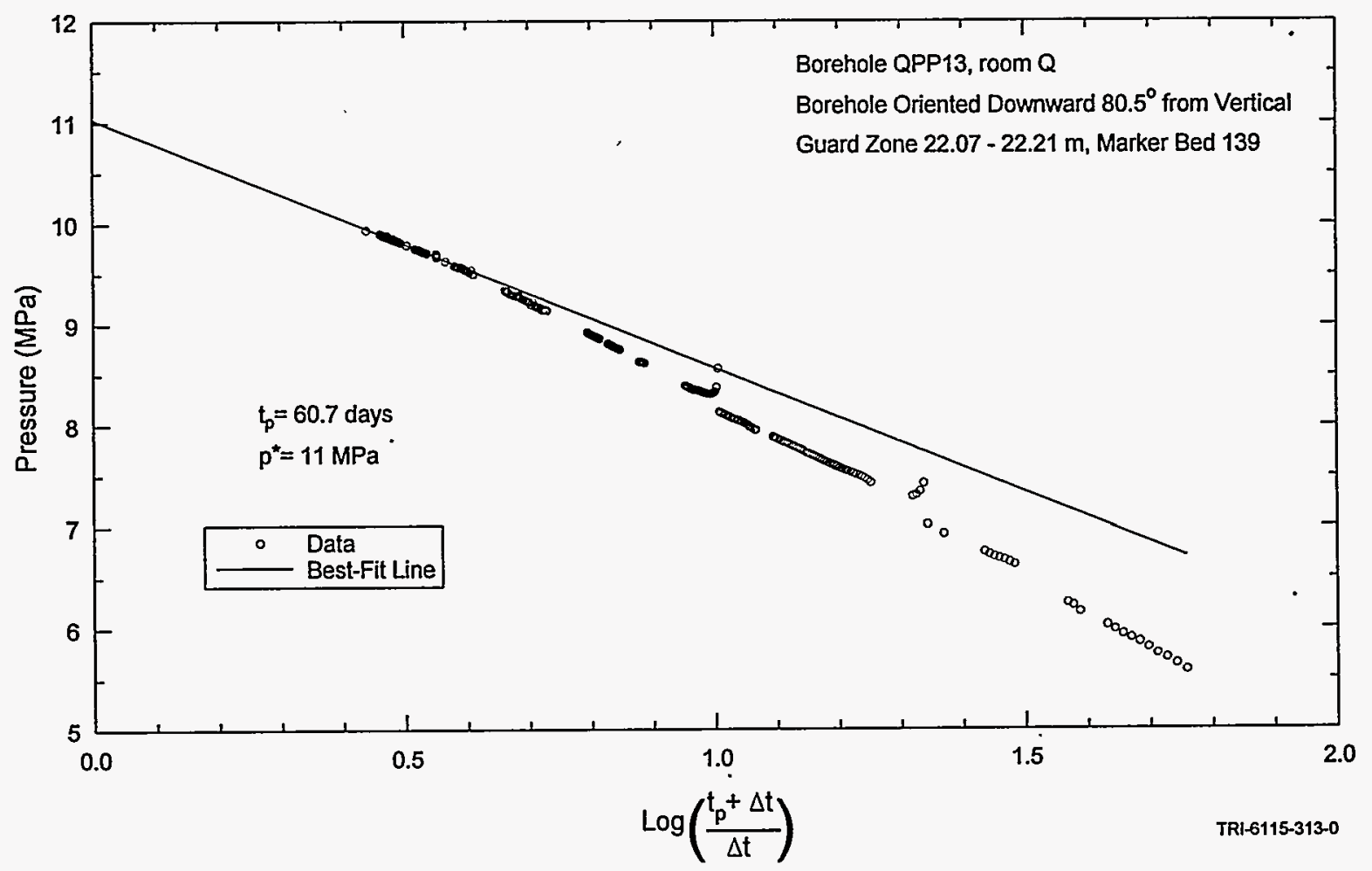

Figure 7-61. Horner plot of the QPP13 pre-mining guard-zone pressure 
If the transmissivity and storativity of the QPP13 test zone were distributed uniformly over just the $0.15-\mathrm{m}$ vertical thickness of Marker Bed 139 within the test zone, the average pre-mining hydraulic conductivity would be approximately 3.4 $\times 10^{-13} \mathrm{~m} / \mathrm{s}$ (permeability of $6.0 \times 10^{-20} \mathrm{~m}^{2}$ ) and the average specific storage would be $4.4 \times 10^{-7} \mathrm{~m}^{-1}$. The average post-mining hydraulic conductivity would be approximately $4.3 \times 10^{-13} \mathrm{~m} / \mathrm{s}$ (permeability of $7.6 \times 10^{-20} \mathrm{~m}^{2}$ ) and the average specific storage would be $4.0 \times 10^{-7} \mathrm{~m}^{-1}$. The apparent changes in the formation properties after mining are small and, therefore, probably not significant considering the uncertainties in the data.

\subsubsection{QPP14}

Borehole video logging indicated that the test zone of borehole QPP14 is contained almost entirely within map unit $\mathrm{PH}-4$, a halite bed containing $<1$ to $3 \%$ polyhalite (Deal et al., 1989), with the bottom of the borehole possibly penetrating the top of Marker Bed 139.

The complete pressure record from the QPP14 test zone is shown in Figure 7-62. The mining of Room $Q$ caused oscillations in the testzone pressure of a few tenths of an MPa, but had no evident long-term effect (Figure 7-63). The data quality from QPP14 was generally good except during the period from approximately February 26 , 1990 to March 25, 1990 (1989 Calendar days 422 to 449), and from January 28, 1991 (1989 Calendar day 758 ) until the end of the monitoring period (June 8, 1992). Reasons for the data degradation are unknown.

The early pre-mining pressure data from the QPP14 test interval showed no clear trend (Figure 7-63). The pressure was increased by fluid injection seven times before Room $Q$ was mined. After each increase, the pressure initially decreased by a few tenths of an MPa, probably

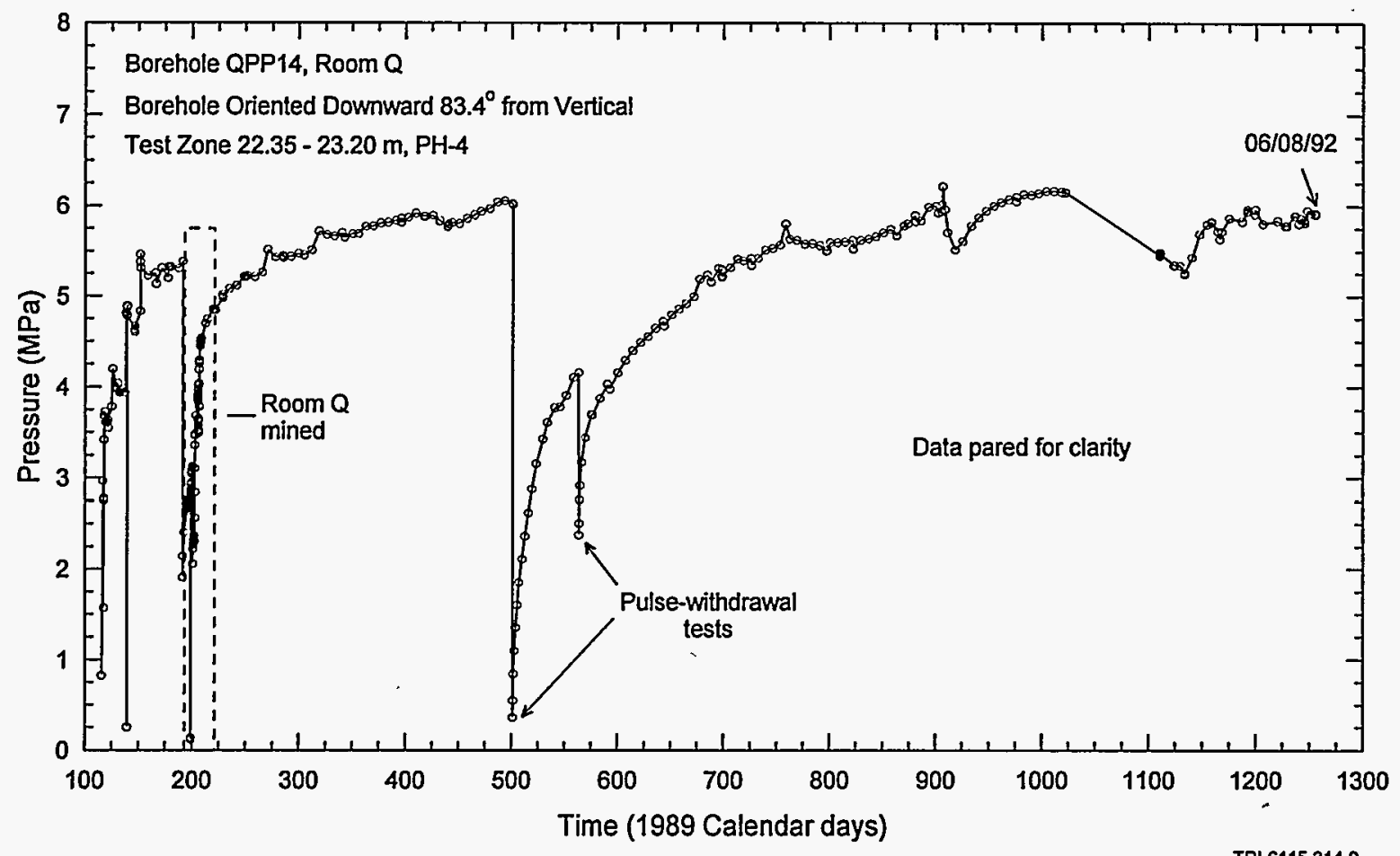

Figure 7-62. QPP14 test-zone pressure. 


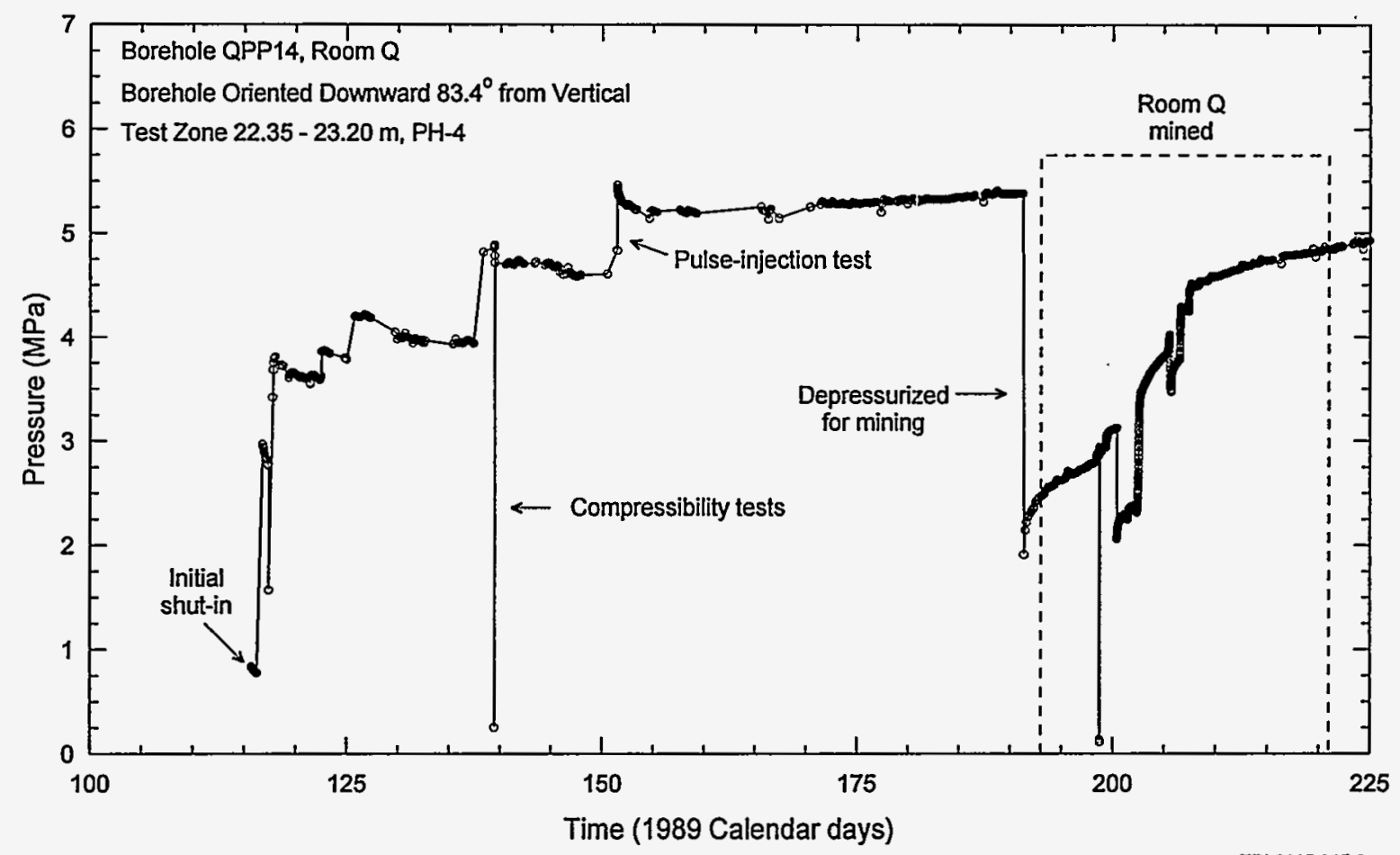

Figure 7-63. QPP14 pre-mining and mining test-zone pressure.

because of compliance effects, and then showed signs of stabilizing. However, after the final pressure increase on May 31, 1989 (1989 Calendar day 151), the test zone was left undisturbed for a longer period of time, and the pressure not only stabilized but also began to increase slightly. When the pressure was subsequently decreased on July 10, 1989 (1989 Calendar day 191) in preparation for mining, it immediately began to increase again. After the excavation of Room $Q$, clear pressure-buildup responses were observed.

Numerical Interpretations. Two pulsewithdrawal tests were conducted in QPP14 after Room $Q$ was mined. No flow test was performed in the borehole. The numerical simulations of the QPP14 pressure responses focused on the premining fluid-injection responses and the pressure buildups observed after the test zone was shut-in following the mining of Room $Q$ and after the two pulse withdrawals. For the pre-mining simulation, the 60-day open-borehole period together with the first two fluid injections were set up as a specifiedpressure history sequence. For the post-mining simulation, the pressures observed before the post-mining shut-in were included as a specifiedpressure history sequence. Specified-pressure history sequences were also used to match anomalous decreases in the test-zone pressure. Pressure pulses were used to represent sudden changes in the test-zone pressure caused by step increases in the packer-inflation pressure (see Figure A-9).

The time available for testing of the QPP14 test zone before mining was inadequate to provide data to allow definitive interpretation of hydraulic parameters. Figure 7-64 shows the best-fit GTFM simulation of the fluid-injection responses using parameters similar to those used for the postmining simulation (see below). The specified parameters for this simulation were a borehole radius of $1.9 \mathrm{~cm}$, a test-zone fluid volume of 


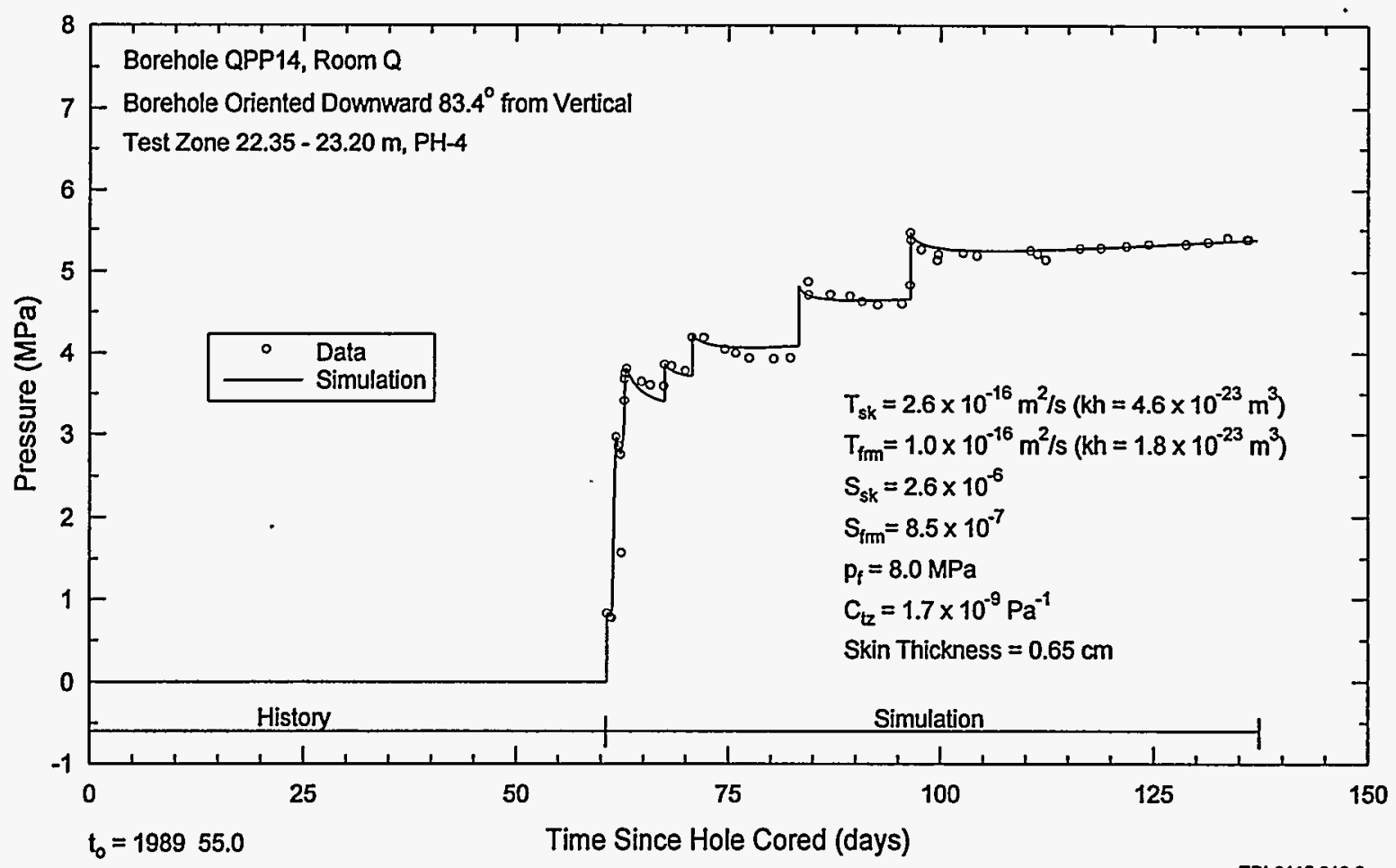

Figure 7-64. GTFM simulation of the QPP14 pre-mining test-zone pressure.

$290 \mathrm{~cm}^{3}$, and a test-zone compressibility of $1.7 \mathrm{x}$ $10^{-9} \mathrm{~Pa}^{-1}$ (the average of the values given in Table 6-1 for QPP14). The fitted parameters were a skin thickness of $0.65 \mathrm{~cm}$, a skin transmissivity of $2.6 \mathrm{x}$ $10^{-16} \mathrm{~m}^{2} / \mathrm{s}$ (permeability-thickness of $4.6 \times 10^{-23}$ $\mathrm{m}^{3}$ ), a skin storativity of $2.6 \times 10^{-6}$, a formation transmissivity of $1.0 \times 10^{-16} \mathrm{~m}^{2} / \mathrm{s}$ (permeabilitythickness of $1.8 \times 10^{-23} \mathrm{~m}^{3}$ ), a formation storativity of $8.5 \times 10^{-7}$, and a formation pore pressure of 8.0 $\mathrm{MPa}$. The skin may or may not represent actual formation conditions; it is used as a device to match the rapid pressure changes observed in the early-time data after each fluid injection.

Figure 7-65 shows the best-fit GTFM simulation for the entire pre-mining and postmining test sequence. The same specified and fitted parameters were used as for the pre-mining simulation with the exception of skin thickness, which was increased to $3.0 \mathrm{~cm}$. The overall pressure trends are well matched, although the early-time responses after each discrete pressure change are visibly fit poorly.

Summary. In simulating the QPP14 responses, we made the simplifying assumptions that flow to the nearly horizontal QPP14 test zone was essentially radial (i.e., the surrounding halite is isotropic) and that end effects or partial-penetration effects were insignificant. The validity and quantitative effects of these assumptions could be evaluated using a three-dimensional numerical model, but such an effort is considered unwarranted given the limited data available.

The pre- and post-mining simulations of the QPP14 test events provided consistent transmissivity and storativity estimates, although these estimates are probably more reliably representative of post-mining conditions than of pre-mining conditions. The only parameter that differed between the pre- and post-mining 


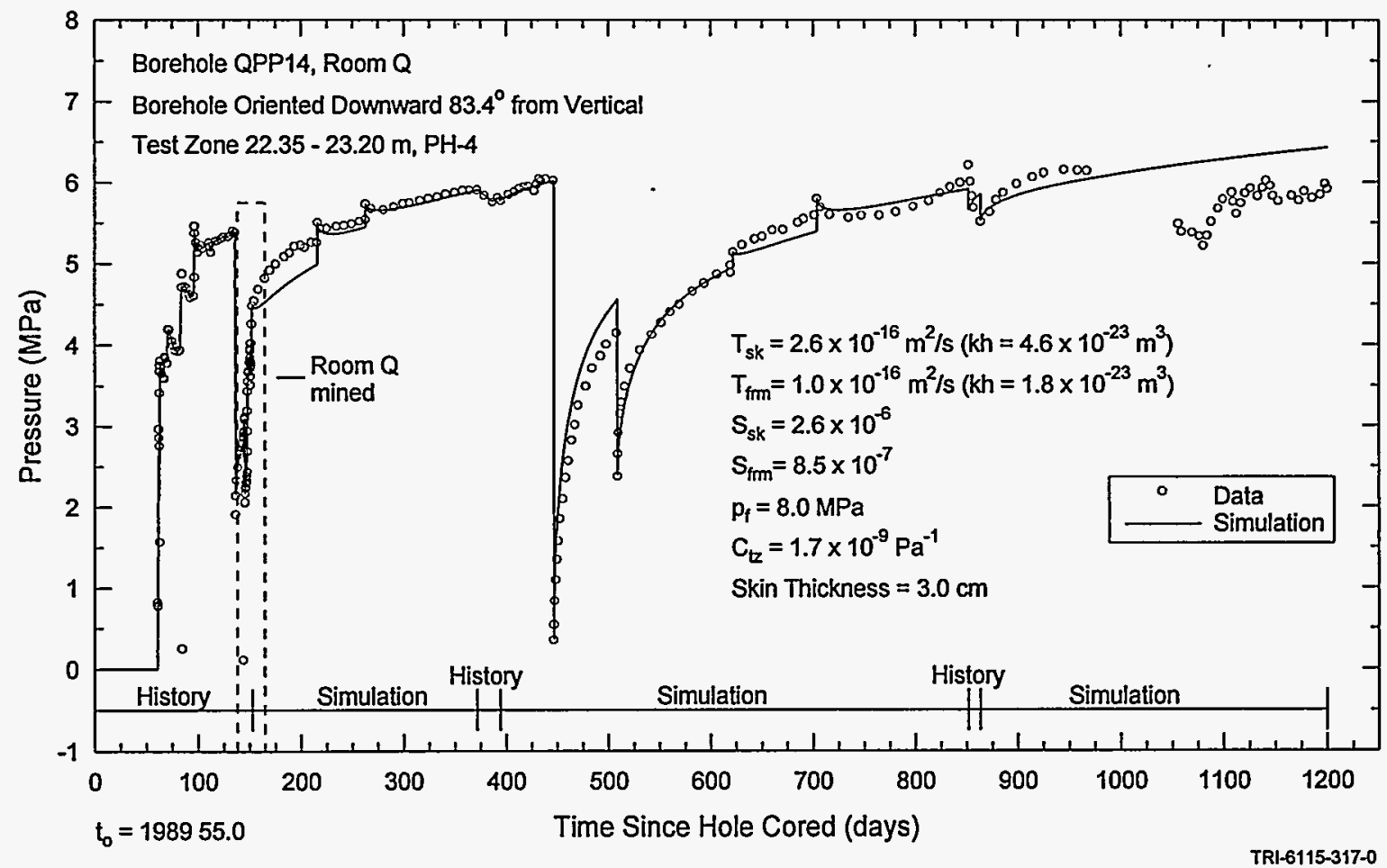

Figure 7-65. GTFM simulation of the QPP14 post-mining test-zone pressure.

simulations was the skin thickness. The skin thickness used for the post-mining simulation was nearly five times that used for the pre-mining simulation. The reason for this difference is unclear and, given the poor quality of the premining data, the difference is probably not meaningful.

If the interpreted formation transmissivity, $1.0 \times 10^{-16} \mathrm{~m}^{2} / \mathrm{s}$, were distributed uniformly along the $0.85-\mathrm{m}$ length of the QPP14 test zone, the hydraulic conductivity of the tested portion of $\mathrm{PH}-4$ would be $1.2 \times 10^{-16} \mathrm{~m} / \mathrm{s}$ (permeability of $2.1 \times$ $10^{-23} \mathrm{~m}^{2}$ ). Likewise, the average specific storage would be about $1.0 \times 10^{-6} \mathrm{~m}^{-1}$.

\subsubsection{QPP15}

The borehole survey data indicate that both the test and guard zones in QPP15 are located in the lower part of map unit 0 , with the bottom of the test zone intersecting the contact with map unit $\mathrm{PH}$ 4. According to Deal et al. (1989), the lower part of map unit 0 consists of halite with $<1 \%$ polyhalite, and map unit $\mathrm{PH}-4$ is primarily composed of halite and contains $<1$ to $3 \%$ polyhalite.

\subsubsection{Test Zone.}

The complete pressure record from the QPP15 test zone is shown in Figure 7-66. Prior to the mining of Room $Q$, the pressure in the QPP15 test interval showed no clear trend (Figure 7-67). The pressure was increased by fluid injection four times between April 26, 1989 and June 14, 1989 (1989 Calendar days 116 and 165). After each increase, the pressure initially decreased by a few tenths of an $\mathrm{MPa}$, probably because of compliance effects, and then appeared to stabilize, first at about 2.7 MPa, then at about 4.6, 5.5, and 6.3 $\mathrm{MPa}$, successively. These apparent pressure stabilizations at arbitrary and different pressures probably reflect extremely low permeability. 


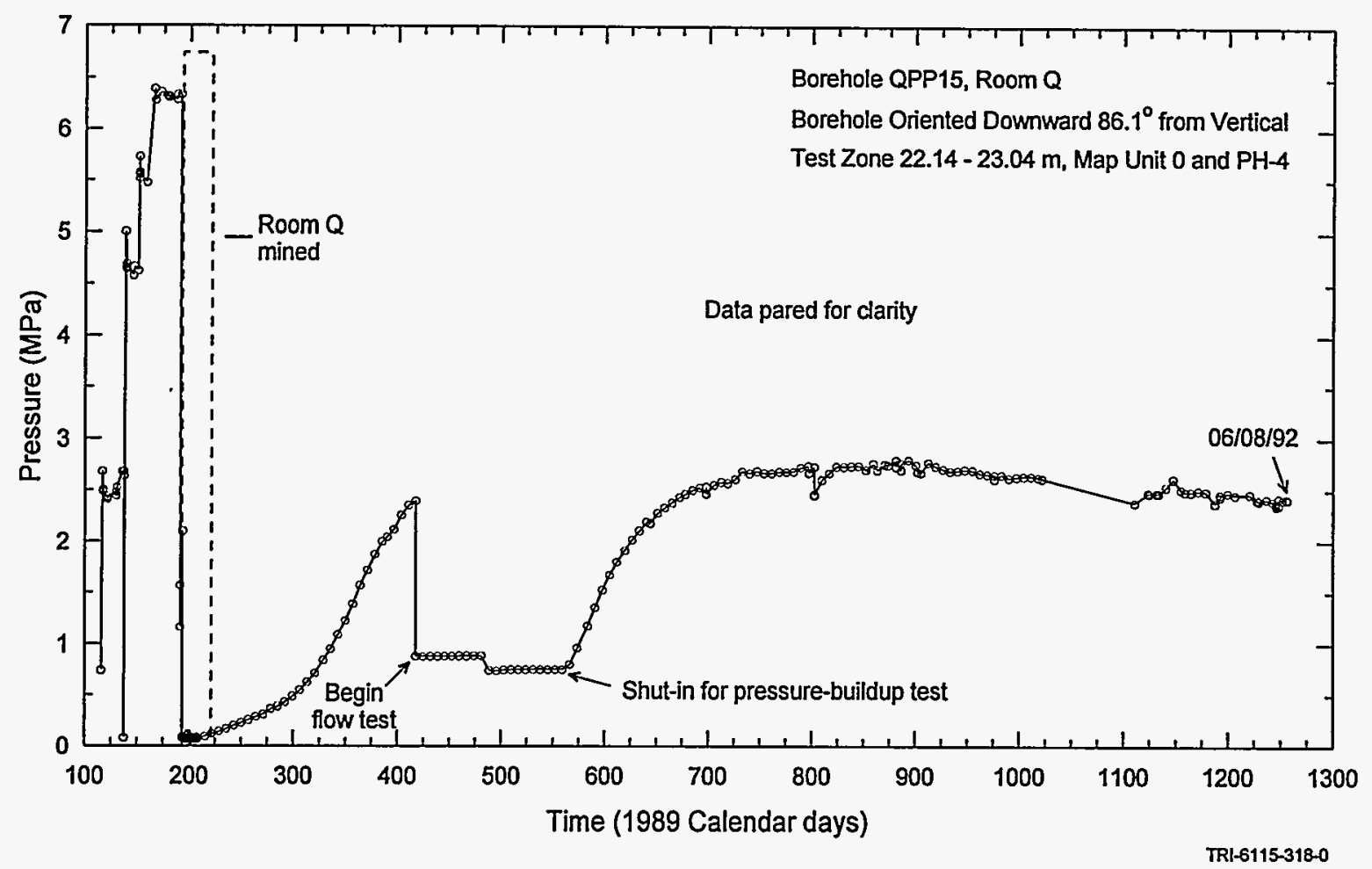

Figure 7-66. QPP15 test-zone pressure.

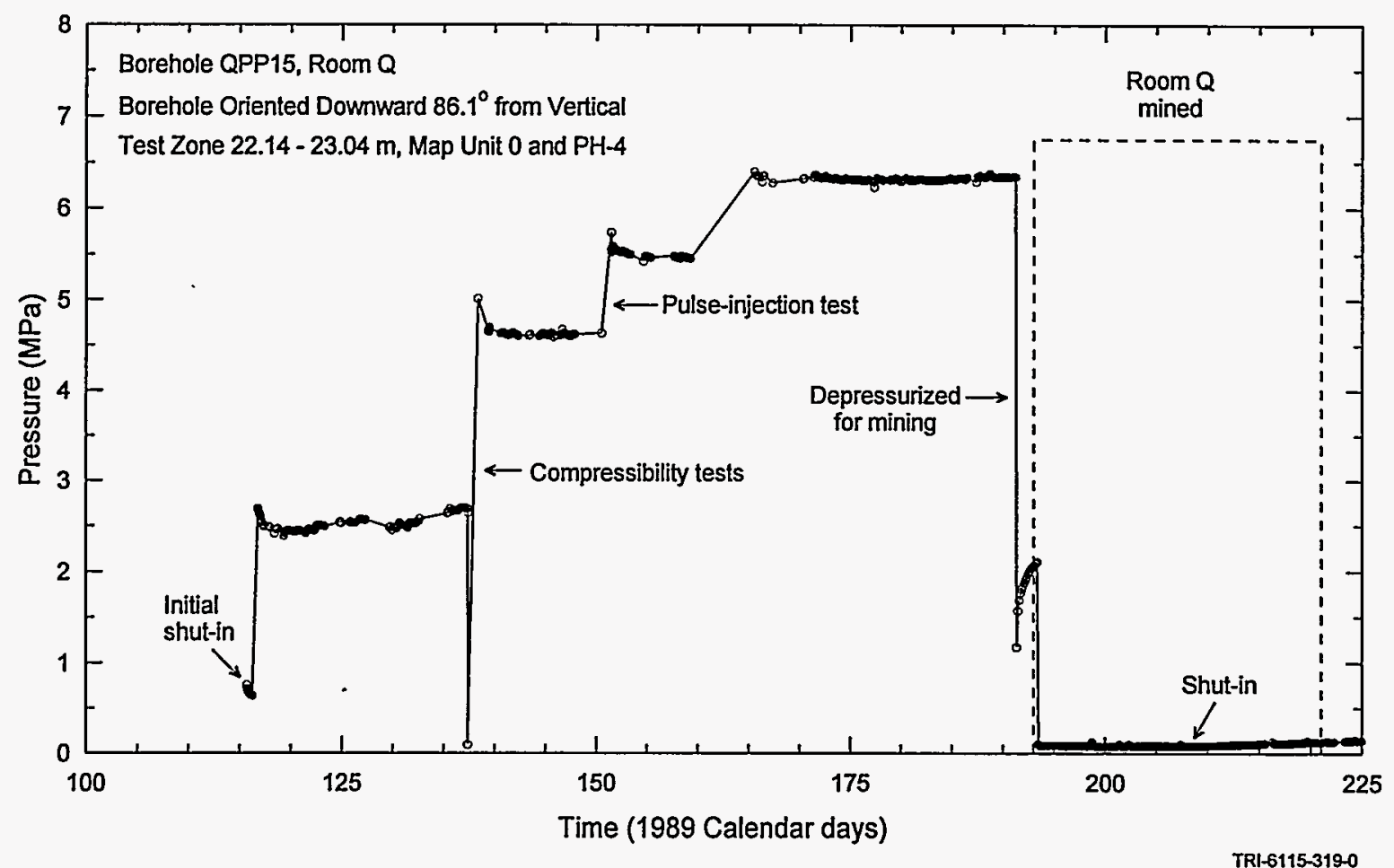

Figure 7-67. QPP15 pre-mining and mining test-zone pressure. 
After the excavation of Room $Q$, the pressure behavior in the QPP15 test zone changed. After the test zone was shut-in on July 26, 1989 (1989 Calendar day 207), a clear pressure-buildup response was observed. The pressure increased from about $0.1 \mathrm{MPa}$ to about 2.4 MPa before a constant-pressure flow test was initiated on February 21, 1990 (1989 Calendar day 417). After the flow test was terminated on July 18 , 1990 (1989 Calendar day 564), the pressure once again increased, reaching a peak of about $2.8 \mathrm{MPa}$ in June 1991. Over the following year, the pressure slowly decreased to about $2.4 \mathrm{MPa}$. The total brine accumulation during the 147-day constant-pressure flow test was only about $7 \mathrm{~cm}^{3}$ (Figure 7-68).

Analytical Interpretations. Type-curve analysis was performed on the rate data from the constant-pressure flow test. Figure 7-69 shows the flow-rate data along with the type curves of Doe (1991) for linear, radial, and spherical flow. The data are noisy because the low rates observed were near the limit of resolution of the instrumentation. The data match the radial-flow type curve reasonably well after about the first day of the test. The data could probably also be fit to the spherical-flow curve, or any nonintegerdimension curve between radial and spherical, but not to the linear-flow curve. The match to the radial-flow type curve provides a transmissivity estimate of $1.2 \times 10^{-15} \mathrm{~m}^{2} / \mathrm{s}$ (permeabilitythickness of $2.1 \times 10^{-22} \mathrm{~m}^{3}$ ).

The pressure-buildup test was analyzed using Interpret/2. For the analysis, the constantpressure flow test was divided into 27 separate flow periods having constant rates ranging from $0.60 \mathrm{~cm}^{3} /$ day to $0.03 \mathrm{~cm}^{3} /$ day. The best fit obtained beiween log-log pressure and pressurederivative type curves and the pressure-buildup data is shown in Figure 7-70. The best-fit Horner and linear-linear matches are shown in Figure 7-71 and 7-72, respectively. All three of the matches

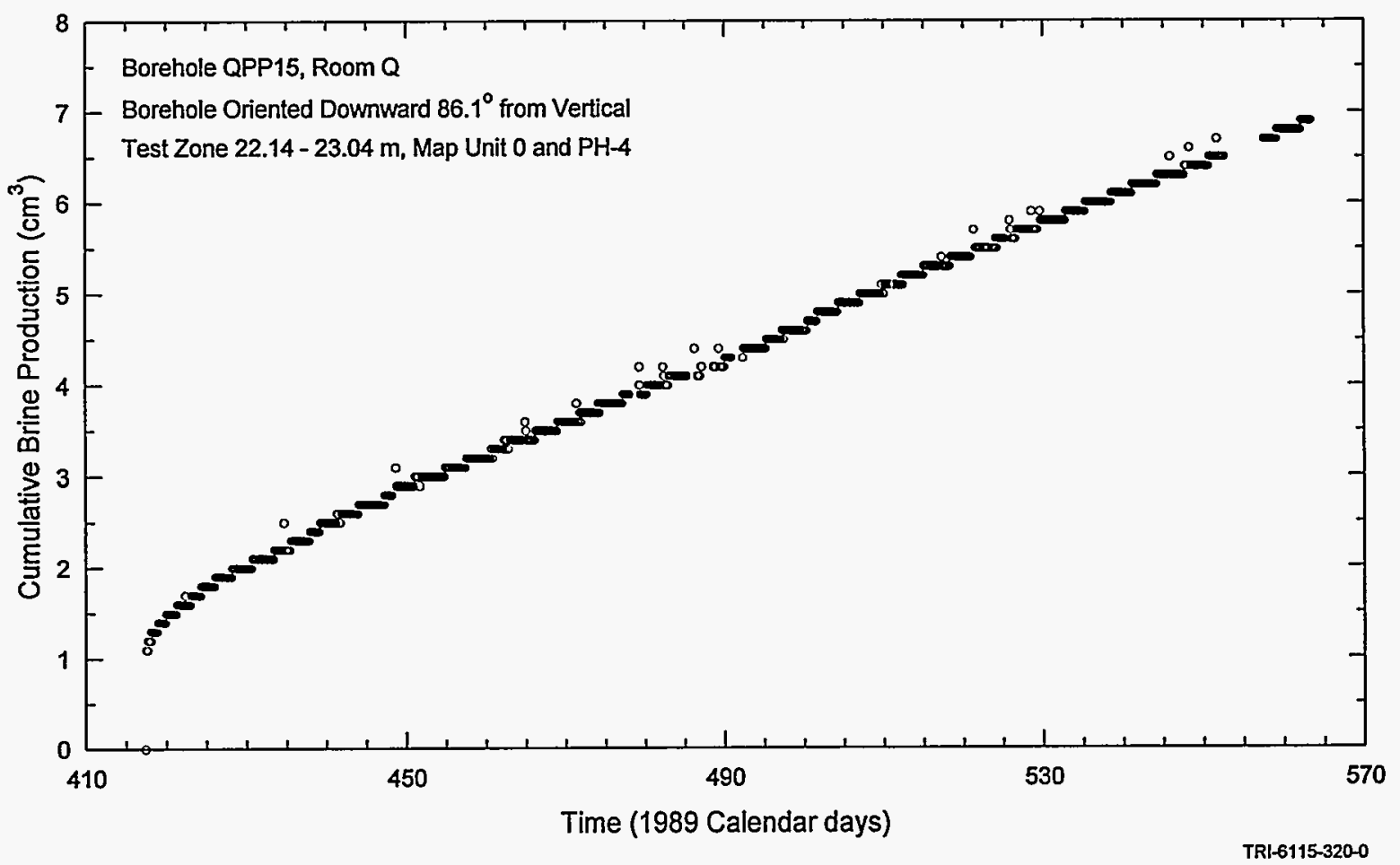

Figure 7-68. QPP15 test-zone brine production. 


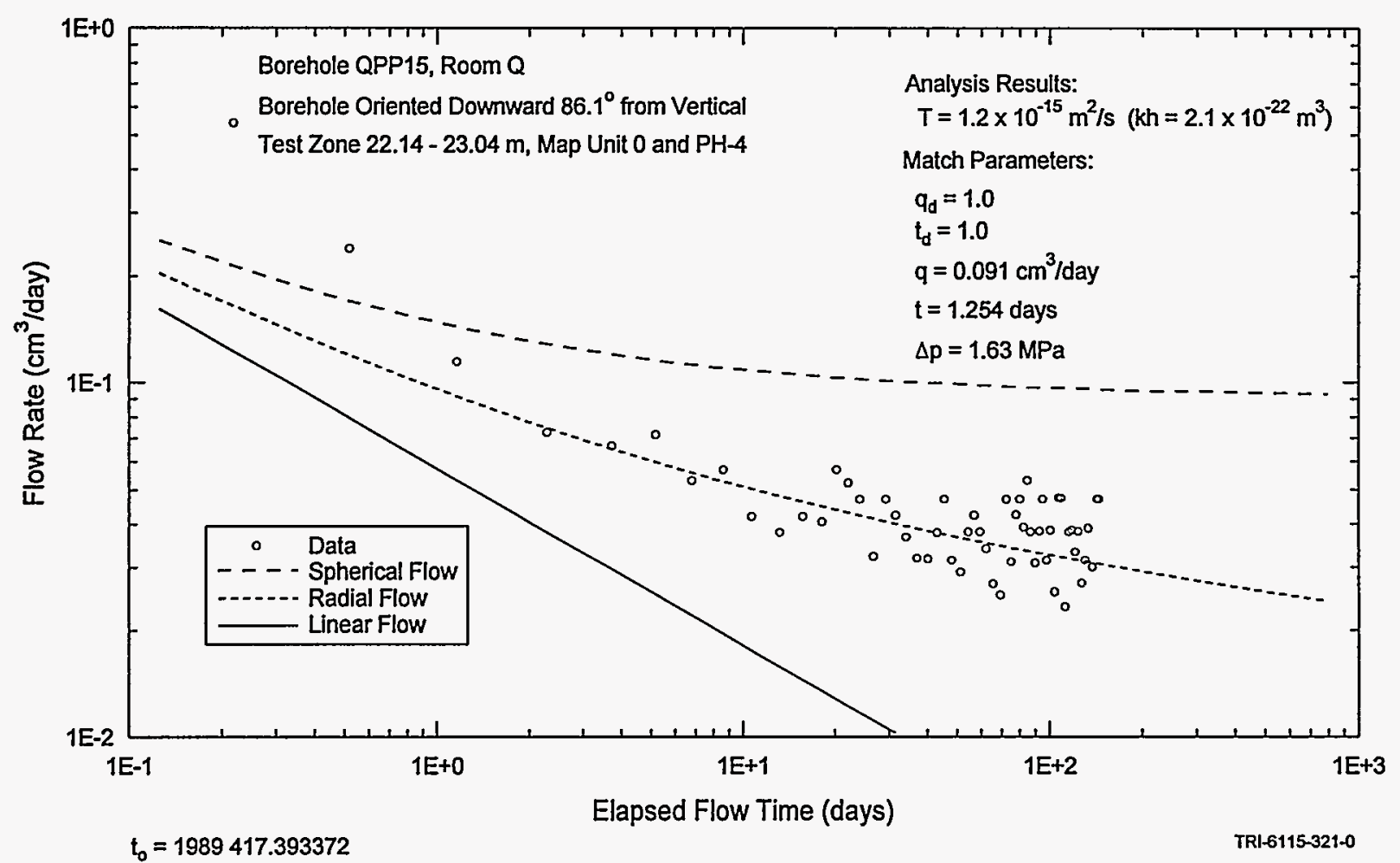

Figure 7-69. Type-curve match of the QPP15 flow rates.

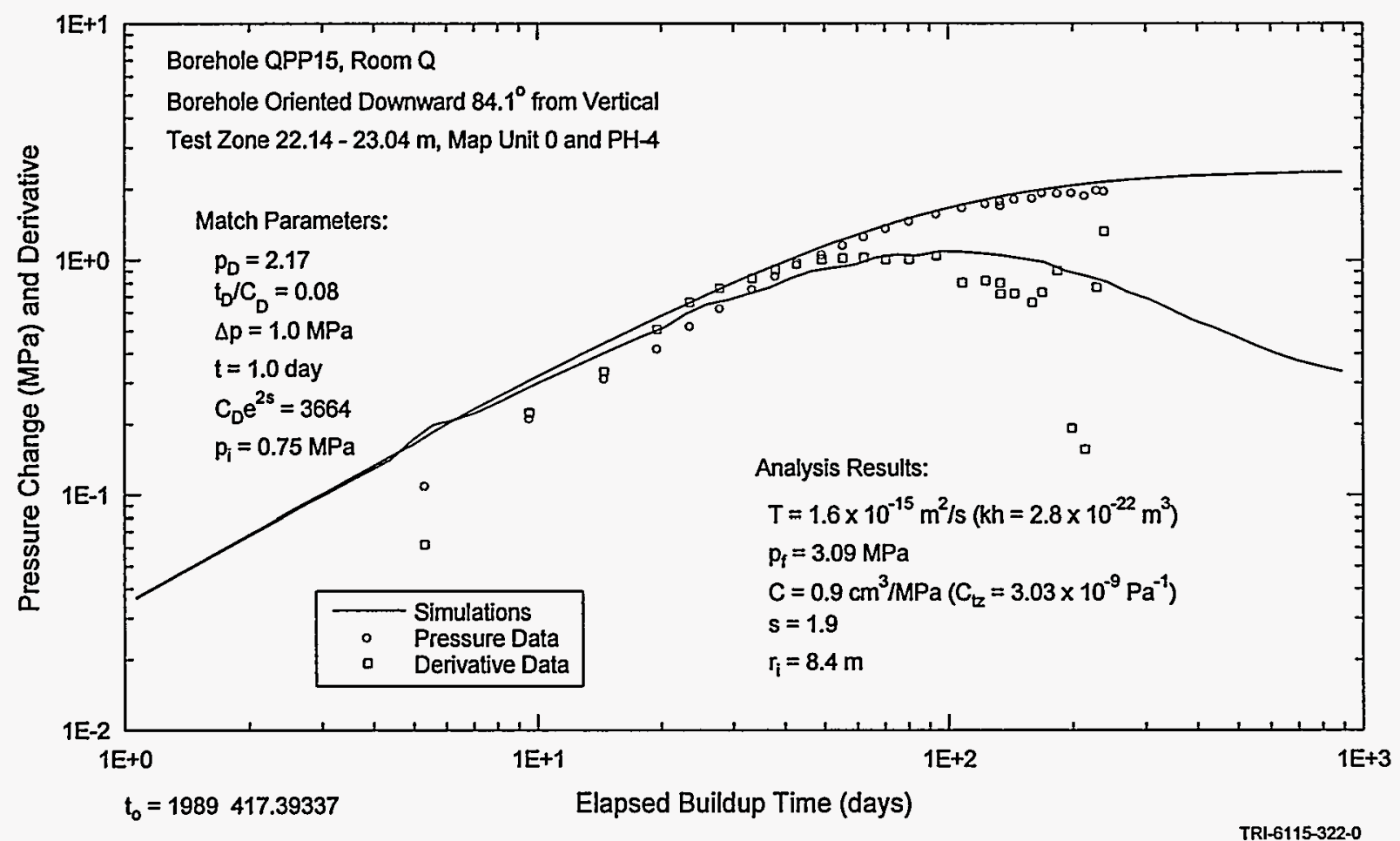

Figure 7-70. Interpret/2 type-curve match of the QPP15 post-flow-test pressure buildup. 


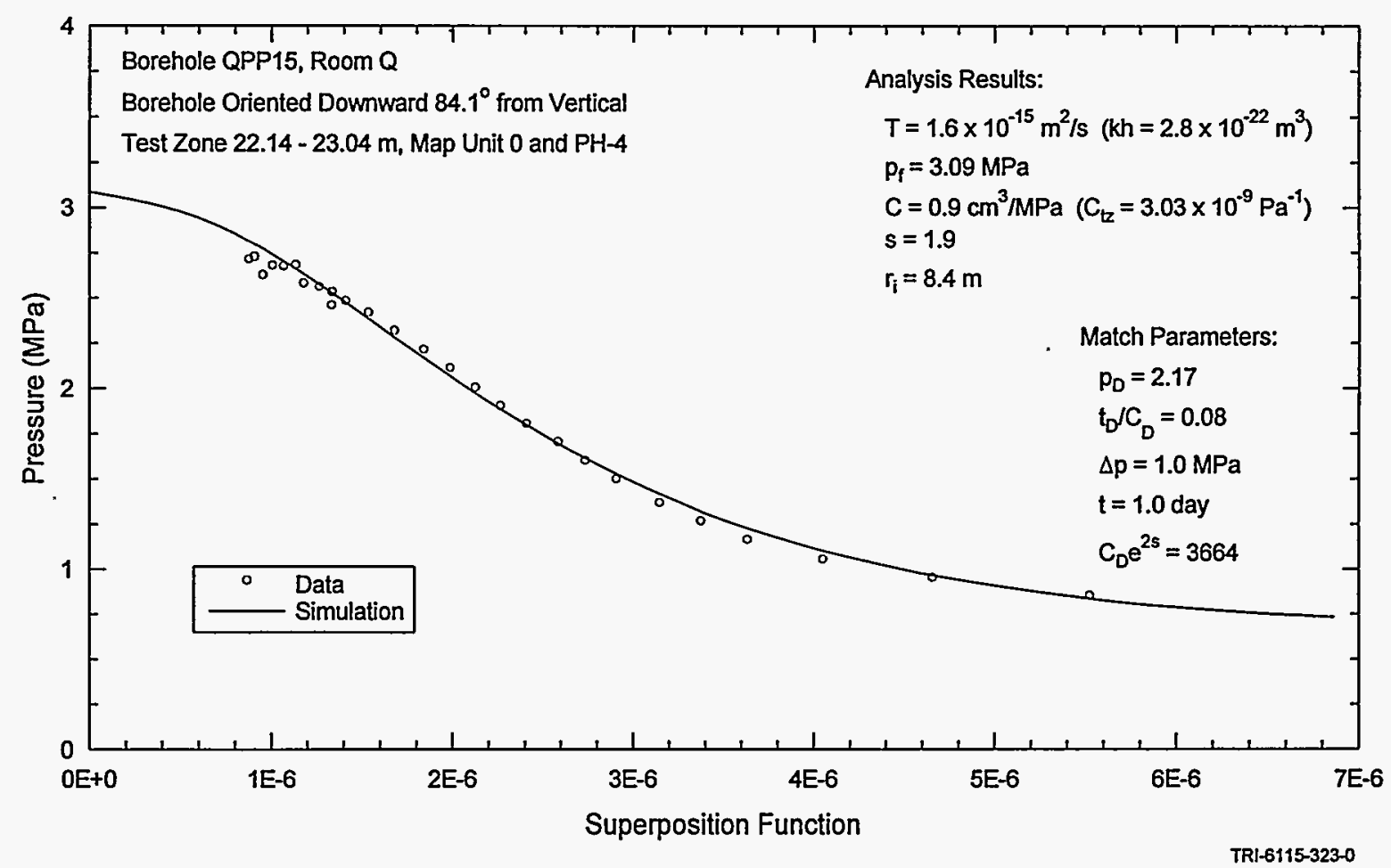

Figure 7-71. Interpret/2 Horner superposition match of the QPP15 post-flow-test pressure buildup.

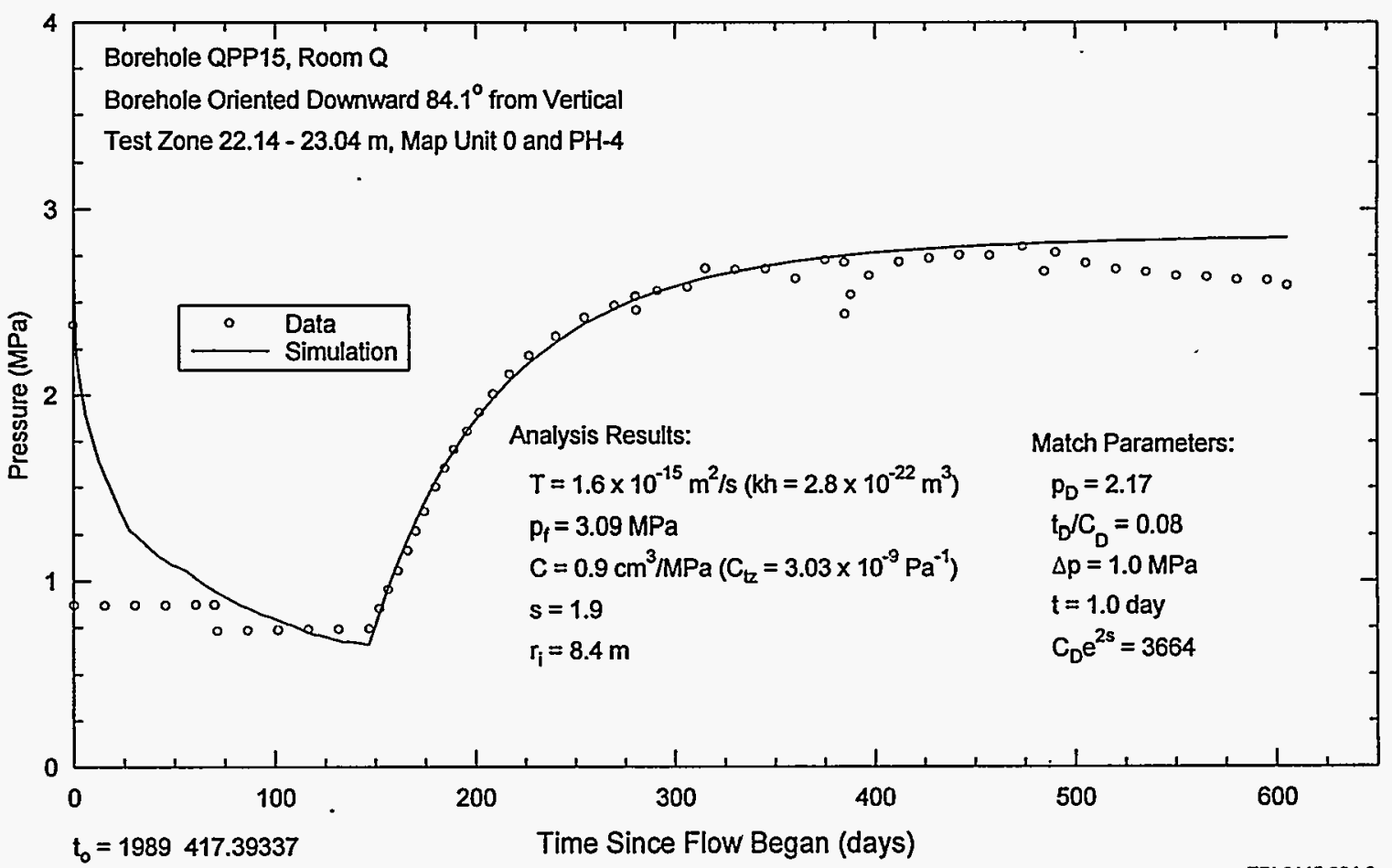

Figure 7-72. Interpret/2 simulation of the QPP15 post-flow-test pressure buildup. 
were produced using the same estimated parameters: a transmissivity of $1.6 \times 10^{-15} \mathrm{~m}^{2} / \mathrm{s}$ (permeability-thickness of $2.8 \times 10^{-22} \mathrm{~m}^{3}$ ), a formation pore pressure of $3.09 \mathrm{MPa}$, a wellborestorage coefficient of $0.9 \mathrm{~cm}^{3} / \mathrm{MPa}$ (corresponding to a test-zone compressibility of $3.0 \times 10^{-9} \mathrm{~Pa}^{-1}$ ), and a wellbore skin factor of 1.9 .

Numerical Interpretations. Because of the change in pressure behavior observed in QPP15 at the time Room Q was mined, numerical GTFM simulations of the post-mining test responses used the onset of mining as time zero. For these simulations, the pore pressure in the formation was assumed to be stable (spatially and temporally constant) before mining began. The test-zone pressures during and following the mining of Room $Q$ and during the flow test were included in the GTFM simulations as specifiedpressure history sequences.
Figures 7-73, 7-74, and 7-75 show the best-fit GTFM simulations for the post-mining pressure response, the cumulative brine production, and the brine-inflow rate, respectively. All three simulations were generated using the same specified and fitted parameters. The specified parameters were a borehole radius of 1.9 $\mathrm{cm}$ and a test-zone fluid volume of $300 \mathrm{~cm}^{3}$. A test-zone compressibility of $2.4 \times 10^{-9} \mathrm{~Pa}^{-1}$, derived from the fluid volume liberated and the associated pressure change at the start of the flow test, was also specified in the simulations. The fitted parameters obtained were a skin thickness of 1.0 $\mathrm{cm}$, a skin transmissivity value of $4.5 \times 10^{-15} \mathrm{~m}^{2} / \mathrm{s}$ (permeability-thickness of $7.9 \times 10^{-22} \mathrm{~m}^{3}$ ), a skin storativity of $9.0 \times 10^{-7}$, a formation transmissivity of $1.6 \times 10^{-15} \mathrm{~m}^{2} / \mathrm{s}$ (permeability-thickness of $2.8 \mathrm{x}$ $10^{-22} \mathrm{~m}^{3}$ ), a storativity value of $2.5 \times 10^{-8}$, and a formation pore pressure of $3.1 \mathrm{MPa}$.

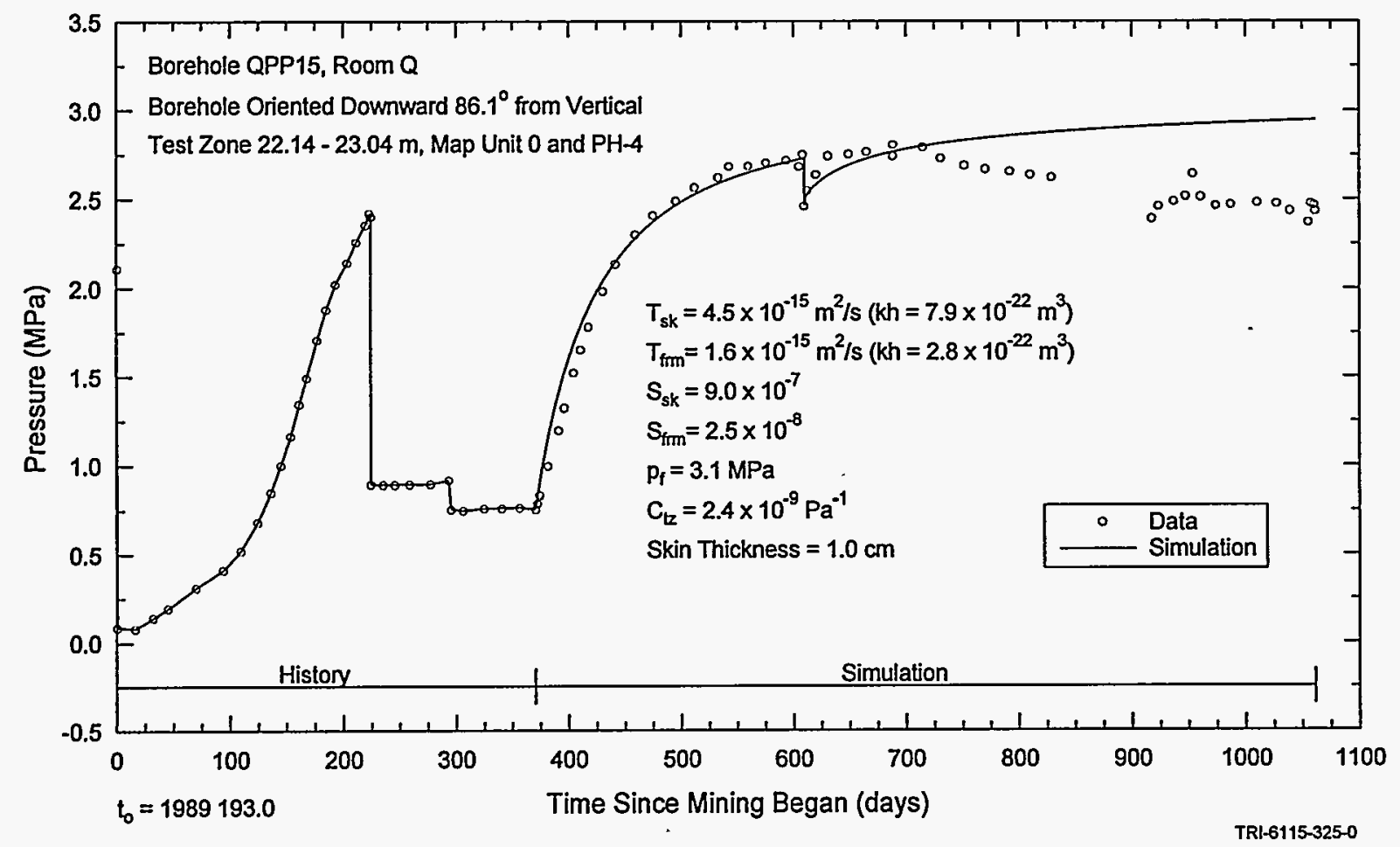

Figure 7-73. GTFM simulation of the QPP15 post-mining test-zone pressure. 


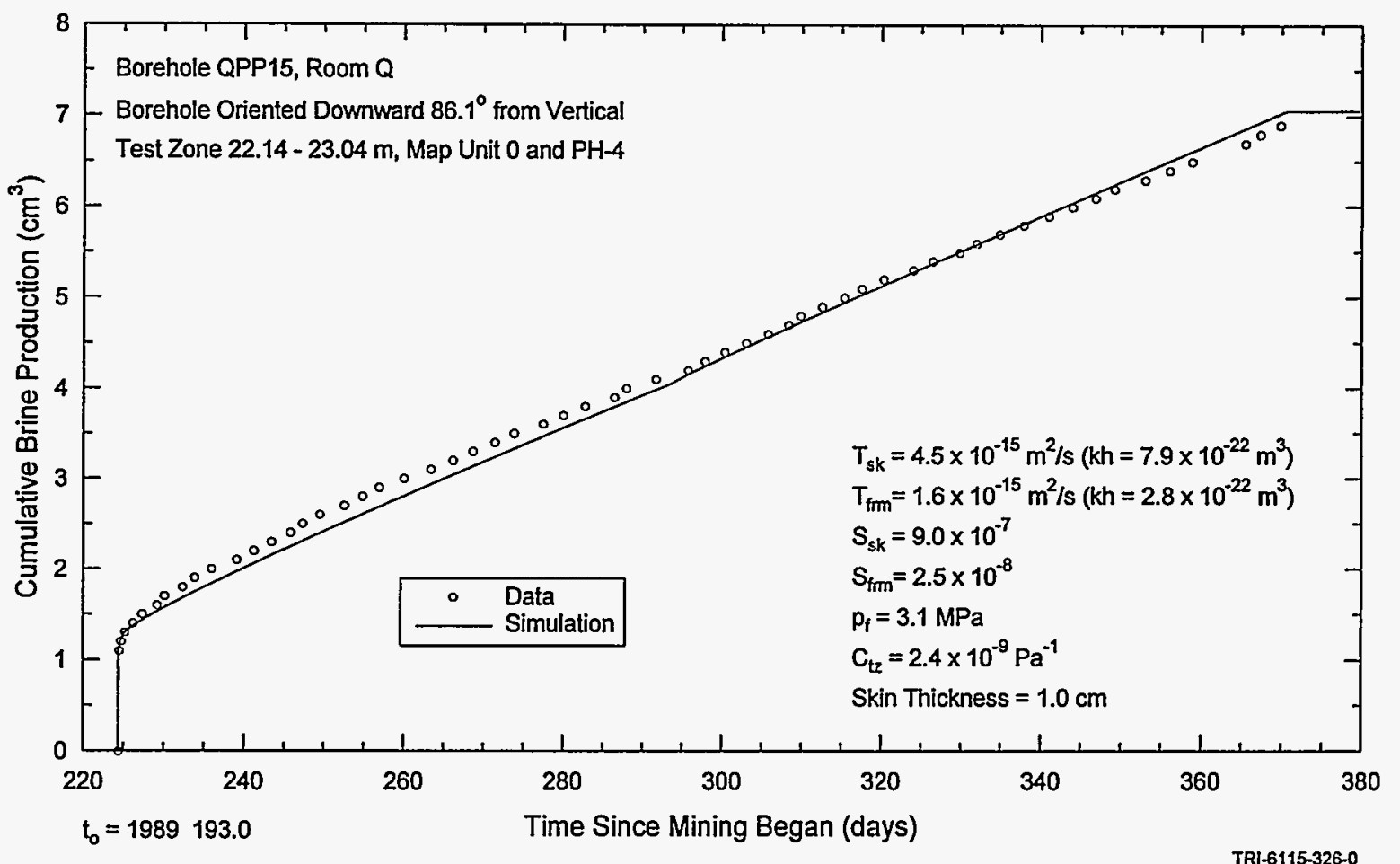

Figure 7-74. GTFM simulation of the QPP15 brine production.

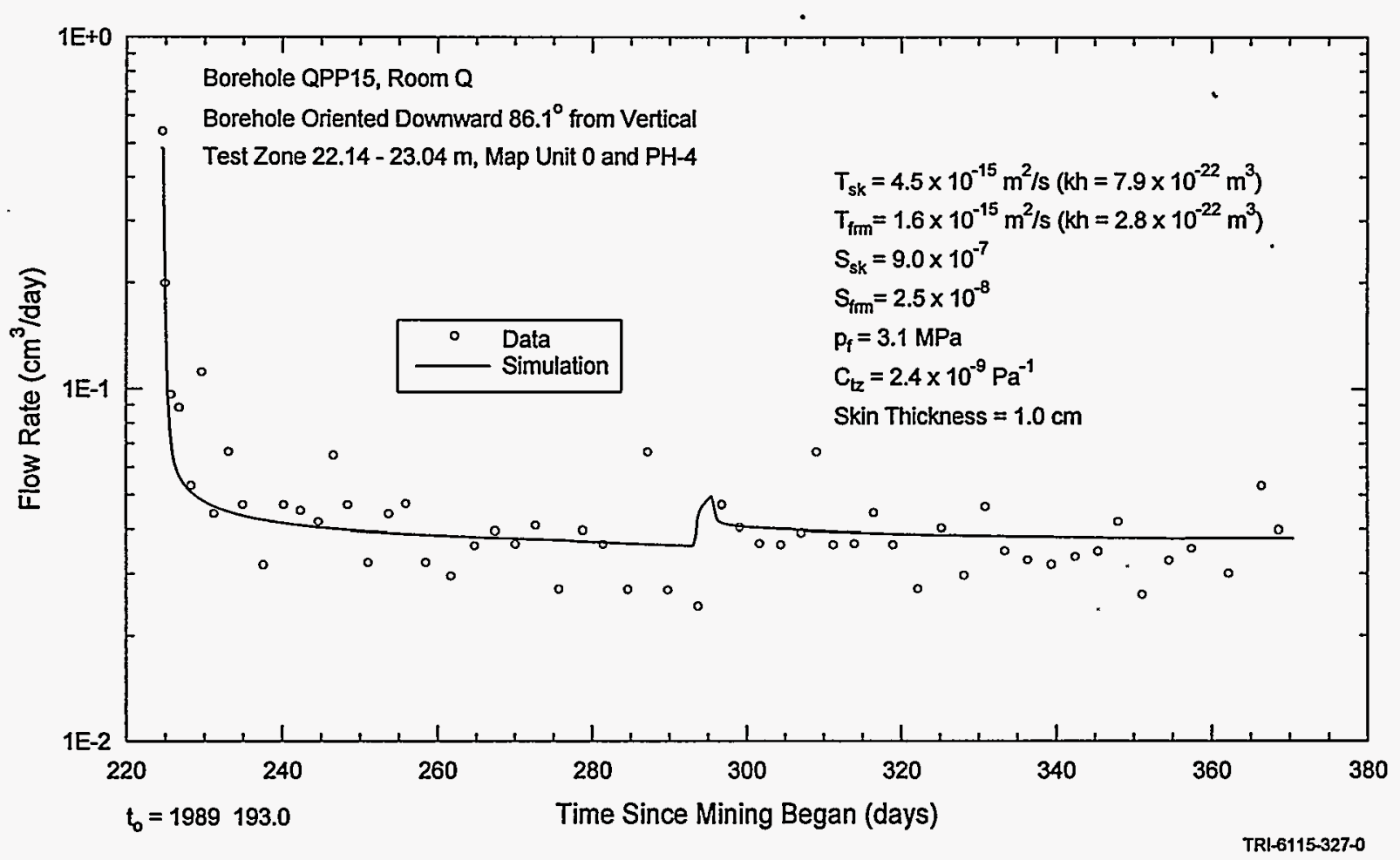

Figure 7-75. GTFM simulation of the QPP15 flow rates. 
Figure 7-76 shows a GTFM simulation fit to the pre-mining observed pressure data. The same specified parameters used for the postmining test sequence were used for the pre-mining test sequence. The parameters fitted to the data were a skin thickness of $1.5 \mathrm{~cm}$, a skin transmissivity value of $1.8 \times 10^{-15} \mathrm{~m}^{2} / \mathrm{s}$ (permeability-thickness of $3.2 \times 10^{-22} \mathrm{~m}^{3}$ ), a skin storativity of $6.3 \times 10^{-7}$, a formation transmissivity of $2.8 \times 10^{-17} \mathrm{~m}^{2} / \mathrm{s}$ (permeability-thickness of $4.9 \times$ $10^{-24} \mathrm{~m}^{3}$ ), a storativity value of $2.1 \times 10^{-6}$, and a formation pore pressure of $11.0 \mathrm{MPa}$. The simulation shown in Figure 7-76 is non-unique because the pre-mining pore pressure could not be estimated with the available data. The value used in the simulation, $7.5 \mathrm{MPa}$, was chosen arbitrarily and similar fits could be obtained by simultaneously adjusting the transmissivity and pore pressure. The purpose of presenting this simulation is to illustrate how low the transmissivity would need to be to produce the observed pressure response.

\subsubsection{Guard Zone.}

The complete pressure record from the QPP15 guard zone is shown in Figure 7-77. The pre-mining pressure response was affected by packer-inflation problems (see Figure A-10) and, therefore, nothing conclusive can be stated about the effect of mining on the pore pressure in the guard zone.

\subsubsection{Summary.}

All of the analytical and numerical interpretations of the QPP15 post-mining tests provided the same value of formation transmissivity for the post-mining test sequence, $1.6 \times 10^{-15} \mathrm{~m}^{2} / \mathrm{s}$ (permeability-thickness of $2.8 \times$ $10^{-22} \mathrm{~m}^{3}$ ). The estimated formation storativity is $2.5 \times 10^{-8}$, and the estimated formation pore pressure is $3.1 \mathrm{MPa}$. Assuming that hydraulic properties are uniform over the $0.90-\mathrm{m}$ length of

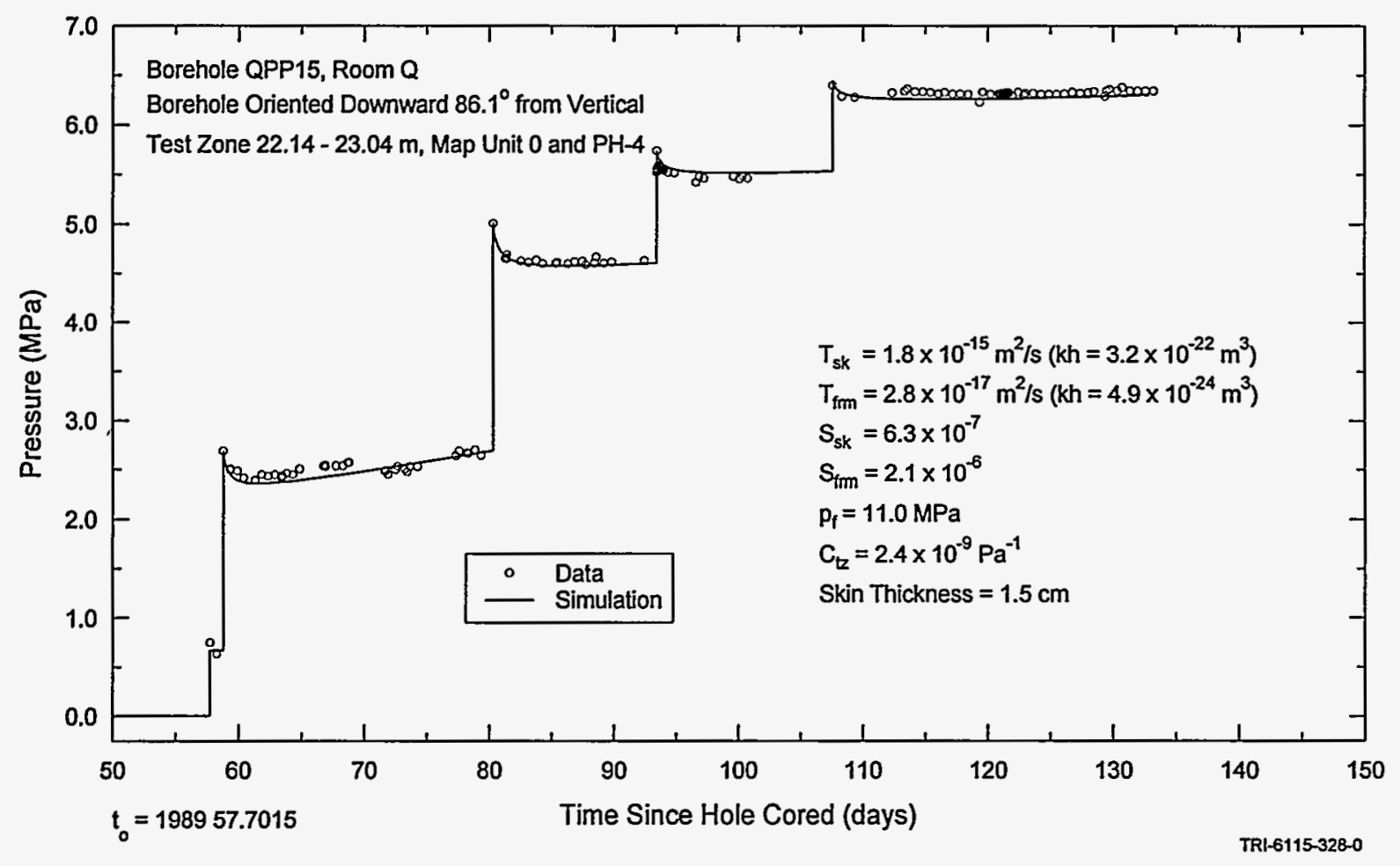

Figure 7-76. GTFM simulation of the QPP15 pre-mining test-zone pressure. 


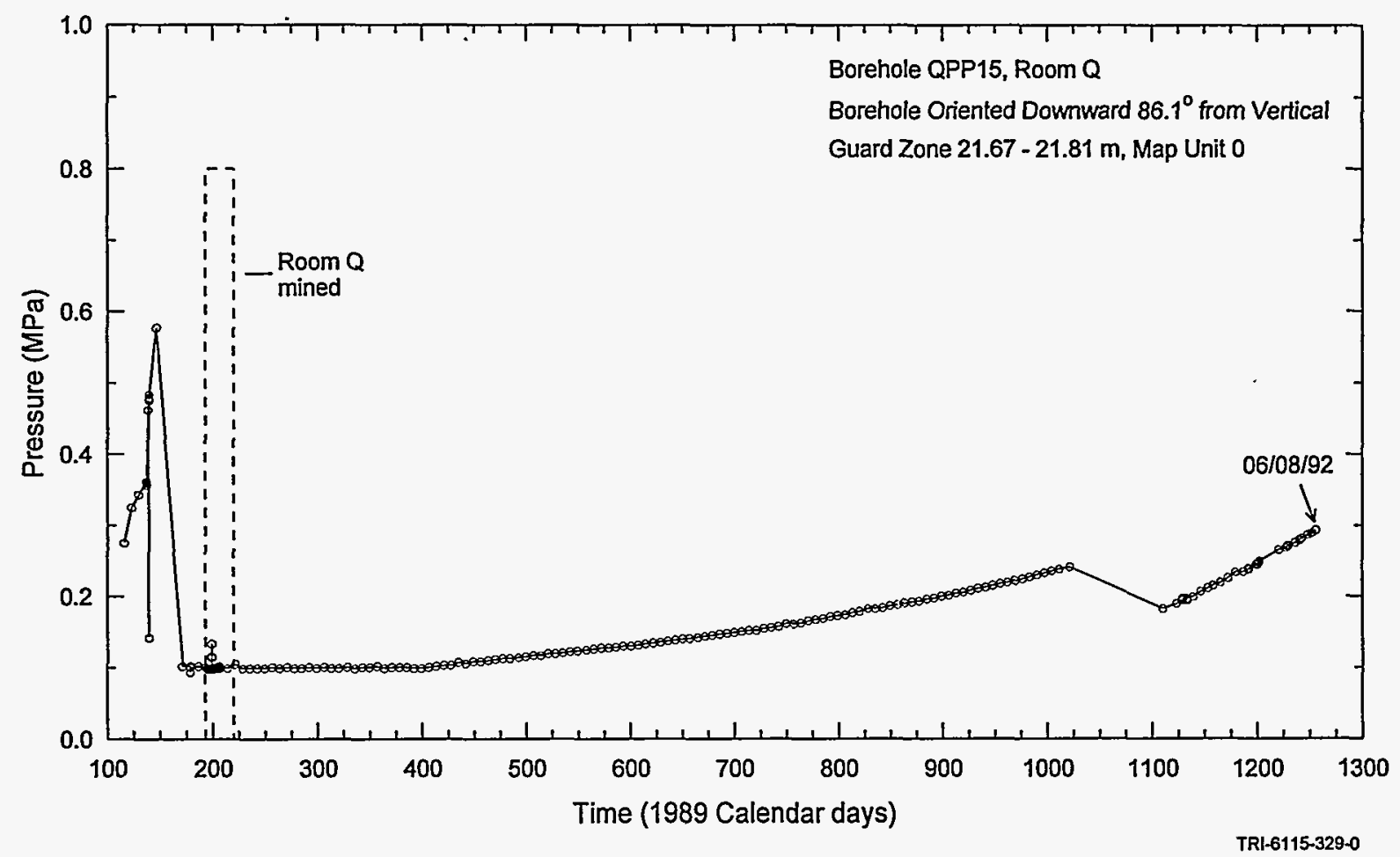

Figure 7-77. QPP15 guard-zone pressure.

the test zone, the average hydraulic conductivity of the tested portion of map unit 0 is $1.8 \times 10^{-15} \mathrm{~m} / \mathrm{s}$ (permeability of $3.1 \times 10^{-22} \mathrm{~m}^{2}$ ) and the average specific storage is $2.8 \times 10^{-8} \mathrm{~m}^{-1}$. Numerical interpretation of the pre-mining test sequence indicated that the formation transmissivity was probably over an order of magnitude lower before mining occurred, although a reliable value could not be determined from the available data. The post-mining GTFM simulations used a negative skin (enhanced permeability at the wellbore) to match rapid early-time pressure changes and high early-time flow rates. We are not certain whether true enhanced permeability exists at the wellbore face or if these phenomena are due to tool movement and/or packer-compliance effects. The analytical interpretations of the tests did not indicate the presence of a negative skin.

\subsubsection{QPP21}

The survey data indicate that both the test and guard zones of borehole QPP21 are located in map unit 3 and the upper part of map unit 2. Map unit 3 is a relatively pure halite unit typically containing $\leq 1 \%$ polyhalite and the upper part of map unit 2 is argillaceous halite containing 1 to $3 \%$ clay (Deal et al., 1989). Because of uncertainty in the extrapolation of stratigraphy, however, the QPP21 test and guard zones could lie anywhere between the upper portion of map unit 0 and the lower portion of map unit 3. 


\subsubsection{Test Zone.}

The test zone in QPP21 was shut-in prior to May 10, 1989 (1989 Calendar day 130) when data collection started. Figure 7-78 presents the entire test-zone pressure record through June 3 , 1992. Pressures before and during mining are shown in Figure 7-79. On May 19, 1989 (1989 Calendar day 139), the testing system was checked for trapped air. This event is observed in the test-zone pressure record as a pressure drop on that day. On May 30, 1989 (1989 Calendar day 150), the test-zone packer pressure was increased. On May 31, 1989 (1989 Calendar day 151), a pulse test was initiated. Operational logs indicate that the mining of Room $Q$ occurred from July 12 to August 8, 1989 (1989 Calendar days 193 to 220 ). The test-zone is reported to have remained shut-in during this period of time.

On February 21, 1990 (1989 Calendar day $417)$, a flow test was initiated by reducing the test- zone pressure from 4.76 to $0.77 \mathrm{MPa}$. No brineinflow volume data has been preserved. Operational logs indicate that the brine-inflow collection system was inoperable. The flow test was terminated on July 18, 1990 (1989 Calendar day 564), by shutting in the test zone and allowing pressures to increase.

Numerical Interpretations. The QPP21 testing was preceded by a 56-day period during which the borehole was at atmospheric pressure. This open-borehole period was included in GTFM simulations as a specified-pressure sequence. Additionally, the test-zone pressures from the initial shut-in through the end of mining, and including the flow test were included as specified-pressure sequences. Only the pulse-injection test prior to mining and the pressure buildups following mining have been interpreted.

GTFM assumes radial flow to a circular test zone oriented perpendicular to the unit being

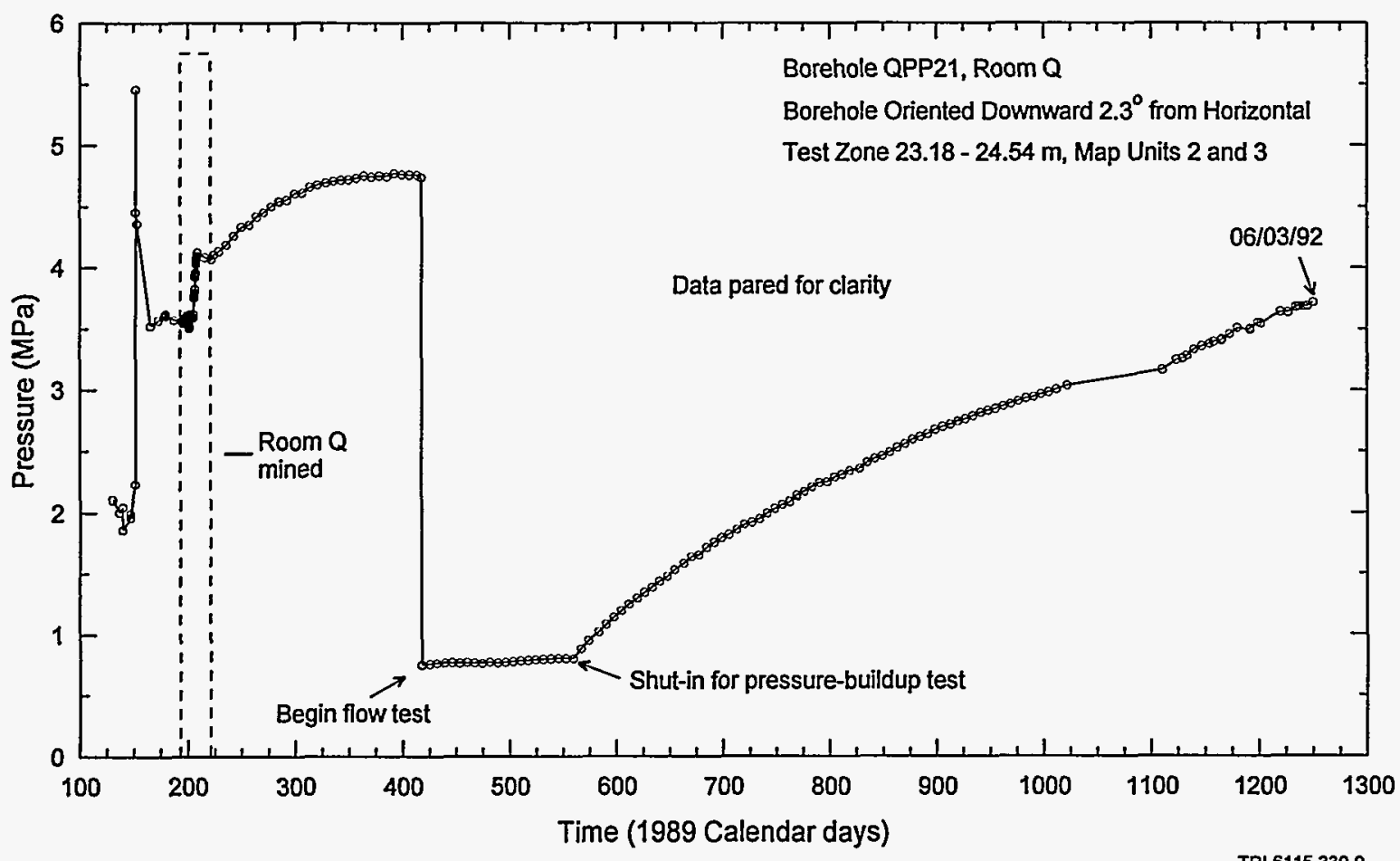

Figure 7-78. QPP21 test-zone pressure. 


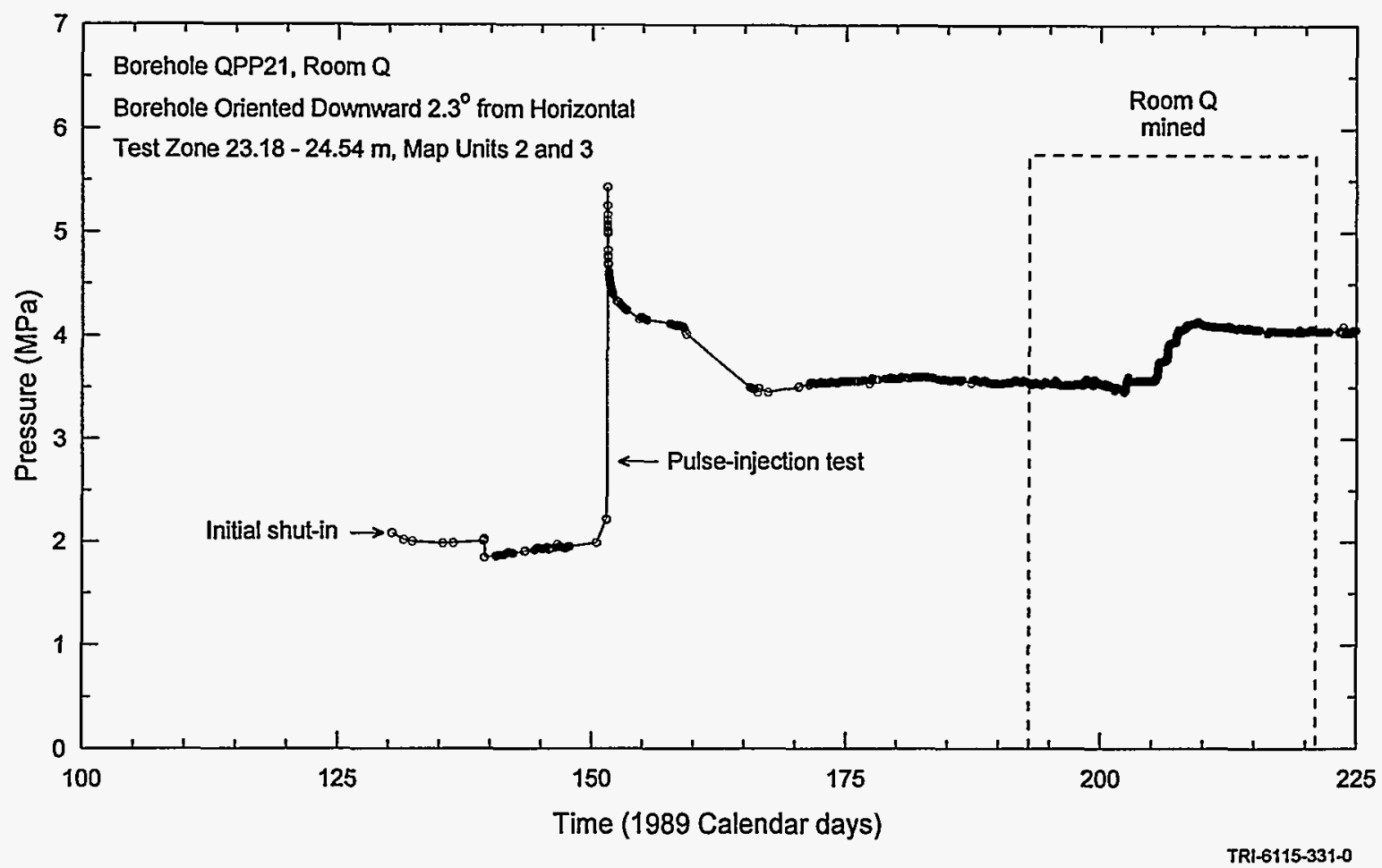

Figure 7-79. QPP21 pre-mining and mining test-zone pressure.

tested. Therefore, because QPP21 is oriented essentially parallel to the bedding, the formation thickness was assumed to be equivalent to the length of the test zone. The borehole radius included in the GTFM simulation was taken to be the cored radius of the borehole.

The best-fit GTFM simulation of the premining pulse-injection test is shown in Figure 7-80. The specified parameters were a borehole radius of $5.1 \mathrm{~cm}$ and a test-zone fluid volume of 6100 $\mathrm{cm}^{3}$. The fitted parameters were a skin thickness of $5.0 \mathrm{~cm}$, a skin transmissivity of $6.8 \times 10^{-14} \mathrm{~m}^{2} / \mathrm{s}$ (permeability-thickness of $1.2 \times 10^{-20} \mathrm{~m}^{3}$ ), a skin storativity of $2.7 \times 10^{-6}$, a formation transmissivity of $6.8 \times 10^{-16} \mathrm{~m}^{2} / \mathrm{s}$ (permeability-thickness of $1.2 \times$ $10^{-22} \mathrm{~m}^{3}$ ), a formation storativity of $2.7 \times 10^{-6}$, a formation pore pressure of $3.85 \mathrm{MPa}$, and a testzone compressibility of $1.0 \times 10^{-9} \mathrm{~Pa}^{-1}$. The low pre-mining formation pore pressure used in the simulation is difficult to rationalize. A GTFM simulation similar to that shown in Figure $7-80$ could probably be obtained using a higher value of formation pore pressure combined with a lower value of formation transmissivity. Therefore, the parameter set presented above should be considered highly uncertain and should be used with caution.

Figures 7-81 and 7-82 show the best-fit GTFM simulation of the pressure response following mining and the Horner plot of the pressure buildup following the flow test, respectively. The specified parameters were a borehole radius of $5.1 \mathrm{~cm}$ and a test-zone fluid volume of $6100 \mathrm{~cm}^{3}$. The fitted parameters were a skin thickness of $5.0 \mathrm{~cm}$, a skin transmissivity of $2.7 \times 10^{-15} \mathrm{~m}^{2} / \mathrm{s}$ (permeability-thickness of $4.7 \times$ $10^{-22} \mathrm{~m}^{3}$ ), a skin storativity of $1.4 \times 10^{-6}$, a formation transmissivity of $1.2 \times 10^{-14} \mathrm{~m}^{2} / \mathrm{s}$ (permeability-thickness of $2.1 \times 10^{-21} \mathrm{~m}^{3}$ ), a formation storativity of $1.4 \times 10^{-6}$, a formation pore pressure of $5.0 \mathrm{MPa}$, and a test-zone compressibility of $1.0 \times 10^{-9} \mathrm{~Pa}^{-1}$ for the pressure 


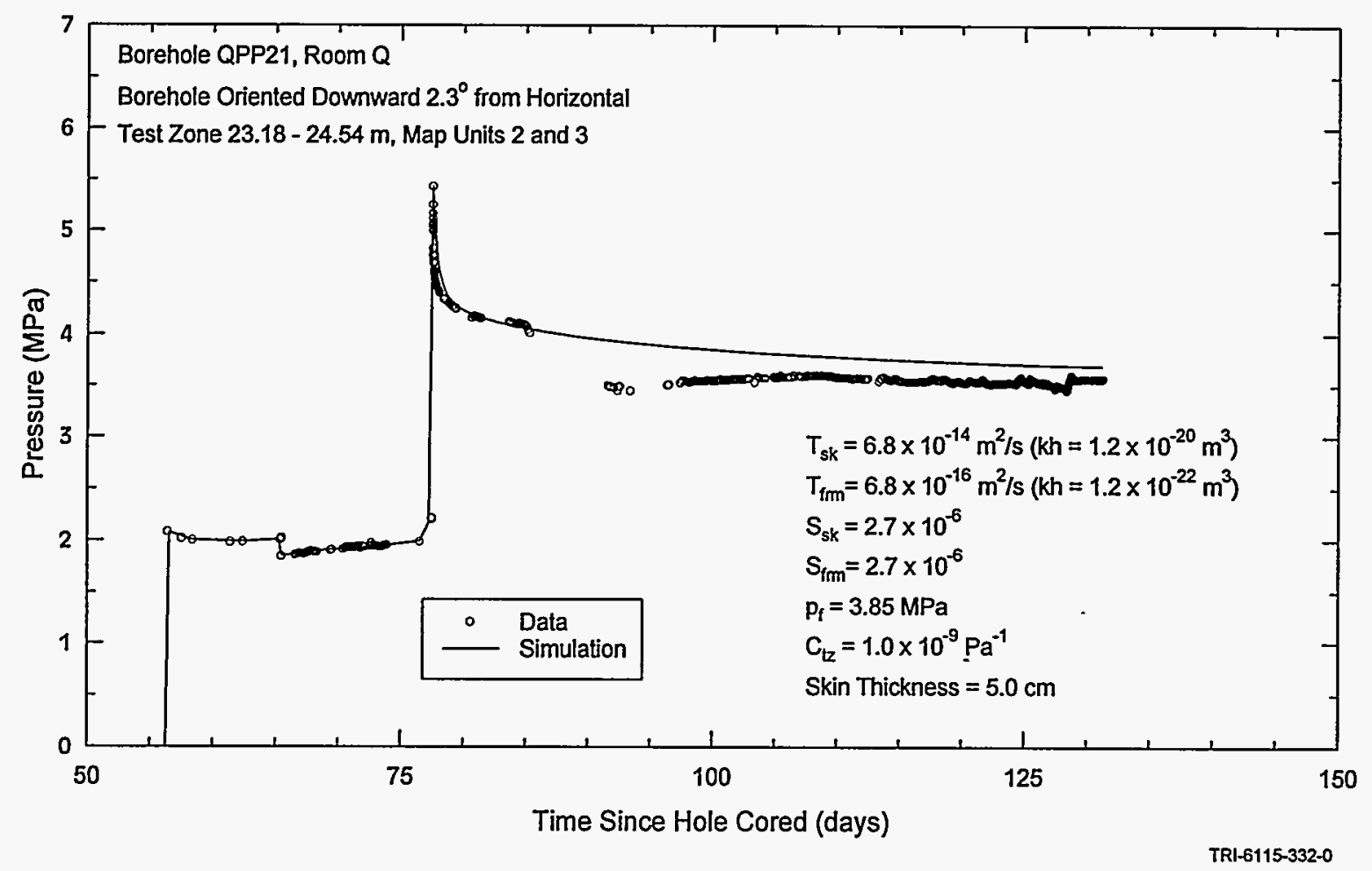

Figure 7-80. GTFM simulation of the QPP21 pre-mining test-zone pressure

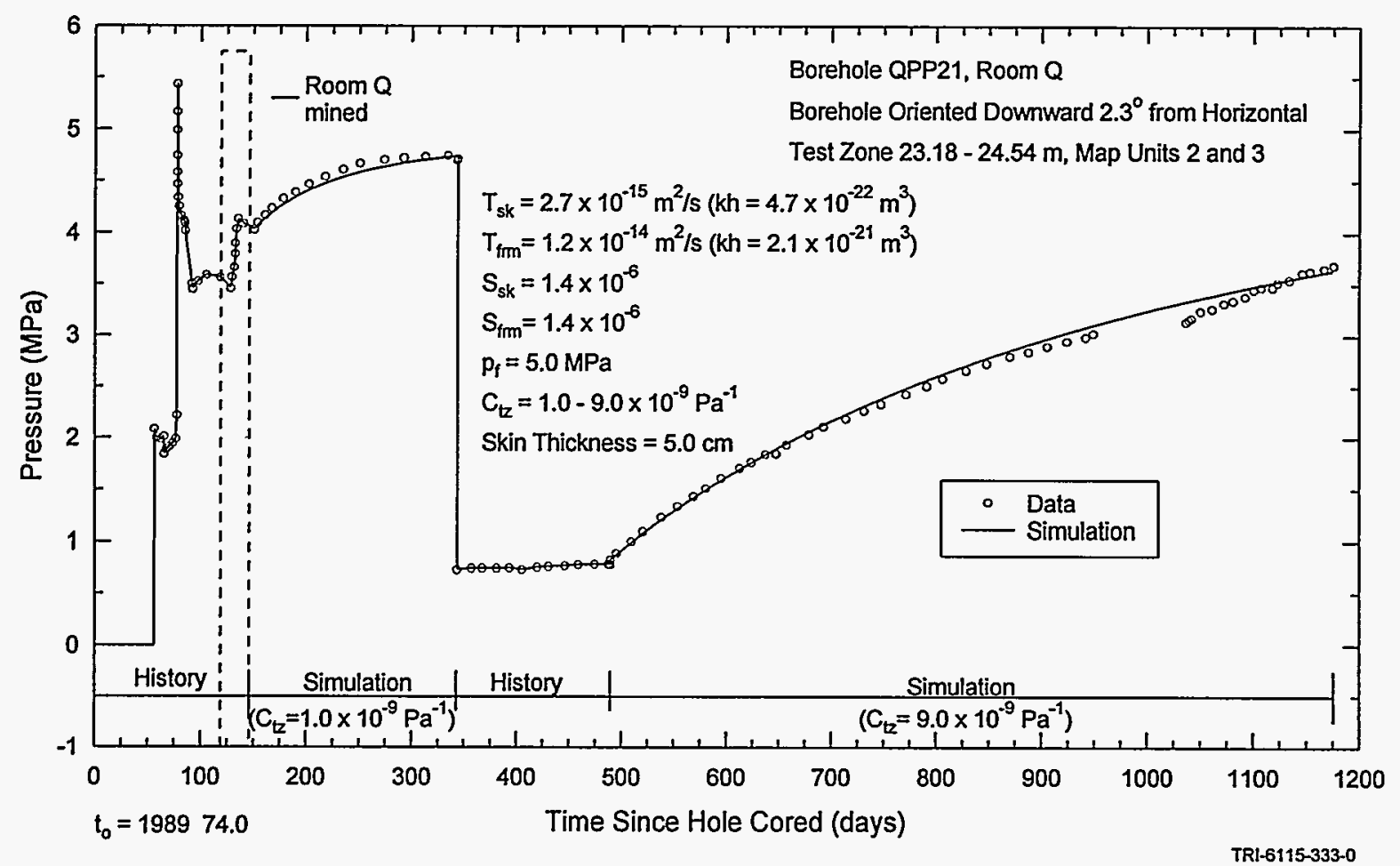

Figure 7-81. GTFM simulation of the QPP21 post-mining test-zone pressure 


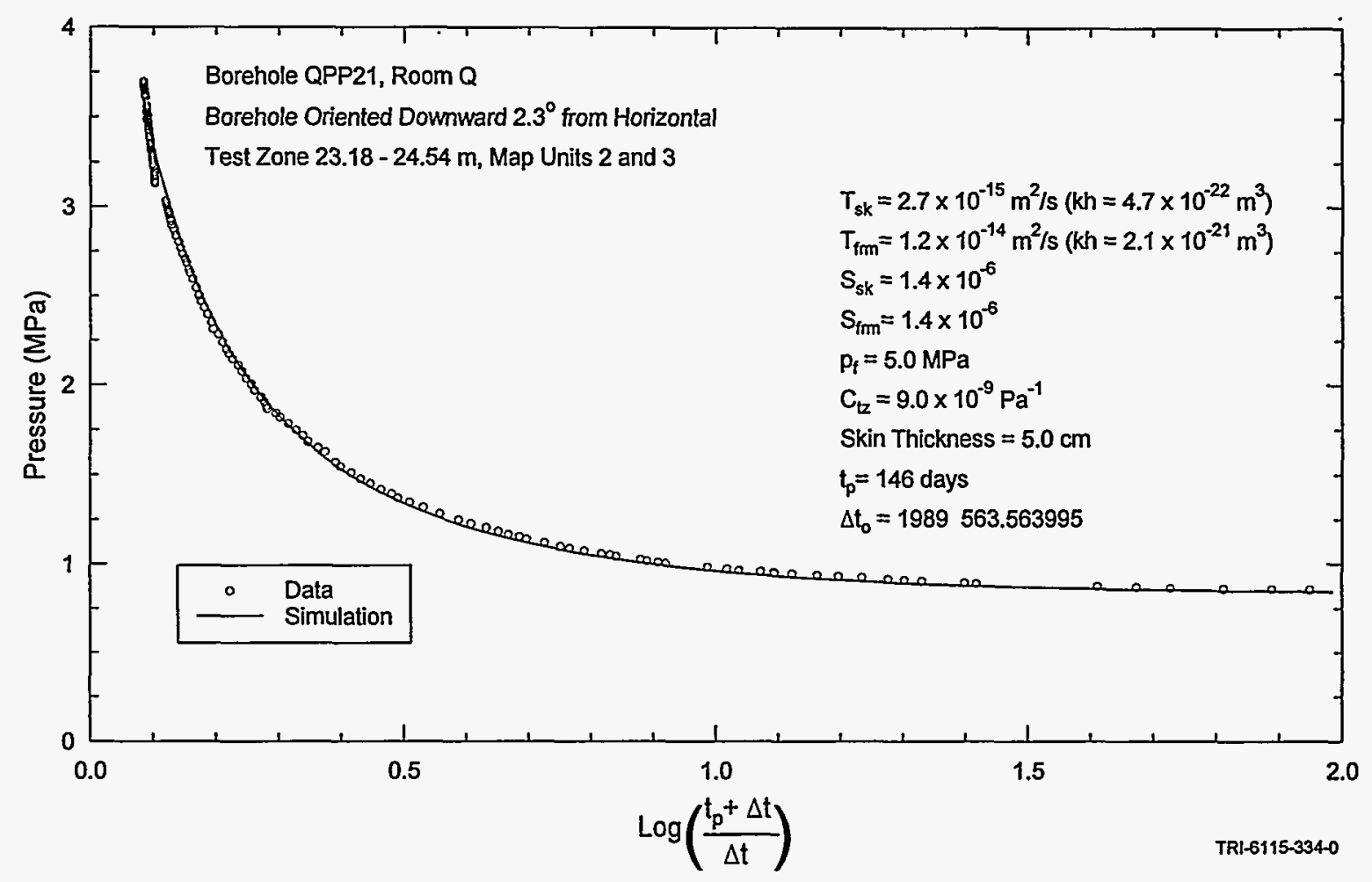

Figure 7-82. GTFM Horner simulation of the QPP21 post-flow-test pressure buildup.

response after mining and $9.0 \times 10^{-9} \mathrm{~Pa}^{-1}$ for the pressure response following the constantpressure flow test. The increased test-zone compressibility following the flow test could indicate that gas was exsolving from solution due to the low-pressure regime imposed during the flow test.

\subsubsection{Guard Zone.}

The complete QPP21 guard-zone pressure record is shown in Figure 7-83. There was minimal pre-mining pressure response in the guard zone, probably because of packer-inflation problems (see Figure A-11). The post-mining data were also affected by packer-inflation problems. However, the late-time data indicate that the packer problems were corrected, at which time the guard-zone pressure began a steady increase. A Horner plot of the post-mining data provides a formation pore pressure estimate of about $7.5 \mathrm{MPa}$ (Figure 7-84).

\subsubsection{Summary.}

Prior to mining, neither the test zone nor guard zone in QPP21 displayed significant pressure responses. In the post-mining environment, however, both zones displayed definite pressure responses, probably reflecting increased permeability. If transmissivity is uniformly distributed along the 1.36-m length of the QPP21 test zone, the average pre-mining hydraulic conductivity was $\leq 5 \times 10^{-16} \mathrm{~m} / \mathrm{s}$ (permeability $\leq 9 \times$ $10^{-23} \mathrm{~m}^{2}$ ). The average pre-mining specific storage was $2 \times 10^{-6} \mathrm{~m}^{-1}$. The average postmining hydraulic conductivity was $8.8 \times 10^{-15} \mathrm{~m} / \mathrm{s}$ (permeability of $1.6 \times 10^{-21} \mathrm{~m}^{2}$ ) and the average specific storage was $1.0 \times 10^{-6} \mathrm{~m}^{-1}$. 


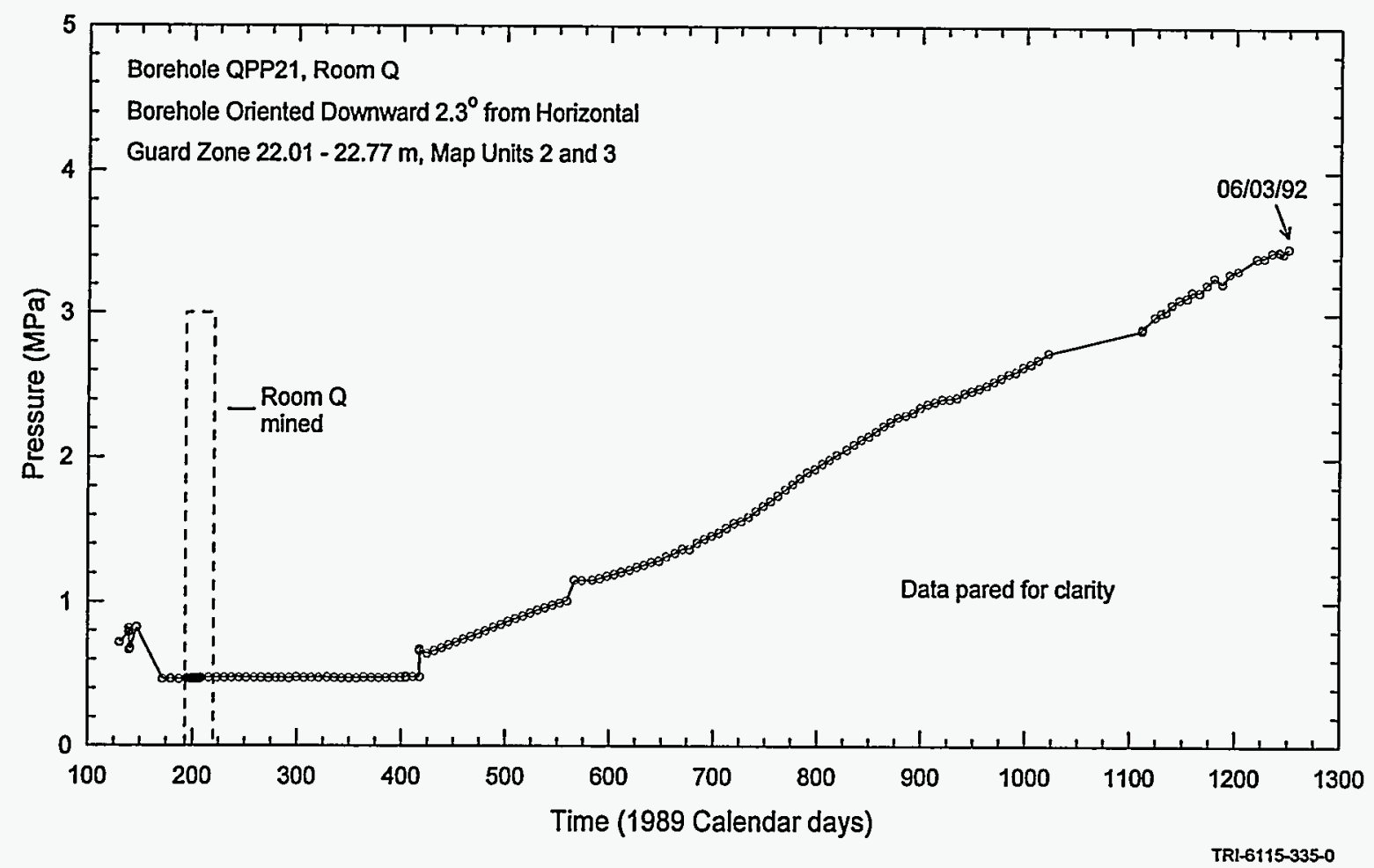

Figure 7-83. QPP21 guard-zone pressure.

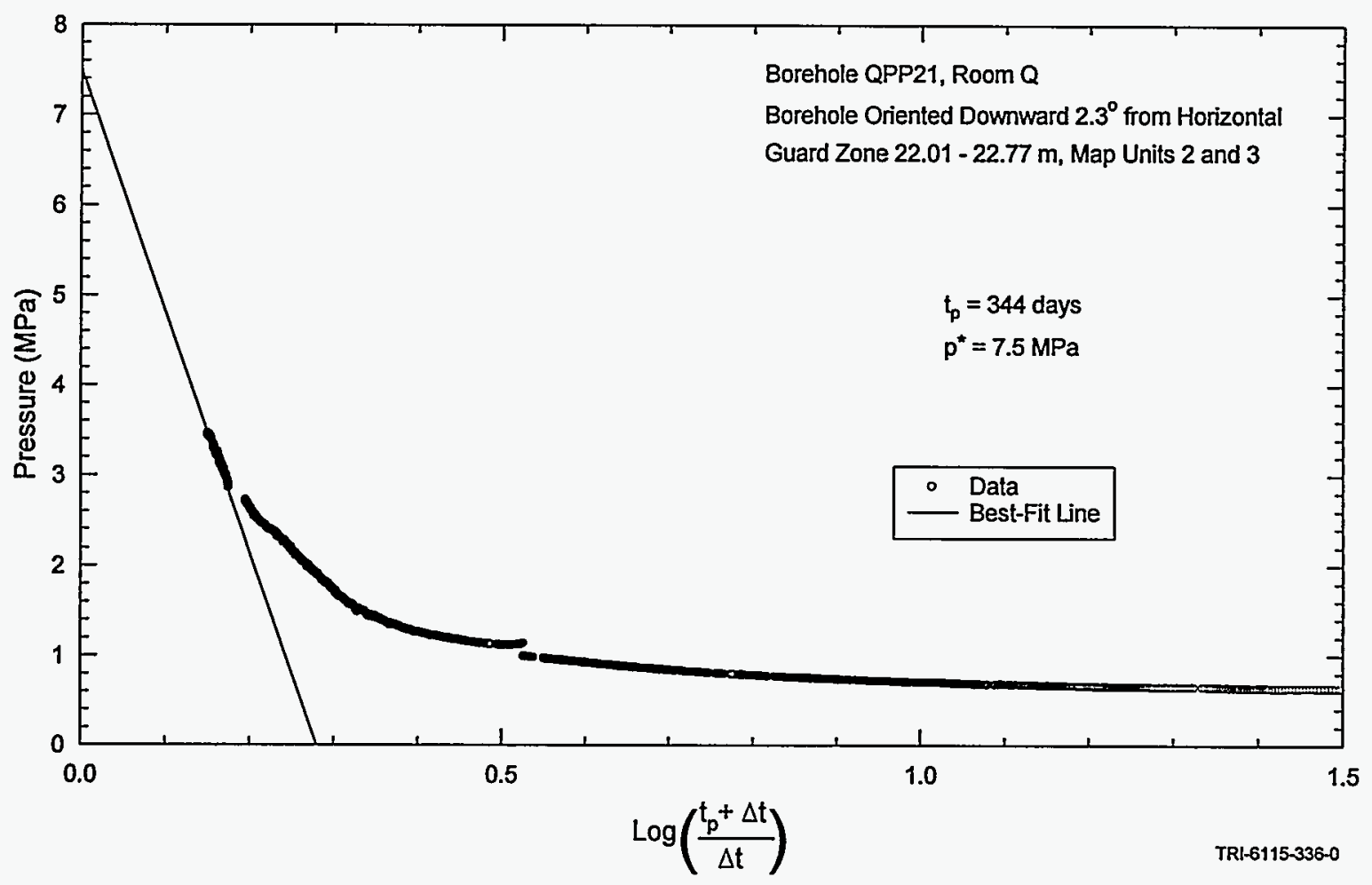

Figure 7-84. Horner plot of the QPP21 post-mining guard-zone pressure. 


\subsubsection{QPP22}

The survey data indicate the test zone of borehole QPP22 is in map unit 3. Map unit 3 is halite containing up to $1 \%$ polyhalite (Deal et al., 1989).

The complete pressure record from the QPP22 test zone is shown in Figure 7-85. Before Room $Q$ was mined, the test-zone pressure rose erratically (see Figure 7-86). The test-zone pressure may have been limited by the ability of the packer, which was continually losing pressure and having to be reinflated (Figure A-12), to hold it. The test-zone pressure was about $8.7 \mathrm{MPa}$ when mining began, and decreased by about $0.6 \mathrm{MPa}$ when mining progressed past the borehole (Figure 7-86). For about 200 days after mining, the testzone pressure generally decreased except during periods immediately after the packer-inflation pressure had been increased. Again, pressures may have been limited by the packer and not by the formation pore pressure.

When the test-zone pressure was decreased on February 21, 1990 (1989 Calendar day 417) to initiate a constant-pressure flow test, the flow line to the brine accumulator was obstructed and the test-zone pressure began to increase in a pulse-test-like response. The pressure increased from 0.9 to $3.2 \mathrm{MPa}$ before the flow line was cleared on May 2, 1990 (1989 Calendar day 487). After the flow line was cleared, the test-zone pressure was again decreased to about $0.9 \mathrm{MPa}$ for the flow test. The test-zone pressure thereafter increased uniformly, presumably in response to filling of the brine accumulator, until the flow test was terminated on July 18, 1990 (1989 Calendar day 564). However, the data from the brine accumulator (Figure 7-87) show that flow effectively stopped on about June 19, 1990 (1989 Calendar day 535). If flow into the accumulator had ceased, perhaps because the

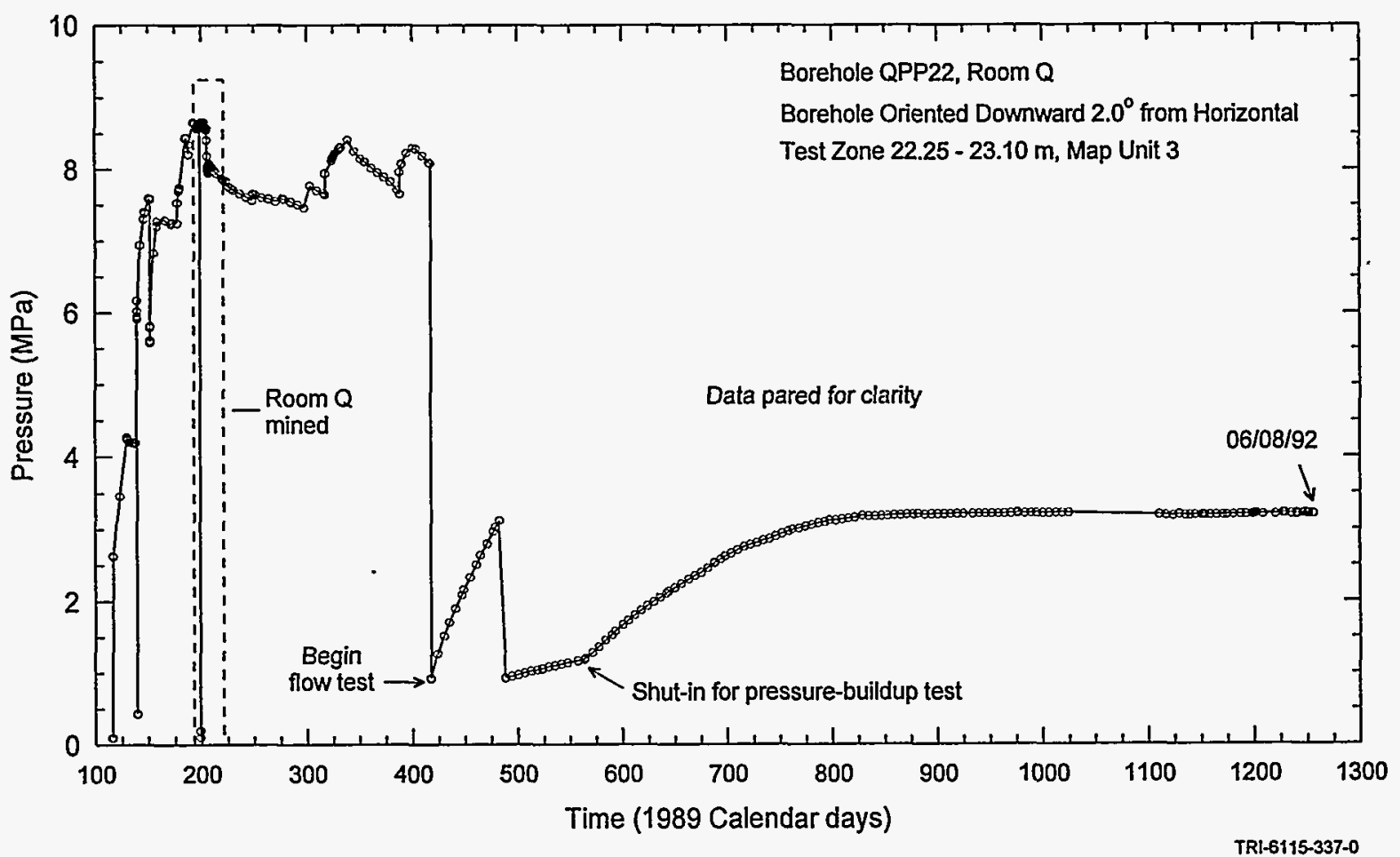

Figure 7-85. QPP22 test-zone pressure. 


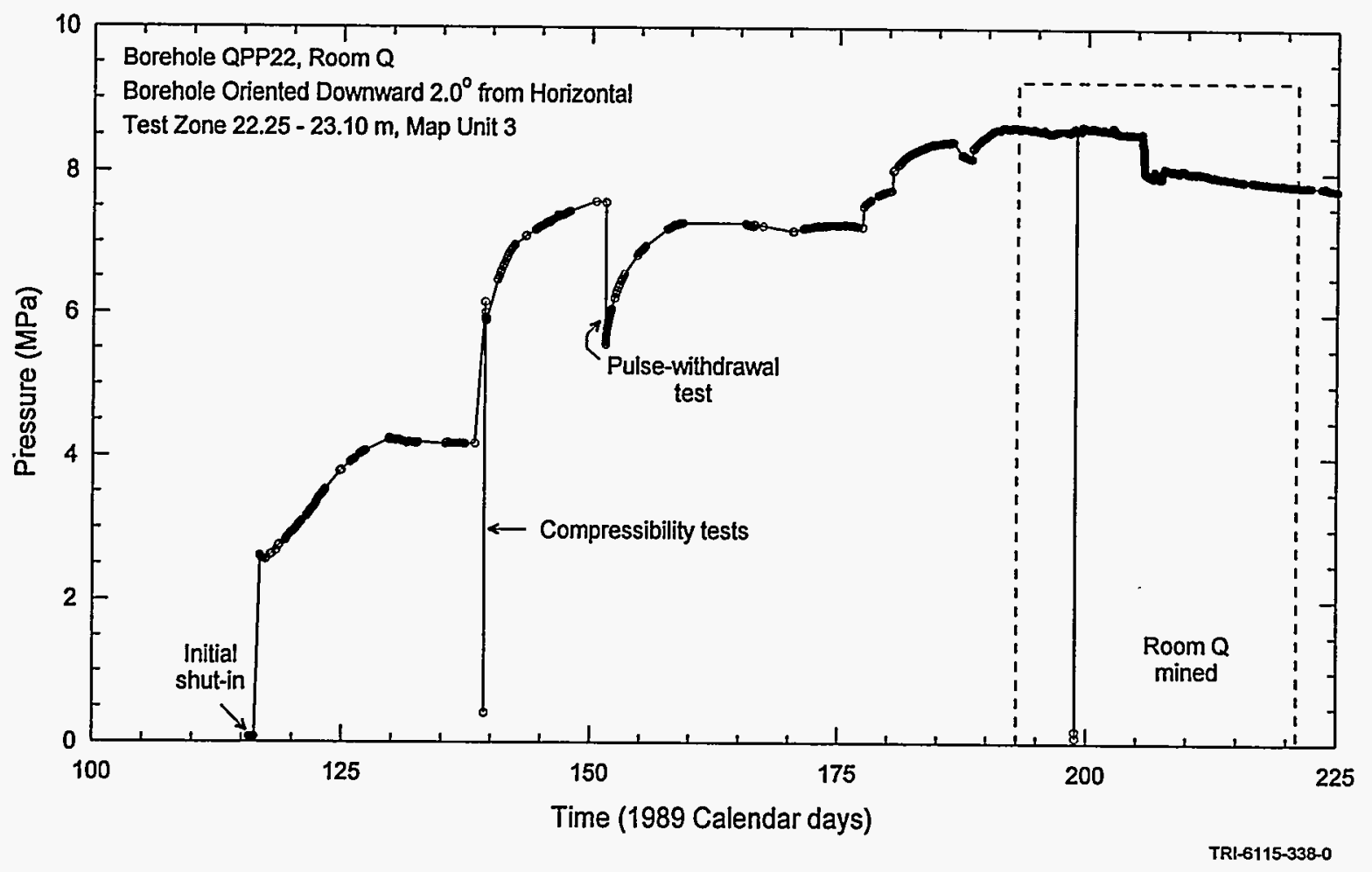

Figure 7-86. QPP22 pre-mining and mining test-zone pressure.

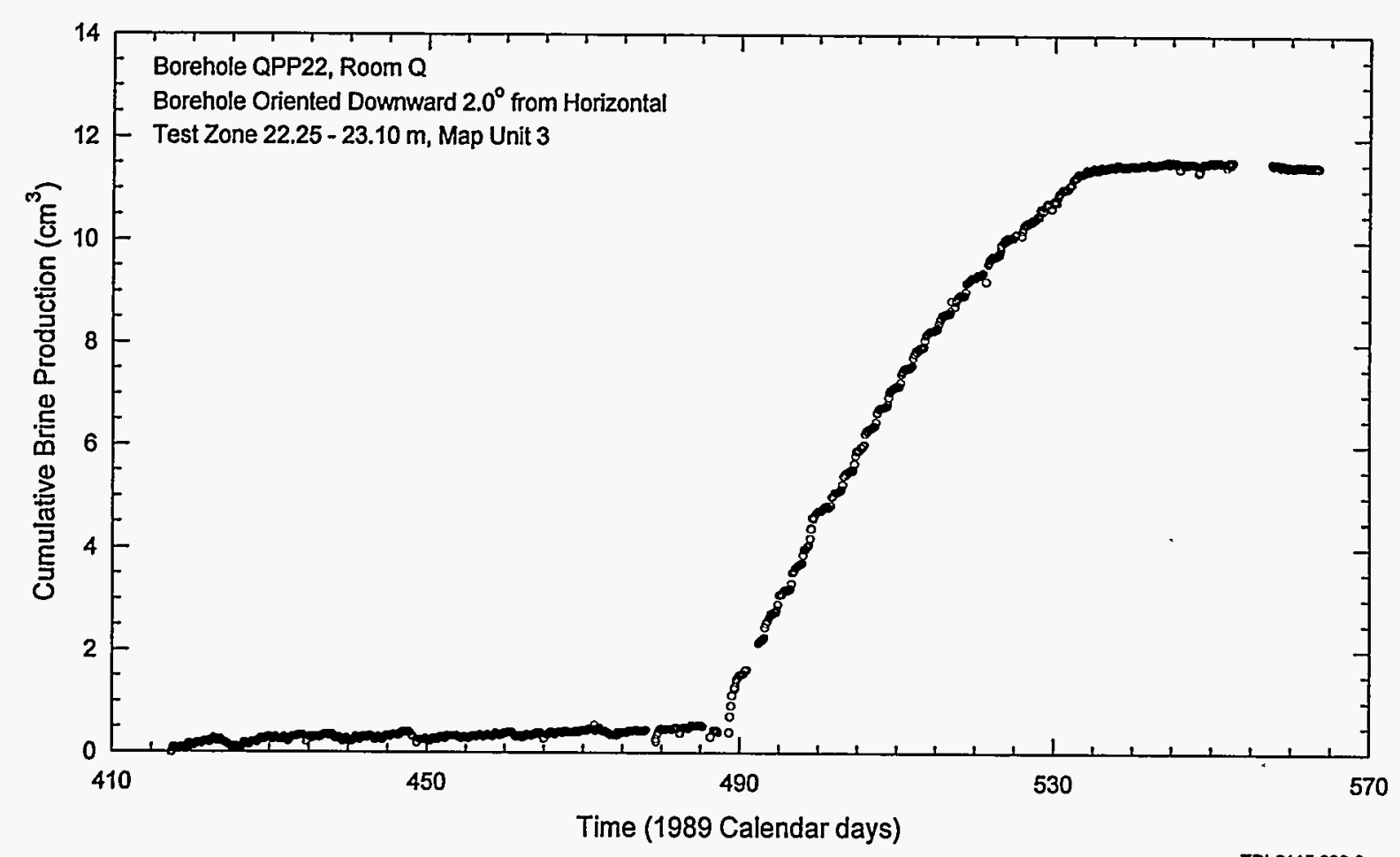

Figure 7-87. QPP22 test-zone brine production 
flow line had again become obstructed, the pressure in the test zone should have begun to increase more rapidly. Instead, the pressure increase stayed on the same trend as when brine was flowing into the accumulator until the test zone was shut-in on July 18,1990, at which time the pressure increase accelerated. Therefore, we conclude that the accumulator data showing no flow are in error.

Whereas the pressure buildup observed after the initial failed attempt to start the flow test was relatively rapid and appeared likely to reach the pretest level of about $8 \mathrm{MPa}$, the pressure buildup observed after the flow test was relatively slow and stopped completely at about $3.2 \mathrm{MPa}$ (Figure 7-85). We suspect, but cannot be certain, that this anomalous pressure behavior is related to the malfunctioning of the packer (see Figure A-12).

Numerical Interpretations. The 36-day open-borehole period before testing began was included in GTFM simulations as a specifiedpressure history sequence. The inconsistent response of test-zone pressures from the initial shut-in through the beginning of the flow test is not suitable for analysis with GTFM and was, therefore, included as a specified-pressure history sequence. The initial buildup during the flow test and the buildup following the flow test were simulated. The portion of the flow test in which flow was not restricted was included in the GTFM simulation as a specified-pressure history sequence.

Figure 7-88 shows the best-fit GTFM simulation of the pressure buildup following the initiation of the "failed" flow test and the buildup following the more successful flow test. The bestfit GTFM simulation of the cumulative brine production is shown in Figure 7-89. The specified parameters for these simulations were a borehole radius of $1.9 \mathrm{~cm}$ and a test-zone fluid volume of $290 \mathrm{~cm}^{3}$. The fitted parameters were a

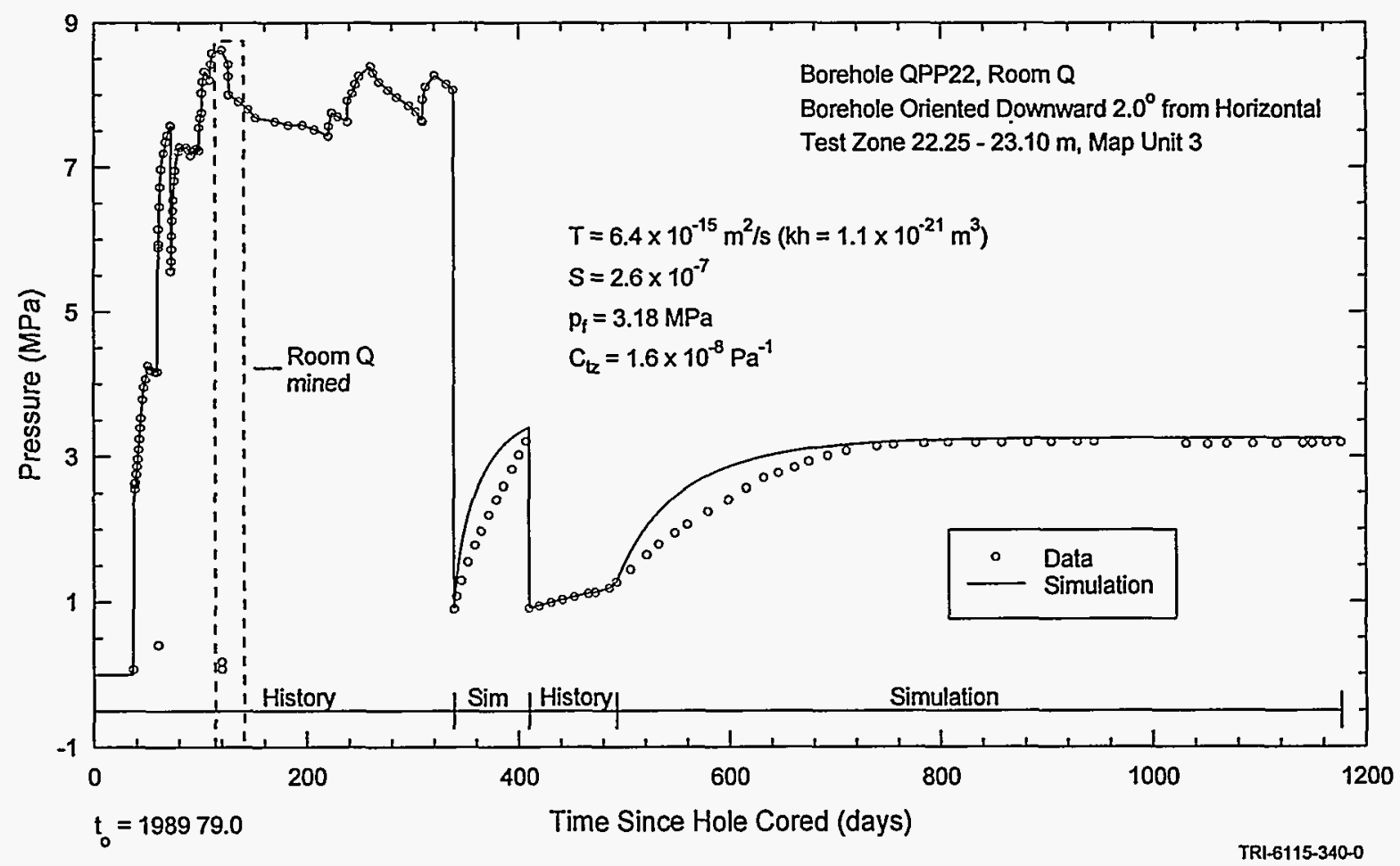

Figure 7-88. GTFM simulation of the QPP22 post-mining test-zone pressure. 


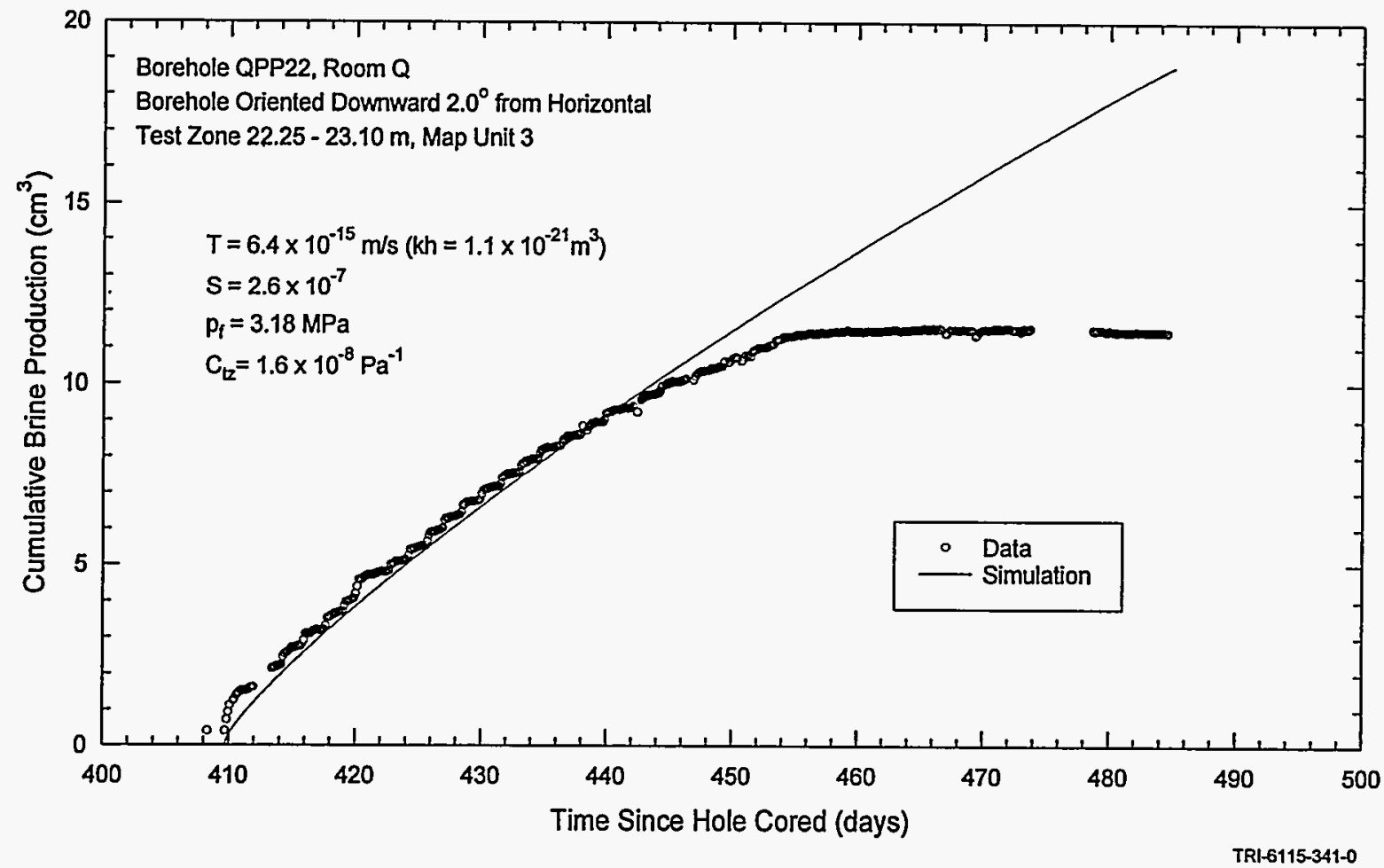

Figure 7-89. GTFM simulation of the QPP22 test-zone brine production.

transmissivity of $6.4 \times 10^{-15} \mathrm{~m}^{2} / \mathrm{s}$ (permeabilitythickness of $1.1 \times 10^{-21} \mathrm{~m}^{3}$ ), a storativity of $2.6 \mathrm{x}$ $10^{-7}$, a formation pore pressure of $3.18 \mathrm{MPa}$, and a test-zone compressibility of $1.6 \times 10^{-8} \mathrm{~Pa}^{-1}$. Assuming that hydraulic properties are uniform over the $0.85-\mathrm{m}$ length of the test zone, the average hydraulic conductivity of the tested portion of map unit 3 is $7.5 \times 10^{-15} \mathrm{~m} / \mathrm{s}$ (permeability of 1.3 $\times 10^{-21} \mathrm{~m}^{2}$ ) and the average specific storage is 3.1 $\times 10^{-7} \mathrm{~m}^{-1}$.

The entire interpretation of the QPP22 tests must be considered highly uncertain because of doubts about the degree of isolation of the test zone provided by the packer, and because of the questionable quality of the data.

\subsubsection{QPP23}

The survey information indicates that the test and guard zones of borehole QPP23 are located in map unit 3 , a relatively pure halite unit typically containing up to $1 \%$ polyhalite (Deal et al., 1989).

\subsubsection{Test Zone.}

The complete record of pressures observed in the QPP23 test zone is shown in Figure 7-90. The pressure for the period before and during the mining of Room $Q$ is shown in Figure 7-91. The operational log indicates that the test-zone packer leaked, requiring that the test-zone packer pressure be increased numerous times throughout the first 565 days of testing (see Figure A-13), causing fluctuations in the test-zone pressure.

On February 21, 1990 (1989 Calendar day 417), a flow test was initiated by reducing the testzone pressure from 5.27 to $1.05 \mathrm{MPa}$. Figure 7-92 presents cumulative brine-inflow volumes. A total of $130 \mathrm{~cm}^{3}$ of brine was recovered during the 147 - 


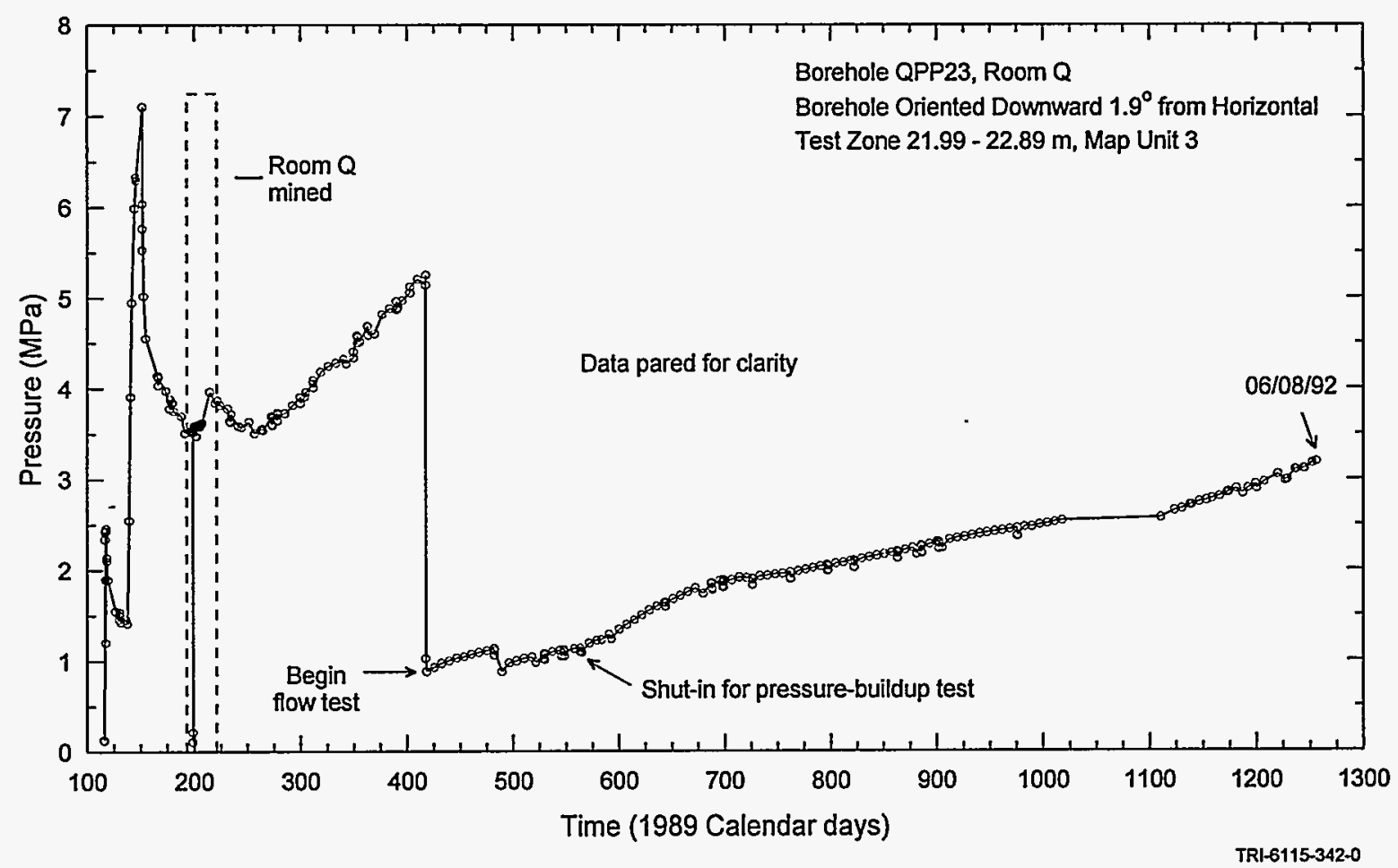

Figure 7-90. QPP23 test-zone pressure.

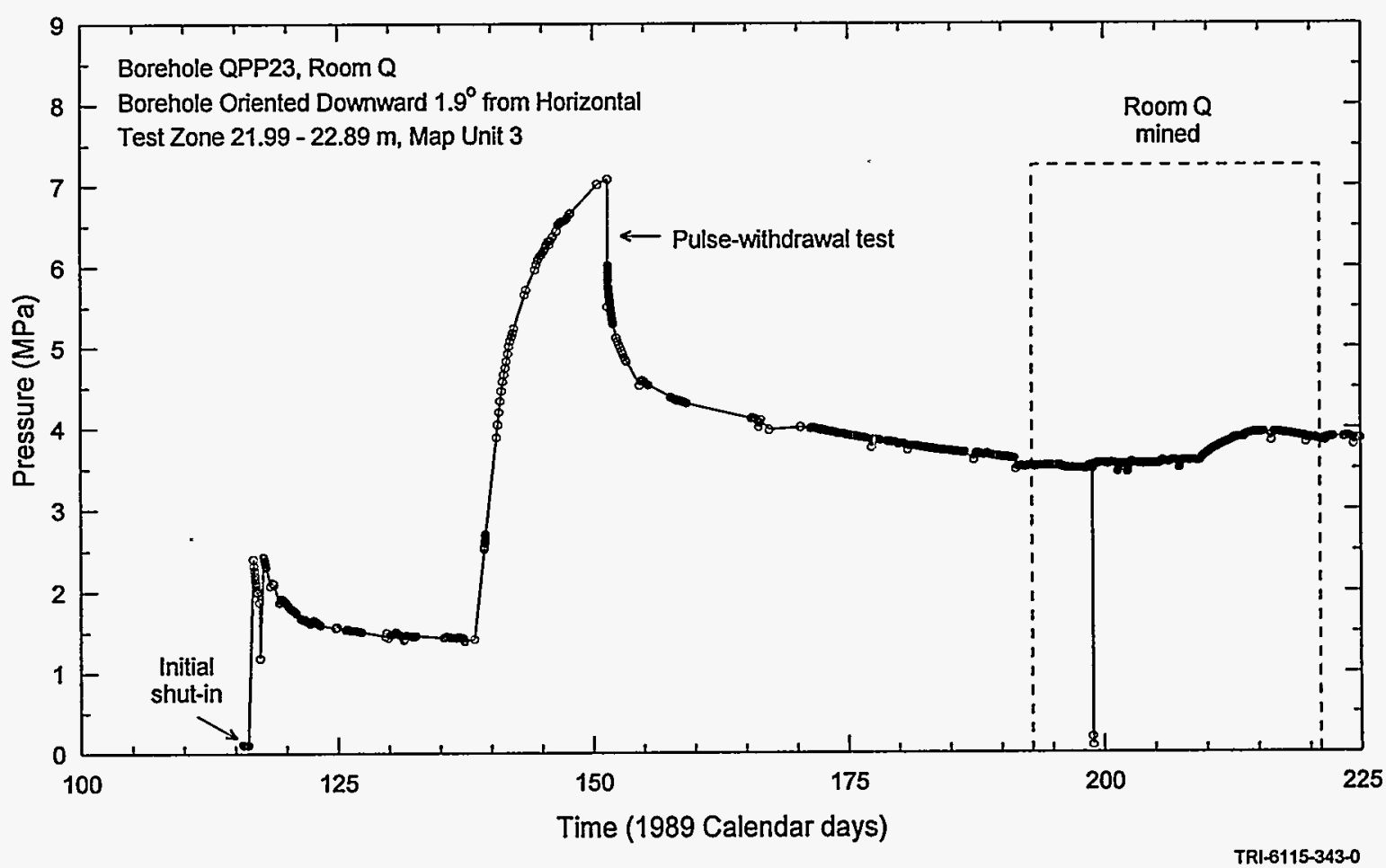

Figure 7-91. QPP23 pre-mining and mining test-zone pressure. 


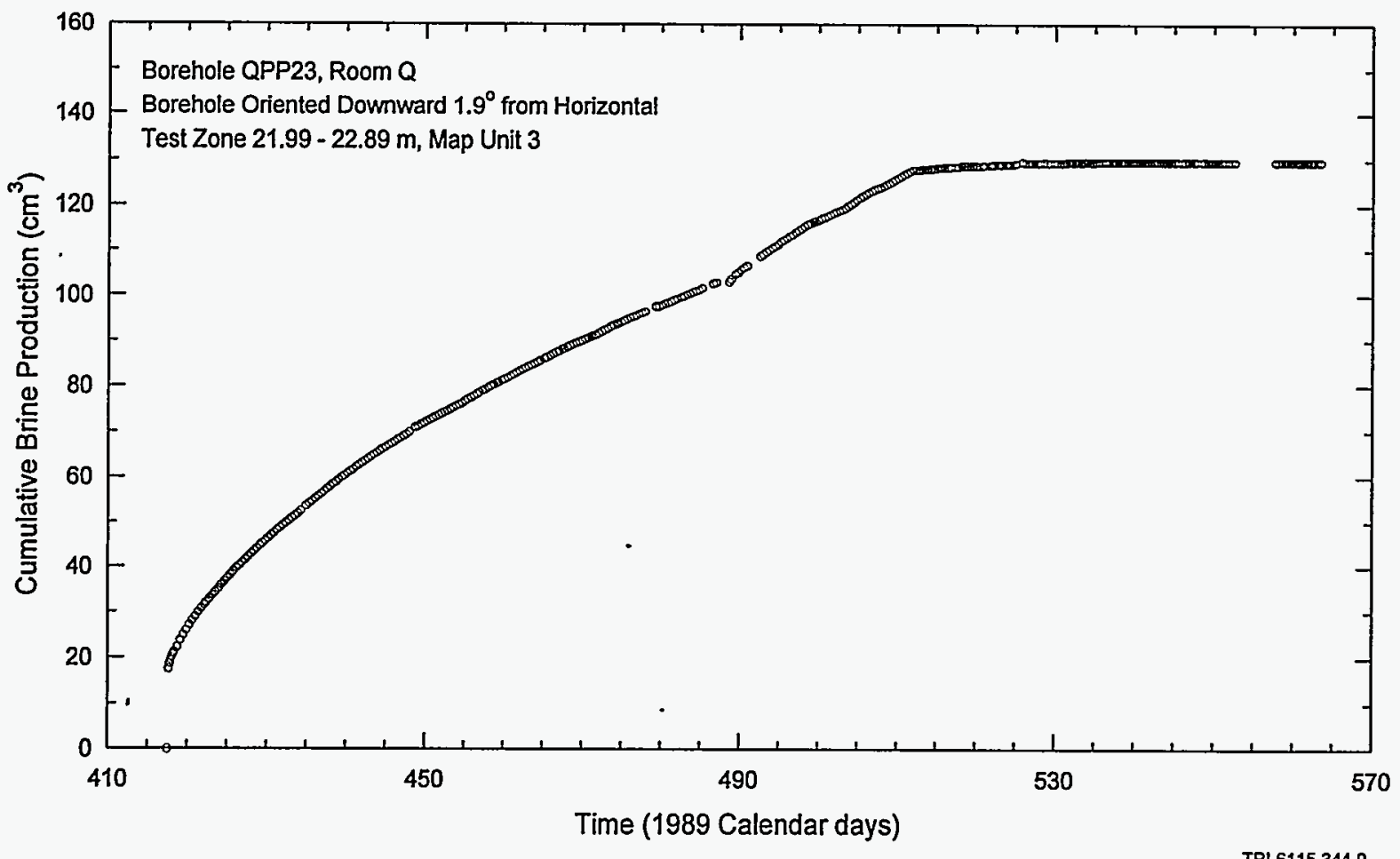

Figure 7-92. QPP23 test-zone brine production.

day flow test. The brine accumulator was drained once during the flow test. The operational logs contain no explanation for the reduced brine production observed during the final 50 days of the flow test. The decrease in brine production does not appear to be correlated with changes in either the zone or packer pressures. Therefore, no explanation is available for the decreased brine production. The flow test was terminated on July 18,1990 (1989 Calendar day 564) by shutting in the test zone and allowing pressures to increase.

Numerical Interpretations. The QPP23 testing was preceded by a 36-day period during which the borehole was at atmospheric pressure. This open-borehole period was included in GTFM simulations as a specified-pressure sequence. The inconsistent pressure behavior of the testzone pressures from the initial shut-in through the beginning of the flow test is not suitable for analysis with GTFM and was, therefore, included as a specified-pressure sequence. The test-zone pressures during the flow test were also included as a specified-pressure sequence. Only the cumulative formation production and flow rate were simulated in GTFM because the pressure recovery following the flow test was believed to be not representative of the formation response.

GTFM assumes radial flow to a circular test zone oriented perpendicular to the unit being tested. Therefore, because QPP23 is oriented essentially parallel to the bedding, the formation thickness was assumed to be equivalent to the length of the test zone. The borehole radius included in the GTFM simulation was taken to be the cored radius of the borehole.

Figures 7-93 and 7-94 show the best-fit GTFM simulations of the brine-inflow volume and the brine-inflow rate. Both simulations were generated using the same specified and fitted parameters. The specified parameters for these simulations were a borehole radius of $1.905 \mathrm{~cm}$, a 


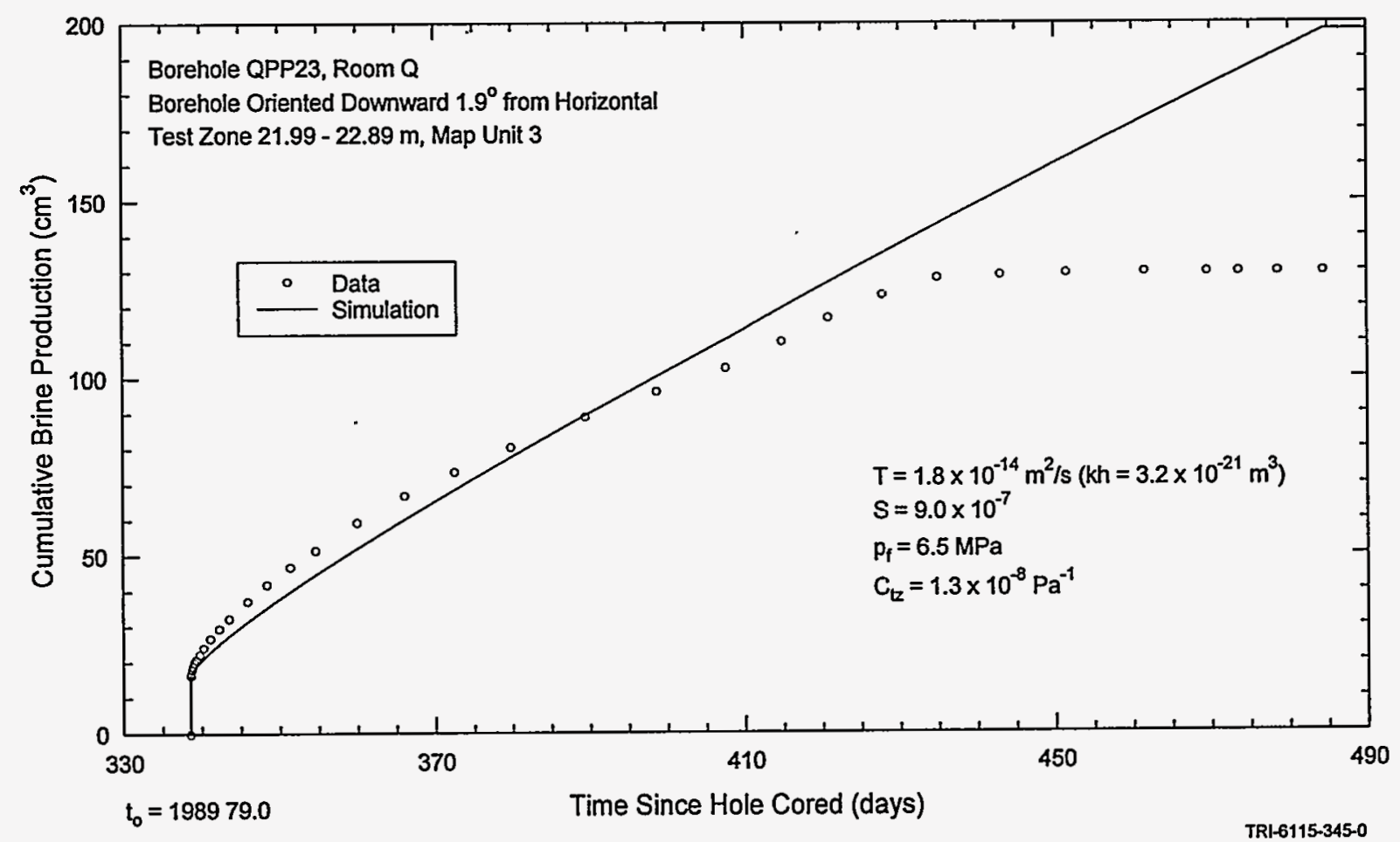

Figure 7-93. GTFM simulation of the QPP23 test-zone brine production.

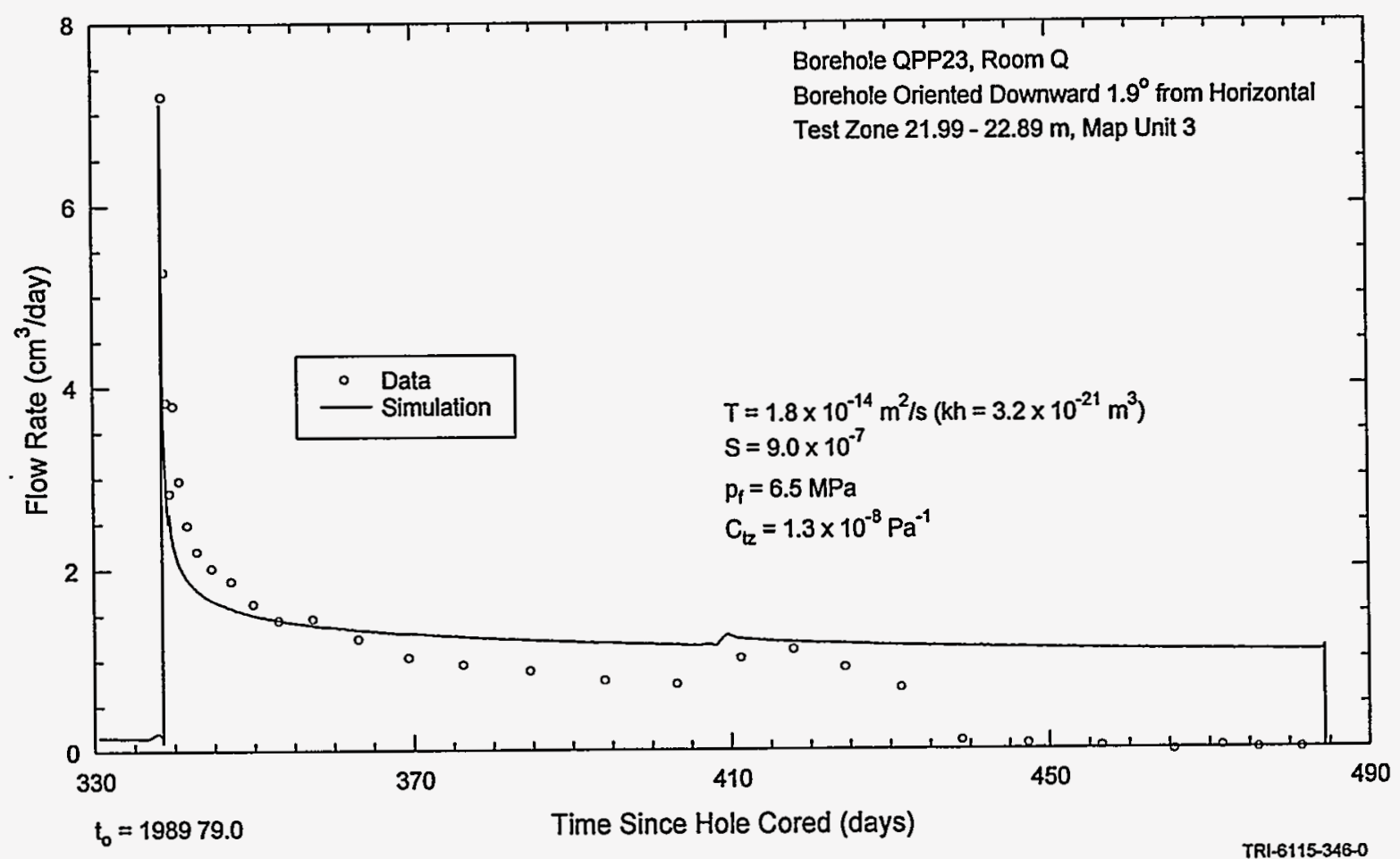

Figure 7-94. GTFM simulation of the QPP23 flow rates. 
test-zone fluid volume of $300 \mathrm{~cm}^{3}$, a formation pore pressure of $6.5 \mathrm{MPa}$, and a test-zone compressibility of $1.3 \times 10^{-8} \mathrm{~Pa}^{-1}$. The formation pore pressure was set to $6.5 \mathrm{MPa}$ based on the post-mining extrapolated pressure from the guard zone. Use of this pressure is justified because the test and guard zones are both in map unit 3 , and because as of March 10,1995, the pressures in the test and guard zones of QPP23 were 6.4 MPa (Appendix B). The test-zone compressibility was calculated based on the initial volume of fluid produced and the associated pressure change at the beginning of the constant-pressure flow test. The fitted parameters were a formation transmissivity of $1.8 \times 10^{-14} \mathrm{~m}^{2} / \mathrm{s}$ (permeabilitythickness of $3.2 \times 10^{-21} \mathrm{~m}^{3}$ ) and a formation storativity of $9.0 \times 10^{-7}$. The fitted parameters have a high uncertainty because of the questionable quality of the data.

\subsubsection{Guard Zone.}

The complete guard-zone pressure record is shown in Figure 7-95. The drop in the guardzone pressure on February 21, 1990 (1989 Calendar day 417) is coincident with the start of the constant-pressure flow test in the test zone. The cause of the pressure drop is thought to be due to the malfunctioning test-zone packer, as is the lack of pressure recovery at the termination of the testzone flow test.

A Horner plot of the pre-mining pressure buildup is shown in Figure 7-96, providing an initial formation pore pressure estimate of $9.8 \mathrm{MPa}$ for map unit 3. Figure 7-97 shows a Horner plot of the post-mining pressure-buildup data before the zone lost pressure during the test-zone flow test. The pore pressure for the post-mining period was

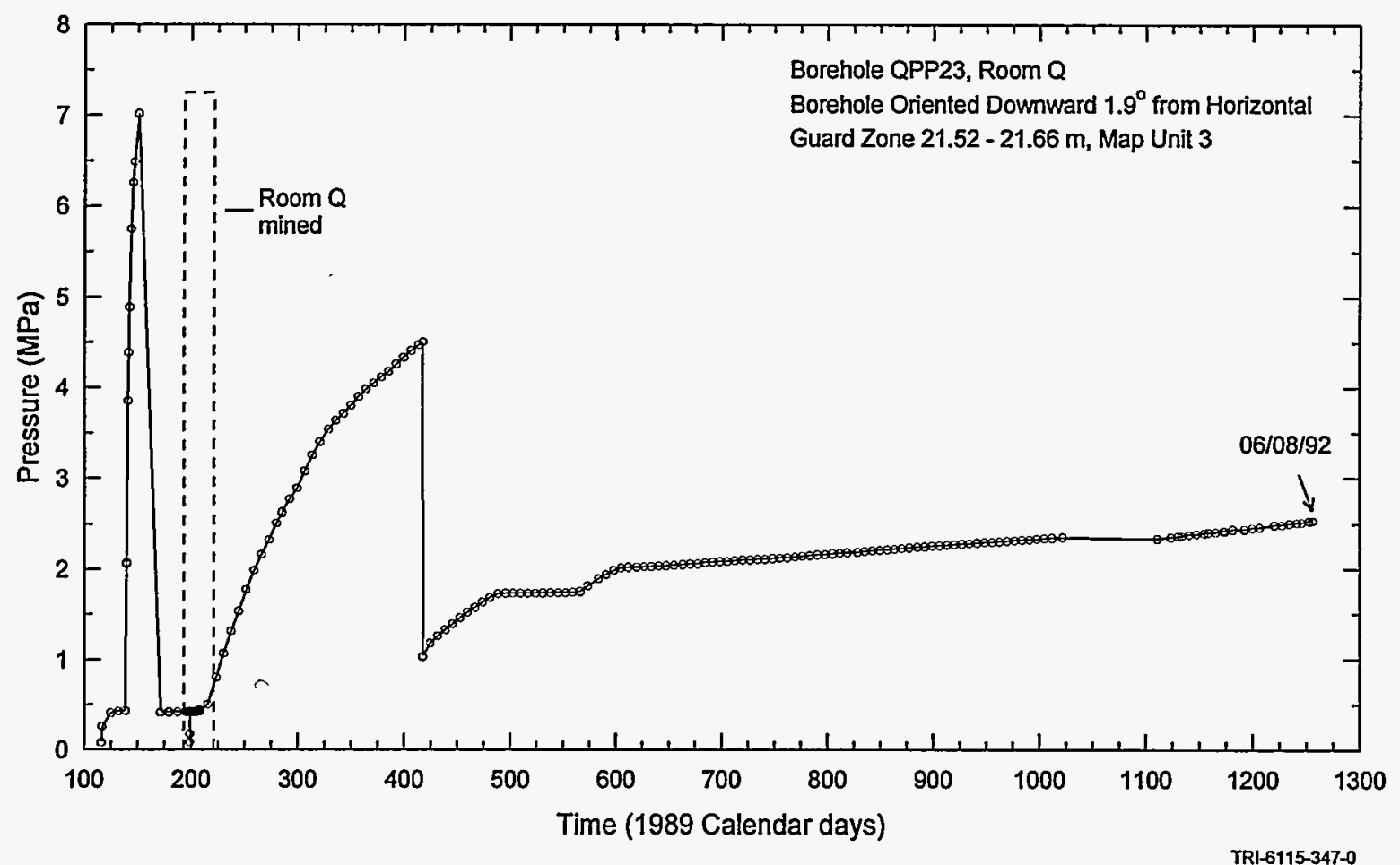

Figure 7-95. QPP23 guard-zone pressure. 


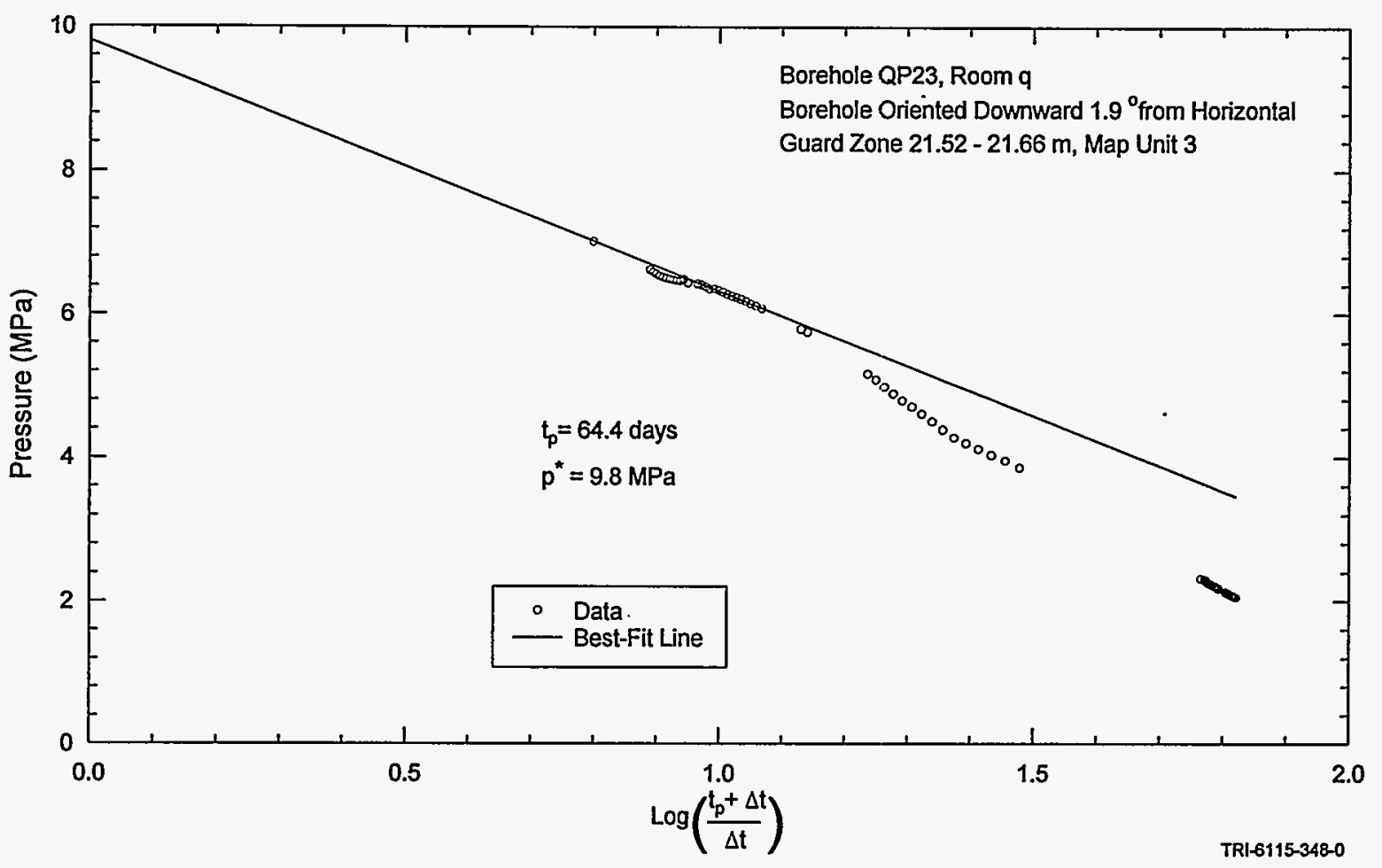

Figure 7-96. Horner plot of the QPP23 pre-mining guard-zone pressure.

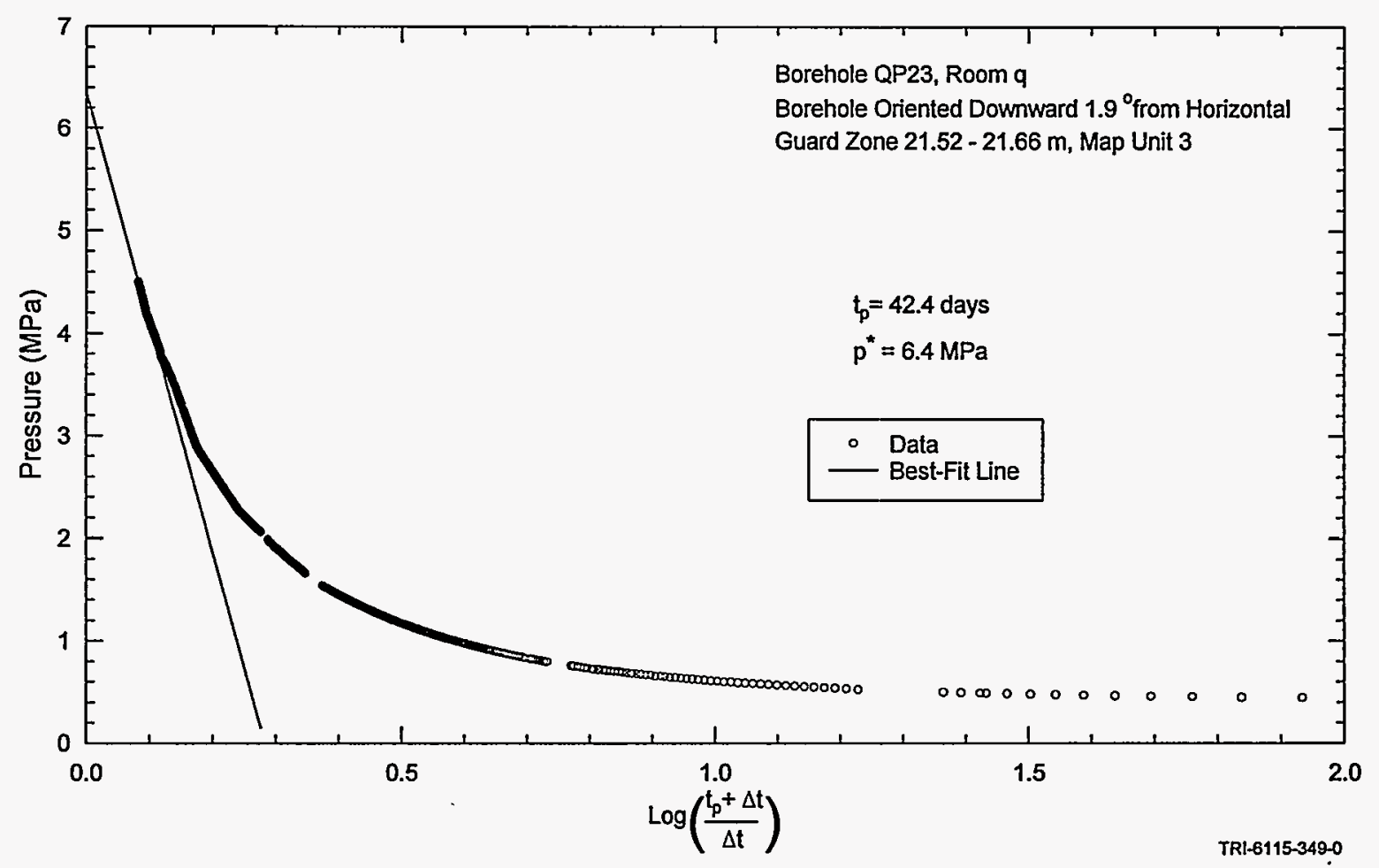

Figure 7-97. Horner plot of the QPP23 post-mining guard-zone pressure. 
estimated at 6.4 MPa. This estimate has since been confirmed by pressure measurements in QPP23 using refurbished packer tools (Appendix B).

\subsubsection{Summary.}

The parameter values interpreted from the post-mining testing of the QPP23 test zone are highly uncertain. If transmissivity is uniformly distributed along the $0.90-\mathrm{m}$ length of the test zone, the average hydraulic conductivity is approximately $2.0 \times 10^{-14} \mathrm{~m} / \mathrm{s}$ (permeability of $3.5 \times$ $10^{-21} \mathrm{~m}^{2}$ ). The average specific storage is $1.0 \mathrm{x}$ $10^{-6} \mathrm{~m}^{-1}$.

Both the test and guard zones were contained in map unit 3 and are expected to have similar behavior. Based on the guard-zone pressure data, the formation pore pressure decreased from $9.8 \mathrm{MPa}$ before mining to $6.4 \mathrm{MPa}$ following mining. The post-mining pressure estimate is consistent with March 1995 pressure measurements (Appendix B).

\subsubsection{QPP24}

The survey data indicate that the test zone of borehole QPP24 is located in map unit 2, an argillaceous halite unit containing up to $3 \%$ clay (Deal et al., 1989). Because of uncertainty in the extrapolation of stratigraphy, however, the QPP24 test zone could lie anywhere between the upper portion of map unit 0 and the lower portion of map unit 3.

The complete pressure record from the QPP24 tests is shown in Figure 7-98, and the pressure record before and during mining is shown in Figure 7-99. The pressure responses observed in the QPP24 test zone are not considered to be interpretable. The initial pressure buildup in QPP24 after shut-in appeared to be trending

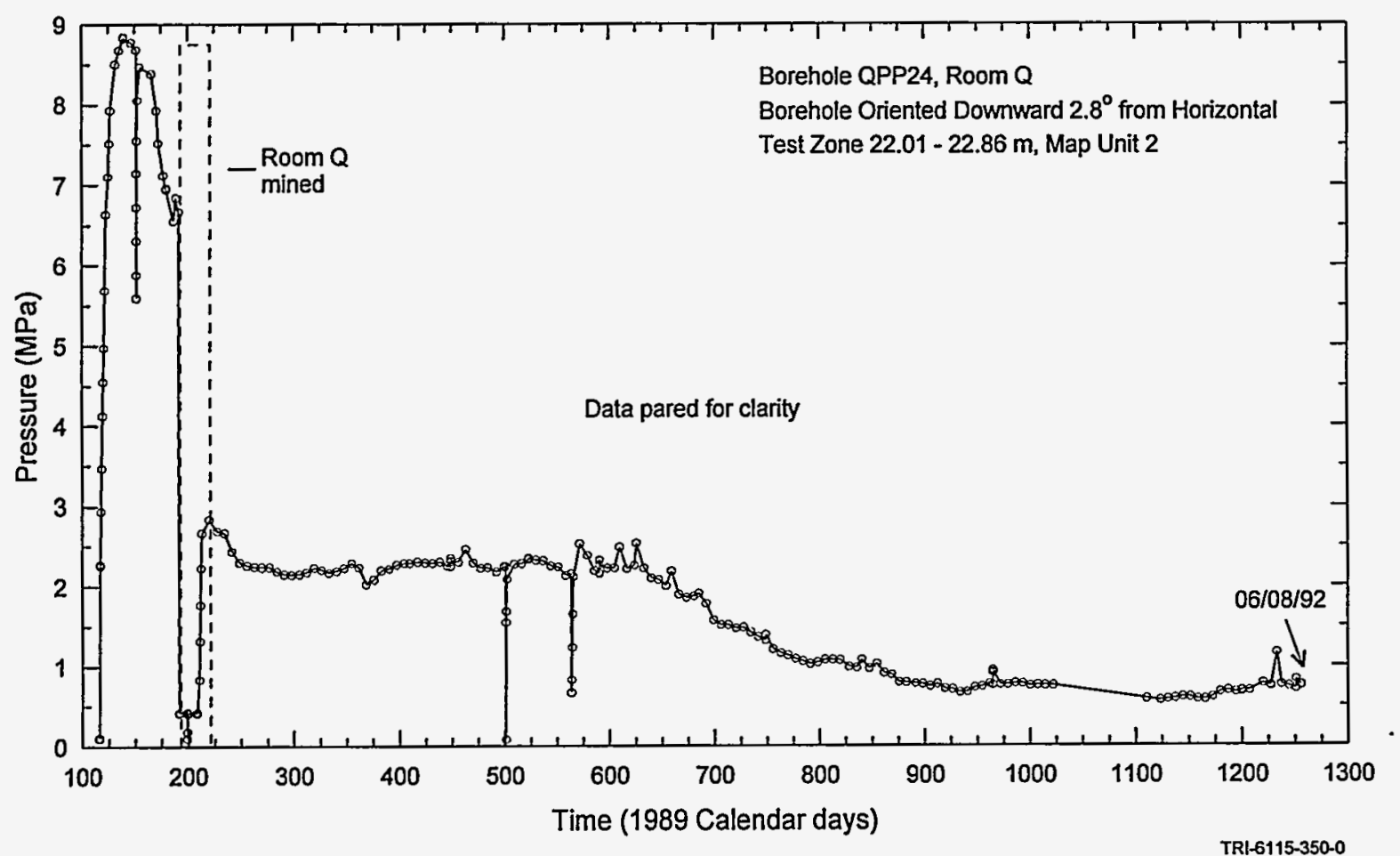

Figure 7-98. QPP24 test-zone pressure. 


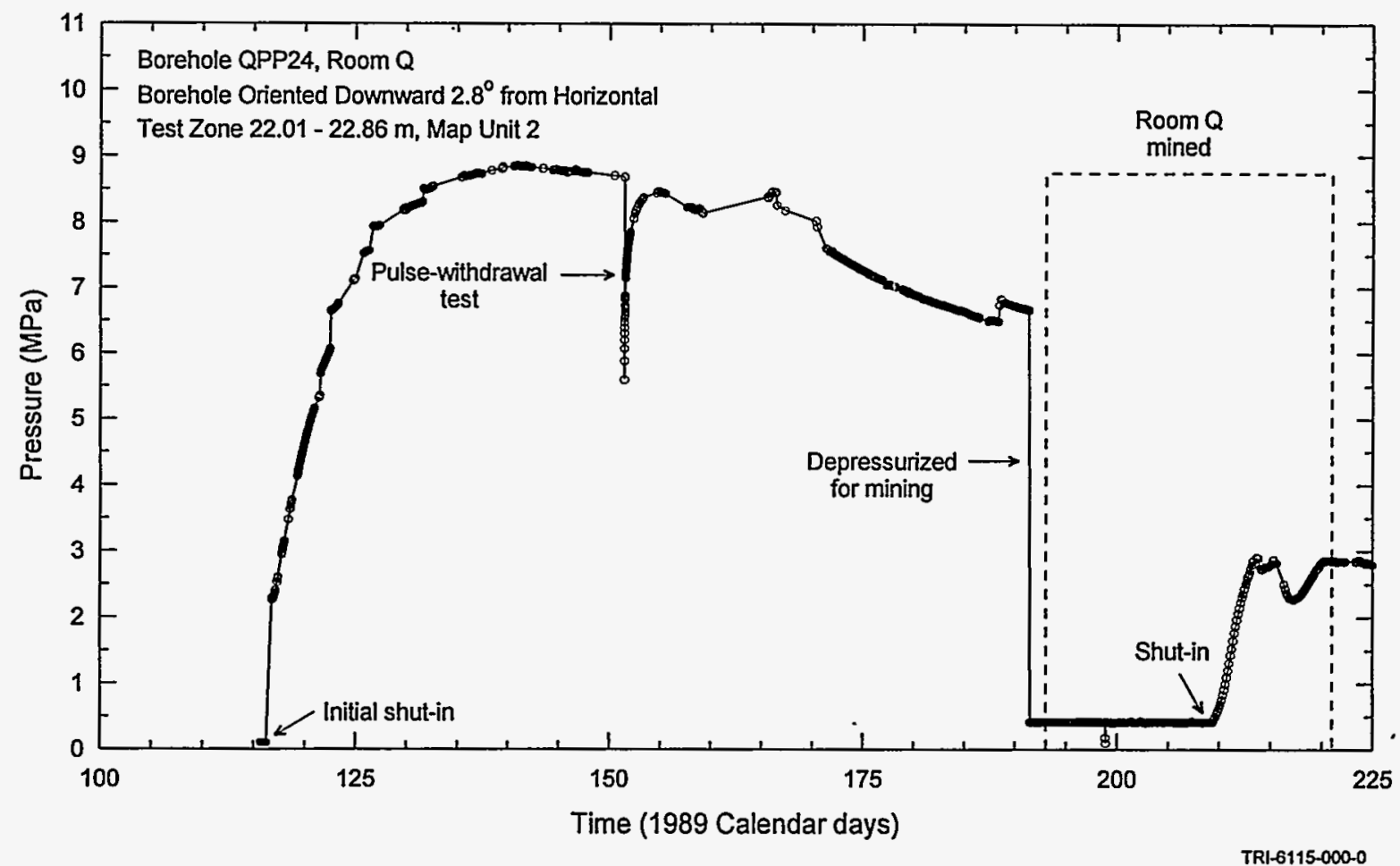

Figure 7-99. QPP24 pre-mining and mining test-zone pressure.

toward some value greater than $9 \mathrm{MPa}$. The pressure peaked on May 20, 1989 (1989 Calendar day 140), however, and declined thereafter (Figure 7-99), perhaps because the single packer in that hole could not maintain isolation of the test zone against a nearly 9-MPa pressure differential.

After Room $Q$ was mined, the pressure in QPP24 got no higher than about $3 \mathrm{MPa}$. From approximately September 5, 1989 to September 27, 1990 (1989 Calendar days 248 to 635), the test-zone pressure oscillated between about 2.3 and $2.2 \mathrm{MPa}$. From approximately September 27 , 1990 to July 18, 1991 (1989 Calendar days 635 to 929), the test-zone pressure slowly declined to about $0.7 \mathrm{MPa}$, where it remained with minor fluctuations for the balance of the monitoring period. These changes in the pressure behavior observed in QPP24 may reflect mining-induced changes in the rock mass (see Section 8).

\subsubsection{QPP25}

The survey information suggests that the test and guard zones of borehole QPP25 lie along the contact between map units 2 and 3. Map unit 2 is an argillaceous halite unit containing up to $3 \%$ clay, and map unit 3 is a relatively pure halite unit typically containing up to $1 \%$ polyhalite (Deal et al., 1989). Because of uncertainty in the extrapolation of stratigraphy, however, the QPP25 test and guard zones could lie anywhere between map units 0 and 3 .

\subsubsection{Test Zone.}

Figure 7-100 presents the complete pressure record from the QPP25 test zone, and Figure 7-101 shows the test-zone pressure record for the period prior to and during mining. 


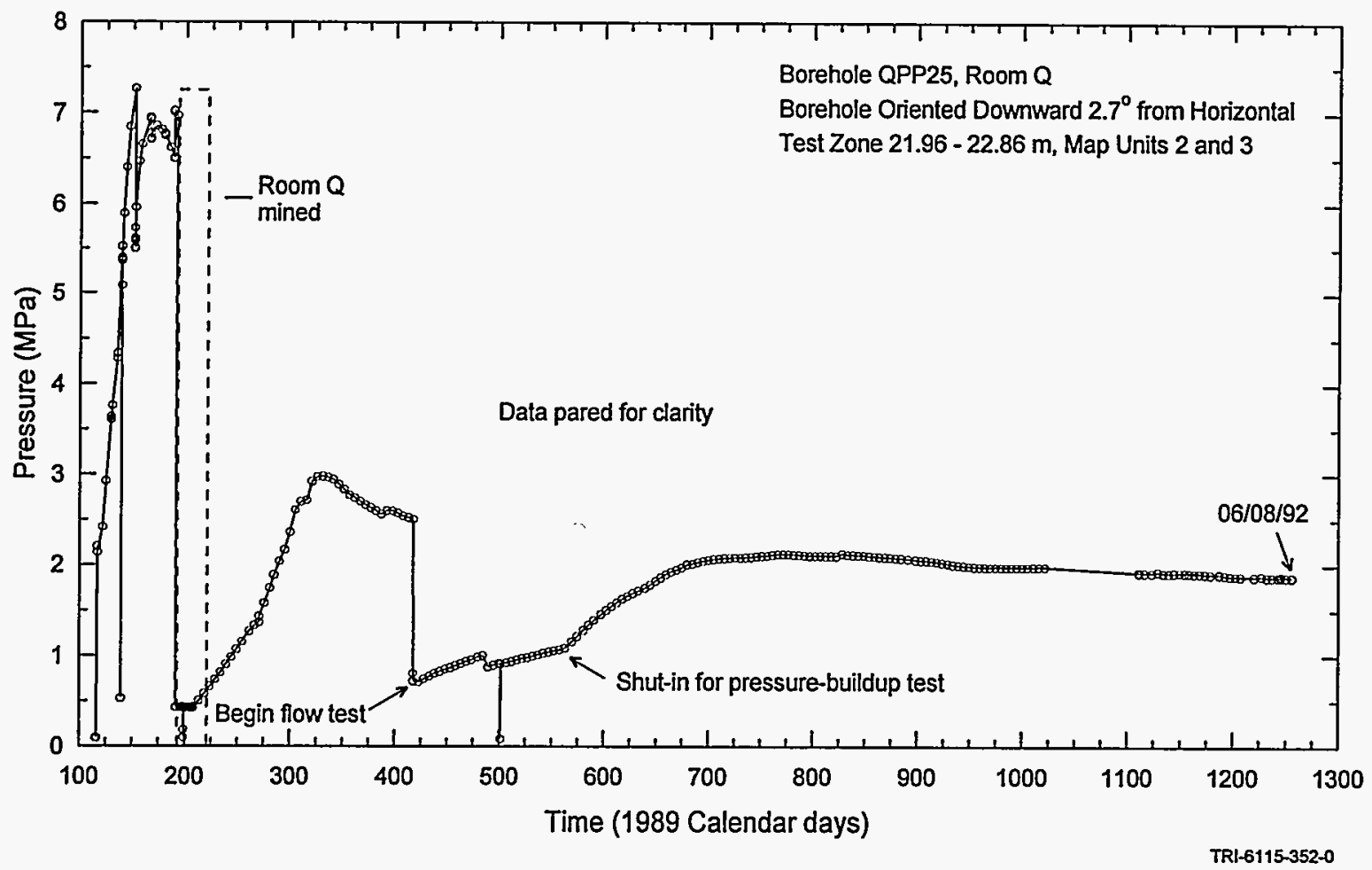

Figure 7-100. QPP25 test-zone pressure.

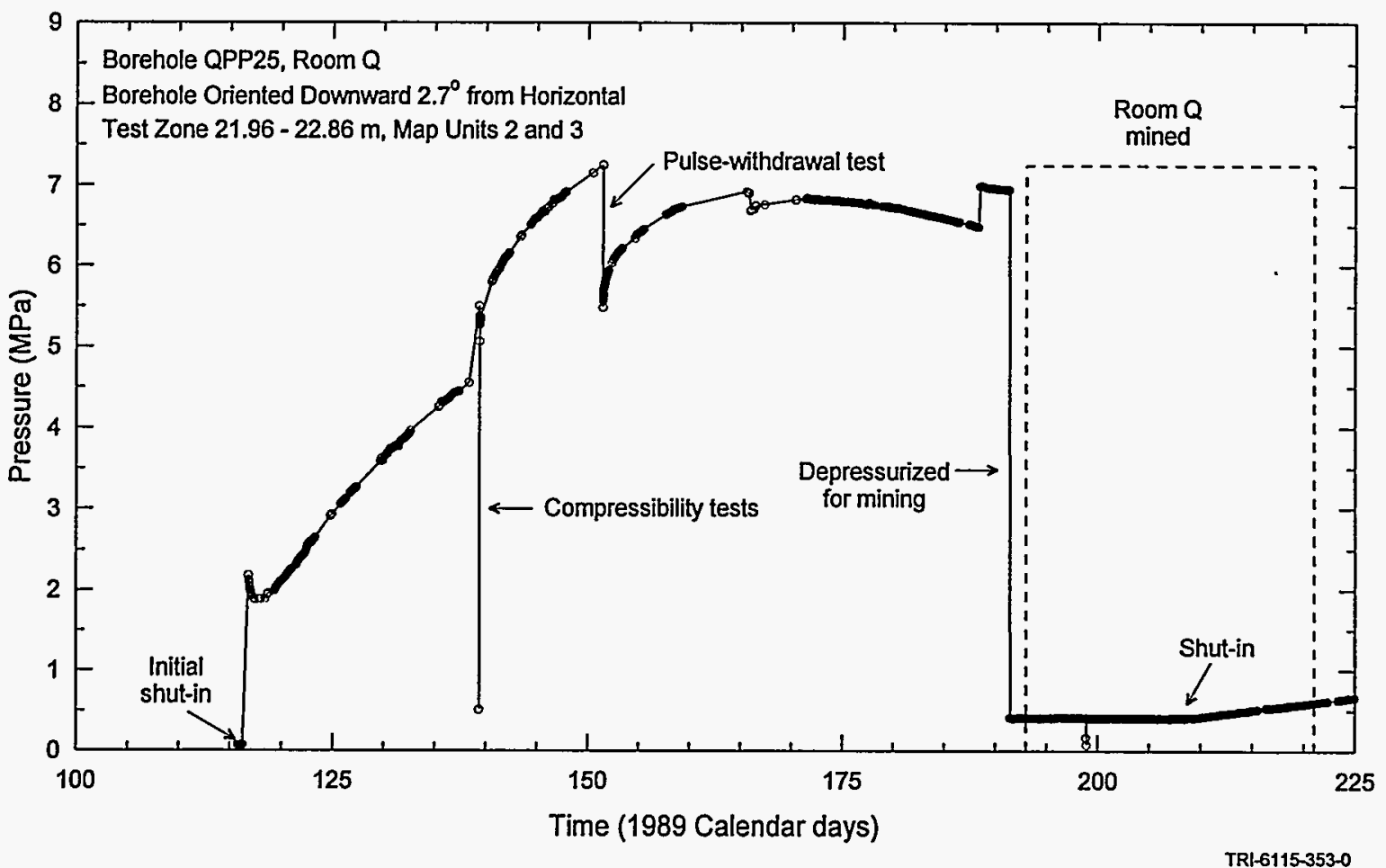

Figure 7-101. QPP25 pre-mining and mining test-zone pressure. 
Figure 7-102 presents cumulative brine-inflow volumes. A total of $85 \mathrm{~cm}^{3}$ of brine was recovered during the 147-day flow test.

The inconsistent pressure behavior observed in QPP25 prior to the mining of Room Q does not lend itself to analysis with radial, porousmedia flow models such as GTFM. The inconsistent pressure behavior following the mining of Room $Q$ and preceding the flow test also does not lend itself to analysis with GTFM. Consequently, the test-zone pressure following the mining of Room $Q$ and preceding the flow test was included in the GTFM simulations as a specifiedpressure history sequence. Additionally, the testzone pressure during the flow test was included as a specified-pressure history sequence. The significant difference in estimated formation pore pressures prior to and following the mining of Room $Q$ required that the post-mining GTFM simulations not include the pre-mining data as a specified-pressure history.

Figures 7-103, 7-104, and 7-105 show the best-fit GTFM simulations of the pressure buildup following the flow test, the brine-inflow volume, and the brine-inflow rate. All three simulations were generated using the same specified and fitted parameters. The specified parameters for these simulations were a borehole radius of $1.905 \mathrm{~cm}$ and a test-zone fluid volume of $300 \mathrm{~cm}^{3}$. The fitted parameters were a transmissivity of $3.6 \times 10^{-14}$ $\mathrm{m}^{2} / \mathrm{s}$ (permeability-thickness of $6.3 \times 10^{-21} \mathrm{~m}^{3}$ ), a storativity of $9.0 \times 10^{-7}$, a formation pore pressure of $2.2 \mathrm{MPa}$, and a test-zone compressibility of $3.0 \mathrm{x}$ $10^{-9} \mathrm{~Pa}^{-1}$. The simulations provide a better visual fit to the flow data than to the pressure-buildup data, which might indicate that a higher value of test-zone compressibility would be appropriate.

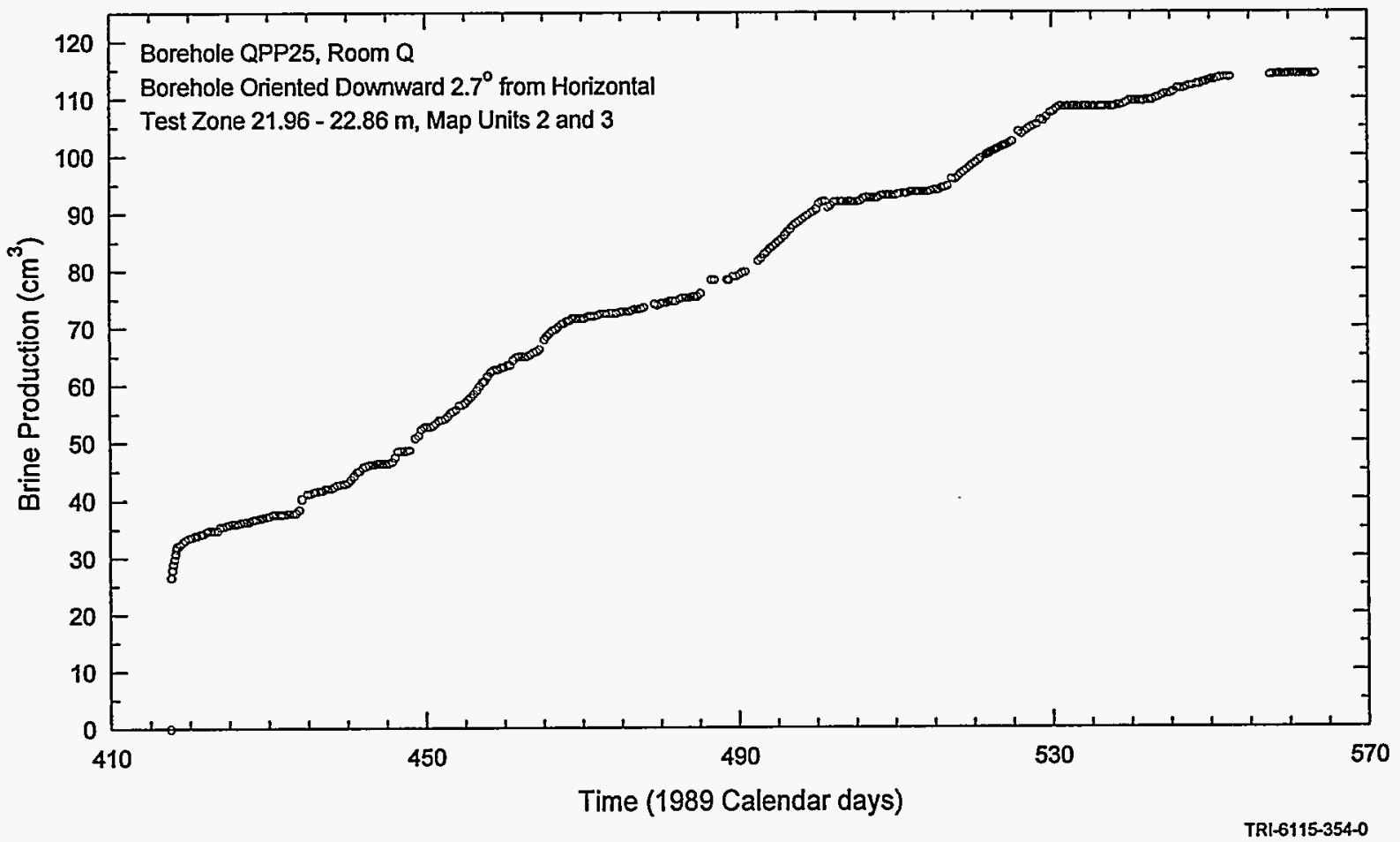

Figure 7-102. QPP25 test-zone brine production 


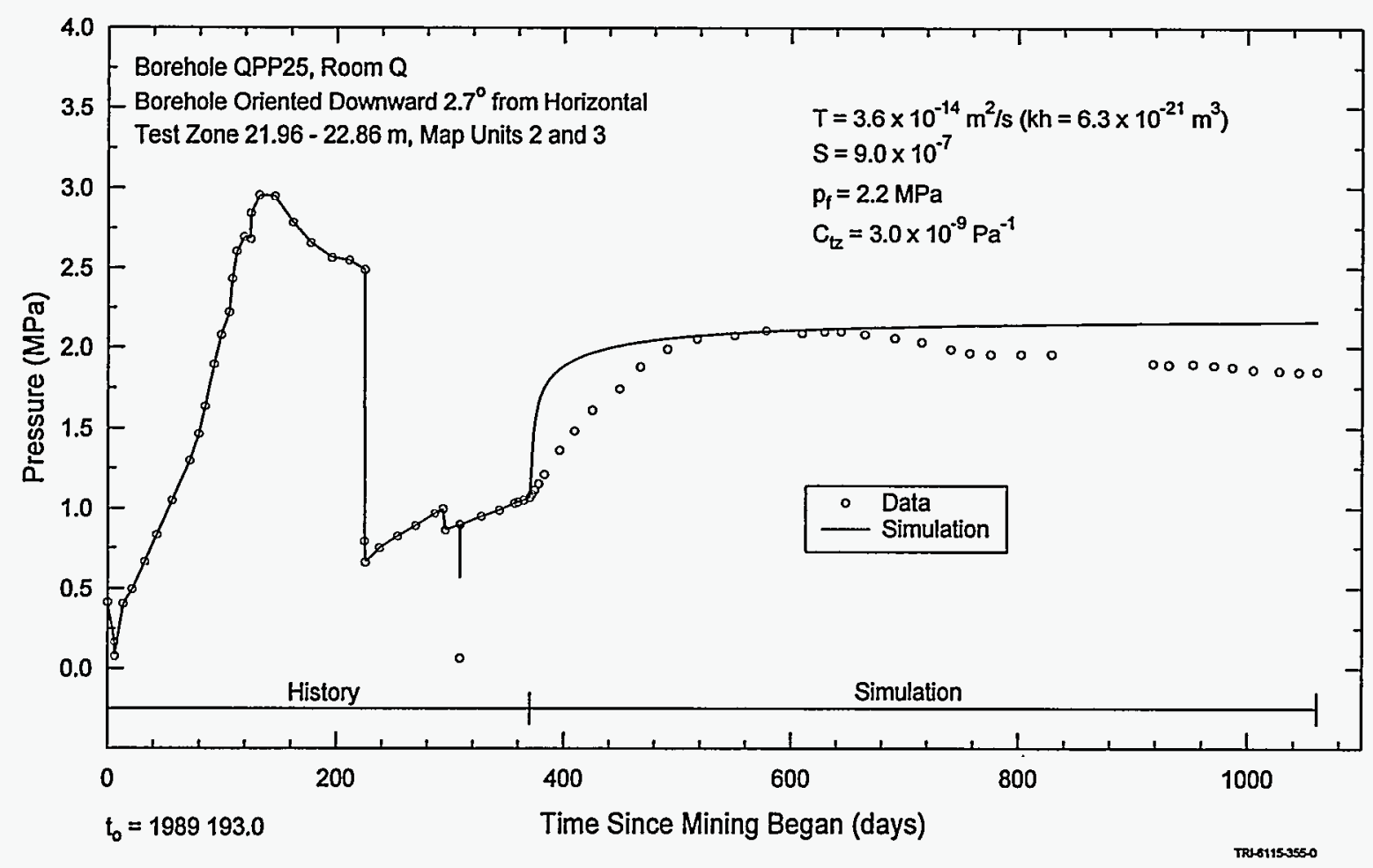

Figure 7-103. GTFM simulation of the QPP25 post-mining test-zone pressure.

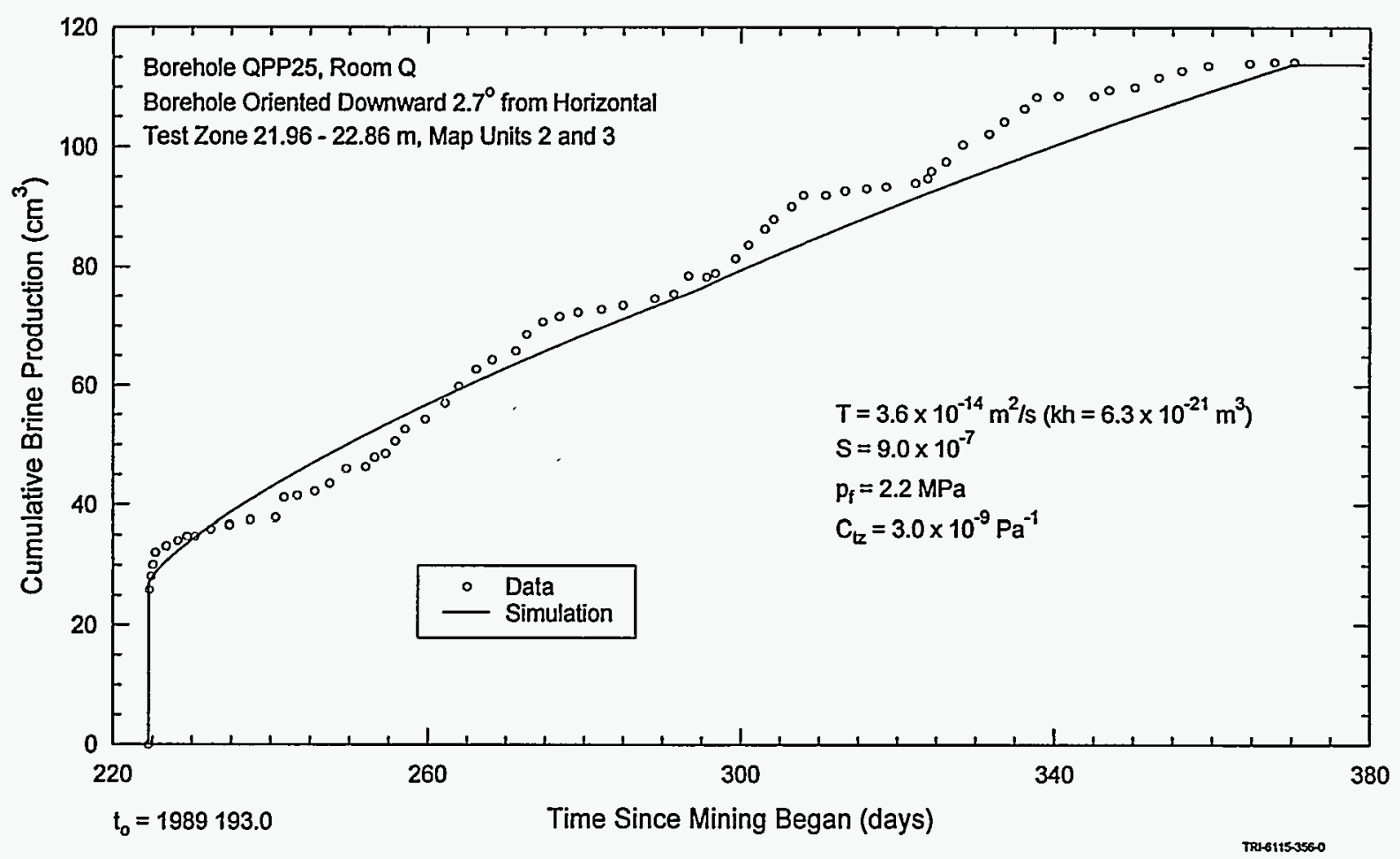

Figure 7-104. GTFM simulation of the QPP25 test-zone brine production. 


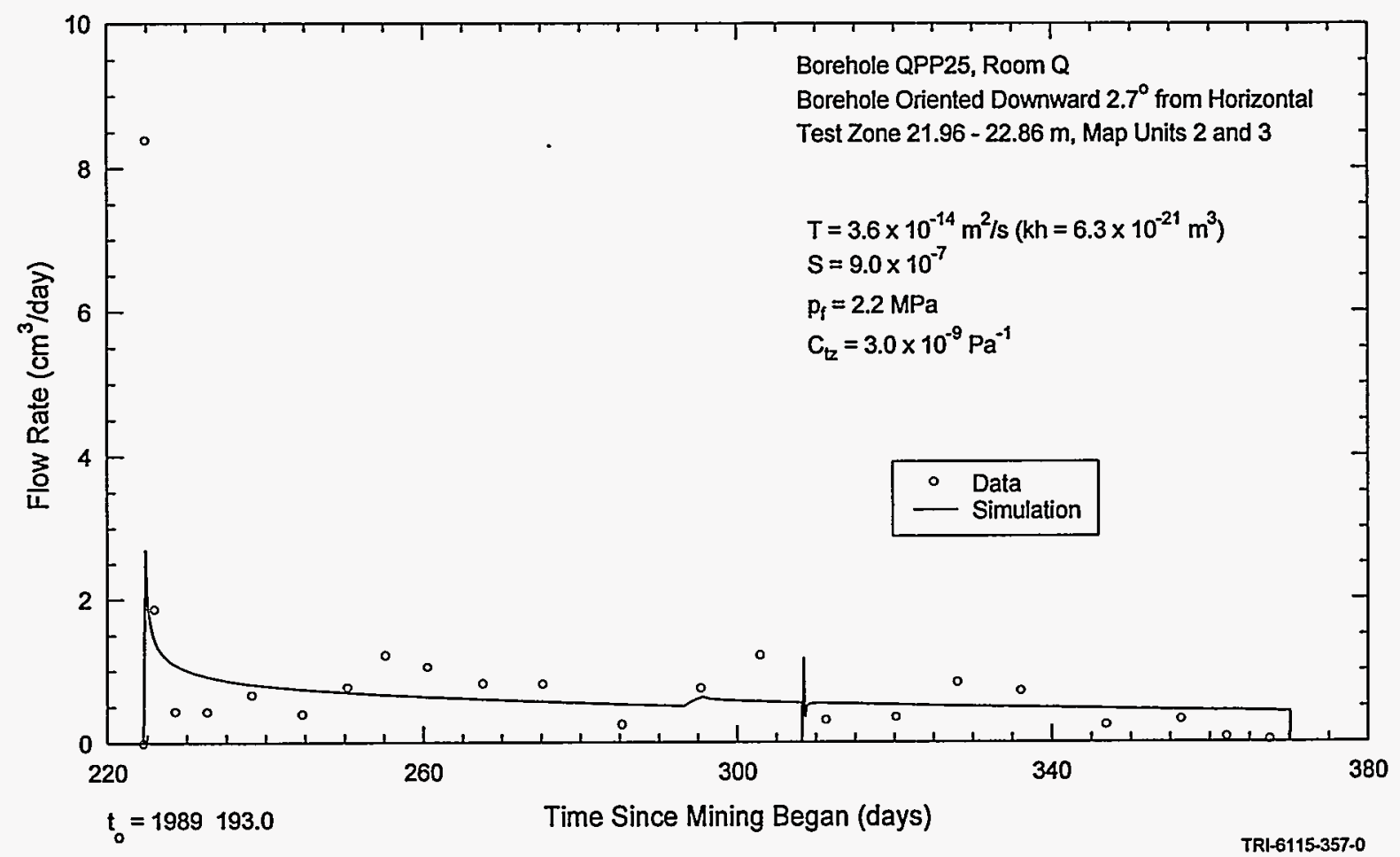

Figure 7-105. GTFM simulation of the QPP25 flow rates.

Although the pre-mining data cannot be quantitatively interpreted, they indicate that the initial formation pore pressure was probably greater than 7.5 MPa. Mining of Room Q, therefore, resulted in a drop in the pore pressure of over $5 \mathrm{MPa}$.

\subsubsection{Guard Zone.}

The complete record of pressures observed in the QPP25 guard zone is shown in Figure 7-106. During the pre-mining period, the pressure in the guard zone was increased from 1.7 to $5.4 \mathrm{MPa}$, after which the pressure continued to increase to $6.6 \mathrm{MPa}$ before the zone was depressurized before mining. Guard-zone pressure changes generally mimicked test-zone pressure changes, although with smaller magnitudes (compare Figures 7-100 and 7-106), suggesting communication between zones through the formation. Figure 7-107 shows a Horner plot of the pre-mining data indicating that the initial formation pore pressure was approximately 9.4 MPa. No analysis of the post-mining data could be performed. However, visual inspection of the data presented in Figure 7-106 suggests that the post-mining pore pressure was in the range of 1.5 to $2.5 \mathrm{MPa}$. Chester (Appendix B) reports that the guard-zone pressure on March 10, 1995 was 1.1 $\mathrm{MPa}$, which confirms that the post-mining pressure is low.

\subsubsection{Summary.}

The only test event in QPP25 amenable to quantitative interpretation was the post-mining flow test in the test zone. If the transmissivity of $3.6 \mathrm{x}$ $10^{-14} \mathrm{~m}^{2} / \mathrm{s}$ interpreted from that test is uniformly distributed along the $0.90-\mathrm{m}$ length of the test zone, the average hydraulic conductivity is $4.0 \times$ $10^{-14} \mathrm{~m} / \mathrm{s}$ (permeability of $7.0 \times 10^{-21} \mathrm{~m}^{2}$ ). The average specific storage is $1.0 \times 10^{-6} \mathrm{~m}^{-1}$. 


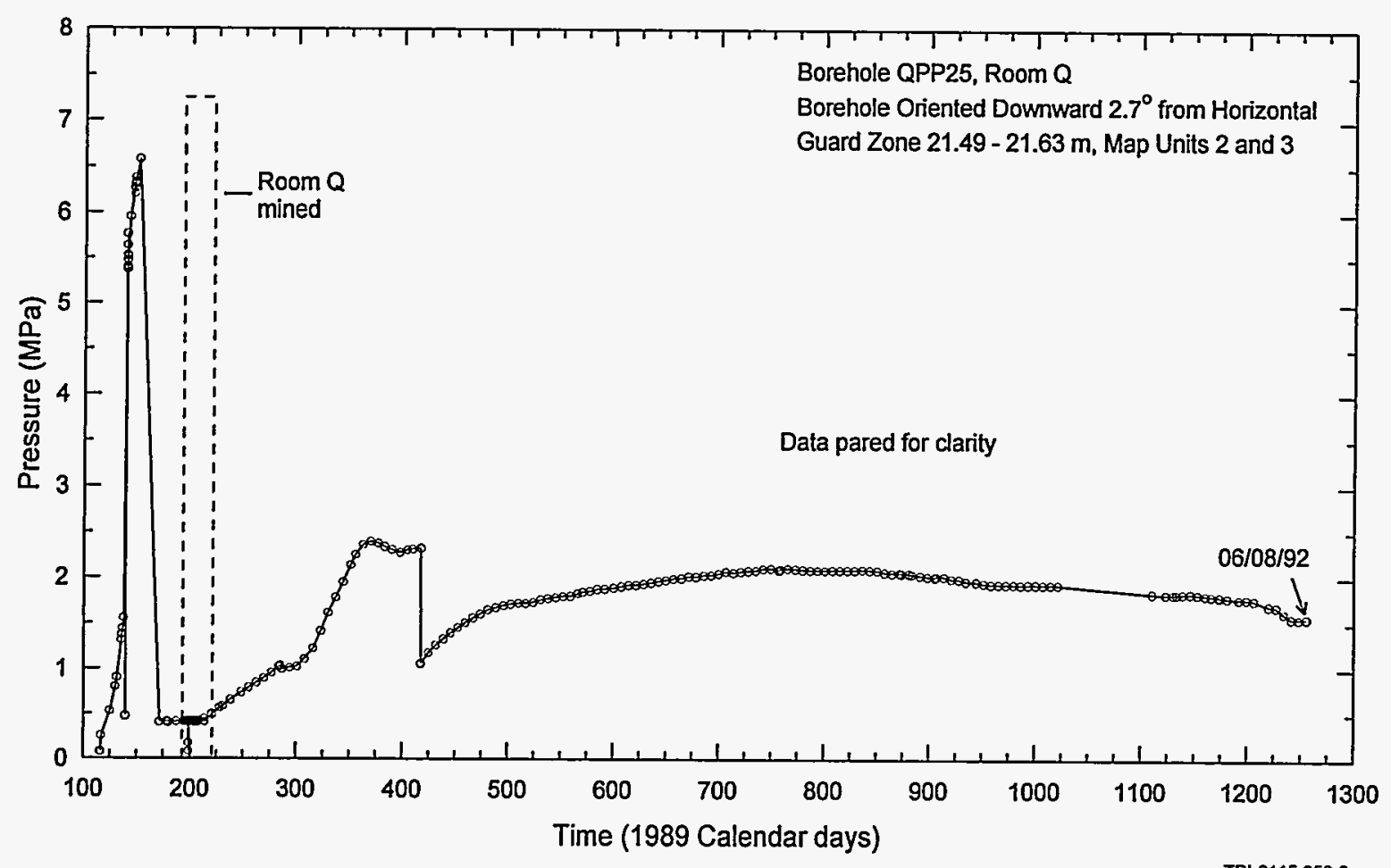

Figure 7-106. QPP25 guard-zone pressure.

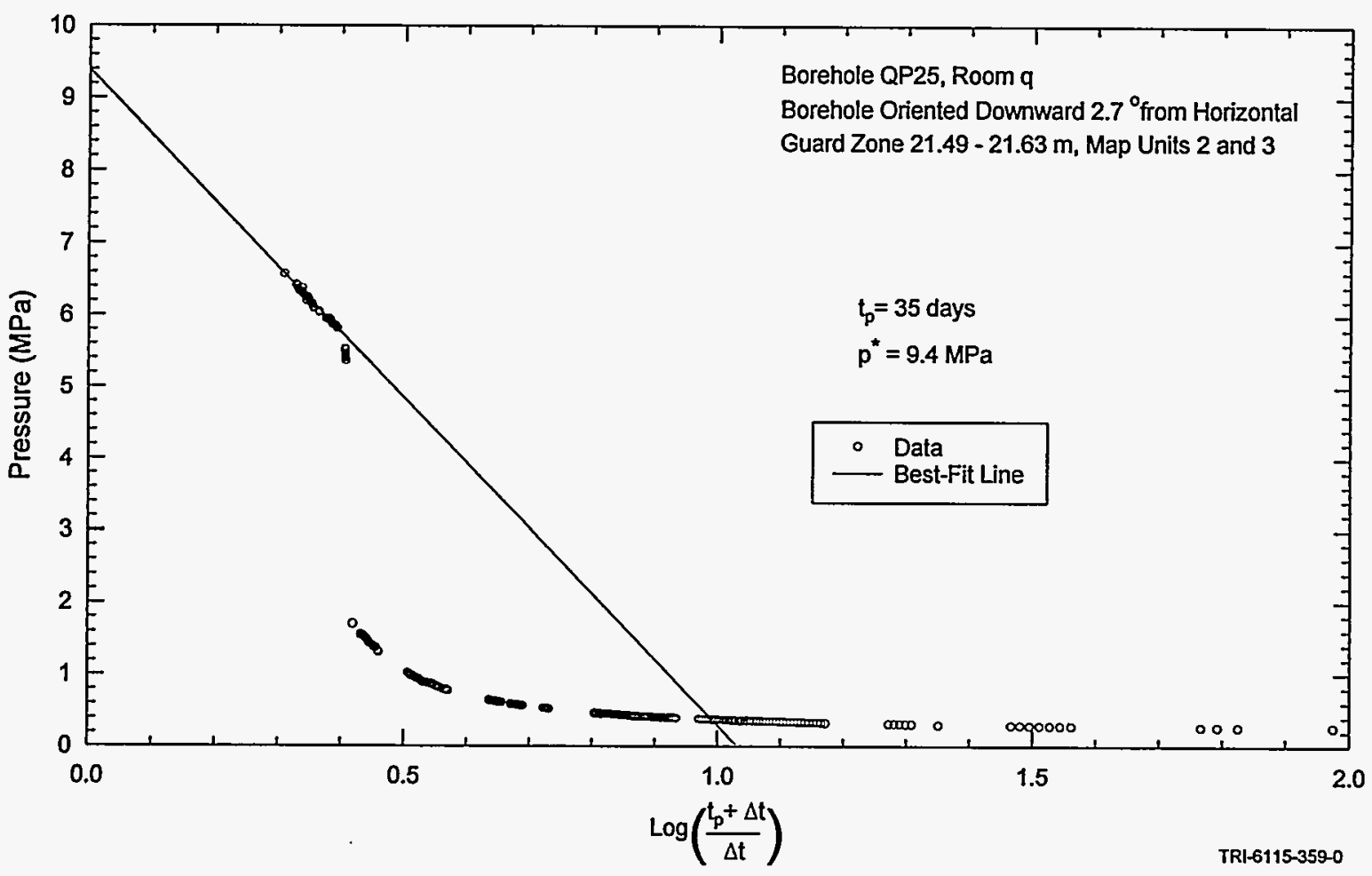

Figure 7-107. Horner plot of the QPP25 pre-mining guard-zone pressure. 
Pressures in both the test and guard zones of QPP25 decreased by over $5 \mathrm{MPa}$ after mining of Room Q.

\subsection{Effects of Room Q Excavation}

Based on qualitative and quantitative observations, conclusions can be drawn about the effect of the Room $Q$ excavation on the formation pressures and hydraulic properties of the Salado Formation strata surrounding Room Q. The changes observed at each borehole are summarized below:

QPP01: Pore pressure was reduced following mining. No statement can be made about the effect of mining on transmissivity and storativity because of the poor quality of the pre-mining data.

QPP02: Neither hydraulic properties nor pore pressure could be estimated because of the poor quality of the pre- and post-mining data.

QPP03: Pore pressure was definitely reduced after mining and the other parameters were unchanged.

QPP04: Mining caused pore pressure to decrease. Hydraulic properties could not be estimated.

QPP05: Before mining, the transmissivity was apparently too low to allow any reliable estimation of hydraulic properties or pore pressure in the time available. After mining, transmissivity was higher, perhaps by as much as three orders of magnitude. The increased transmissivity allowed estimation of a low $(\sim 0.3 \mathrm{MPa})$ pore pressure, which was probably affected by the proximity of Room $Q$.
QPP11: Before mining, the transmissivity was apparently too low to allow any reliable estimation of hydraulic properties or pore pressure in the time available. After mining, transmissivity appeared to be higher, allowing pore pressure to be estimated.

QPP12: Based on the GTFM simulations, neither the pore pressure, transmissivity, nor storativity were altered by excavation of Room Q. However, the poor quality of the pre-mining data increases the uncertainty of the interpretation.

QPP13: The pore pressure showed a significant decrease following excavation, while the transmissivity and storativity did not change significantly. The long-term pressure decrease observed in the post-mining period was caused by equipment problems and does not reflect changes in the formation properties.

QPP14: Before mining, apparent low transmissivity and poor test conditions prevented any reliable estimation of hydraulic properties. After mining, transmissivity appeared to be higher and pore pressure could be estimated.

QPP15: Before mining, the transmissivity was apparently too low to allow any reliable estimation of hydraulic properties or pore pressure in the time available. After mining, transmissivity was higher, perhaps by as much as two orders of magnitude. The increased transmissivity allowed estimation of a low pore pressure that steadily declined, perhaps because of the proximity of Room $Q$.

QPP21: Before mining, the transmissivity was apparently too low to allow any reliable 
estimation of hydraulic properties or pore pressure in the time available. After mining, transmissivity appeared to be higher, and hydraulic properties and pore pressure could be estimated.

QPP22: The pre-mining pore pressure was greater than the post-mining pressure, but no quantitative comparison of transmissivity and storativity was possible because of the low quality of the pre-mining data.

QPP23: Pre-mining data were affected by equipment problems that prevented estimation of hydraulic properties or pore pressure. Qualitatively, pore pressure appeared to be lower after mining.
QPP24: Mining caused pore pressure to decrease. Hydraulic properties could not be estimated.

QPP25: The pre-excavation transmissivity and storativity were not quantifiable because of procedural/equipment problems. The formation pore pressure was clearly lower after mining.

Table 7-3 shows the nature of the changes in pore pressure, pressure response, and transmissivity observed after excavation of Room Q. 
Table 7-3. Changes Observed After Mining

\begin{tabular}{|c|c|c|c|}
\hline Borehole & $\begin{array}{c}\text { Pore } \\
\text { Pressure }\end{array}$ & Pressure Response & Transmissivity \\
\hline QPP01 & - & existed & NA \\
\hline QPP02 & NA & NA & NA \\
\hline QPP03 & - & existed & NC \\
\hline QPP04 & - & existed & NA \\
\hline QPP05 & NA & established & + \\
\hline QPP11 & NA & established & $(+)$ \\
\hline QPP12 & NC & existed & NC \\
\hline QPP13 & - & existed & NC \\
\hline QPP14 & NA & established & + \\
\hline QPP15 & NA & established & + \\
\hline QPP21 & NA & established & + \\
\hline QPP22 & - & existed & NA \\
\hline QPP23 & $(-)$ & existed & NA \\
\hline QPP24 & - & existed & NA \\
\hline QPP25 & - & existed & NA \\
\hline
\end{tabular}

NA: data inadequate for comparison

NC: no change after excavation

+ : increase after excavation

$\therefore$ decrease after excavation

existed: responses observed before mining

established: responses established after mining

parentheses () indicate uncertainty 


\section{MECHANISMS AND PROCESSES AFFECTING SALADO PROPERTIES AROUND ROOM Q}

Hydraulic testing in the boreholes around Room $Q$ has shown that excavation of the room affected the hydraulic properties and pore pressure of the surrounding rock. Excavation of a room changes both the stress field and the porepressure field in the formation. The stress field changes because of the removal of a volume of rock from within the overall rock mass. The pore pressure field changes because the removal of the rock creates a fluid sink at atmospheric pressure drawing flow towards it. These two fields are coupled because a change in the stress in a rock mass causes an instantaneous change in the pore pressure throughout the affected volume of rock. The change in pore pressure is given by Skempton's (1954) coefficient as some fraction of the change in stress. Therefore, pore pressures around Room $Q$ should have decreased both in response to flow towards the room and in response to the reduction in stress around the room. The changes in the stress field and creep of halite towards the room may have resulted in dilatancyinduced microfractures or other changes in pore structure or connectivity in the rock. Microfracturing could result in significant increases in the permeability of the rock. If microfracturing effectively increases the connected pore volume, it could also result in reduced pore pressures. The potential roles played by these processes in causing the changes observed around Room $Q$ are discussed below.

\subsection{Stress Changes Around Room Q}

Ehgartner (1990) numerically simulated the stress field at the approximate locations of the boreholes during excavation of Room Q. Munson et al. (1993) also simulated the stresses around
Room $Q$ as a function of time. The stress modeling was performed using a finite-element code that implemented the Munson-Dawson model (Munson and Dawson, 1979) to calculate the transient deformation of the evaporites. The Salado stratigraphy was modeled by Ehgartner as a single, homogeneous layer of argillaceous halite. Munson et al. represented the stratigraphy explicitly, except that Marker Bed 138 and anhydrite " $a$ " were not included in the model.

Ehgartner (1990) simulated the stress field during mining at distances of $0.91,1.83,3.05$, 6.10 , and $12.19 \mathrm{~m}$ from the wall of Room $\mathrm{Q}$ in the plane normal to Room $Q$ in which the boreholes terminated. Ehgartner's modeling showed that the mean stress (average of the horizontal and vertical stress components) increased as the mining machine approached the plane of the test zones, followed by a rapid decrease as the mining machine passed beyond that plane. All but the outer two boreholes in each array were depressurized prior to mining, making only a limited comparison between Ehgartner's model and observed pressures possible. Pressures in all of the QPPX1 and QPPX2 boreholes were perturbed as the mining machine approached (see Figures 7-2, 7-9, 7-31, 7-37, 7-79, and 7-86). After the mining machine passed the boreholes on 1989 Calendar day 205, the pressures generally returned to their pre-mining trends, although some offsets were noted. Ehgartner's predicted change in the stress field as the mining machine passed was a short-term transient effect, which agrees well with the observed borehole pressure responses. Therefore, the rapid changes in borehole pressures during the mine-by were probably due to the instantaneous stress changes occurring in the rock. 
Munson et al. (1993) modeled the evolution of the stress field around Room $Q$ with time. The calculated stresses at the borehole locations are presented in Figures 8-1 through 8-3. Calculated mean stresses before mining ranged from 14.5 to $15.2 \mathrm{MPa}$, reflecting the lithostatic load at each location. The mean stress at each borehole location decreased most rapidly in the first one to two months after mining. For the balance of the 3.5-yr modeling period, the mean stress declined at a continually decreasing rate. These reductions in stress should have caused reductions in pore pressures at all borehole locations. Either reductions in pore pressure after mining or abnormally low post-mining pressures (i.e., well below undisturbed lithostatic pressure) were, in fact, observed at all boreholes with the exception of QPP12.

Figure 8-4 shows the mean stress calculated by Munson et al. (1993) at $3.5 \mathrm{yr}$ after mining for each borehole location as a function of radial distance from the Room $Q$ axis. Also plotted are the higher of: 1) interpreted post-mining testzone pressures; 2) extrapolated post-mining guard-zone pressures; or 3 ) test-zone pressures measured in March 1995 (Appendix B). For every borehole array, the measured borehole pressures are significantly lower than the madeled mean stresses. The measured borehole pressure trends as a function of distance from the room are not entirely consistent with the modeled stress trends, indicating that stress relief alone cannot account for the observed pressures.

\subsection{Changes in Pore Structure/ Connectivity}

Removing a volume of rock in the form of a drift or tunnel in a ductile geologic medium induces the formation to flow toward the empty space. The net effect is that a fixed volume of rock is forced to fill a larger volume than it had prior to mining.

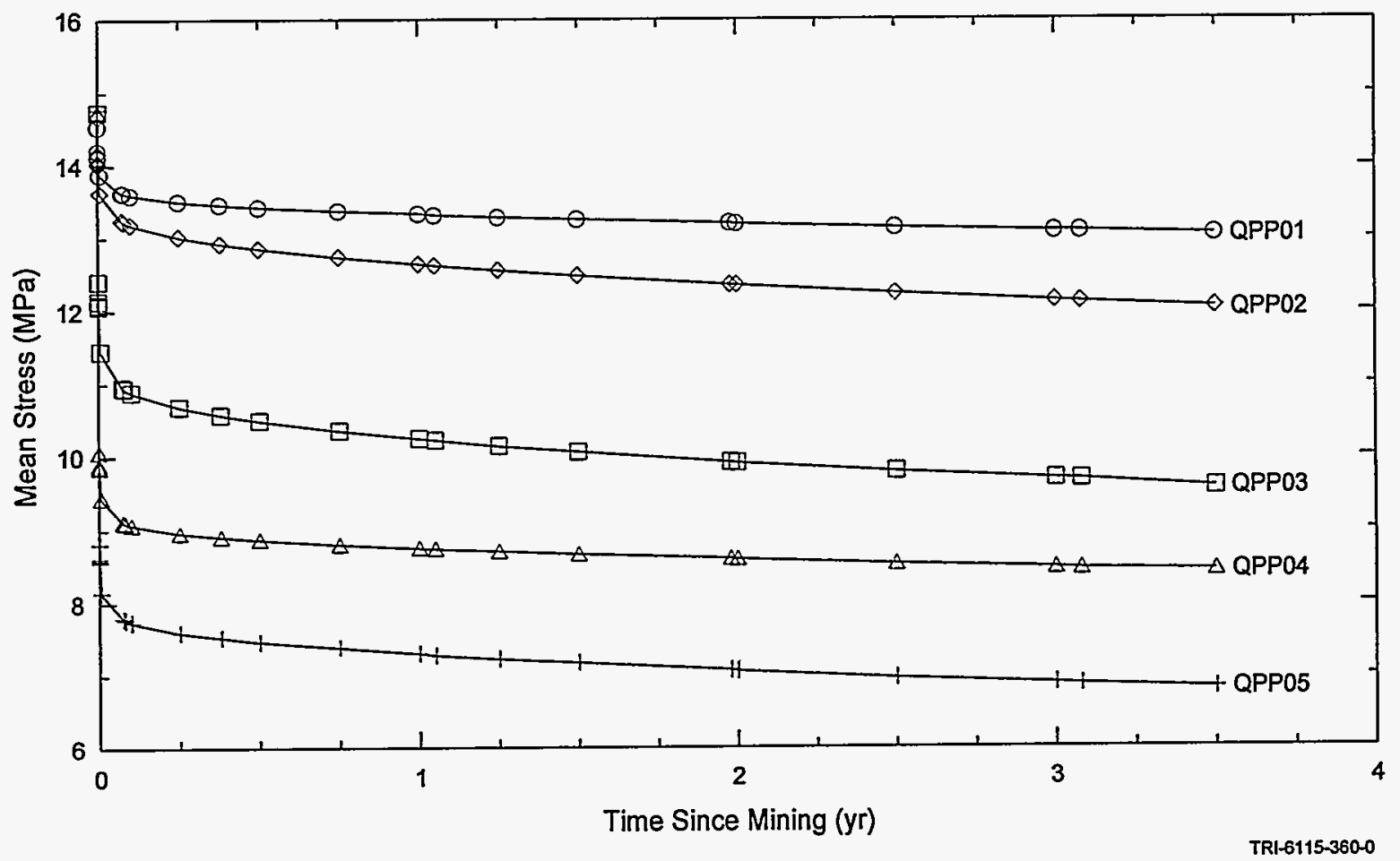

Figure 8-1. Simulated mean stresses at the QPPOx borehole positions. 


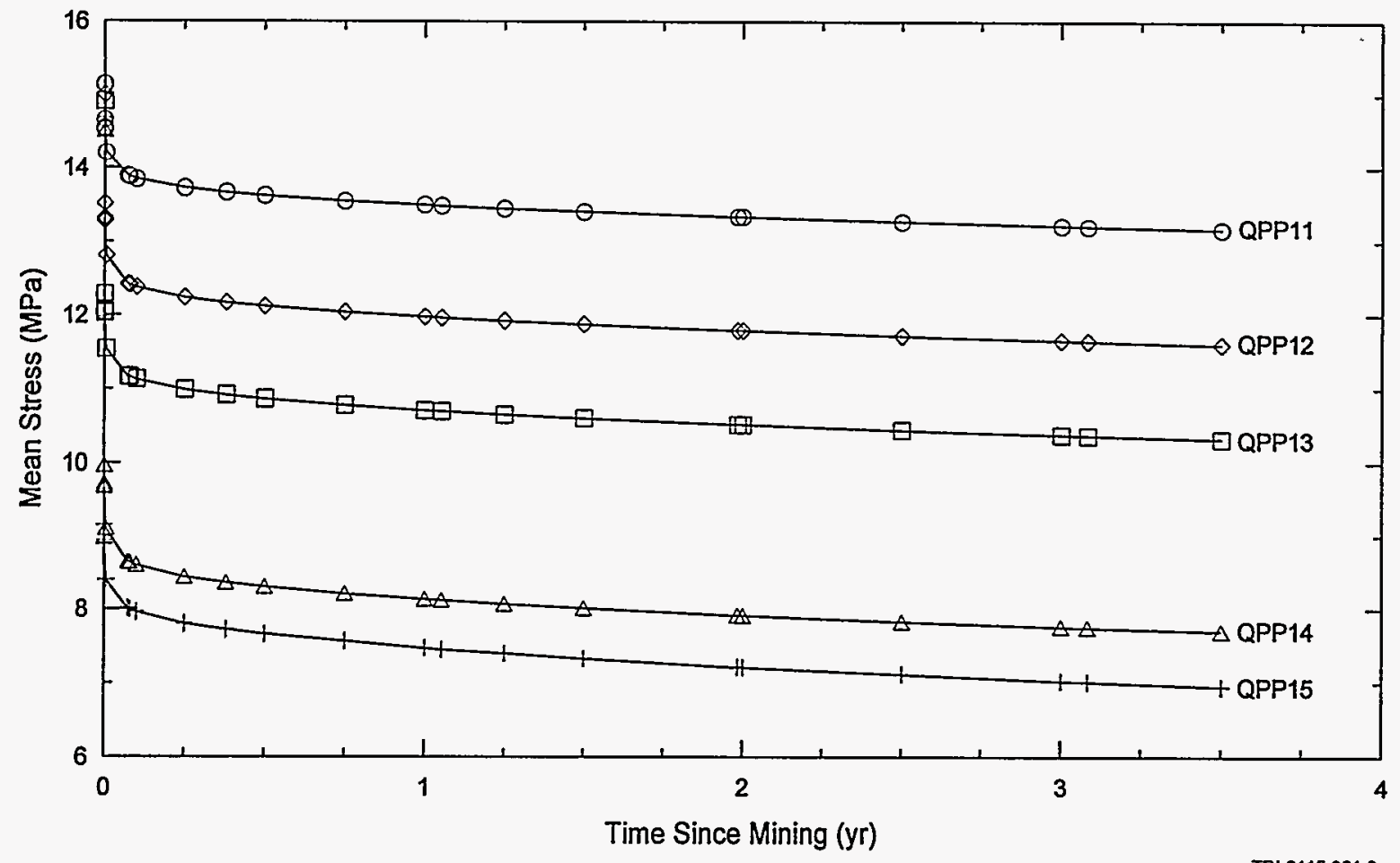

Figure 8-2. Simulated mean stresses at the QPP1x borehole positions.

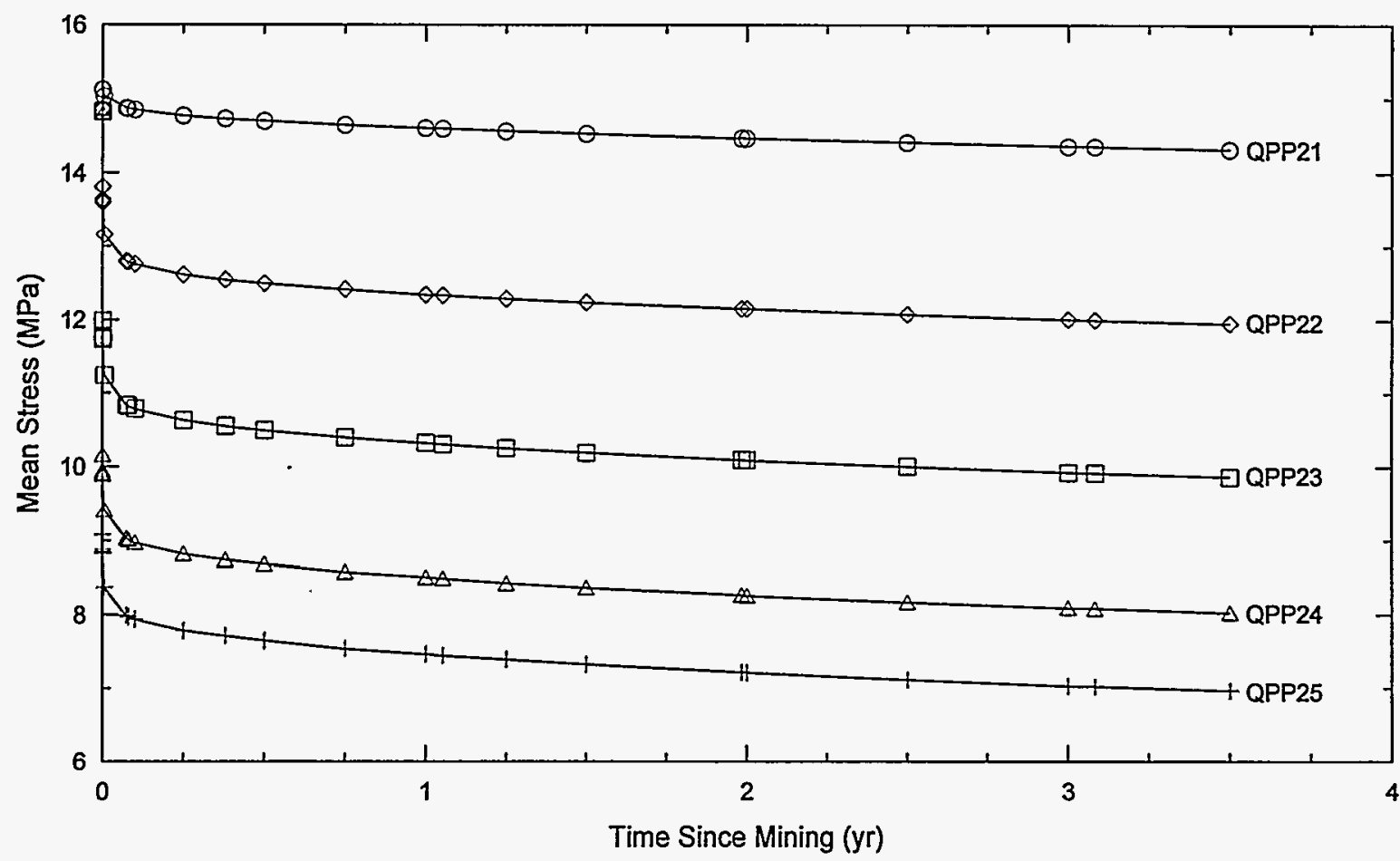

Figure 8-3. Simulated mean stresses at the QPP2x borehole positions. 


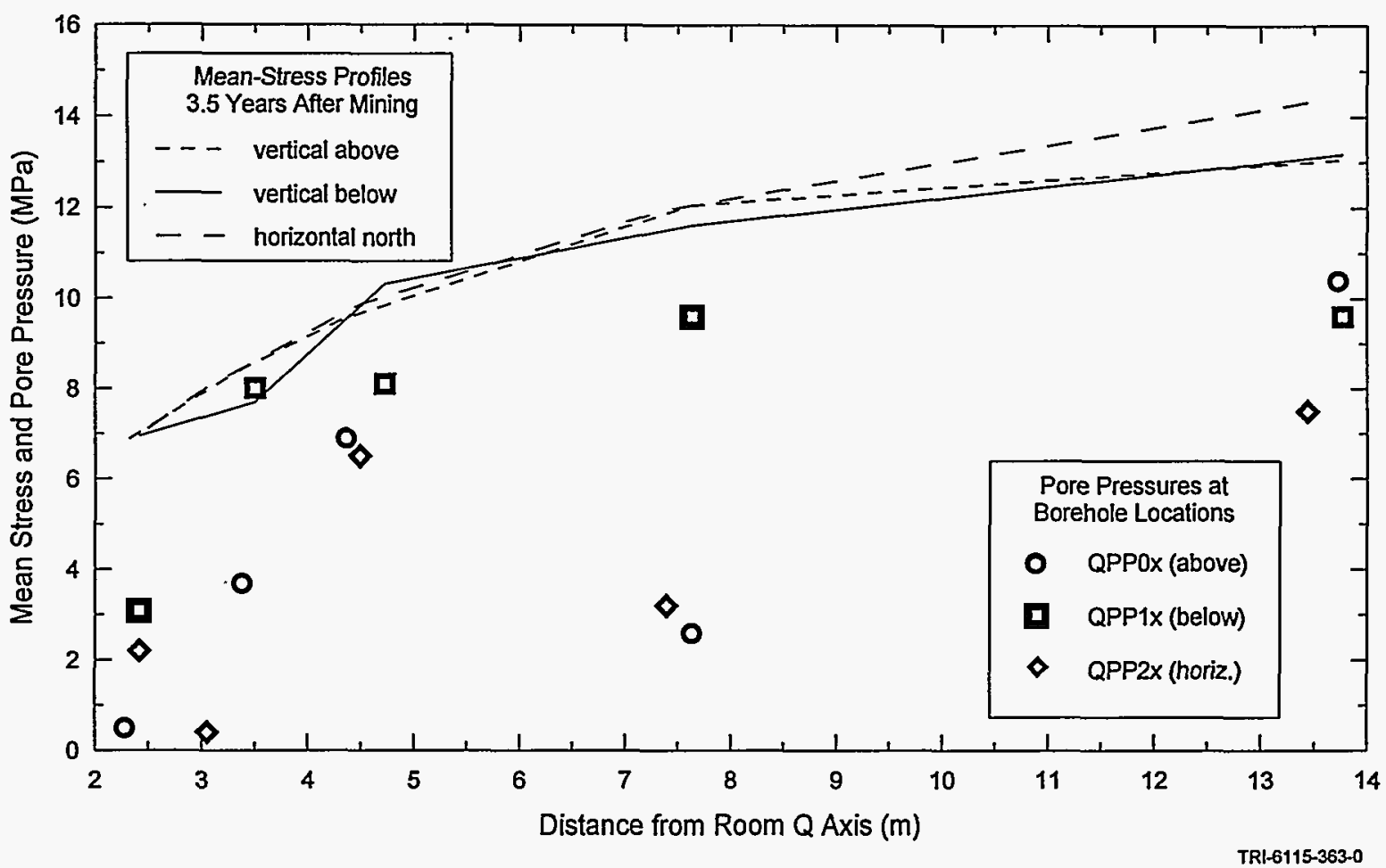

Figure 8-4. Mean stresses and interpreted formation pore pressures around Room Q.

Peach (1991) has shown that the permeability of salt increases in response to excavation of a drift. Peach performed laboratory experiments and field evaluations on natural rock salt, synthetic rock salt, and a synthetic rock salt-anhydrite composite material to determine how permeability was affected by confining pressure. Peach concluded that: 1) the permeability of the three materials increased as the confining pressure was reduced; 2) the permeability of the natural salt decreased from disturbed values of $10^{-17} \mathrm{~m}^{2}$ to undisturbed values of $<10^{-21} \mathrm{~m}^{2}$ over a distance of $3 \mathrm{~m}$ from an excavation; 3 ) the large changes in permeability were accompanied by small amounts of dilatancy $(0.2 \%) ; 4)$ the large and rapid changes in permeability accompanying stress relief are not consistent with classical models relating permeability to already-connected porosity; and 5) the increase in permeability can be interpreted as a connectivity-development (or percolation) phenomenon, whereby pores which were previously not connected become connected by slip along crystal faces and microfracturing.

If similar phenomena were active in the Salado Formation around Room $Q$, post-mining tests should show higher transmissivities and storativities than pre-mining tests, and post-mining pore pressures should be lower due to increased porosity. Five boreholes that showed extremely low transmissivities that were difficult to quantify before mining (QPP05, QPP11, QPP14, QPP15, and QPP21) showed increased (measureable) transmissivities after mining (Table 7-3). Three of these boreholes (QPP05, QPP14, and QPP15) are in close proximity to Room $Q$, but the other two boreholes are at the most distant locations tested. Changes in storativity could not be defined with any certainty. Pore pressures decreased after mining in eight of the nine boreholes for which pre- 
and post-mining comparisons are possible. The fact that the outermost boreholes in each array showed either increased transmissivity or decreased pore pressure after mining suggests that stress was reduced and microfracturing occurred up to $14 \mathrm{~m}$ from the Room $\mathrm{Q}$ axis.

\subsection{Brine Flow}

Brine requires two conditions to flow: permeability and a hydraulic gradient. Before Room $Q$ was mined, the permeabilities of some of the Salado strata were immeasurably low and hydraulic gradients within the Salado were probably extremely low. After Room $Q$ was mined, permeabilities increased in some strata and a very high gradient was created between the atmospheric pressure in the room and the pore pressures in the formation. As a result, brine present in the Salado should have begun flowing toward Room $Q$, causing pore pressures to decrease. This process would affect the boreholes closest to the room first and would be expressed as pressure reductions propagating away from the room with time. Given hydraulic properties such as those listed in Table 7-2, the outer boreholes in the arrays would likely not show pressure reductions caused by flow towards Room $Q$ until several years after mining. Pressures in the inner boreholes are most likely to have been reduced by flow towards Room $Q$, but the inner boreholes are also those at which stress reductions and microfracturing should have been the greatest, reducing pore pressures through those mechanisms as well. Therefore, the pore-pressure reductions attributable solely to brine flow cannot easily be determined.

\subsection{Conclusions}

Hydraulic properties and pore pressures around Room $Q$ appear to have changed in response to changes in the stress field, microfracturing or other changes in pore structure or connectivity, and flow towards the room. Porepressure reductions and/or low post-mining pore pressures at the holes farthest from Room $Q$ (the QPPX1 holes) are almost certainly not caused by flow towards the room and must, therefore, be related to changes in the stress field. Similarly, pore-pressure reductions that were apparent within a few days or weeks of the mine-by, such as at QPP03, are also more likely related to changes in the stress field than to flow towards Room $Q$. Pore-pressure reductions that were manifested months to years after mining (such as at QPP22) may be partially caused by flow towards the room, but may also reflect continuing relaxation of the stress field. Permeability changes observed in boreholes such as QPP05, QPP11, QPP14, QPP15, and QPP21 are most probably the result of microfracturing or other changes in pore structure or connectivity. In some boreholes, particularly those closest to Room Q (the QPPx5 holes), the observed changes may be caused by a combination of factors. Table 8-1 shows what factors are thought to have affected hydraulic properties and pore pressures at the different boreholes. 
Table 8-1. Effects Observed at Room Q Boreholes

\begin{tabular}{|c|c|c|c|}
\hline Borehole & Stress Reduction & Pore Connectivity & Flow towards Room Q \\
\hline QPP01 & yes & no & no \\
\hline QPP02 & possibly & no & no \\
\hline QPP03 & yes & no & no \\
\hline QPP04 & yes & possibly & possibly \\
\hline QPP05 & yes & yes & yes \\
\hline QPP11 & possibly & yes & no \\
\hline QPP12 & no & no & no \\
\hline QPP13 & yes & no & yes \\
\hline QPP14 & possibly & yes & no \\
\hline QPP15 & yes & yes & yes \\
\hline QPP21 & yes & yes & no \\
\hline QPP22 & possibly & no & possibly \\
\hline QPP23 & possibly & no & no \\
\hline QPP24 & yes & no & possibly \\
\hline QPP25 & yes & no & yes \\
\hline
\end{tabular}




\section{SUMMARY AND CONCLUSIONS}

Fifteen boreholes were drilled and instrumented around Room $Q$ so that tests could be conducted to determine the effects of room excavation on the hydraulic properties of the surrounding Salado Formation. Pressure-buildup and pressure-pulse tests were conducted in all of the boreholes before Room $Q$ was mined. The data sets from only eight of the boreholes are adequate for parameter estimation, and five of those are of poor quality. Constant-pressure flow tests and pressure-buildup tests were conducted after Room $Q$ was mined, producing eleven interpretable data sets, including two of poor quality. Test interpretation was hindered by: 1) lack of knowledge of test-zone compressibilities as a function of pressure; 2) test-zone pressure changes caused by variations in packer-inflation pressures and possible leaks around packers; and 3) lack of a numerical model capable of direct coupling between geomechanical and hydraulic responses. These problems increase the uncertainty associated with the parameter values interpreted from the tests.

The transmissivity and storativity values interpreted from the hydraulic-test data are probably reliable only to within about an order of magnitude. Pre-mining transmissivities interpreted from the three good-quality data sets ranged from $1 \times 10^{-15}$ to $5 \times 10^{-14} \mathrm{~m}^{2} / \mathrm{s}$ (permeability-thickness products of $2 \times 10^{-22}$ to $9 \times 10^{-21} \mathrm{~m}^{3}$ ) for test intervals ranging in length from 0.85 to $1.37 \mathrm{~m}$. Pre-mining average permeabilities, which can be considered representative of undisturbed, far-field conditions, were $6 \times 10^{-20}$ and $8 \times 10^{-20} \mathrm{~m}^{2}$ for anhydrite, and $3 \times 10^{-22} \mathrm{~m}^{2}$ for halite. Interpreted pre-mining storativities ranged from $7 \times 10^{-8}$ to $2 \times$ $10^{-6}$. Average specific storage values were $4 \times$ $10^{-7}$ and $3 \times 10^{-6} \mathrm{~m}^{-1}$ for anhydrite, and $3 \times 10^{-6}$ $\mathrm{m}^{-1}$ for halite.
Post-mining transmissivities interpreted from the nine good-quality data sets ranged from 1 $\times 10^{-16}$ to $3 \times 10^{-13} \mathrm{~m}^{2} / \mathrm{s}$ (permeability-thickness products of $2 \times 10^{-23}$ to $5 \times 10^{-20} \mathrm{~m}^{3}$ ). Post-mining average permeabilities for anhydrite ranged from 8 $\times 10^{-20}$ to $1 \times 10^{-19} \mathrm{~m}^{2}$. These values are thought to be representative of anhydrite only slightly (if at all) disturbed by the WIPP excavations. Postmining average permeabilities for halite ranged from $2 \times 10^{-23}$ to $5 \times 10^{-20} \mathrm{~m}^{2}$ and are representative of halite affected to different degrees by the nearby excavation. Interpreted post-mining storativities ranged from $3 \times 10^{-8}$ to $7 \times$ $10^{-6}$. Average specific storage values ranged from $4 \times 10^{-7}$ to $4 \times 10^{-6} \mathrm{~m}^{-1}$ for anhydrite, and from $3 \times$ $10^{-8}$ to $8 \times 10^{-6} \mathrm{~m}^{-1}$ for halite.

Pore pressures decreased by several $\mathrm{MPa}$ after mining at all boreholes for which reliable preand post-mining comparisons are possible, except for QPP12, where no change was observed.

The changes in hydraulic properties and pore pressures that were observed can be attributed to one or a combination of three processes: stress reduction, changes in pore connectivity, and flow towards Room Q. Stress reduction occurred as a result of the mining of the rock to create Room $Q$. It should have led to both instantaneous and long-term reductions in pore pressures because of coupling between the stress field and the pore-pressure field. Stress reduction should be the most important of the three processes at the borehole locations farthest from Room Q. Changes in pore connectivity, which may occur as microfracturing, probably occur as the halite surrounding Room $Q$ creeps towards the opening, as well as through dilatancy. Changes in pore connectivity are probably responsible for the increases in transmissivity noted at some of the 
boreholes, and may also have. led to some reduction in pore pressures. Flow towards Room $Q$ would affect the boreholes closest to the room first and would be expressed as pore-pressure reductions propagating away from the room with time. Pressures in the boreholes closest to the room are most likely to have been reduced by flow towards Room $Q$, but the inner boreholes are also those at which stress reductions and microfracturing should have been the greatest, reducing pore pressures through those mechanisms as well. The effects of the three processes cannot be individually quantified with the available data. 


\section{REFERENCES}

Barrows, L.J., S.-E. Shaffer, W.B. Miller, and J.D. Fett. 1983. Waste Isolation Pilot Plant (WIPP) Site Gravity Survey and Interpretation. SAND82-2922. Albuquerque, NM: Sandia National Laboratories.

Beauheim, R.L., G.J. Saulnier, Jr., and J.D. Avis. 1991. Interpretation of Brine-Permeability Tests of the Salado Formation at the Waste Isolation Pilot Plant Site: First Interim Report. SAND90-0083. Albuquerque, NM: Sandia National Laboratories.

Beauheim, R.L., R.M. Roberts, T.F. Dale, M.D. Fort, and W.A. Stensrud. 1993. Hydraulic Testing of Salado Formation Evaporites at the Waste Isolation Pilot Plant Site: Second Interpretive Report. SAND92-0533. Albuquerque, NM: Sandia National Laboratories.

Borns, D.J. 1985. Marker Bed 139: A Study of Drillcore From a Systematic Array. SAND85-0023. Albuquerque, NM: Sandia National Laboratories.

Bourdet, D., J.A. Ayoub, and Y.M. Pirard. 1989. "Use of Pressure Derivative in Well-Test Interpretation," SPE Formation Evaluation. Vol. 4, no. 2, 293-302.

Bredehoeft, J.D., and S.S. Papadopulos. 1980. "A Method for Determining the Hydraulic Properties of Tight Formations," Water Resources Research. Vol. 16, no. 1, 233-238.

Deal, D.E., R.J. Abitz, D.S. Belski, J.B. Case, M.E. Crawley, R.M. Deshler, P.E. Drez, C.A. Givens, R.B. King, B.A. Lauctes, J. Myers, S. Niou, J.M. Pietz, W.M. Roggenthen, J.R. Tyburski, and M.G. Wallace. 1989. Brine Sampling and Evaluation Program 1988 Report. DOEMIPP 89-015. Carlsbad, NM: US DOE.

Doe, T.W. 1991. "Fractional Dimension Analysis of Constant-Pressure Well Tests," Proceedings 1991 SPE Annual Technical Conference \& Exhibition, Formation Evaluation \& Reservoir Geology, Dallas, TX, October 6-9, 1991. SPE 22702. Richardson, TX: Society of Petroleum Engineers of AIME. 461-467.

Ehgartner, B. 1990. Geomechanical Analyses in Support of the Waste Isolation Pilot Plant (WIPP). SAND90-0285. Albuquerque, NM: Sandia National Laboratories.

Finley, S.J., D.J. Hanson, and R. Parsons. 1992. Small-Scale Brine Inflow Experiments - Data Report Through 6/6/91. SAND91-1956. Albuquerque, NM: Sandia National Laboratories.

Gringarten, A.C., D.P. Bourdet, P.A. Landel, and V.J. Kniazeff. 1979. "A Comparison Between Different Skin and Wellbore Storage Type Curves for Early-Time Transient Analysis," Society of Petroleum Engineers 54th Annual Technical Conference \& Exhibition, Las Vegas, NV, September 23-26, 1979. SPE 8205. Richardson, TX: Society of Petroleum Engineers.

Horne, R.N. 1990. Modern Well Test Analysis, A Computer-Aided Approach. 2nd ed. Palo Alto, CA: Petroway, Inc.

Howarth, S.M., E.W. Peterson, P.L. Lagus, K.H. Lie, S.J. Finley, and E.J. Nowak. 1991. "Interpretation of In-Situ Pressure and Flow Measurements of the Salado Formation at the Waste Isolation Pilot Plant," Proceedings SPERocky Mountain Regional/Low Permeability Reservoirs Symposium and Exhibition, Denver, CO, April 15-17, 1991. SPE 21840. Richardson, TX: Society of Petroleum Engineers. 355-369. 
Jacob, C.E., and S.W. Lohman. 1952. "Nonsteady Flow to a Well of Constant Drawdown in an Extensive Aquifer," Transactions, American Geophysical Union. Vol. 33, no. 4, 559-569.

Jensen, A.L., C.L. Howard, R.L. Jones, and T.P. Peterson. 1993. Room Q Data Report: Test Borehole Data from April 1989 through November 1991. SAND92-1172. Albuquerque, NM: Sandia National Laboratories.

Jones, C.L., C.G. Bowles, and K.G. Bell. 1960. Experimental Drill Hole Logging in Potash Deposits of the Carlsbad District, New Mexico. USGS Open-File Report 60-84. Denver, CO: U.S. Geological Survey.

Krieg, R.D. 1984. Reference Stratigraphy and Rock Properties for the Waste Isolation Pilot Plant (WIPP) Project. SAND83-1908. Albuquerque, NM: Sandia National Laboratories.

McTigue, D.F. 1993. Permeability and Hydraulic Diffusivity of Waste Isolation Pilot Plant Repository Salt Inferred from Small-Scale Brine Inflow Experiments. SAND92-1911. Albuquerque, NM: Sandia National Laboratories.

Munson, D.E., and P.R. Dawson. 1979. Constitutive Model for the Low Temperature Creep of Salt (With Application to WIPP). SAND79-1853. Albuquerque, NM: Sandia National Laboratories.

Munson, D.E., J.R. Weatherby, and K.L. DeVries. 1993. "Two- and Three-Dimensional Calculations of Scaled In Situ Tests using the M-D Model of Salt Creep," International Journal of Rock Mechanics and Mining Sciences \& Geomechanics Abstracts. Vol. 30, no. 7, 1345-1350.

Neuzil, C.E. 1982. "On Conducting the Modified 'Slug' Test in Tight Formations," Water Resources Research. Vol. 18, no. 2, 439-441.

Nowak, E.J. 1989. "Test Plan: Brine Inflow and Related Tests in the Brine Inflow Room (Room Q) of the Waste Isolation Pilot Plant (WIPP)." Albuquerque, NM: Sandia National Laboratories.

Peach, C.J. 1991. "Influence of Deformation on the Fluid Transport Properties of Salt Rocks." Geologica Ultraiectina, no. 77. Utrecht, the Netherlands: Instituut voor Aardwetenschappen der Rijksuniversiteit Utrecht. (Copy on file in the Nuclear Waste Management Center Library, Sandia National Laboratories, Albuquerque, NM.)

Pickens, J.F., G.E. Grisak, J.D. Avis, D.W. Belanger, and M. Thury. 1987. "Analysis and Interpretation of Borehole Hydraulic Tests in Deep Boreholes: Principles, Model Development, and Applications," Water Resources Research. Vol. 23, no. 7, 1341-1375.

Skempton, A.W. 1954. "The Pore-Pressure Coefficients $A$ and $B, "$ Géotechnique. Vol. IV, 143-147.

Tang, R.W. 1988. "A Model of Limited-Entry Completions Undergoing Spherical Flow," SPE Formation Evaluation. Vol. 3, no. 4, 761-770.

Westinghouse Electric Corporation. 1989. Geotechnical Field Data and Analysis Report, July 1987-June 1988, Volume II. DOEMIPP 89-009. Carlsbad, NM: US DOE. 
APPENDIX A

PLOTS OF PACKER PRESSURES DURING TESTING 


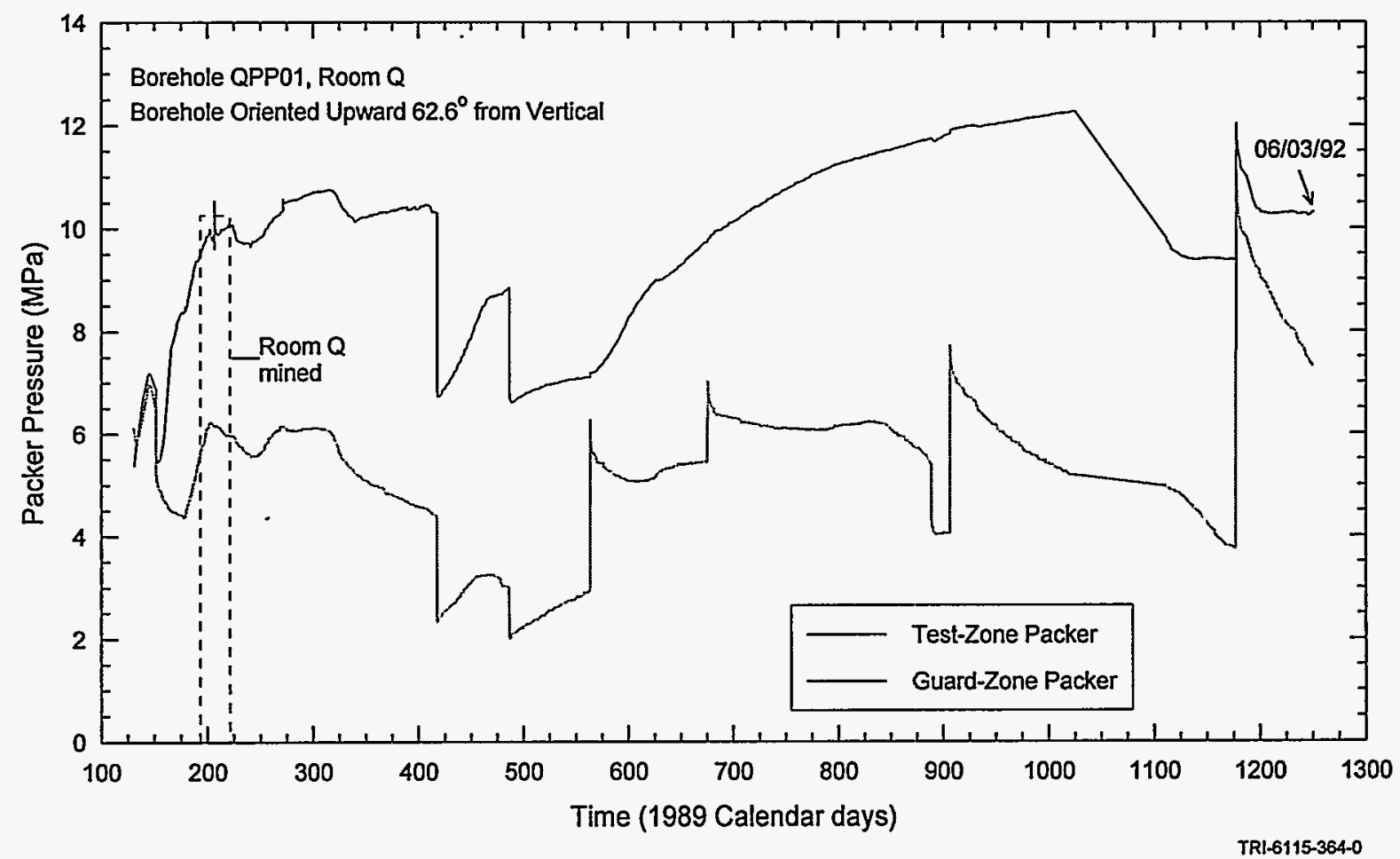

Figure A-1. QPP01 packer pressures.

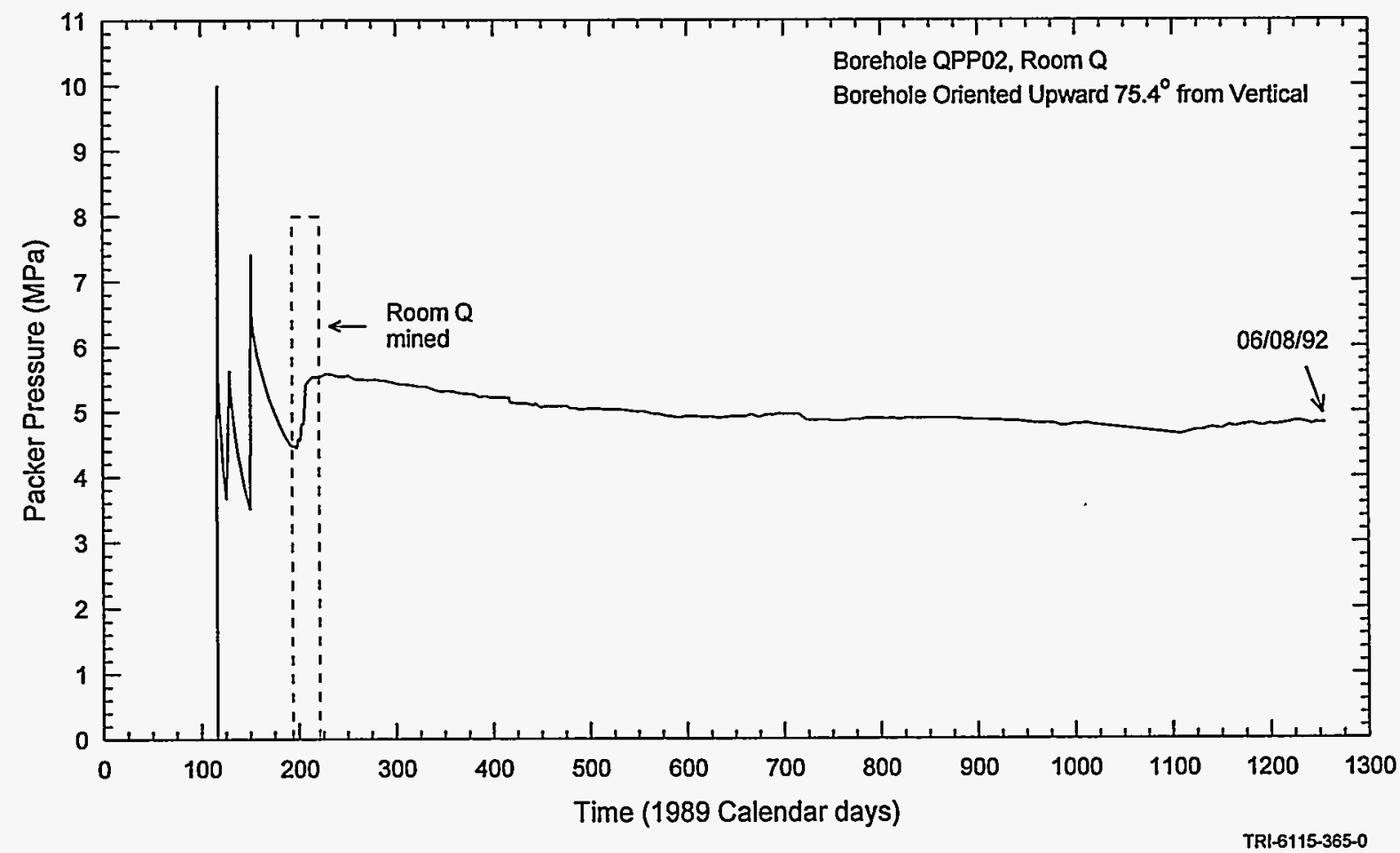

Figure A-2. QPP02 packer pressure. 


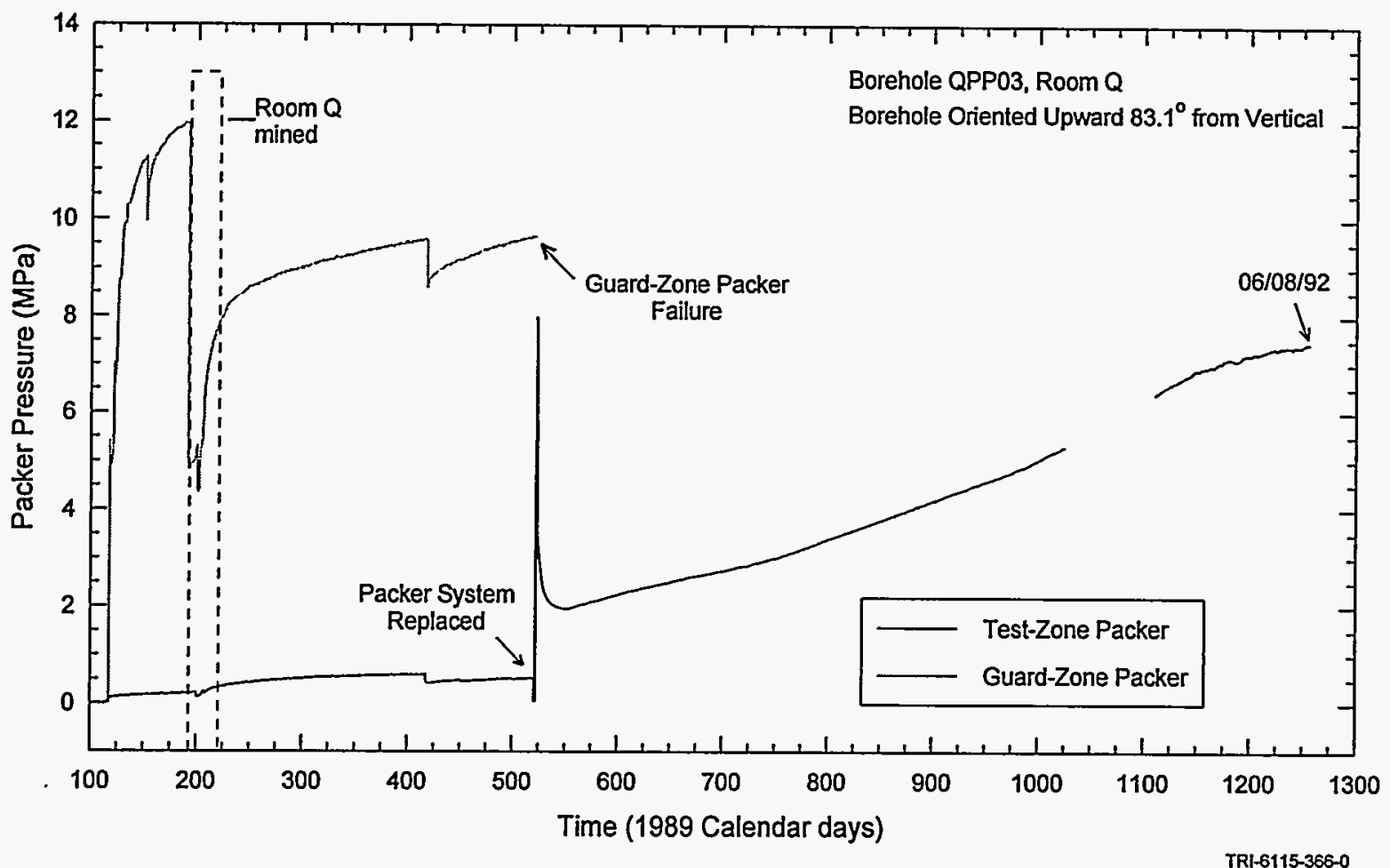

Figure A-3. QPP03 packer pressures.

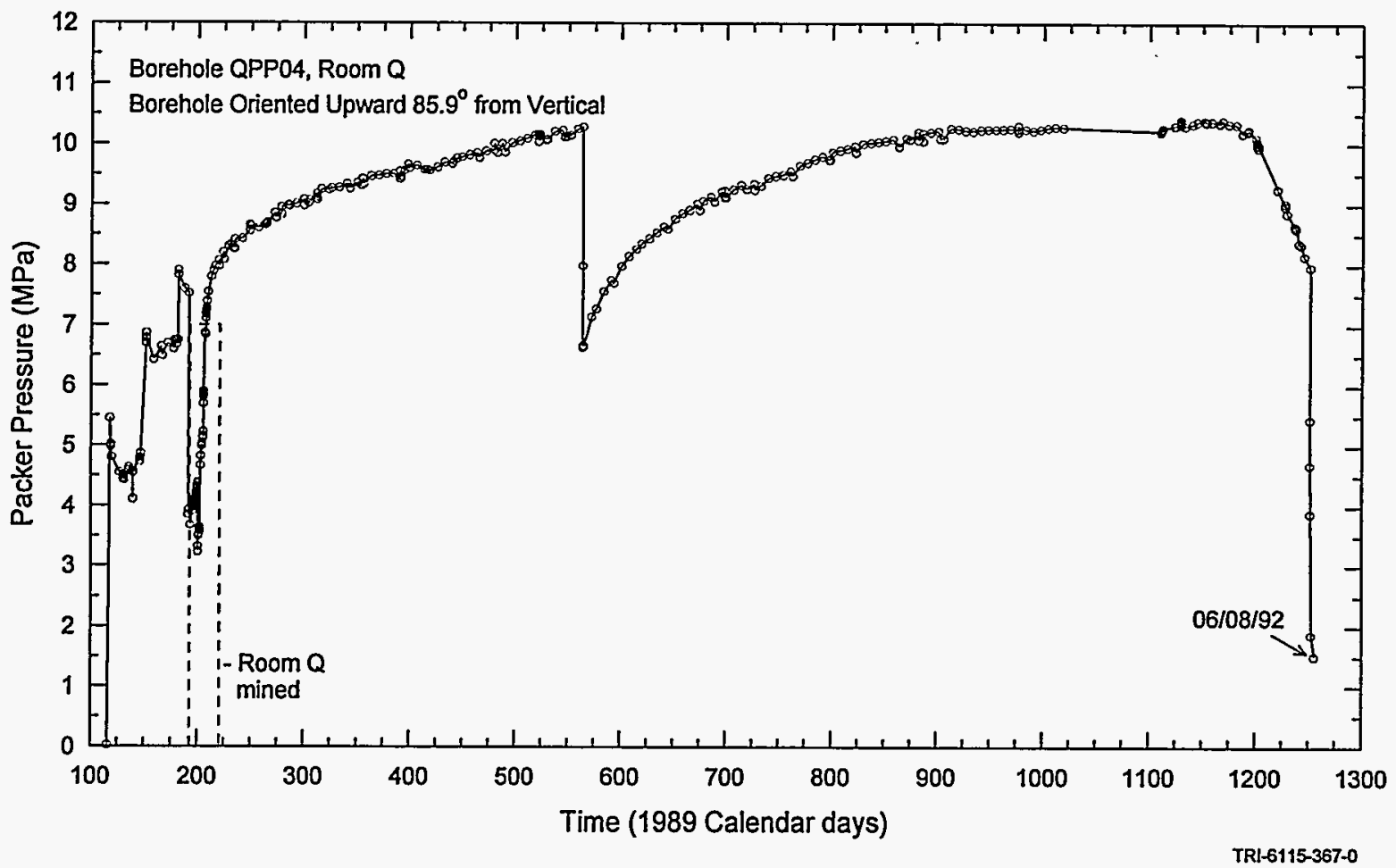

Figure A-4. QPP04 packer pressure. 


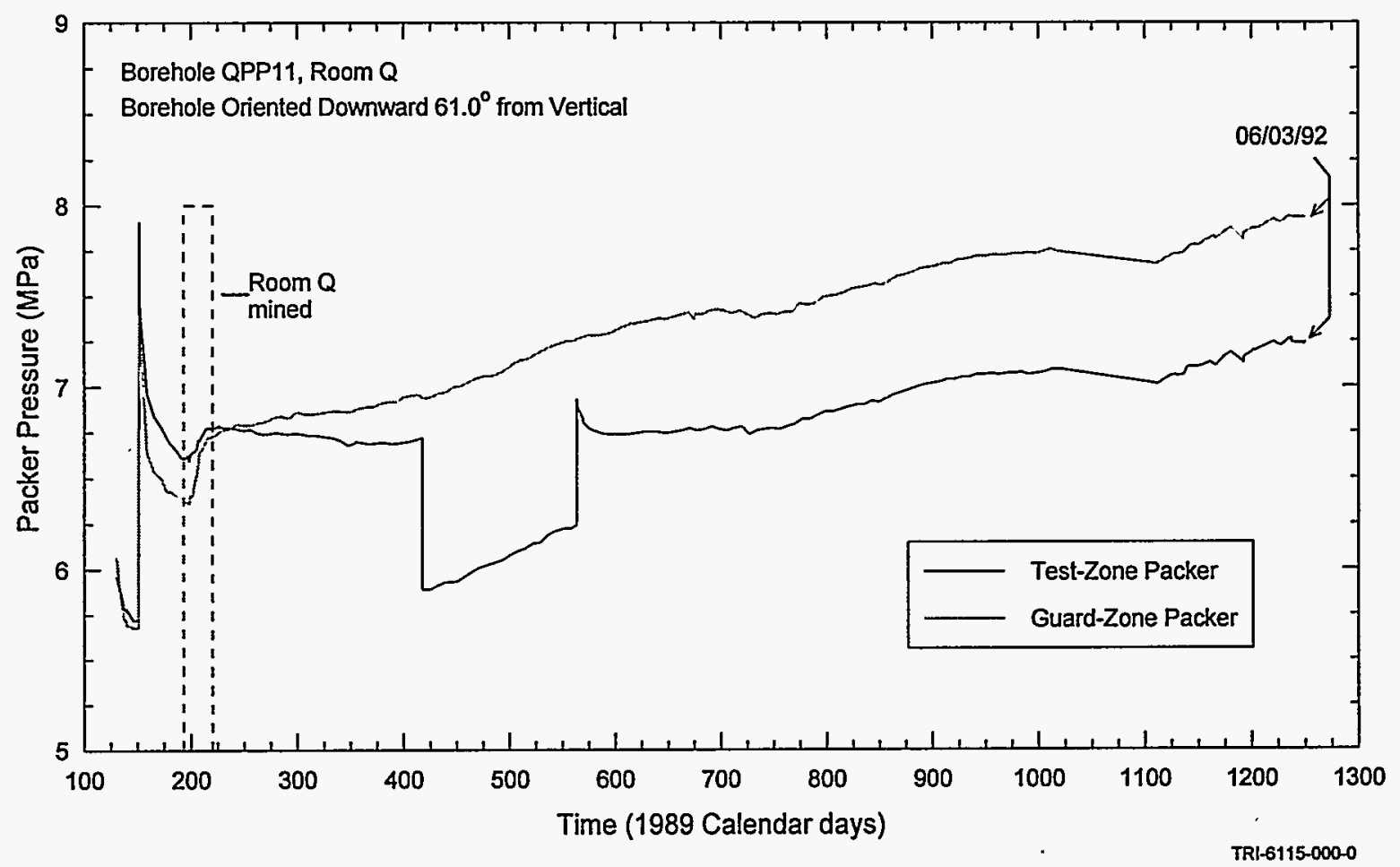

Figure A-5. QPP05 packer pressures.

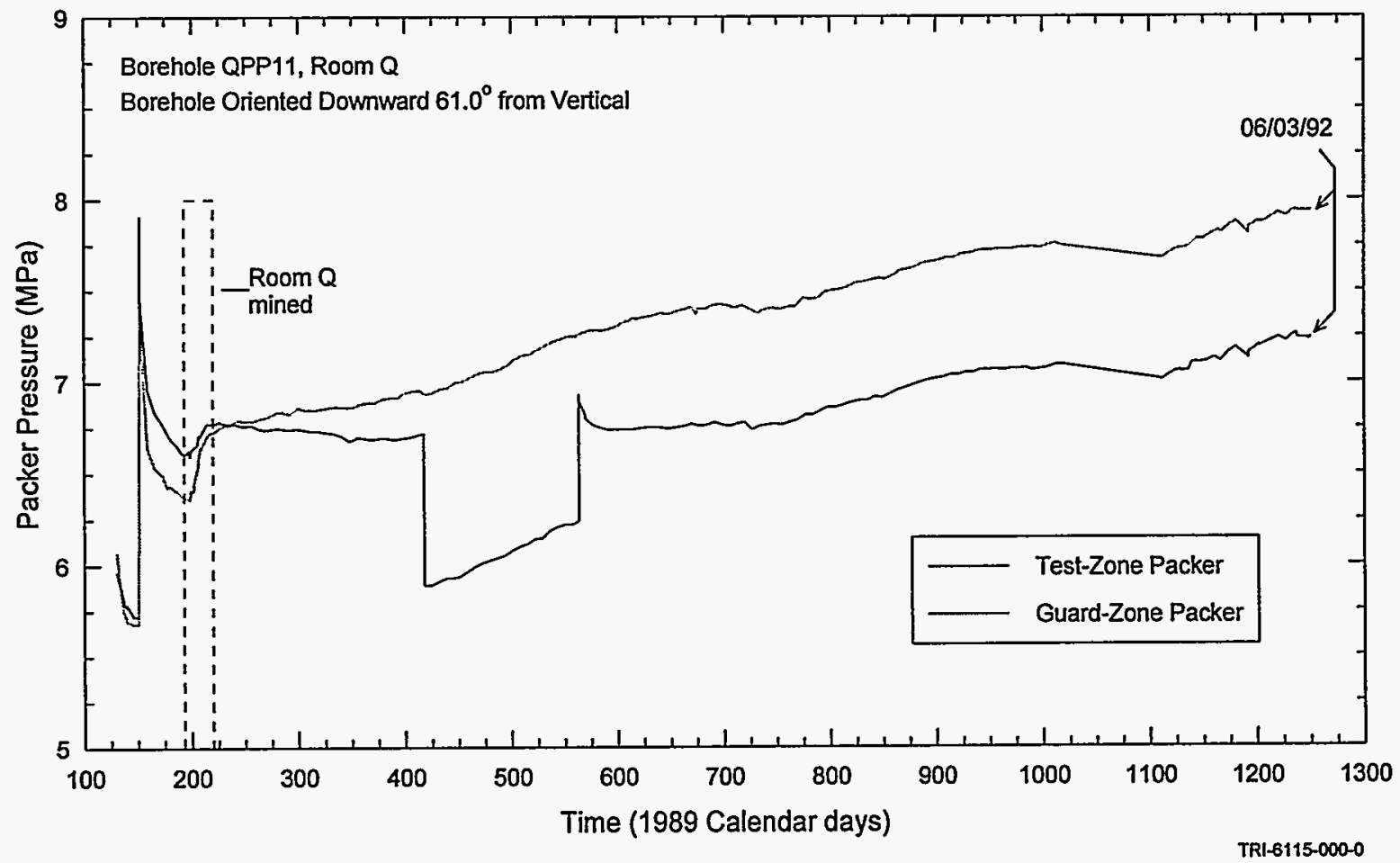

Figure A-6. QPP11 packer pressures. 


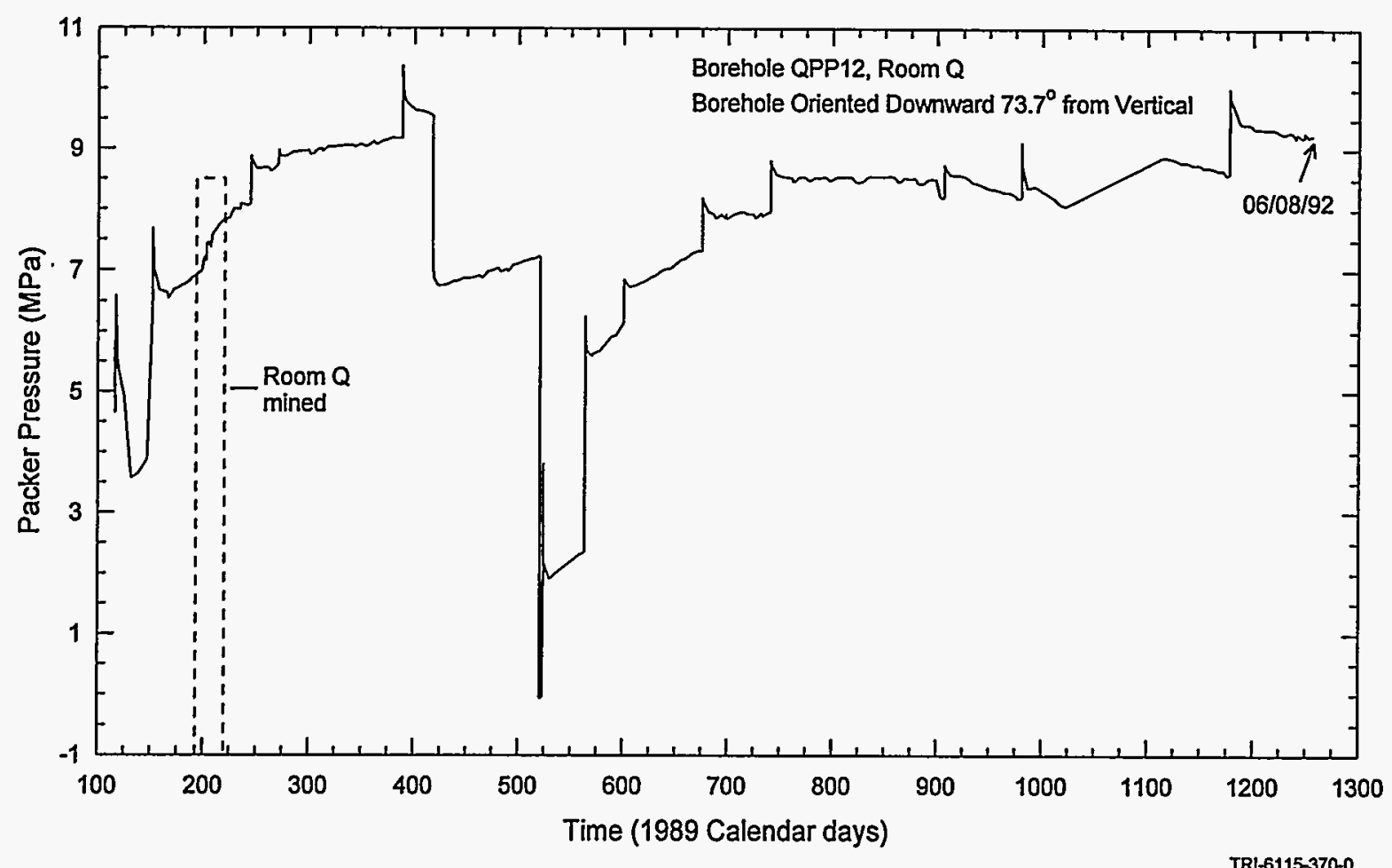

Figure A-7. QPP12 packer pressure.

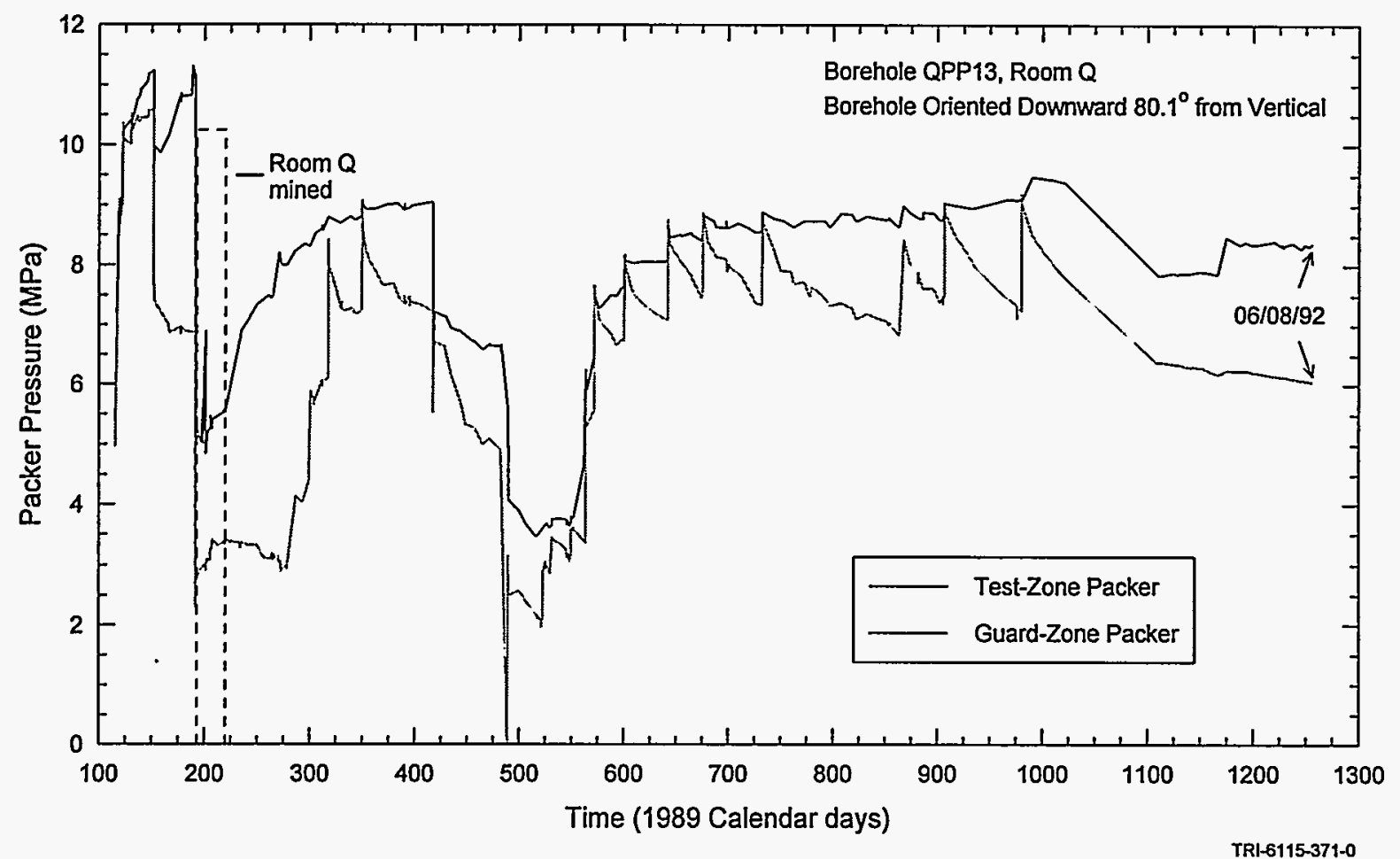

Figure A-8. QPP13 packer pressures. 


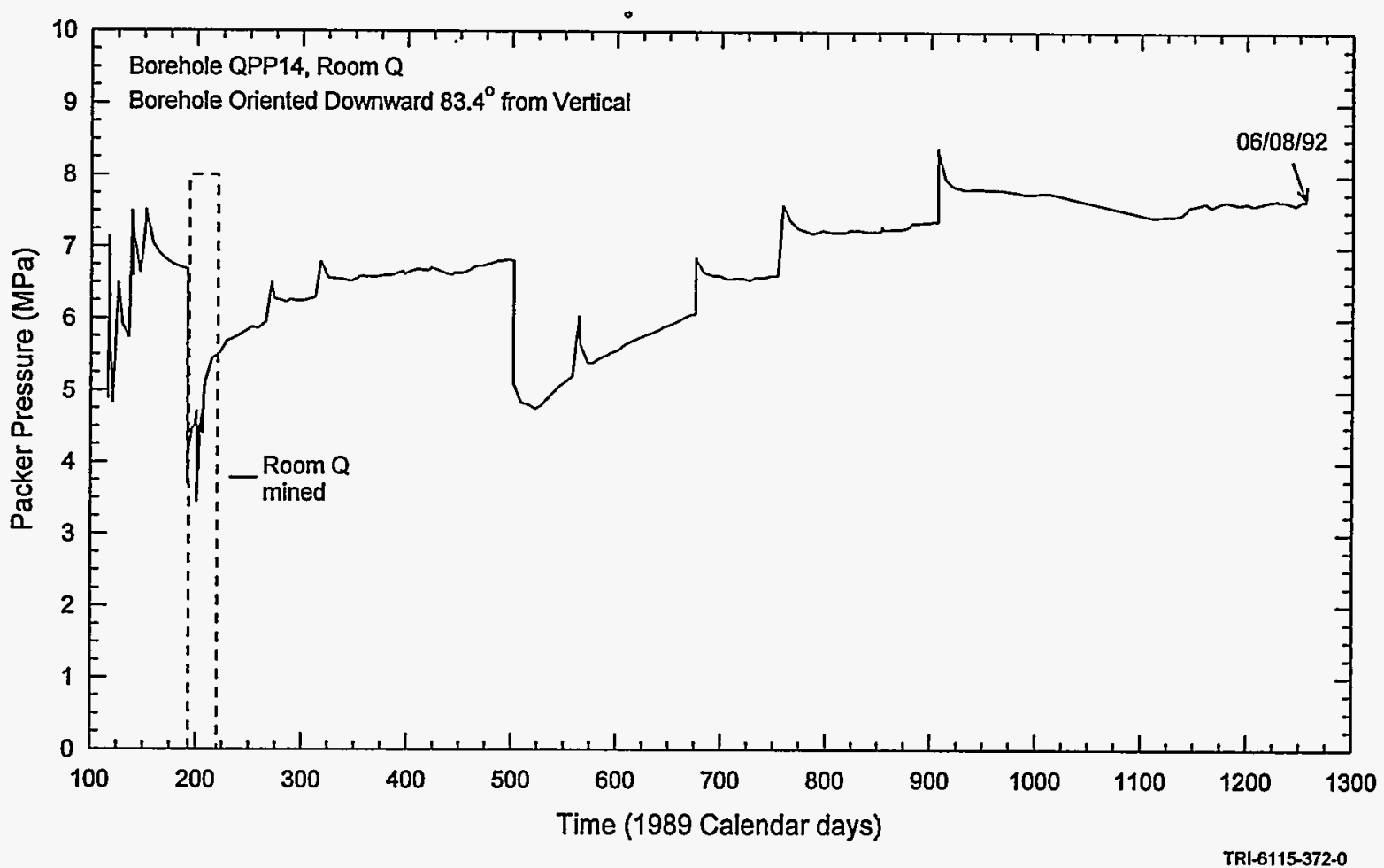

Figure A-9. QPP14 packer pressure.

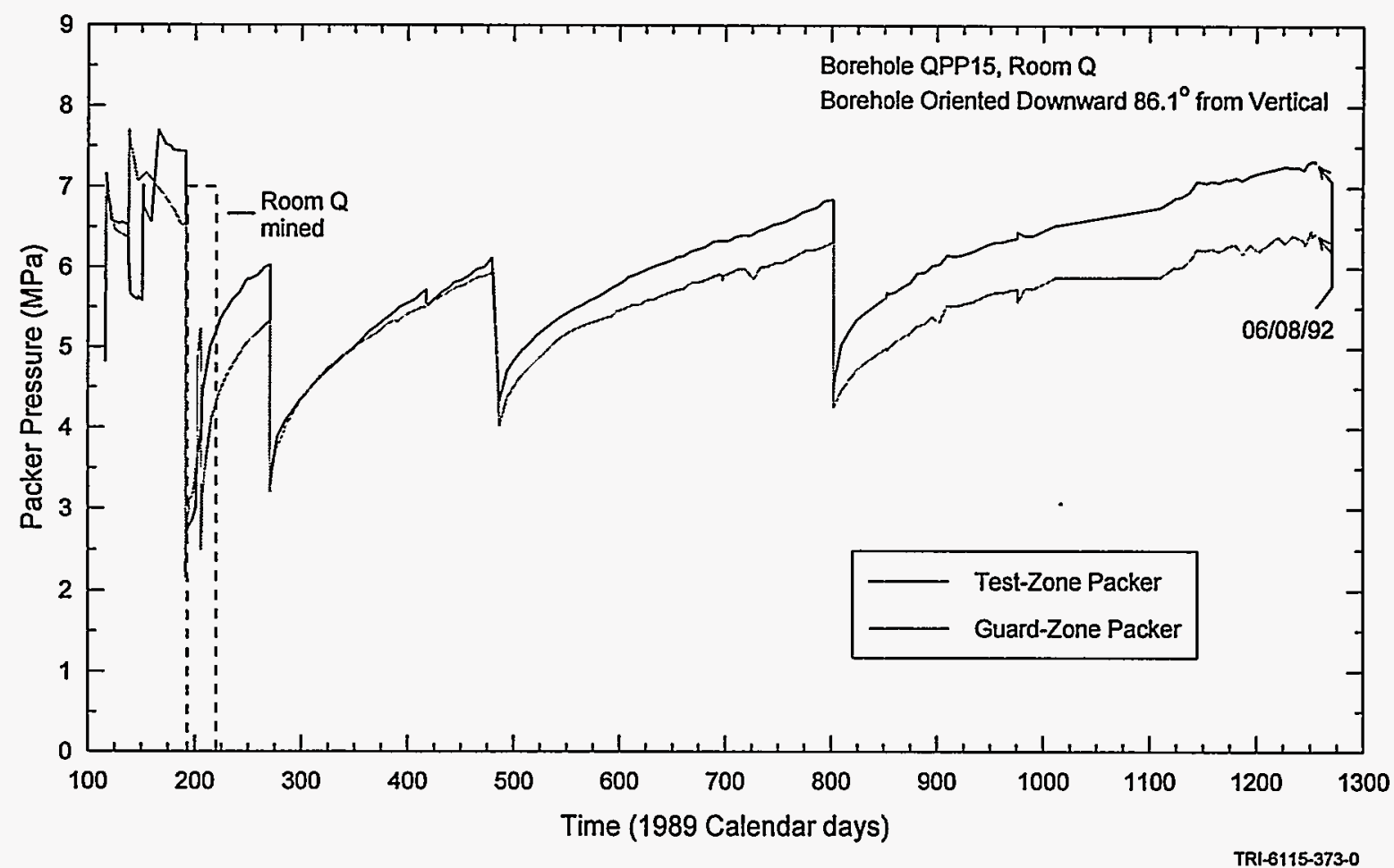

Figure A-10. QPP15 packer pressures. 


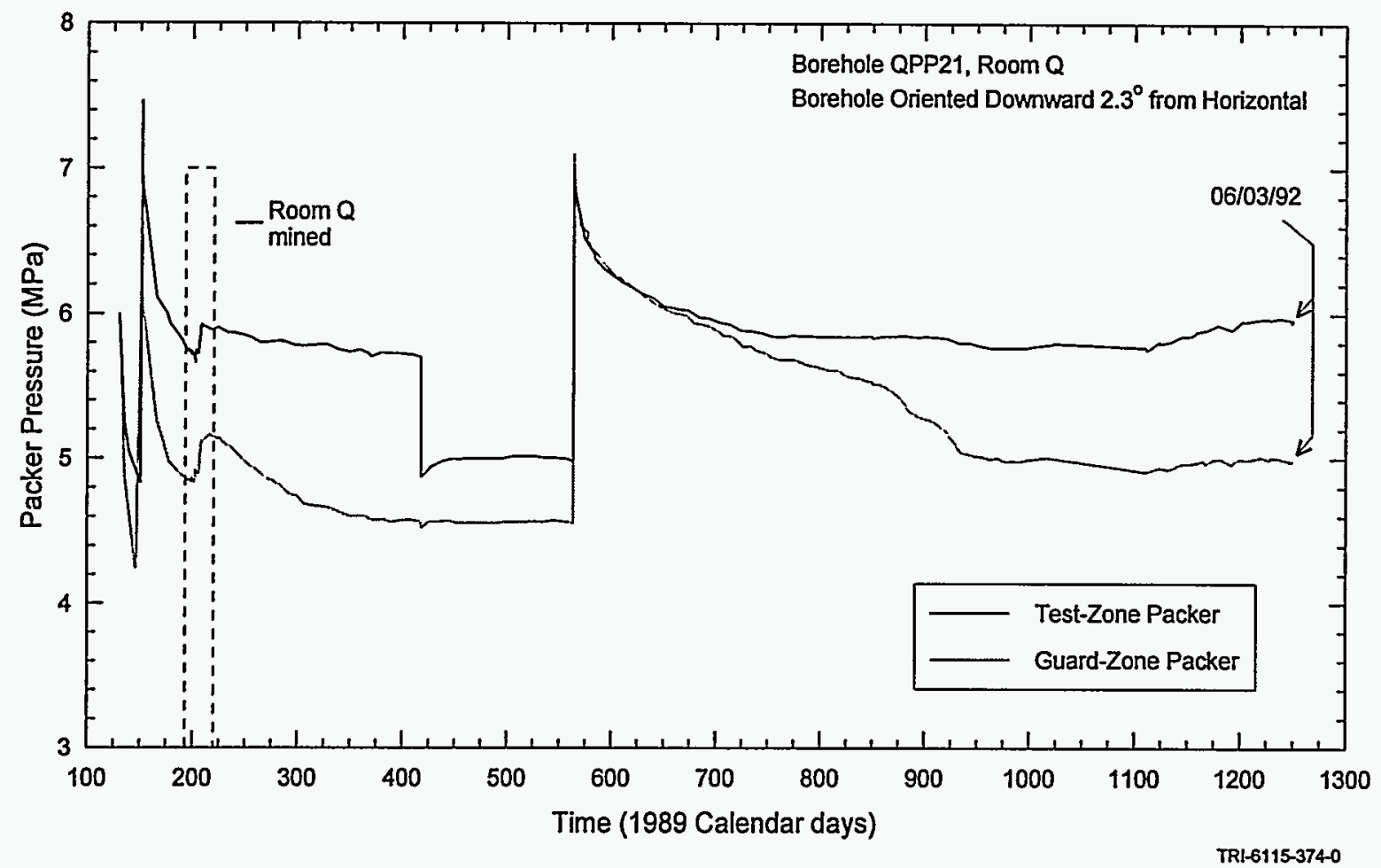

Figure A-11. QPP21 packer pressures.

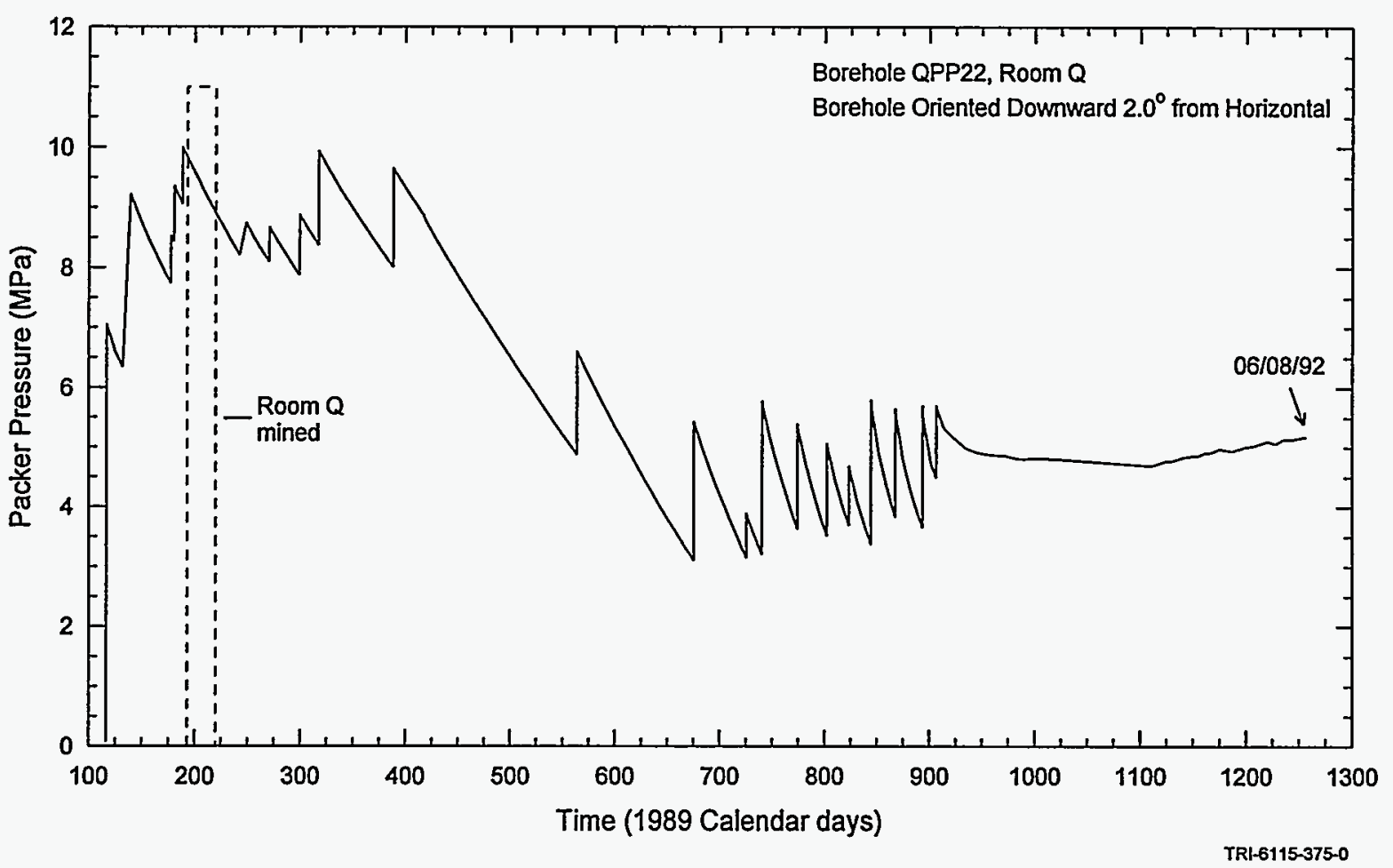

Figure A-12. QPP22 packer pressure. 


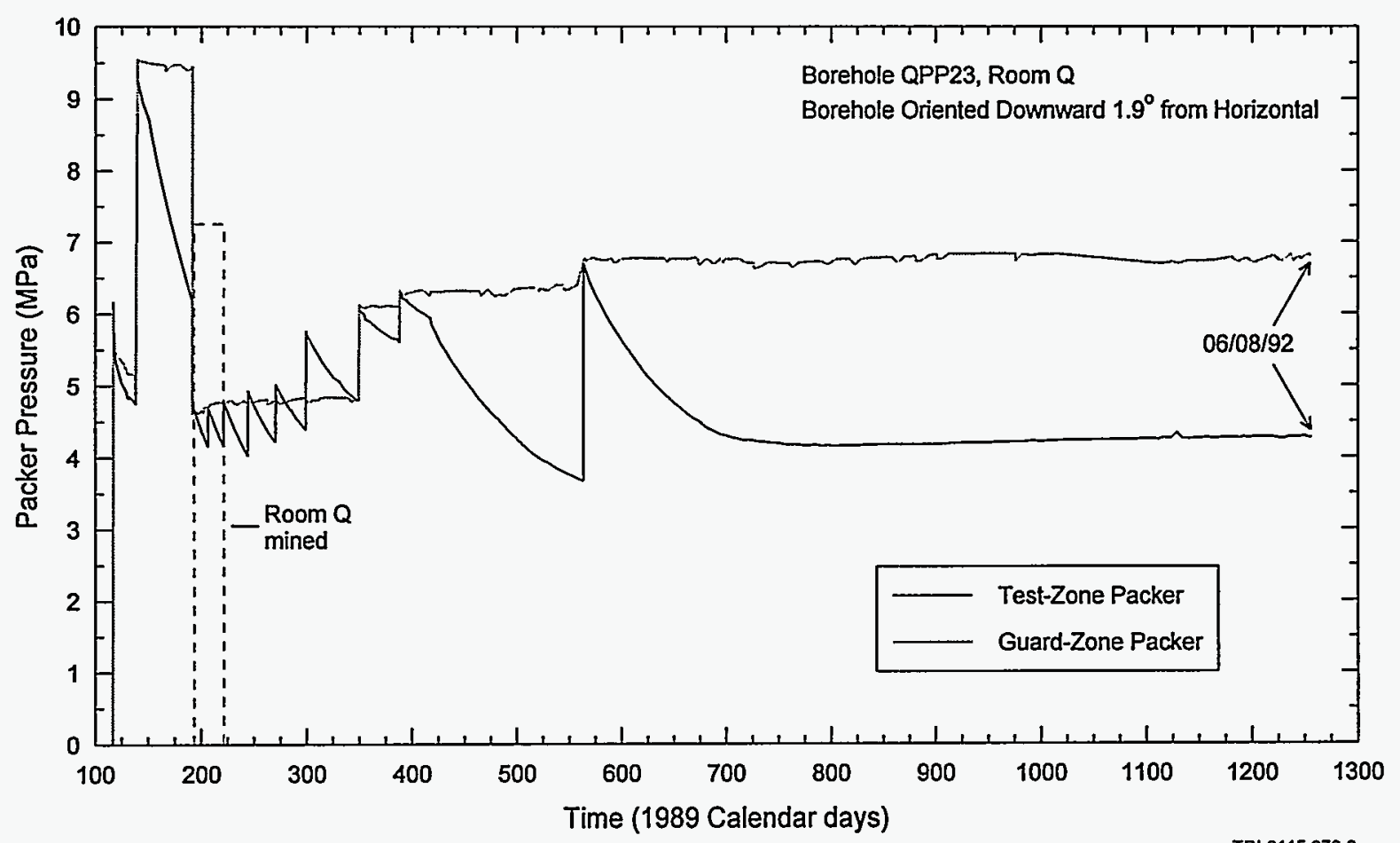

Figure A-13. QPP23 packer pressures.

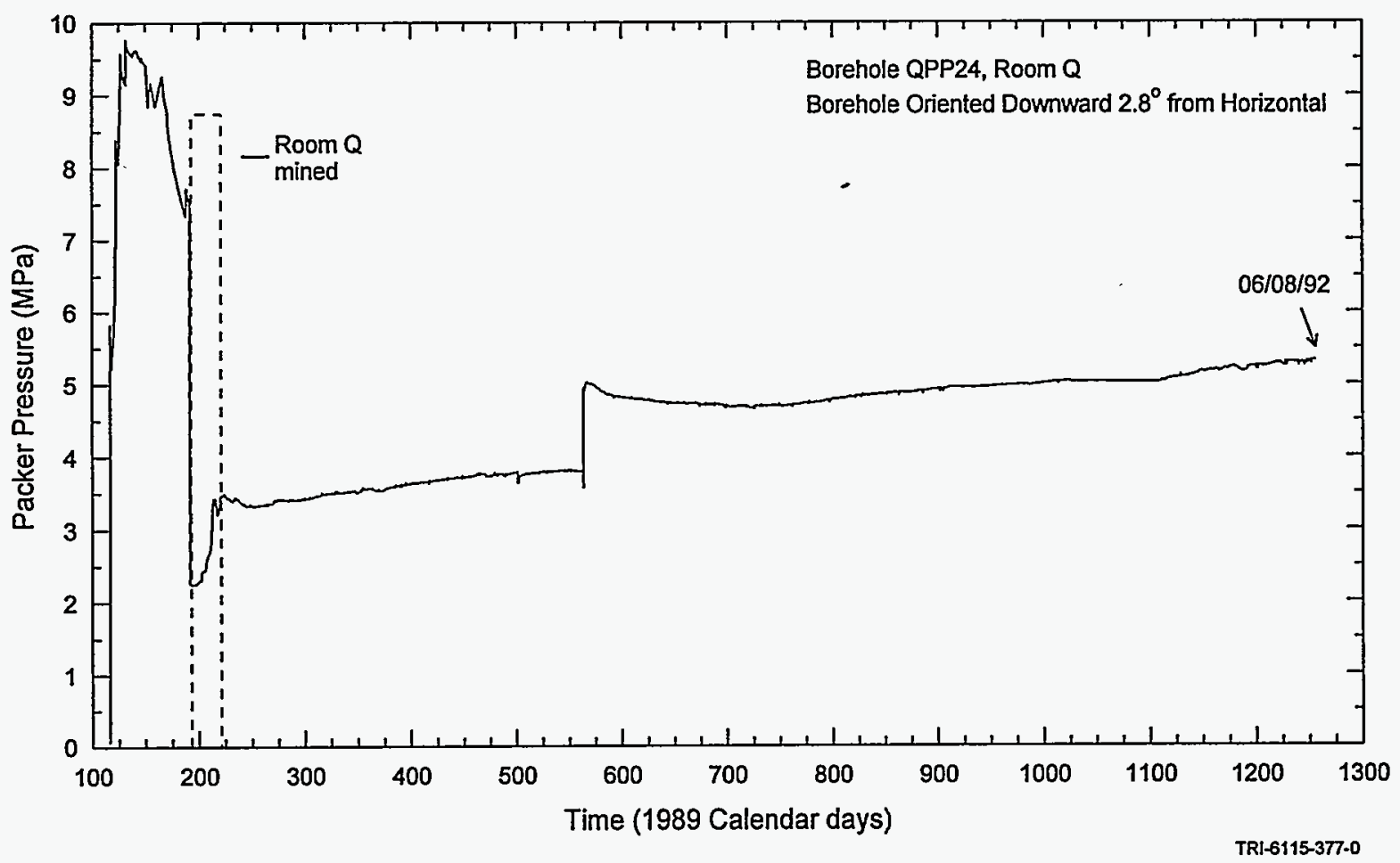

Figure A-14. QPP24 packer pressure. 


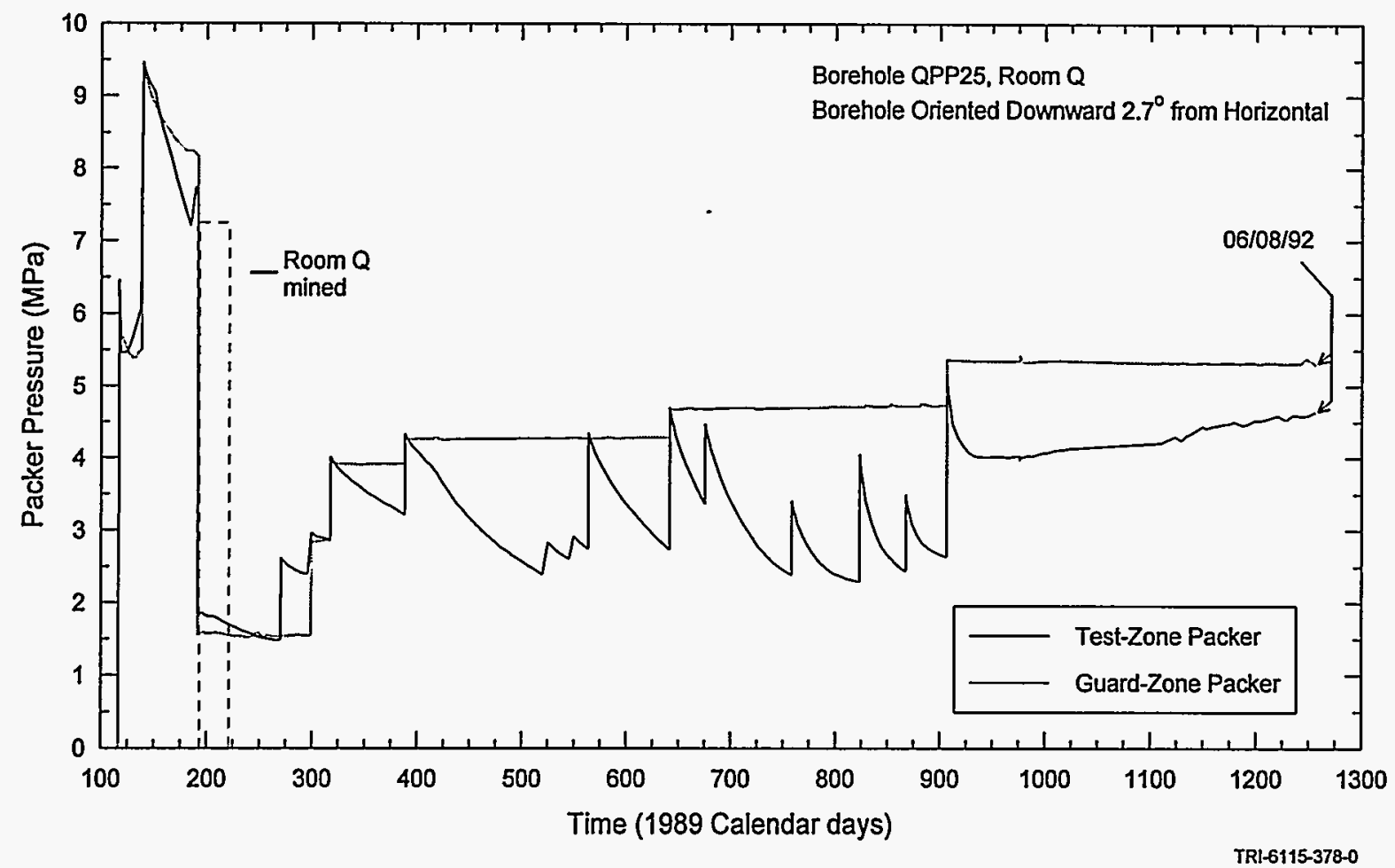

Figure A-15. QPP25 packer pressures. 


\section{APPENDIX B}

BOREHOLE PRESSURES IN MARCH 1995 


\section{Sandia National Laboratories}

date: March 22, 1995

Albuquerque. Now Mexico 87185-300

to: A. Lee Jensen, SNL, MS1324

from: Curtis A. Chester, Intera, MS300 Cuftech

subject: Room Q Borehole Pretest Test Zone Pressures for Stations 000, 100, \& 200

The following data reflects the fixed point test zone pressures for boreholes surrounding Room Q. The following data was taken on or prior to 10 March 1995.

Station 000 (vertically inclined - above Room Q)

$\mathrm{TZ}$

QPP01 - $\quad$ (not on line)

QPP02 - $\quad 2.6 \mathrm{MPa}$

QPP03 - $\quad 6.1 \mathrm{MPa}$

QPP04 - $\quad 3.7 \mathrm{MPa}$

QPP05 - $\quad 0.5 \mathrm{MPa}$
$\mathrm{GZ}$

(not on line)

6.1 Mpa (communication between $\mathrm{TZ} \& \mathrm{GZ}$ )

$0.5 \mathrm{MPa}$

Station 100 (vertically declined - below Room Q)

TZ

QPP11 - $\quad$ (not on line)

QPP12 - $\quad$ 6.0 MPa

QPP13 - $\quad 6.6 \mathrm{MPa}$

QPP14 - $\quad 5.4 \mathrm{MPa}$

QPP15 - $\quad 2.7 \mathrm{MPa}$
GZ

(not on line)

$6.4 \mathrm{MPa}$

$0.6 \mathrm{MPa}$

Station 200 (lateral - beside Room Q)

$\mathrm{TZ}$

QPP21 - $\quad$ (not on line)

QPP22 - $\quad 3.1 \mathrm{Mpa}$

QPP23 - $\quad 6.4 \mathrm{MPa}$

QPP24 - $\quad 0.4 \mathrm{Mpa}$

QPP25 - $\quad 1.8 \mathrm{MPa}$
GZ

(not on line)

$6.4 \mathrm{MPa}$

$1.1 \mathrm{MPa}$

If you have any questions or need additional information, please don't hesitate to contact me.

Copy to:

(1) Rick Beauheim, SNL $M s / 324$

(1) Paul Domski, Intera

(1) Wayne Stensrud, Intera

(1) Randy Roberts, Intera

(2) SWCF - A WBS 1.1.4.3.3 - TD 


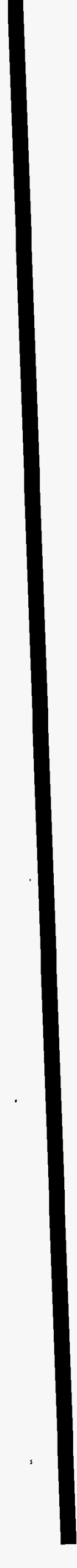




\section{WIPP}

\section{UC721 - DISTRIBUTION LIST (SAND96-0435)}

\section{Federal Agencies}

US Department of Energy (6)

Office of Civilian Radioactive Waste Mgmt.

Attn: Deputy Director, RW-2

Associate Director, RW-10/50

Office of Prog. \& Resources Mgmt.

Office of Contract Business Mgmt.

Director, RW-22

Analysis \& Verification Division

Associate Director, RW-30

Office of Systems \& Compliance

Associate Director, RW-40

Office of Storage \& Transportation

Director, RW-4/5

Office of Strategic Planning and

International Programs

Office of External Relations

Forrestal Building

Washington, DC 20585

US Department of Energy

Albuquerque Operations Office

Attn: National Atomic Museum Library

P.O. Box 5400

Albuquerque, NM 87185-5400

US Department of Energy

Research \& Waste Management Division

Attn: Director

P.O. Box E

Oak Ridge, TN 37831

US Department of Energy (5)

Carlsbad Area Office

Attn: G. Dials

D. Galbraith

M. McFadden

R. Lark

J. A. Mewhinney

P.O. Box 3090

Carlsbad, NM 88221-3090

US Department of Energy

Office of Environmental Restoration and

Waste Management

Attn: J. Lytle, EM-30

Forrestal Building

Washington, DC 20585-0002
US Department of Energy (3)

Office of Environmental Restoration and Waste Management

Attn: M. Frei, EM-34, Trevion II

Washington, DC 20585-0002

US Department of Energy

Office of Environmental Restoration and Waste Management

Attn: S. Schneider, EM-342, Trevion II

Washington, DC 20585-0002

US Department of Energy (2)

Office of Environment, Safety \& Health

Attn: C. Borgstrom, EH-25

R. Pelletier, EH-231

Washington, DC 20585

US Department of Energy (2)

Idaho Operations Office

Fuel Processing \& Waste Mgmt. Division 785 DOE Place

Idaho Falls, ID 83402

US Environmental Protection Agency (2)

Radiation Protection Programs

Attn: M. Oge

ANR-460

Washington, DC 20460

US Geological Survey (2)

Water Resources Division

Attn: P. Hsieh

A. F. Moench

345 Middlefield Rd.

Menlo Park, CA 94025

\section{Boards}

Defense Nuclear Facilities Safety Board

Attn: D. Winters

625 Indiana Ave. NW, Suite 700

Washington, DC 20004

Nuclear Waste Technical Review Board (2)

Attn: Chairman

$$
\text { S. J. S. Parry }
$$

1100 Wilson Blvd., Suite 910

Arlington, VA 22209-2297 


\section{State Agencies}

Attorney General of New Mexico

P.O. Drawer 1508

Santa Fe, NM 87504-1508

Environmental Evaluation Group (3)

Attn: Library

7007 Wyoming NE

Suite F-2

Albuquerque, NM 87109

NM Energy, Minerals, and Natural

Resources Department

Attn: Library

2040 S. Pacheco

Santa Fe, NM 87505

NM Environment Department (3)

Secretary of the Environment

Attn: Mark Weidler

1190 St. Francis Drive

Santa Fe, NM 87503-0968

NM Bureau of Mines \& Mineral Resources

Socorro, NM 87801

NM Environment Department

WIPP Project Site

Attn: P. McCasland

P.O. Box 3090

Carlsbad, NM 88221

\section{Laboratories/Corporations}

Battelle Pacific Northwest Laboratories Attn: R. E. Westerman, MSIN P8-44

Battelle Blvd.

Richland, WA 99352

Golder Associates

Attn: T. W. Doe

4104 148th Avenue, NE

Redmond, WA 98052

INTERA, Inc. (10)

Attn: G. A. Freeze

P. S. Domski (7)

R. M. Roberts

M. B. Kloska

1650 University Blvd. NE, Suite 300

Albuquerque, NM 87102
INTERA, Inc. (5)

Attn: J. F. Pickens

6850 Austin Center Blvd., Suite 300

Austin, TX 78731

INTERA, Inc. (4)

Attn: W. Stensrud

P.O. Box 2123

Carlsbad, NM 88221

L. Lehman and Associates, Inc.

Attn: L. Lehman

1103 W. Burnsville Parkway

Suite 209

Minneapolis, MN 55337

Los Alamos National Laboratory

Attn: B. Erdal, INC-12

P.O. Box 1663

Los Alamos, NM 87544

RE/SPEC, Inc

Attn: Angus Robb

4775 Indian School NE, Suite 300

Albuquerque, NM 87110-3927

National Ground Water Information Center

Attn: J. Bix

6375 Riverside Dr.

Dublin, OH 43017

RE/SPEC, Inc

Attn: J. L. Ratigan

P.O. Box 725

Rapid City', SD 57709

Tech Reps, Inc. (3)

Attn: J. Chapman (1)

Loretta Robledo (2)

5000 Marble NE, Suite 222

Albuquerque, NM 87110

Westinghouse Electric Corporation (5)

Attn: Library

J. Epstein

J. Lee

B. A. Howard

R. Kehrman

P.O. Box 2078

Carlsbad, NM 88221 
S. Cohen \& Associates

Attn: Bill Thurber

1355 Beverly Road

McLean, VA 22101

National Academy of Sciences, WIPP Panel

Howard Adler

Oxyrase, Incorporated

7327 Oak Ridge Highway

Knoxville, TN 37931

Bob Andrews

Board of Radioactive Waste Management

GF456

2101 Constitution Ave.

Washington, DC 20418

Rodney C. Ewing

Department of Geology

University of New Mexico

Albuquerque, NM 87131

Charles Fairhurst

Department of Civil and Mineral Engineering

University of Minnesota

500 Pillsbury Dr. SE

Minneapolis, MN 55455-0220

B. John Garrick

PLG Incorporated

4590 MacArthur Blvd., Suite 400

Newport Beach, CA 92660-2027

Leonard F. Konikow

US Geological Survey

431 National Center

Reston, VA 22092

Carl A. Anderson, Director

Board of Radioactive Waste Management

National Research Council

HA 456

2101 Constitution Ave. NW

Washington, DC 20418

Christopher G. Whipple

ICF Kaiser Engineers

1800 Harrison St., 7th Floor

Oakland, CA 94612-3430
John O. Blomeke

720 Clubhouse Way

Knoxville, TN 37909

Sue B. Clark

University of Georgia

Savannah River Ecology Lab

P.O. Drawer E

Aiken, SC 29802

Konrad B. Krauskopf

Department of Geology

Stanford University

Stanford, CA 94305-2115

Della Roy

Pennsylvania State University

217 Materials Research Lab

Hastings Road

University Park, PA 16802

David A. Waite

$\mathrm{CH}_{2} \mathrm{M}$ Hill

P.O. Box 91500

Bellevue, WA 98009-2050

Thomas A. Zordon

Zordan Associates, Inc. 3807 Edinburg Drive

Murrysville, PA 15668

Individuals

D. W. Powers

Star Route Box 87

Anthony, TX 79821

Universities

New Mexico Tech (3)

Department of Geoscience

Attn: J. Wilson

F. Phillips

R. Bowman

Socorro, NM 87801

Texas A\&M University

Department of Geology

Attn: P. A. Domenico

College Station, TX 77843 
University of Arizona

Department of Hydrology

Attn: S. P. Neuman

Tucson, AZ 85721

University of California (3)

Lawrence Berkeley Laboratory

Earth Sciences Division

Attn: K. Karasaki

J. C. Long

C. F. Tsang

1 Cyclotron Road

Berkeley, CA 94720

University of Kansas

Kansas Geological Survey

Attn: J. Butler

1930 Constant Ave.

Campus West

Lawrence, KS 66046

University of New Mexico

Geology Department

Attn: Library

141 Northrop Hall

Albuquerque, NM 87131

University of Washington

College of Ocean \& Fishery Sciences

Attn: G. R. Heath

583 Henderson Hall, HN-15

Seattle, WA 98195

University of Wisconsin-Madison (2)

Department of Geology and Geophysics

Attn: M. P. Anderson

H. F. Wang

1215 W. Dayton St.

Madison, WI 53706

\section{Libraries}

Thomas Brannigan Library

Attn: D. Dresp

106 W. Hadley St.

Las Cruces, NM 88001

Government Publications Department

Zimmerman Library

University of New Mexico

Albuquerque, NM 87131
New Mexico Junior College

Pannell Library

Attn: R. Hill

Lovington Highway

Hobbs, NM 88240

New Mexico State Library

Attn: N. McCallan

325 Don Gaspar

Santa Fe, NM 87503

New Mexico Tech

Martin Speere Memorial Library

Campus Street

Socorro, NM 87810

WIPP Public Reading Room

Carlsbad Public Library

$101 \mathrm{~S}$. Halagueno St.

Carlsbad, NM 88220

\section{Foreign Addresses}

Studiecentrum Voor Kernenergie

Centre d'Energie Nucleaire

Attn: A. Bonne

SCK/CEN Boeretang 200

B-2400 Mol, BELGIUM

Atomic Energy of Canada, Ltd. (2)

Whiteshell Laboratories

Attn: B. Goodwin

C. Davison

Pinawa, Manitoba, CANADA ROE ILO

Environment Canada

National Water Research Institute

Canada Centre for Inland Lakes

Attn: K. S. Novakowski

867 Lakeshore Road

P.O. Box 5050

Burlington, Ontario, CANADA L7R 4A6

Francois Chenevier (2)

ANDRA

Route de Panorama Robert Schumann

B. P. 38

92266 Fontenay-aux-Roses, Cedex, FRANCE 
Claude Sombret

Centre d'Etudes Nucleaires de la Vallee Rhone

CEN/VALRHO

S.D.H.A. B.P. 171

30205 Bagnols-Sur-Ceze, FRANCE

Commissariat a L'Energie Atomique

Attn: D. Alexandre

Centre d'Etudes de Cadarache

13108 Saint Paul Lez Durance Cedex, FRANCE

OECD Nuclear Energy Agency

Attn: Jean-Pierre Olivier

Division of Radiation Protection and Waste Management

38, Boulevard Suchet

75016 Paris, FRANCE

Bundesanstalt fur Geowissenschaften und

Rohstoffe

Attn: M. Langer

Postfach 510153

D-30631 Hannover, GERMANY

Bundesministerium fur Forschung und

Technologie

Postfach 200706

5300 Bonn 2, GERMANY

Institut fur Tieflagerung

Attn: K. Kuhn

Theodor-Heuss-Strasse 4

D-3300 Braunschweig, GERMANY

Gesellschaft fur Anlagen und

Reaktorsicherheit (GRS)

Attn: B. Baltes

P. Bogorinski

Schwertnergasse 1

D-50667 Cologne, GERMANY

Shingo Tashiro

Japan Atomic Energy Research Institute

Tokai-Mura, Ibaraki-Ken, 319-11

JAPAN

Netherlands Energy Research Foundation ECN

Attn: J. Prij

3 Westerduinweg

P.O. Box 1

1755 ZG Petten, THE NETHERLANDS
Utrecht University (2)

Institute of Earth Sciences

HPT Lab/Department of Geology

Attn: C. J. Peach

C. J. Spiers

Budapestlaan 4

P.O. Box 80.021

3508 TA Utrecht, THE NETHERLANDS

Conterra $\mathrm{AB}$

Attn: A. Winberg

Krokslätts Fabriker 30

S-431 37 Mölndal, SWEDEN

Geosigma $A B$

Attn: P. Andersson

P.O. Box 894

S-751 08 Uppsala, SWEDEN

Kemakta Konsult AB

Attn: L. Birgersson

Box 12655

S-112 93 Stockholm, SWEDEN

Statens Kärnkraftinspektion

Attn: B. Duerstorp

Box 27106

S-102 52 Stockholm, SWEDEN

Svensk Karnbransleforsorjning AB (3)

Attn: F. Karlsson

A. Strom

K. E. Almen

Project KBS (Karnbranslesakerhet)

Box 5864

S-102 48 Stockholm, SWEDEN

Colenco Ltd.

Attn: S. Löw

Mellingerstrasse 207

CH-5404 Baden, SWITZERLAND

Nationale Genossenschaft fur die Lagerung (2)

Radioaktiver Abfalle

Attn: S. Vomvoris

P. Zuidema

Hardstrasse 73

CH-5430 Wettingen, SWITZERLAND

SolExperts Ltd.

Attn: E. Wyss

Ifangstrasse 12

CH-8603 Schwerzenbach, SWITZERLAND 
AEA Technology

Attn: J. H. Rees

D5W/29 Culham Laboratory

Abington, Oxfordshire OX14 3DB

UNITED KINGDOM

AEA Technology

Attn: W. R. Rodwell

044/A31 Winfrith Technical Centre

Dorchester, Dorset DT2 8DH

UNITED KINGDOM

AEA Technology

Attn: J. E. Tinson

B4244 Harwell Laboratory

Didcot, Oxfordshire OXII ORA

UNITED KINGDOM

Golder Associates

Attn: J. H. Black

Landmere Lane

Edwalton, Nottingham NG12 4DE

UNITED KINGDOM

\section{Internal}

$\begin{array}{lll}\frac{\text { MS }}{1324} & \frac{\text { Org. }}{6115} & \text { P. B. Davies } \\ 1324 & 6115 & \text { A. R. Lappin } \\ 1324 & 6115 & \text { R. L. Beauheim (10) } \\ 1324 & 6115 & \text { S. M. Howarth } \\ 1324 & 6115 & \text { T. Christian-Frear } \\ 1320 & 6719 & \text { E. J. Nowak } \\ 1322 & 6121 & \text { J. R. Tillerson } \\ 1328 & 6749 & \text { D. R. Anderson } \\ 1328 & 6749 & \text { P. Vaughn } \\ 1328 & 6741 & \text { H. N. Jow } \\ 1335 & 6705 & \text { M. Chu } \\ 1341 & 6811 & \text { A. L. Stevens } \\ 1341 & 6747 & \text { D. R. Schafer } \\ 1341 & 6748 & \text { J. T. Holmes } \\ 1343 & 6751 & \text { K. W. Larson } \\ 1395 & 6700 & \text { P. Brewer } \\ 1395 & 6800 & \text { L. Shephard } \\ 1395 & 6707 & \text { M. Marietta } \\ 1395 & 6841 & \text { V. H. Slaboszewicz } \\ & & \\ 1330 & 6752 & \text { C. B. Michaels (2) } \\ 1330 & 6752 & \text { NWM Library (20) } \\ 9018 & 8523-2 & \text { Central Technical Files } \\ 0899 & 4414 & \text { Technical Library (5) } \\ 0619 & 12615 & \text { Print Media } \\ 0100 & 7613-2 & \text { Document Processing (2) } \\ & & \text { for DOE/OSTI } \\ & & \end{array}$

